NISTIR 7445

\title{
THE STRUCTURE AND \\ EXTINCTION OF LOW STRAIN RATE NON-PREMIXED FLAMES BY AN AGENT IN MICROGRAVITY
}

\author{
Anthony Hamins \\ Matthew Bundy \\ Chang Bo Oh \\ S. Paul Fuss \\ Jennifer Logue
}



NISTIR 7445

\title{
THE STRUCTURE AND EXTINCTION OF LOW STRAIN RATE NON-PREMIXED FLAMES BY AN AGENT IN MICROGRAVITY
}

\author{
Anthony Hamins \\ Matthew Bundy \\ Chang Bo Oh \\ S. Paul Fuss \\ Jennifer Logue
}

Buildina and Fire Research Laboratory

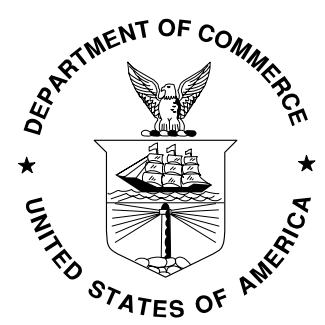

U.S. Department of Commerce Carlos M. Gutierrez, Secretary

Technology Administration Robert Cresanti, Under Secretary of Commerce for Technology 


\title{
THE STRUCTURE AND EXTINCTION OF LOW STRAIN RATE NON-PREMIXED FLAMES BY AN AGENT IN MICROGRAVITY
}

\author{
A Final Report on NASA Contract NNC04CB07C \\ Period of Support (2/19/2004 to 3/31/2007) \\ by \\ The National Institute of Standards and Technology \\ Building and Fire Research Laboratory \\ Gaithersburg, MD 20899
}

Please note that certain trade names and company products are mentioned in the text to specify adequately the experimental procedure and equipment used or to identify types of currently available commercial products. In no case does such identification imply recommendation or endorsement by the National Institute of Standards and Technology, nor does it imply that the products are necessarily the best available for the purpose. 
FINAL REPORT

THE STRUCTURE AND EXTINCTION OF LOW STRAIN RATE NON-PREMIXED FLAMES BY AN AGENT IN MICROGRAVITY

\section{Table of Contents}

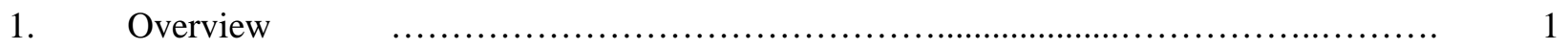

2. Description of Suppression Experiments and Experimental Configuration .......... 2

3. Axisymmetric Flame Simulations investigating Nitrogen as an Agent ................... 4

4. Axisymmetric Flame Simulations investigating $\mathrm{CO}_{2}$ as an Agent ........................ 5

5. Suppression Limits of Low Strain Rate 1-g Non-Premixed Propane Flames .................. 5

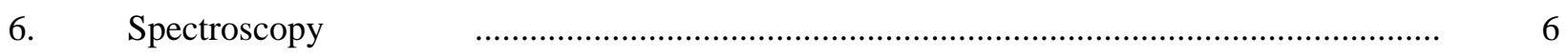

7. References

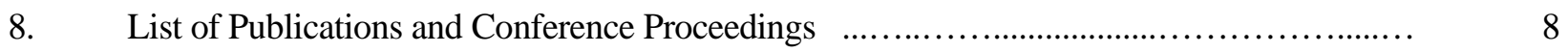

9. Appendix 1: The Two-Dimensional Structure of Low Strain Rate Counterflow Nonpremixed Methane Flames in Normal and Microgravity Flames ............................................................ 9

10. Appendix 2: Effect of Buoyancy on the Radiative Extinction Limit of Low Strain Rate Non-Premixed Methane-Air Flames.

11. Appendix 3: Numerical Study of the Suppression of Methane-Air Flames with Carbon Dioxide in Normal Gravity and Microgravity

12. Appendix 4: Suppression Limits of Low Strain Rate 1-g Non-Premixed Propane Flames.

13. Appendix 5: A Technique for Extrapolating Absorption Coefficient Measurements to High Temperatures

14. Appendix 6: Determination of Planck Mean Absorption Coefficients for $\mathrm{CF}_{3} \mathrm{Br}$ 139

15. Appendix 7: Determination of Planck Mean Absorption Coefficients for Hydrocarbon Fuels 


\section{THE STRUCTURE AND EXTINCTION OF LOW STRAIN RATE NON-PREMIXED FLAMES BY AN AGENT IN MICROGRAVITY}

This final report describes the study that has been supported through the National Aeronautics and Space Administration (NASA) microgravity grants program from February 2004 through March 2007. This work was a continuation of a NASA microgravity grant that was active from February 1999 through September 2003. The work has used computations and measurements to investigate the structure and suppression of low strain rate non-premixed flames. This final report, on the latest grant, includes a summary of the work done on the contract and a list of publications.

The work during this grant period focused on both measurements and calculations and included the following:

- Continued development of the two-dimensional simulation with finite rate chemistry. [Hamins et al., 2007; Oh et al., 2007]. These publications are provided in Appendices 1 and 2. These calculations considered extinction of methane-air diffusion flames with $\mathrm{N}_{2}$ added to the fuel stream. The work compares calculations with our earlier measurements made in normal gravity and in microgravity using the NASA $2.2 \mathrm{~s}$ drop tower.

- Two-dimensional calculations were completed that considered the extinction of methane-air diffusion flames with $\mathrm{CO}_{2}$ added to the fuel stream in normal and microgravity. This study is provided in Appendix 3. The computations were compared to the $\mathrm{N}_{2}$ addition results described in [Hamins et al., 2007; Oh et al., 2007].

- Flame extinction studies on the normal gravity extinction of propane were conducted. The results of this study are provided in Appendix 4.

- Finally, spectroscopic measurements were conducted on key flame intermediates to support detailed modeling of radiative exchange in near-extinction flames. Wakasuki et al. [2005] developed a method to estimate the temperature dependence of absorption coefficients through an extrapolation algorithm. This publication is provided in Appendix 5. Spectroscopic measurements are important to understand the mechanisms of extinction associated with flames being suppressed by agents. $\mathrm{CF}_{3} \mathrm{Br}$ (Halon 1301) is one of the most important suppressants and has been used on space platforms for many years. Suppression studies often use $\mathrm{CF}_{3} \mathrm{BR}$ as a reference or baseline in considering the effectiveness of alternative agents. As part of this study, Fourier Transform Infrared Spectroscopy (FTIR) measurements were made on $\mathrm{CF}_{3} \mathrm{Br}$ at elevated temperatures. Those measurements are reported in Appendix 6. Appendix 7 presents similar spectral measurements and analysis for propane, heptane and propylene.

The seven manuscripts mentioned above are included as appendices in this final report. The remainder of the report presents an overview of the work and the main findings of the project. Detailed information on each of the topics can be found in the appendices.

\section{Overview}

When the original grant proposal was written in 1997, a review of the literature indicated that there had been little work on the extinction of flames by an agent in microgravity, and practically none on low strain rate diffusion flame extinction by an agent. There have been several relevant studies since that time. 
The work of Maruta et al. [1998] is mentioned in several places in this report. Maruta conducted the first comprehensive extinction measurements of very low strain nonpremixed flames in microgravity using the $10 \mathrm{~s}$ JAMIC drop tower in Japan. In that study, the extinction of methane-air diffusion flames with $\mathrm{N}_{2}$ added to the fuel stream was measured under microgravity conditions. The minimum methane concentration required to sustain combustion was measured to decrease as the strain rate decreased until a critical value was observed. As the global strain rate was further reduced, the required methane concentration increased. This behavior was denoted as a "turning point" and was attributed to the enhanced importance of radiative loss in low strain rate flames. In terms of fire safety, the turning point agent concentration represents a fundamental limit for nonpremixed flames, assuring suppression for all flow conditions. Bundy et al. [2003] observed similar behavior in low strain rate normal gravity flames.

Most recently, Han et al. [2007] reported on the structure of ultra low-stretch $\left(\approx 2 \mathrm{~s}^{-1}\right)$ methane nonpremixed flames. Their study considered radiation effects and extinction in curved flames established in normal gravity by flowing diluted fuel in a downward direction through a porous spherically symmetric burner with a large radius of curvature. Heat losses to the burner were characterized and the computational results were found to be consistent with experimental observations. This study was different in the sense that conductive heat losses to the burner were always avoided. This impacted the range of strain rates that were investigated, because flame thickness increases as the strain rate decreases. Here, the global strain rate $\left(\mathrm{a}_{\mathrm{g}}\right)$ was varied from $7 \mathrm{~s}^{-1}$ to $50 \mathrm{~s}^{-1}$ in microgravity flames and from $14 \mathrm{~s}^{-1}$ to $50 \mathrm{~s}^{-1}$ in normal gravity flames to avoid conductive heat losses to the burner. This was confirmed through consideration of the profile of temperature near the burner boundaries To maximize the range of strain rates considered in the normal gravity flames, the approach used in Bundy et al [2003] was applied in which the velocity ratio of the air stream to the fuel stream was adjusted such that the flame location was forced towards the center of the flowfield, away from the burner ducts. By avoiding heat losses to the burner, it is possible to have an understanding of flame structure while avoiding inadvertent flame holder effects, which may be important in the stability of a flame (i.e., flame suppression studies).

\section{Description of Suppression Experiments and Experimental Configuration}

The experimental apparatus consisted of a counterflow burner, a gas supply system for the air, agent, and fuel, an igniter, an electronic sequencer, and a flash-memory computer processor to control the electronics and acquire data. The burner, shown in Fig. 1, consisted of two $15 \mathrm{~mm}$ inner diameter tubes aligned along the same axis with a separation distance of $15 \mathrm{~mm}$. The flame was established between the burner ducts. Fine mesh steel screens (200 mesh) were mounted at the burner duct exits to straighten the gas flow. The burner and combustion chamber design considered the volume of combustion products formed and consequent changes in chamber pressure. The key to the suppression measurement was control of the reactant flows, which was facilitated by fast response $(\approx 10 \mathrm{~ms})$ pressure controllers positioned upstream of selected critical flow orifices. The time response of mass flow controllers was too slow $(\approx 0.7 \mathrm{~s})$ for a 2.2 s drop experiment.

In the experiments, conditions were selected to repeat the work of Maruta et al. [1998], who performed experiments in the $10 \mathrm{~s}$ JAMIC drop tower. Figure 2 summarizes our suppression and 
modeling results. Experiments were in general agreement with the results of Maruta. The simulations in Fig. 2 are discussed below. In addition to the flame suppression measurements, the time varying temperature was determined in the near-extinction microgravity flames using thin filament intensity measurements. The method was similar to that used by Pitts [1998]. Hamins et al [2007] describes the temperature measurements.

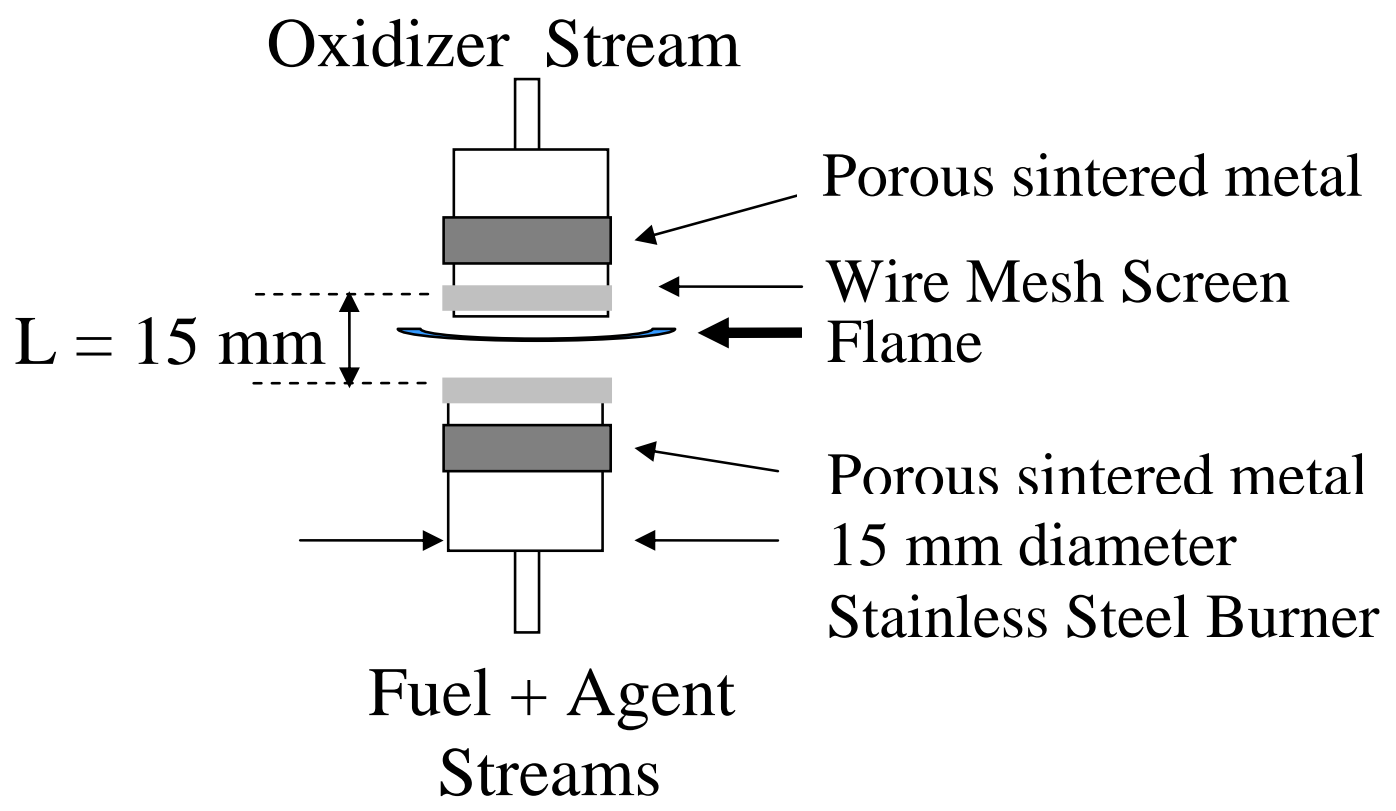

Figure 1. Stainless Steel Opposed Flow Diffusion Flame (OFDF) Burner with agent added to the fuel stream. Some experiments will add agent to the oxidizer stream.

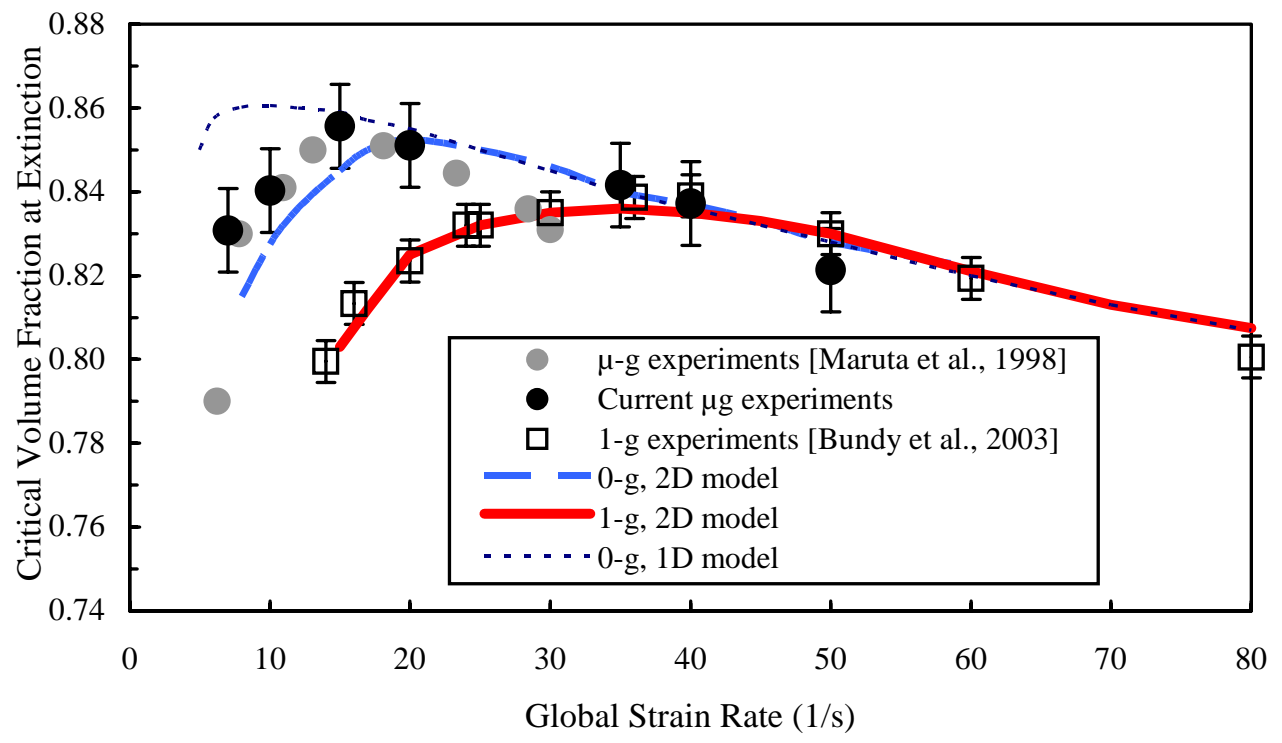

Figure 2. Computed and measured critical nitrogen volume fraction in the fuel stream for suppression of $\mathrm{CH}_{4}$ flames in microgravity $(\mu-g)$ and normal gravity (1-g). Our microgravity $\mathrm{N}_{2}$ fuel stream extinction measurements are 
compared with those of Maruta et. al [1998], with Oppdif simulations based on the assumption of an optically thin radiating gas, and with the 2D model developed here (also assuming the optically thin limit).

\section{Axisymmetric Flame Simulations investigating Nitrogen as an Agent}

A transient two-dimensional flame simulation based on one step chemistry was developed to simulate the drop tower experiments. The details can be found in Oh et al. [2007] (see Appendix 1). Figure 3 is an example of the model results. The figure compares the computed flame heat release rate with photos of flame shape in normal gravity and microgravity for methane-air nonpremixed flames at $\mathrm{ag}_{\mathrm{g}}=20 \mathrm{~s}^{-1}$ and a fuel stream $\mathrm{N}_{2}$ volume fraction of 0.80 .

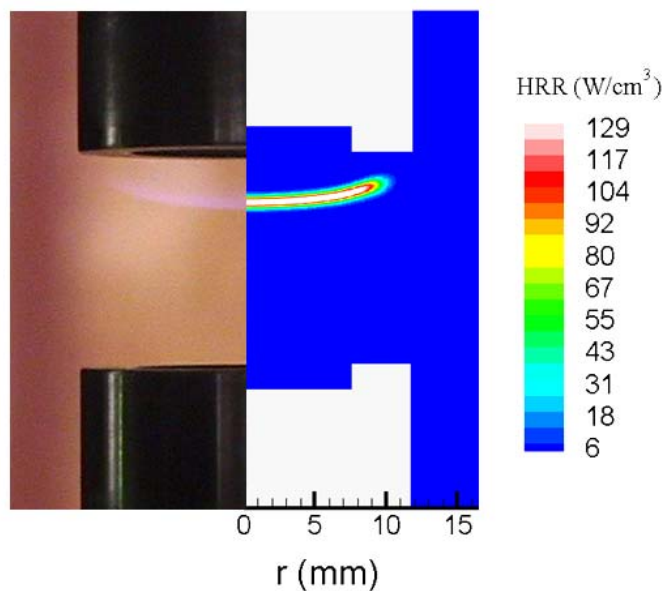

(a) $1-g$

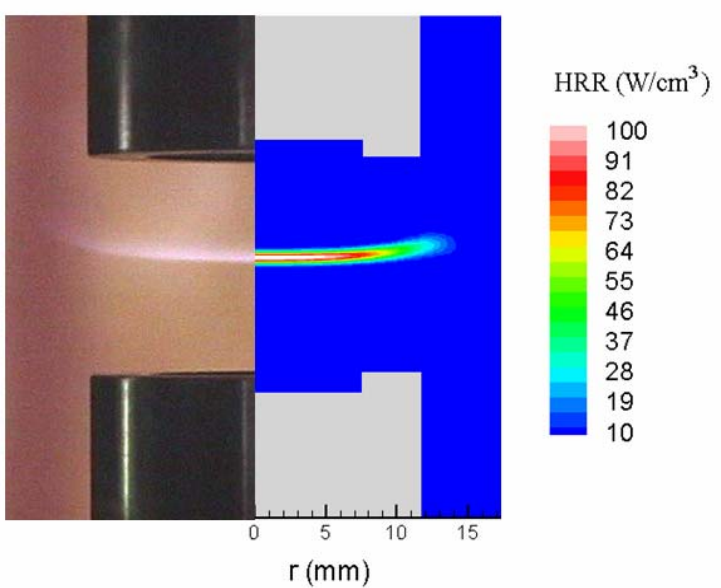

(b) 0 -g

Figure 3. Comparison of flame shape in normal gravity and microgravity for methane-air nonpremixed flames at $\mathrm{a}_{\mathrm{g}}=20 \mathrm{~s}^{-1}$ and a fuel stream $\mathrm{N}_{2}$ volume fraction of 0.80 . The left hand sides are photographs, while the right hand sides are simulation results. (The thin blue flames are faint, but clearly visible when the photos are viewed in color.)

The numerical model is a time-dependent axisymmetric two-dimensional (2D) computation that considers buoyancy effects and radiative heat transfer. A three-step global reaction mechanism was used in both the 1D and 2D computations to predict the measured extinction limit and flame temperature. Photographic images of flames undergoing the process of extinction were compared with model calculations. The axisymmetric numerical model was validated by comparing flame shapes, temperature profiles, and extinction limits with experiments and with the 1D computational results. The 2D computations yielded insight into the extinction mode and flame structure. The contribution by each term in the energy equation to the heat release rate was evaluated to investigate the multi-dimensional structure and radiative extinction of the normal gravity (1-g) flames. Two combustion regimes depending on the extinction mode were identified. Lateral heat loss effects and multi-dimensional flame and flow structure were also found. At low strain rates in 1-g flames ("Regime A"), the flame is extinguished from the weak outer edge of the flame, which is attributed to a multi-dimensional flame structure and flow field. At high strain rates, ("Regime B"), the flame extinction initiates near the flame centerline due to an increased diluent concentration in the reaction zone, similar to the extinction mode of $1 \mathrm{D}$ 
flames. These two extinction modes can be clearly explained by consideration of the specific maximum heat release rate.

Hamins et al. [2007] studied the structure and extinction of the non-premixed flames through comparison of the counterflow suppression experiments and temperature measurements (global strain rates from $7 \mathrm{~s}^{-1}$ to $50 \mathrm{~s}^{-1}$ ) with the $2 \mathrm{D}$ calculations (see Appendix 2). The measurements were used to validate the two-dimensional flame simulation. The simulations yielded insight into the differences between microgravity and normal gravity suppression results, and also explained the inadequacy of the one-dimensional model results to explain the microgravity suppression results. Figure 2 highlights these results and is a focus of the study by Hamins et al. [2007]. Figure 2 also shows the results of the 1D simulations, which exhibit gross trends similar to the measurements. The calculations deviated from Maruta's measurements for the lowest strain conditions, where the calculations overpredict the required agent concentrations. The 2D model successfully predicted the microgravity results [Hamins et al., 2007]. The use of the axisymmetric simulation yielded valuable information on flame shape and the effects of buoyancy on low strain rate normal gravity flames. By providing physical insight, the axisymmetric simulations are a useful tool for guiding the design and interpretation of drop tower experiments where the gravitational level changes or for simulating flame structure and extinction in a relatively moderate gravitational environment such as the moon.

\section{Axisymmetric Flame Simulations investigating Carbon Dioxide as an Agent}

The objective of this study was to numerically investigate the structure and extinction characteristics of low strain rate counterflowing methane-air nonpremixed flames using carbon dioxide as the agent. An axisymmetric 2D computational model, including buoyancy effects and radiative heat transfer was developed. The model was validated through comparison of the 2D model with experiments and 1D computational results for counterflow nonpremixed flames diluted by nitrogen. Once validated, the calculation was used in this study to explore the near-extinction flame structure for flame suppressed by $\mathrm{CO}_{2}$. The details of this study are presented in Appendix 3.

The simulations yielded insight into the effectiveness of $\mathrm{CO}_{2}$ as an agent, highlighting differences in the radiative loss when $\mathrm{CO}_{2}$ rather than $\mathrm{N}_{2}$ is used as a suppressant. The differences between microgravity and normal gravity suppression results were modeled. The results lends confidence in the viability of the axisymmetric model, extending its application to cases beyond methane-air flames with $\mathrm{N}_{2}$ as an agent.

\section{Suppression Limits of Low Strain Rate Non-Premixed Propane Flames}

The suppression of low strain rate non-premixed propane flames was investigated experimentally in a counterflow configuration. The detailed results of this study are presented in Appendix 4. The critical concentration of $\mathrm{N}_{2}, \mathrm{CO}_{2}$, and $\mathrm{CF}_{3} \mathrm{Br}$ added to the fuel and the critical concentration of $\mathrm{N}_{2}$ added to the oxidizer stream required to obtain extinction of propane-air non-premixed flames was measured as a function of the global strain rate. In agreement with previous measurements performed with methane-air diffusion flames, limiting non-premixed flame 
extinction behavior in which the agent concentration obtained a value that insures suppression for all global strain rates was observed.

A series of extinction measurements varying the air: fuel velocity ratio showed that the critical $\mathrm{N}_{2}$ concentration was invariant with this ratio, unless conductive losses were present. In terms of fire safety, the measurements confirm the existence of a fundamental limit for suppressant requirements in normal gravity flames as was previously seen in methane-air flames. This can be thought of as analogous to agent flammability limits in premixed flames. The critical agent volume fraction in the propane fuel stream assuring suppression for all global strain rates was measured to be $0.923 \pm 0.003$ for $\mathrm{N}_{2}, 0.879 \pm 0.004$ for $\mathrm{CO}_{2}$, and $0.517 \pm 0.01$ for $\mathrm{CF}_{3} \mathrm{Br}$. These results were somewhat higher than the results for methane. The critical agent volume fraction in the oxidizer stream assuring suppression for all global strain rates in the propane flames was measured as $0.354 \pm 0.003$ for $\mathrm{N}_{2 .}$.

Measurements using thin filament pyrometry measures flame temperatures for diluted propaneair flame near extinction for several different strain rates. Insight was gained into the near extinction flame temperatures as a function of strain rate.

\section{Spectroscopy}

To support the calculation of the structure and extinction of diffusion flames suppressed by Halon 1301, spectral transmission measurements were conducted on $\mathrm{C}_{3} \mathrm{H}_{8}, \mathrm{C}_{7} \mathrm{H}_{16}, \mathrm{C}_{3} \mathrm{H}_{6}$, and $\mathrm{CF}_{3} \mathrm{Br}$ at elevated temperatures using Fourier Transform Infrared Spectroscopy [Wakasuki et al., 2007; Fuss et al., 2001]. A Mattson model 7020 FTIR was arranged so that the infrared (IR) beam passed through the interferometer but is then diverted outside the spectrometer, bypassing the standard sample compartment, through a quartz flow cell located inside a three zone tube furnace and onto an external detector. A detailed description of the apparatus and procedure is given in Wakasuki et al. [2007] (see Appendix 5) and Fuss et al. [2001]. The entire optical path was purged with $\mathrm{N}_{2}$ to eliminate absorption from ambient water vapor and $\mathrm{CO}_{2}$. The flow cell provided a measurement path length of $0.32 \mathrm{~m}$ and the ends were sealed with Zinc Selenide (ZnSe) windows, which transmit in the spectral region of interest. This experimental configuration measured spectra at temperatures as high as $\approx 700 \mathrm{~K}$. It will be possible to extrapolate this data to higher temperatures using the approach developed in Appendix 5. That methodology fits the absorption coefficient parameters in a simplified expression, and uses the parameters to extrapolate data to higher temperatures [Wakasuki et al., 2005]. The approach was validated using absorption data for water vapor, $\mathrm{CO}$, and $\mathrm{CO}_{2}$ from the HITEMP database [Hitran, 1998].

After acquiring transmission measurements, the temperature dependent Planck mean absorption coefficients for $\mathrm{CF}_{3} \mathrm{Br}$ were calculated for the first time (see Appendix 6). Previously, Planck mean absorption coefficients were determined for $\mathrm{HF}$ and $\mathrm{HBr}$, species that are important products when $\mathrm{CF}_{3} \mathrm{Br}$ is present [Fuss and Hamins, 2002]. These species participate in radiative exchange in a flame or fire when $\mathrm{CF}_{3} \mathrm{Br}$ is present. $\mathrm{HF}$ and $\mathrm{HBr}$ are the major $\mathrm{F}$ and $\mathrm{Br}$ containing molecular products [Hamins et al., 1994b] when $\mathrm{CF}_{3} \mathrm{Br}$ is added to a flame. In preparation for radiative calculations involving $\mathrm{CF}_{3} \mathrm{Br}$, we have used previously developed high temperature spectral information for $\mathrm{HBr}$ and $\mathrm{HF}$ [Rothman et al., 1992] to calculate the Planck absorption-emission coefficients for these molecules [Fuss and Hamins, 2002]. For molecules 
not in the high temperature spectral database such as $\mathrm{C}_{3} \mathrm{H}_{8}$ and $\mathrm{CF}_{3} \mathrm{Br}$, the infrared spectra was measured using a high temperature furnace in conjunction with an FTIR instrument. Planck mean absorption coefficients for $\mathrm{C}_{3} \mathrm{H}_{8}$ and $\mathrm{CF}_{3} \mathrm{Br}$ are useful in this regard, allowing narrowband spectral parameters to be determined for these molecules to provide input data for the RADCAL radiation sub-model. Similar measurements and analysis (Planck determination) are presented for $\mathrm{C}_{3} \mathrm{H}_{8}, \mathrm{C}_{7} \mathrm{H}_{16}$, and $\mathrm{C}_{3} \mathrm{H}_{6}$ in Appendix 7.

In $\mathrm{CF}_{3} \mathrm{Br}$ inhibited flames, Seshadri [1975] and Masri [1994] report that the volume fraction of $\mathrm{CF}_{3} \mathrm{Br}$ is comparable to that of $\mathrm{CO}$ in the high temperature reaction zone. For a flame with the $\mathrm{CF}_{3} \mathrm{Br}$ suppressant added to the air stream of a diffusion flame, the concentrations of $\mathrm{CO}_{2}, \mathrm{H}_{2} \mathrm{O}$, and $\mathrm{CO}$ will fall as a function of distance from the high temperature reaction zone, and $\mathrm{CF}_{3} \mathrm{Br}$ will be larger than any other species that participates in radiative exchange. In cool flame regions, $\mathrm{CF}_{3} \mathrm{Br}$ may absorb flame radiation, and block its emission to the surroundings. The inclusion of $\mathrm{CF}_{3} \mathrm{Br}$ in radiative emission calculations of $\mathrm{CF}_{3} \mathrm{Br}$ inhibited hydrocarbon flames may be significant and ought to be considered, depending on the combustion configuration. Estimates of the impact of $\mathrm{CF}_{3} \mathrm{Br}$ in the cool flame region showed that, for optically thin conditions, $\mathrm{CF}_{3} \mathrm{Br}$ was found to account for approximately $80 \%$ of the total emission in the region approximately $1.5 \mathrm{~mm}$ from the reaction zone, where the temperature is $675 \mathrm{~K}$. In summary, $\mathrm{CF}_{3} \mathrm{BR}$ is expected to play a significant role in the total radiative emission from the flame, which will impact the structure and extinction of these flames.

\section{References}

Bundy, M., Hamins, A., and Lee. K.Y., Suppression Limits of Low Strain Rate Non-Premixed Methane Flames, Combust. Flame, 133, 299-310 (2003).

Fuss, S.P., and Hamins, A., Determination of Planck Mean Absorption Coefficients for $\mathrm{HBr}$, $\mathrm{HCl}$, and HF, ASME J. Heat Transfer, 124, 26-30 (2002).

Hamins, A., Trees, D., Seshadri, K., and Chelliah, H., Combust. Flame, 99, 221 (1994b).

Hamins, A., Bundy, M., Puri, I. K., McGrattan, K. B. and Park, W. C., Proc. 6 ${ }^{\text {th }}$ Int'l $^{\text {' }}$ Microgravity Combustion Workshop, 101 (2001).

Hamins, A., Bundy, M., Oh, C.B., Kim, S.C., "Effect of Buoyancy on the Radiative Extinction Limit of Low Strain Rate Non-Premixed Methane-Air Flames,” Combust Flame, to appear, 2007; (see Appendix 2).

Han, B., Ibarreta, A.F., C.J. Sung, J. T’ien, Combust. Flame, 149 (2007) 173-190.

HITRAN (high-resolution transmission molecular absorption database), .J Quant. Spec. Rad. Tran., 60, 665-710 (1998).

Lee, K.Y., Cha, D.J., Hamins, A., and Puri, I.K., Combust. Flame, 104, 27 (1996).

Lutz, A., Kee, R. J., Grcar, J. and Rupley, F. M., “A Fortran Program Computing Opposed Flow Diffusion Flames,” SAND96-8243, Sandia National Laboratories, Livermore, CA (1997).

Maruta, K., Massaharu, Y. Hongsheng, G., Ju, Y., Niioka, T, Combust. Flame, 112, 181 (1998).

Masri, A.R., "Chemical Inhibition of Nonpremixed Flames of Hydrocarbon Fuels with $\mathrm{CF}_{3} \mathrm{Br}$," Combust Sc Tech, 96, pp. 189-212 (1994).

McGrattan, K. B., Baum, H. R., Rehm, R. G., Hamins, A., Forney, G. P., Floyd, J. E., and Hostikka, S., "Fire Dynamics Simulator Technical Reference Guide,” v.2, NISTIR 6467, National Institute of Standards and Technology, Gaithersburg, MD (2001). 
Macdonald, M.A., Jayaweera, T.M., Fisher, E.M., and Gouldin, F.C., Proc. Twenty-Seventh Symp. (Int.) on Combustion, The Combustion Institute, Pittsburgh, pp. 2749-2756, 1998.

Oh, C.B., Hamins, A., Bundy, M., Park, J., "The Two-Dimensional Structure of Low Strain Rate Counterflow Nonpremixed Methane Flames in Normal and Microgravity," Combust Theory Modeling, to appear, 2007; (see Appendix 1).

Pitts, W.M., Smyth, K. C., and Everest, D. A., Proc. Twenty-Seventh Sym. (Int.) on Combustion, The Combustion Institute, Pittsburgh, pp. 563-569, 1998.

Puri, I.K. and Hamins, A., A Numerical Investigation of Radiative Effects in Near-Extinction Methane-Air Nonpremixed Flames, submitted to Combustion \& Flame, 2002.

Rothman, L., Gamache, R., Tipping, R., Rinsland, C., Smith, M., Benner, D., Malathy, D., Flaud, J.M., Peyret-Camy, C., Perrin, A., Goldman, A., Massie, S., Brown, L., and Toth, R., J. Quant. Spectroc. Radiat. Transf., 48, 469 (1992).

Seshadri, K. and Williams, F.A., Halogenated Fire Suppressants. ACS Symposium Series 16. April 23-24, 1975, San Antonio, TX, American Chemical Society, Washington DC, (Ed.: R.G. Gann) pp. 149-182, 1975.

Smyth, K., and Everest, D., Proc. Twenty-Sixth Symp. (Int.) on Combustion, The Combustion Institute, Pittsburgh, pp. 1385-1392, 1996.

Wakatsuki, K., Jackson, G.S., Kim, J., Hamins, A.. M.R. Nyden, and S.P. Fuss, Determination of Planck Mean Absorption Coefficients for Hydrocarbon Fuels, in review, Combust. Sci. Tech., 2007.

\section{List of Publications}

Refereed Publications:

1. K. Wakatsuki, S.P. Fuss, A. Hamins, M.R. Nyden, G. S. Jackson, and J. Kim, “A technique for extrapolating absorption coefficient measurements to high temperatures," Proceedings of the $30^{\text {th }}$ (Int.) Sym. Combust., 1565-1573 (2005) ; see Appendix 5.

2. A. Hamins, M. Bundy, C.B. Oh, S.C. Kim, "Effect of Buoyancy on the Radiative Extinction Limit of Low Strain Rate Non-Premixed Methane-Air Flames,” Combust Flame, to appear, 2007; see Appendix 2.

3. C.B. Oh, A. Hamins, M. Bundy, J. Park, "The Two-Dimensional Structure of Low Strain Rate Counterflow Nonpremixed Methane Flames in Normal and Microgravity," Combust Theory Modeling, to appear, 2007; see Appendix 1.

4. K.Wakatsuki, G.S. Jackson, J.Kim, A.Hamins, M.R. Nyden, and S.P. Fuss, Determination of Planck Mean Absorption Coefficients for Hydrocarbon Fuels, in review, Combust. Sci. Tech., 2007; see Appendix 7.

\section{Conference Presentations}

1. Hamins, A., Bundy, M., Oh, C.B., Park, and Puri, I.K., "Suppression of Low Strain Rate Nonpremixed Flames by an Agent," presented at the Microgravity Combustion Workshop, Cleveland, OH, June, 2004. 


\title{
Appendix 1
}

\section{The Two-Dimensional Structure of Low Strain Rate Counterflow Nonpremixed Methane Flames in Normal and Microgravity}

\begin{abstract}
The structure and extinction of low strain rate nonpremixed methane-air flames was studied numerically and experimentally. A time-dependent axisymmetric two-dimensional (2D) model considering buoyancy effects and radiative heat transfer was developed to capture the structure and extinction limits of normal gravity $(1-\mathrm{g})$ and zero gravity $(0-\mathrm{g})$ flames. For comparison with the 2D modeling results, a one-dimensional (1D) flamelet computation using a previously developed numerical code was exercised to provide information on the 0 -g flames. A 3-step global reaction mechanism was used in both the 1D and 2D computations to predict the measured extinction limit and flame temperature. Photographic images of flames undergoing the process of extinction were compared with model calculations. The axisymmetric numerical model was validated by comparing flame shapes, temperature profiles, and extinction limits with experiments and with the 1D computational results.

The 2D computations yielded insight into the extinction mode and flame structure. A specific maximum heat release rate was introduced to quantify the local flame strength and to elucidate the extinction mechanism. The contribution by each term in the energy equation to the heat release rate was evaluated to investigate the multi-dimensional structure and radiative extinction of the $1-\mathrm{g}$ flames. Two combustion regimes depending on the extinction mode were identified. Lateral heat loss effects and multi-dimensional flame and flow structure were also found. At low strain rates in 1-g flames ("Regime A"), the flame is extinguished from the weak outer edge of the flame, which is attributed to a multidimensional flame structure and flow field. At high strain rates, ("Regime B"), the flame extinction initiates near the flame centerline due to an increased diluent concentration in the reaction zone, similar to the extinction mode of 1D flames. These two extinction modes can be clearly explained by consideration of the specific maximum heat release rate.
\end{abstract}




\section{Introduction}

The counterflow flame geometry is a convenient configuration for control of the flow field strain rate as well as the flame position [1]. From an experimental perspective, the counterflow configuration has been used to acquire well-defined data on the structure and extinction behavior of flames. Furthermore, the counterflow configuration is amenable to mathematical and numerical analysis, and has provided useful insight into local "flamelet" structure [1-4].

It is common engineering practice to develop and apply models that are as simple as possible, while maintaining the salient physics. Viewed as a flamelet, the counterflow flame is typically modeled as one-dimensional (1D). Experimental observations under microgravity conditions have confirmed that counterflow flames are nearly flat [5]. Under normal gravity conditions, high strain rate flames are also flat near the flow field centerline as buoyancy is dominated by convection. As the strain rate decreases in normal gravity, however, buoyancy forces become relatively more important and counterflow flames are clearly curved. Onedimensional flame codes such as OPPDIF [6], which are based on a similarity solution that neglects buoyancy fail to describe the multi-dimensional structure of low strain rate normal gravity flames, nor do they capture the dynamics of a flame during the transition from normal gravity to microgravity. To gain physical insight, a numerical method is needed that is capable of simulating realistic flames that are multidimensional due to the influence of buoyancy. The price of using a multidimensional modeling approach is simplification of the complex flame chemistry, such that the duration of a computation is practical. Such approximations are acceptable provided that the most significant observables are adequately represented.

There have been many studies on the structure and extinction of moderately strained counterflow nonpremixed flames [1-4, 7]. Relatively few studies, however, have considered low strain rate flames. Maruta et al. [5] conducted the first comprehensive extinction measurements of very low strain nonpremixed flames in microgravity using the $10 \mathrm{~s}$ JAMIC drop tower in Japan. In that study, the extinction of methane-air diffusion flames with $\mathrm{N}_{2}$ added to the fuel stream was measured under microgravity conditions. The minimum methane concentration required to sustain combustion was found to decrease as the strain rate decreased until a critical value was observed. As the global strain rate was further reduced, the required methane concentration increased. This behavior was denoted as a "turning point" and was attributed to the enhanced importance of radiative loss in low strain rate flames. In terms of fire safety, the turning point agent concentration represents a fundamental limit for nonpremixed flames, assuring suppression for all flow conditions. Bundy et al. [8] observed similar behavior in low strain rate normal gravity flames. Recently, the extinction behavior of ultra low-stretch, buoyant counterflowing nonpremixed flames established in a large Tsujitype burner was investigated [9]. In that study, information about the extinction limit was not provided although multi-dimensional effects on flame extinction were discussed.

The objective of this study was to investigate the structure and extinction characteristics of low strain rate, counterflowing methane-air nonpremixed flames in normal gravity, which was observed but not fully clarified in previous work [8]. In this study, an axisymmetric (2D) computational model including buoyancy effects and radiative heat transfer was developed and validated for counterflow nonpremixed flames by comparison with experiments and 1D computational results. The flame structure and flow field were investigated using the computational results. Extinction limits were also investigated. 


\section{Experiments}

Experiments for counterflow flames were performed using a burner with an inner burner duct diameter (D) of $23.4 \mathrm{~mm}$ and a duct separation distance (L) of $15.0 \mathrm{~mm}$. Four $80 \mathrm{mesh} / \mathrm{cm}$ stainless steel screens were positioned $1.6( \pm 0.1) \mathrm{mm}$ from the duct exits and at $1.6 \mathrm{~mm}$ intervals to impose a top-hat velocity profile. A water-cooled jacket about the top burner duct prevented heating of the metal burner and preheating of the supplied reactants. The reactant flows were controlled using mass flow controllers that were calibrated using a dry cell primary flow meter with an uncertainty of $1 \%$. The details of the burner system and experimental methods were described previously [8].

Flame temperature measurements were conducted using thin filament pyrometry [10]. The details of the measurement and calibration methods are given in Refs. [8, 10]. Still images were taken with a $35 \mathrm{~mm}$ camera (without optical filters), using a shutter time of $1 \mathrm{~s}$ and an f 2.8 aperture to compare the steady flame shapes with computations. Images of extinguishing flames were also recorded with a digital video camera to clarify the difference between flame extinguishing modes at low and high strain rates, while the nitrogen mole fraction in the fuel stream $(\mathrm{Ca})$ was varied from 0.79 to the critical nitrogen mole fraction at extinction ("the extinction limit; $\mathrm{Ca}_{\mathrm{ex}}$ "). Experimental data for the extinction limits as a function of a global strain rate for methane-air normal gravity (1-g) counterflow flames was compared with previous results [8].

The global strain rate, $\mathrm{a}_{g}$, was defined as [11]:

$$
\mathrm{a}_{g}=\frac{2 V_{O}}{L}\left(1+\frac{V_{F} \sqrt{\rho_{F}}}{V_{O} \sqrt{\rho_{O}}}\right)=\frac{2 V_{r} V_{F}}{L}\left(1+\frac{\sqrt{\rho_{F}}}{V_{r} \sqrt{\rho_{O}}}\right)
$$

where the $V$ denotes the velocity and $\rho$ the density of the reactant streams at the duct boundaries, $L$ is the duct separation distance, and the subscripts $\mathrm{O}$ and $\mathrm{F}$ represent the air and fuel streams, respectively. The velocity ratio, $V_{r}$, is defined as equal to $V_{O} / V_{F}$. The global strain rate concept allows quantification of a characteristic flame residence time or flow time.

\section{Model formulation and numerical methods}

\subsection{Numerical methods for a two-dimensional model}

A transient two-dimensional simulation of the 1-g counterflow diffusion flames formed between two opposed circular ducts of finite dimensions was developed. A coupled set of governing equations with a low Mach number approximation [12] was used in an axisymmetric configuration. The governing equations were written as follows:

$$
\begin{aligned}
& \frac{\partial \rho}{\partial t}+\nabla \cdot(\rho \mathbf{u})=0 \\
& \frac{\partial(\rho \mathbf{u})}{\partial t}+\nabla \cdot(\rho \mathbf{u u})=-\nabla p_{1}+\nabla \cdot \mu\left[(\nabla \mathbf{u})+(\nabla \mathbf{u})^{\mathbf{T}}-\frac{2}{3}(\nabla \cdot \mathbf{u}) \mathbf{I}\right]+\left(\rho-\rho_{0}\right) \mathbf{g} \\
& \frac{\partial\left(\rho Y_{i}\right)}{\partial t}+\nabla \cdot\left(\rho \mathbf{u} Y_{i}\right)=\nabla \cdot\left(\rho D_{i m} \nabla Y_{i}\right)+W_{i} \dot{\omega}_{i}, \quad(i=1,2, \cdots N) \\
& \rho c_{p}\left(\frac{\partial T}{\partial t}+\mathbf{u} \cdot \nabla T\right)=\nabla \cdot(\lambda \nabla T)+\rho \sum_{i=1}^{N}\left(c_{p i} D_{i m} \nabla Y_{i} \cdot \nabla T\right)-\sum_{i=1}^{N} W_{i} h_{i}^{0} \dot{\omega}_{i}+\dot{q}_{r}
\end{aligned}
$$




$$
p_{0}=\rho R_{0} T \sum_{i=l}^{N}\left(\frac{Y_{i}}{W_{i}}\right)
$$

where $p_{0}$ and $p_{1}$ represent the thermodynamic and hydrodynamic pressure, respectively; the superscript $\mathbf{T}$ is the transpose tensor; $\mathbf{I}$ is the identity tensor, $\mathbf{u}$ is the velocity vector, $T$ is the temperature, $\dot{q}_{r}$ is the volumetric radiative heat loss rate, $\rho$ is the density; $\mu$ is the viscosity; $\lambda$ is the thermal conductivity, $R_{0}$ is the universal gas constant, and $Y_{i}, h_{i}^{0}, \dot{\omega}_{i}$, and $c_{p i}$ are the mass fraction, heat of formation, production rate, and specific heat of species $i$, respectively. $D_{i m}$ is the mixture-averaged diffusion coefficient, which is written in the following form:

$$
D_{i m}=\frac{1-Y_{i}}{\sum_{j \neq 1}^{N} X_{j} / D_{j i}}
$$

where $D_{j i}$ are the binary diffusion coefficients obtained from the collision integrals [13] and $X_{j}$ are the volume fractions of species $\mathrm{j}$. A detailed description of the transport model can be found elsewhere [13]. The buoyancy term was included in the momentum equations to capture 1-g flames features. The Soret and Dufour effects were not considered.

QUICK [14] and a second-order central difference schemes were used to discretize the convective and diffusive terms in the governing equations. A predictor-corrector scheme nearly identical to that of Najm et al. [15] was used for time integration of the governing equations. For the time integration of the species and energy equations, a second-order Adams-Bashforth scheme was used for the predictor step and a second-order quasi-CrankNicolson scheme was used for the corrector step. A second-order Adams-Bashforth scheme was used for both the predictor and the corrector steps in the time integration of the momentum equation. Efficient algebraic relaxation for the velocity-pressure correction was performed using the HSMAC method [16], which was modified to consider density variation. CHEMKIN-II [17] and TRANFIT [13] were adopted for the calculation of thermodynamic and transport properties. The numerical code used in this study was validated previously by comparing the results with experiments for steady counterflow flames [18]. The detailed numerical scheme has been described elsewhere [19].

The experimental inlet duct geometry and computational domain are shown in Figure 1. The fuel and air issued from the lower and upper ducts, respectively. The inner duct diameter was $23.4 \pm 0.1 \mathrm{~mm}$. The separation distance between the two duct exits and the nozzle rim thickness (W) were $15 \mathrm{~mm}$ and $3.2 \mathrm{~mm}$, respectively. In a previous study [8], it was shown that the flame temperature could affect the inflow boundary temperature of the upper duct at low strain rates due to buoyancy effects, and that the flame location could be affected by the inflow temperature of the upper duct. The nozzle protrusion length $\left(\mathrm{L}_{\mathrm{p}}\right)$ is the length of the inner rim, just before the location of the fine mesh metal screens in the experimental apparatus, which were described previously. A sensitivity analysis showed that the value of $\mathrm{L}_{\mathrm{p}}$ affects the character of the flow field and therefore must be included in the model. In the experiment and the computation, $\mathrm{L}_{\mathrm{p}}$ was equal to $1.2 \mathrm{~mm}$. The computational domain in the axial and radial directions was $40 \mathrm{~mm}$ and $50 \mathrm{~mm}$, respectively.

For the computation, a 268 x 90 grid system was used. A uniform grid spacing of $0.15 \mathrm{~mm}$ and $0.3 \mathrm{~mm}$ were used in the axial and radial directions, respectively. Because a global reaction mechanism was used in the computations, the smallest length scale in these laminar flames is the heat release rate region. The heat release zone for conditions considered in this study is relatively thick, due to the low strain rate conditions. In Figs. 11 and 13, it is seen that the width of the heat release rate region is approximately $1.7 \mathrm{~mm}$ to $2.0 \mathrm{~mm}$. Generally, at least 10 grid 
points are needed to resolve the heat release rate region. A grid sensitivity study was conducted for a number of limiting flame conditions in which 3 grids sizes $(\mathrm{dx})$ were tested: $0.20 \mathrm{~mm}, 0.15 \mathrm{~mm}$ and $0.10 \mathrm{~mm}$. The results for $\mathrm{dx}=0.15 \mathrm{~mm}$ were within $0.4 \%$ and $0.3 \%$ for the maximum temperature and the extinction limits, respectively, of the results using $\mathrm{dx}=0.1 \mathrm{~mm}$ for simulation of normal gravity flames $\left(\mathrm{a}_{\mathrm{g}}=60 \mathrm{~s}^{-1}\right.$ and $\left.15 \mathrm{~s}^{-1}\right)$. Consequently, a grid system with $\mathrm{dx}=0.15 \mathrm{~mm}$ was considered sufficient to resolve the flames considered in this study.

Symmetry boundary conditions were applied for the velocities, species mass fractions, and temperature on the centerline. Uniform axial velocity without a radial velocity component was imposed on the fuel and air duct exits. As in the experiment, $\mathrm{N}_{2}$ flowed from the lower concentric duct (Side A) with an axial velocity of $0.03 \mathrm{~m} / \mathrm{s}$ [8], creating a curtain about the reactants. A slip boundary condition was applied to Side B. Side C was treated as an outflow boundary, because the incoming flow mainly escaped from the upper boundary in the normal gravity flame computations. No-slip and Neumann boundary conditions were applied for the velocity and its gradient, respectively, on the burner walls. The inflow temperatures for the fuel, air and curtain streams were set to be $298 \mathrm{~K}$, and the wall temperature was also taken to be $298 \mathrm{~K}$. The air stream was composed of $21 \%$ oxygen and $79 \%$ nitrogen by volume, and the fuel stream was composed of methane diluted by nitrogen. The ambient curtain flow was set to pure nitrogen to prevent secondary combustion of fuel.

The computational time required to obtain the initial steady flame was typically $24 \mathrm{CPU}$ hours on a $2 \mathrm{GHz}$ PC.

\subsection{Chemical reaction mechanism and radiation model}

A 3-step irreversible reaction mechanism [20] for methane oxidation was used in the 2D computation, because the mechanism was relatively less stiff compared to other global mechanisms that were considered. The pre-exponential factor and the activation energy in the reaction mechanism were slightly adjusted, so that the $2 \mathrm{D}$ numerical code reasonably predicted the experimentally determined extinction limit (see Fig. 5) and the flame temperature profile of a moderately strained methane-air nonpremixed flame $\left(\mathrm{a}_{\mathrm{g}}=40 \mathrm{~s}^{-1}\right)$. A moderately strained flame was selected so that radiative heat losses would not significantly influence the calculation results. The reaction mechanism used in this study was:

$$
\begin{aligned}
& \mathrm{CH}_{4}+1.5 \mathrm{O}_{2} \rightarrow \mathrm{CO}+2 \mathrm{H}_{2} \mathrm{O} \\
& \mathrm{CO}+0.5 \mathrm{O}_{2} \rightarrow \mathrm{CO}_{2} \\
& \mathrm{CO}_{2} \rightarrow \mathrm{CO}+0.5 \mathrm{O}_{2}
\end{aligned}
$$

and the associated reaction rates were:

$$
\begin{aligned}
& -\mathrm{d}\left[\mathrm{CH}_{4}\right] / \mathrm{dt}=10^{11.68} \exp (-23,500 / \mathrm{T})\left[\mathrm{CH}_{4}\right]^{0.7}\left[\mathrm{O}_{2}\right]^{0.8} \\
& -\mathrm{d}[\mathrm{CO}] / \mathrm{dt}=10^{12.35} \exp (-19,200 / \mathrm{T})[\mathrm{CO}]^{1.0}\left[\mathrm{H}_{2} \mathrm{O}\right]^{0.5}\left[\mathrm{O}_{2}\right]^{0.25} \\
& -\mathrm{d}\left[\mathrm{CO}_{2}\right] / \mathrm{dt}=10^{12.50} \exp (-20,500 / \mathrm{T})[\mathrm{CO}]^{1.0}\left[\mathrm{H}_{2} \mathrm{O}\right]^{0.5}\left[\mathrm{O}_{2}\right]^{0.25}
\end{aligned}
$$

with the reactions rates in units of $\mathrm{kmole} / \mathrm{m}^{3}$-s.

Experiments (Figs. 7 and 9) have shown that the near-extinction $\mathrm{N}_{2}$ diluted flames considered here are completely non-luminous (band radiation only). This may be due to the relatively cool flame temperatures, precluding the formation of soot particles that otherwise occur in undiluted methane flames. The assumption of no thermal radiation by soot in the $\mathrm{N}_{2}$ diluted flames was thereby warranted. Therefore, an optically-thin radiation sub-model [21] was implemented, which considered heat loss from the participating gaseous species $\mathrm{CH}_{4}, \mathrm{CO}_{2}$, $\mathrm{H}_{2} \mathrm{O}$ and $\mathrm{CO}$. 
The volumetric rate of radiative heat loss in the energy equation was written as:

$$
\dot{q}_{r}=-4 \sigma K_{p}\left(T^{4}-T_{\infty}^{4}\right)
$$

where $\sigma$ is the Stefan-Boltzmann constant, $T$ and $T_{\infty}$ are the local flame and the ambient temperature, respectively. The term $K_{p}$ is the Planck mean absorption coefficient of the mixture, which is expressed as:

$$
K_{p}=P_{\mathrm{CH}_{4}} K_{\mathrm{CH}_{4}}+P_{\mathrm{CO}_{2}} K_{\mathrm{CO}_{2}}+P_{\mathrm{H}_{2} \mathrm{O}} K_{\mathrm{H}_{2} \mathrm{O}}+P_{\mathrm{CO}} K_{\mathrm{CO}}
$$

where $P_{i}$ and $K_{i}$ denote the partial pressure and the Planck mean absorption coefficient of species $i$, respectively. Data for $K_{p}$ were taken from Ref. [21].

\subsection{One-dimensional model computation}

For comparison with the two-dimensional (2D) model results, a previously developed onedimensional (1D) flamelet code [6] was used to compute the near-extinction flame structure and the agent extinction requirements in low and moderate strain rate diluted methane-air diffusion flames. The numerical code solves the conservation equations using detailed models of molecular transport. An optically thin radiation model [21], the same as in the 2D model, was also adopted in the 1D code. Both, the detailed chemistry of GRI-3.0 [22] and the 3-step global reaction mechanism (Eqs. 8-13) were used in the 1D computations. The counterflow code does not include a buoyancy term in the momentum equation. In this context, the simulations represent zero gravity conditions, but are also a good representation of moderate and high strain rate 1 -g conditions. The inlet boundary conditions at the burner ducts are the same as the 2D computation.

\section{Results and discussion}

\subsection{Validation of the computational results}

The computed flame shape and temperature profiles were compared with measurements to validate the 1D and 2D models. Figure 2 compares photographs of the thin non-luminous 1-g flames and computed flame shapes using the 2D model for the fuel stream diluted with $\mathrm{N}_{2}$, such that the flames were near extinction. The high heat release rate region represents the high temperature zone and the peak heat release rate can be considered to be near the flame surface. The computed flame shape and the flame surface location were similar to those shown in the Fig. 2 photographs. The photographs in Fig. 2 show that the flame size, the shape, and the flame surface location of the 1-g flames were reasonably well predicted by the 2D computations for a variety of global strain rate and velocity ratio conditions (see Eq. 1).

Figure 3 compares the temperature profiles computed by the $1 \mathrm{D}$ and $2 \mathrm{D}$ models with measurements [10] of methane-air nonpremixed counterflow flames for $a_{g}=20 \mathrm{~s}^{-1}$ in both microgravity and 1-g. The flames were highly diluted and at near-extinction conditions with $\mathrm{Ca}=0.81$. For the 0 -g conditions, the $1 \mathrm{D}$ and 2D computations, using the 3 -step mechanism, resulted in nearly identical calculation results for the temperature profiles. For both the microgravity and the 1-g flames, the temperature profiles computed by the $2 \mathrm{D}$ model were in good agreement with previous measurements obtained using thin filament pyrometry [10]. The flame locations were also reasonably predicted by the 2D computation. The 1D model computations (which neglect buoyancy), using either the 3 -step reaction mechanism or 
detailed chemistry, could not accurately predict the location of the 1-g flame, although the flame location and temperature profile in microgravity were well-predicted. The measured and computed temperature profiles show that the flame was broader in microgravity than in $1-\mathrm{g}$, and that the location of the flame shifts towards the center of the flow field in microgravity.

Figure 4 compares the axial velocity profiles computed by the $1 \mathrm{D}$ and $2 \mathrm{D}$ models for the $0-\mathrm{g}$ flame. The 2D computation for the $1-\mathrm{g}$ flame is also shown. The velocity profile of the microgravity flame computed by the $2 \mathrm{D}$ model was nearly identical to that computed by the 1D model, providing confidence that the current 2D model is reasonable. There was little difference in the 1D results, using the full or simplified chemistry model in predicting the velocity profiles. It should be noted, however, that the $1 \mathrm{D}$ model could not simulate the low strain rate 1-g flame structure reasonably, because it does not consider buoyancy effects. The 2D model developed here provides a more complete description of the flame physics as seen in the flame structure, including the flame temperature, location, and velocity profile at low strain rates. As expected, the $1-\mathrm{g}$ velocity profile was completely different than the 0 -g profile, with the stagnation point shifting almost $4 \mathrm{~mm}$ towards the air duct, similar to the shift of the temperature maxima.

\subsection{Extinction limits and characteristics}

The extinction limits were determined by increasing the agent $\left(\mathrm{N}_{2}\right)$ flow and simultaneously decreasing the fuel flow, while maintaining a constant global strain rate, until a critical agent volume fraction in the fuel stream was attained and the flame was experimentally observed to extinguish or the calculation did not converge to a solution. This efficiency of this process was optimized by beginning the calculation or experiment at near-extinction, but stable flame conditions. The rate of change of reactants was sufficiently slow such that the extinction conditions were not affected. A comparison between the measured [8] and computed extinction limits is shown in Figure 5. The 1D model cannot reasonably predict the extinction limits of 1-g flames at low strain rates, when buoyancy effects become dominant, since the buoyancy term was not included in this model. The 1D model yielded nearly the same result using either the 3 step chemistry or GRI-3.0. The results of the 2D model for the 1-g flames are in excellent agreement with the measurements at both low and high strain rates. The results also show that the extinction limit of microgravity flames (1D) is higher than that of 1-g flames at low strain rates $\left(\mathrm{a}_{\mathrm{g}}<35 \mathrm{~s}^{-1}\right)$, whereas those of both microgravity and 1-g flames are nearly identical at high strain rates. In addition, the turning point (i.e., maxima of $\mathrm{Ca}$ ) in the 1-g flame shifts towards much higher strain rates than in microgravity.

The turning point in the microgravity extinction limit curve is a well-known phenomenon, which is attributed to radiative heat loss effects [5, 23]. The turning point in 1-g flames differs phenomenologically from the microgravity case. The turning point of 1 -g flames is not only due to radiative heat loss effects, but is also attributed to multi-dimensional flame extinction effects for the geometry considered in this study. The 1-g flames can be classified into two extinction modes, denoted here as Regimes A and B. It is possible to differentiate these two modes based on the global strain rate, at a value of about $\mathrm{a}_{\mathrm{g}} \approx 35 \mathrm{~s}^{-1}$. The nature of these two regimes is described below.

Figures 6 and 7 show the computed results and experimental photos of the temporal evolution of 1 -g flame extinction at a strain rate of $a_{g}=60 \mathrm{~s}^{-1}$. "Regime B" is characterized by the extinction mechanism, such that an increasing diluent (nitrogen) concentration in the reaction 
zone extinguishes the flame everywhere, over the entire flowfield. The nitrogen mole fraction in the fuel stream of the 1-g flame $(\mathrm{Ca})$ was increased at time equal zero from an initial steady value of 0.79 to 0.825 , its value at the extinction limit. The left hand side of the computational results shows the computed flame temperature, while the right hand side shows the computed local heat release rate. The right hand side of the figures also shows the flow streamlines. Figure 6 shows that the extinction of the $1-\mathrm{g}$ flame initiates near the centerline as the increased nitrogen volume fraction in the fuel stream reaches the flame surface. The zone around the centerline becomes weak as the heat release rate (HRR) decreases and the entire flame abruptly extinguishes. The photographs of the flame extinction process shown in Fig. 7 substantiate these features. The radiant intensity of the flame appears to decrease as $\mathrm{Ca}$ increases, until the flame suddenly extinguishes. This flame extinction mechanism is typical of a moderately or highly strained 1D counterflow flame.

The computed results and photographs for the temporal evolution of 1-g flame extinction at a low strain rate $\left(a_{\mathrm{g}}=20 \mathrm{~s}^{-1}\right)$ are shown in Figs. 8 and 9, respectively. The flame, characterized by what is denoted here as multi-dimensional extinction, belongs to "Regime A". Note that the extinction of the low strain rate $1-g$ flame initiates at the outer flame edge. That is, the flame shrinks radially from the outer flame edge towards the center of the flowfield. Photographs of the actual flame extinction process (shown in Fig. 9) confirm the calculated flame behavior. This unique extinction mechanism is different than that of the high strain flame shown in Figs. 6 and 7. It is evident that the 1-g flames have a multi-dimensional flame structure. Thus, at low strain rates, a 1D model cannot reasonably predict the structure, nor the extinction of $1-\mathrm{g}$ flames.

To investigate flame extinction characteristics in more detail, a "specific maximum heat release rate" (SMHRR) is introduced as defined by Sung et al. [24] as the maximum heat release rate along a normal through the flame divided by the local strain rate $\left(\mathrm{a}_{l}\right)$. The parameter SMHRR is a measure of the flame strength, and can be used to compare the local flame strength or stability along a flame surface. A smaller value of SMHRR implies that the flame is weak or easier to extinguish. In obtaining the SMHRR, a local strain rate was defined as the normal velocity gradient to the flame surface at the maximum heat release rate location, consistent with the definition given in Ref. [25]. Table 1 compares the local flame strength at selected three locations A, B and C. The location A represents the centerline position. Location $\mathrm{C}$ represents the outer flame edge region, which has one-half the value of the heat release rate of the centerline. Location B represents a radial position midway between the centerline and the outer flame edge. Table 1 shows that the calculated local flame strength at the outer edge is weaker than at the centerline for the case $a_{g}=20 \mathrm{~s}^{-1}$, whereas this is not the case for the case $a_{g}=60 \mathrm{~s}^{-1}$. For $a_{g}=60 \mathrm{~s}^{-1}$, both the local strain rate and the heat release rate at the outer flame edge are simultaneously lower, as compared to the centerline. However, for the case $a_{g}=20 \mathrm{~s}^{-1}$, the local strain rate at the outer flame edge is not lower than at the centerline, even though the local heat release rate is lower than at the centerline. Thus, the SMHRR at the outer flame edge becomes small, and flame extinction initiates from the weak outer flame edge at low strain rates $\left(a_{\mathrm{g}}=20 \mathrm{~s}^{-1}\right)$. These calculation results are consistent with experimental observations as shown, for example, in Fig. 9.

\subsection{Multi-dimensional flame structure}

The left hand side of Fig. 10 shows the distributions of the 2D modeling results for methane and oxygen mole fractions in 1-g counterflow flames. Flow streamlines are presented on the 
right-hand side of each figure. The white background represents regions, in which the volume fractions of fuel and oxygen are below 0.05. The white gap between the fuel and oxygen roughly corresponds to the heat release rate region. In the figures, A, B and C are located at the same locations defined in Table 1 . For $\mathrm{a}_{\mathrm{g}}=60 \mathrm{~s}^{-1}$, the fuel encloses the oxygen distribution region. However, for low strain rates $\left(\mathrm{a}_{\mathrm{g}}=20 \mathrm{~s}^{-1}\right)$, the fuel does not enclose the entire oxygen distribution region, and the fuel is not located beyond the burner duct $(r>R)$. The two 1-g flames $\left(\mathrm{a}_{\mathrm{g}}=20 \mathrm{~s}^{-1}\right.$ and $\left.60 \mathrm{~s}^{-1}\right)$ exhibit a curved multi-dimensional flame structure. Table 1 shows for the case $a_{\mathrm{g}}=20 \mathrm{~s}^{-1}$, that the local strain rate at location $\mathrm{C}$ (where $\mathrm{r} / \mathrm{R}=1.1$; see Fig. $10)$ is much higher than at location $\mathrm{A}(\mathrm{r} / \mathrm{R}=0)$. Thus, the low strain rate flame becomes weak at the outer flame edge. For this case $\left(\mathrm{a}_{\mathrm{g}}=20 \mathrm{~s}^{-1}\right)$, the fuel concentration drops rapidly beyond the flame edge near location $\mathrm{C}$. The streamlines become dense in the downstream region because there is no heat release there. The streamline distributions are associated with a high local strain rate around location $\mathrm{C}$.

To investigate the local 1-g flame in more detail, the flame structure and the local flow field normal to the flame surface at locations, A, B, and C (shown in Fig. 10) are considered in Figs. 11 and 12 (for $\mathrm{a}_{\mathrm{g}}=60 \mathrm{~s}^{-1}$ ), and Figs. 13 and 14 (for $\mathrm{a}_{\mathrm{g}}=20 \mathrm{~s}^{-1}$ ). For each condition, the radial location for locations $\mathrm{A}, \mathrm{B}$, and $\mathrm{C}$ are specified in Table 1. The abscissa represents the normal distance from the flame surface at each selected location. The location $\mathrm{x}=0 \mathrm{~mm}$ refers to the flame surface location defined by the maximum heat release rate. The local strain rate was defined using the flame stretch concept [26], rather than the oxidizer side maximum velocity gradient [25] because the oxidizer side maximum velocity gradient is not easily defined at all flame locations. In Fig. 11, the flame structure, as represented by the local species mole fractions and temperature, at location $\mathrm{B}$, is nearly identical to that on the centerline at location $\mathrm{A}$. The flame structure at location $\mathrm{C}$ is different than at locations $\mathrm{A}$ and $\mathrm{B}$. The temperature gradient at location $\mathrm{C}$ is smaller than at the centerline, and the fuel distribution is bell-shaped, which is not typical of 1D flames. On the other hand, the oxidizer distribution in the mixing layer is similar to that at the centerline. The normal velocity component to the flame surface and the local strain rate are shown in Fig. 12. The trends of the normal velocity component and the local strain rate profiles relative to the flame surface are related to the temperature profiles shown in Fig. 11, and the flow field at location $\mathrm{C}$ is different from those at locations $\mathrm{A}$ and $\mathrm{B}$ as seen in Fig. 12. That is, the local strain rate at location $\mathrm{C}$ is much lower than at the centerline. In a typical nonpremixed flame, as the strain rate increases, the heat release rate also increases, because the amount of fuel and oxidizer supplied to the flame surface increases. Figure 11 shows that at the flame edge (location $\mathrm{C}$ ), the fuel concentration gradient in the mixing layer is smaller than at the center, and the heat release rate is relatively smaller than the centerline. In total, the flame strength at the outer flame edge as measured by the SMHRR is similar to that at the centerline for $\mathrm{a}_{\mathrm{g}}=60 \mathrm{~s}^{-1}$.

The case $\mathrm{a}_{\mathrm{g}}=20 \mathrm{~s}^{-1}$ is shown in Figs. 13 and 14. The flame structure and the local flow field at locations $A$ and $B$ are similar to those at the centerline for $a_{g}=60 \mathrm{~s}^{-1}$. The fuel concentration gradient in the mixing layer is similar across the flame (locations $\mathrm{A}, \mathrm{B}$, and $\mathrm{C}$ ), even though the local strain rate is much larger at the flame edge (location C). This implies that the fuel supplied to the flame surface at the flame edge is relatively small, and does not follow the profile of a typical nonpremixed flame. Figure 13 shows that the heat release rate at the flame edge is relatively small, and Table 1 shows that the SMHRR at the flame edge is weak compared to the centerline. Consequently, the 1-g flame is extinguished from the relatively weak flame edge at low strain rates, while the region near the centerline is strong enough to sustain combustion. This also explains why the extinction limit of the multi-dimensional 1-g flame is somewhat lower than that of a typical one-dimensional 0 -g flame. 
It is useful to consider the different processes that contribute to the heat release rate and flame stability. For this reason, the relative contribution by each term in the energy equation is considered. The energy equation can be expressed as follows:

$$
\begin{aligned}
& \underbrace{\rho c_{p}\left(\frac{\partial T}{\partial t}\right)}_{0}=-\underbrace{\rho c_{p} u \frac{\partial T}{\partial x}}_{\mathrm{Cx}}-\underbrace{\rho c_{p} v \frac{\partial T}{\partial r}}_{\mathrm{Cr}}+\underbrace{\frac{\partial}{\partial x}\left(\lambda \frac{\partial T}{\partial x}\right)}_{\mathrm{Dx}}+\underbrace{\frac{1}{r} \frac{\partial}{\partial r}\left(r \lambda \frac{\partial T}{\partial r}\right)}_{\mathrm{Dr}} \\
& +\underbrace{\sum_{i=1}^{N} \rho c_{p i} D_{i m} \frac{\partial Y_{i}}{\partial x} \frac{\partial T}{\partial x}}_{\mathrm{Mx}}+\underbrace{\sum_{i=1}^{N} \rho c_{p i} D_{i m} \frac{\partial Y_{i}}{\partial r} \frac{\partial T}{\partial r}}_{\mathrm{Mr}}+\underbrace{\dot{q}_{r}}_{\mathrm{Rs}} \underbrace{-\sum_{i=1}^{N} W_{i} h_{i}^{0} \dot{\omega}_{i}}_{\mathrm{Cs}}
\end{aligned}
$$

where $\mathrm{Cx}$ and $\mathrm{Cr}$ are the axial and radial convection terms, $\mathrm{Dx}$ and $\mathrm{Dr}$ are the axial and radial diffusion terms, $\mathrm{Mx}$ and $\mathrm{Mr}$ are the axial and radial inter-diffusion terms, $\mathrm{Rs}$ is the radiation heat loss rate, and $\mathrm{Cs}$ is the chemical heat release rate. Each term in the energy equation has units of energy per unit time per unit volume.

Figure 15 shows the computed fractional contribution by each term in the energy equation normalized by the heat release source term $\left(C_{s}\right.$ in Eq. 16) in the 0 -g flames as a function of the global strain rate. The relative contribution of each term was obtained by integrating over the flame surface at the centerline. The contribution of the radial convection and interdiffusion terms are also negligible. Axial conduction and diffusion are the largest heat loss mechanisms. The contributions of the axial conduction and diffusion terms to the heat loss are of similar importance in both $0-\mathrm{g}$ and $1-\mathrm{g}$ flames. Thus, radiation and radial conduction mainly contribute to heat loss from the centerline. The relative contribution of the radiative heat loss increases exponentially as the global strain rate decreases in 0 -g flames. In $1-\mathrm{g}$ flames, however, the relative contribution of the radiative heat loss increases linearly as the global strain rate decreases and becomes constant at low strain rates $\left(\mathrm{a}_{\mathrm{g}}<20 \mathrm{~s}^{-1}\right)$. Radial conduction plays an import role in the heat loss mechanism at low strain rates and its contribution becomes similar to that of the radiative heat loss. The reason that the radial conductive heat loss ("lateral heat loss") becomes important at low strain rates $\left(\mathrm{a}_{\mathrm{g}}<20 \mathrm{~s}^{-1}\right)$ is that the flame thickness in the radial direction is small compared with high strain rate flames. As shown in Table 2, the local strain rate in the 1-g flame is much higher than the 0 -g flame due to buoyancy effects for low global strain rates $\left(\mathrm{a}_{\mathrm{g}} \leq 30 \mathrm{~s}^{-1}\right.$; Regime A in Fig. 5), and the thickness of a $1-\mathrm{g}$ flame is smaller than the 0 -g flame. This is also seen in Fig.3. Figure 16 shows that a detailed accounting of the relative contribution of the radiative heat loss from the 1-g flame shows that it is smaller than in the 0 -g flame. Finally, this small radiative heat loss contribution leads to a maximum temperature at the centerline of the low strain $\left(\mathrm{a}_{\mathrm{g}}=20\right.$ $\mathrm{s}^{-1}$ ) 1-g flame that is higher than in the analogous 0 -g flame. This is consistent with previous studies that have indicated that radiative heat loss is an important heat loss mechanism in low strain rate microgravity flames [5].

\section{Summary of results}

A fundamental study of the structure and extinction of normal gravity nonpremixed methane- 
air flames was conducted using computations and experiments. An axisymmetric flame was computed using a global 3-step chemical reaction mechanism. Computations of normal gravity flames showed good agreement with experimental observations of flame curvature, flame location, temperature profile [10] and extinction limits [8]. An axisymmetric formulation was shown to be very important in explaining the multi-dimensional structure of 1-g counterflow nonpremixed flames, which cannot be understood using a one-dimensional model.

The 1-g flame was classified in two regimes. The specific maximum heat release rate was introduced to quantify the local flame strength and to elucidate the extinction mechanism. For relatively high strain rates (Regime B), an increased diluent concentration in the reaction zone causes extinction, and flame extinction initiates near the flame centerline. In this regime, the extinction limit is nearly identical to $1 \mathrm{D}$ flame results. For relatively low strain rates (Regime A), a unique multi-dimensional flame structure and corresponding extinction mechanism occur. The fuel distribution and the buoyancy effects make the local strain rate at the outer edge of low strain 1-g flames much higher than at the centerline. The lateral heat loss effects were identified from an analysis of the overall fractional contribution by each term in the energy equation to the heat release. The relative contribution of the radiative heat loss from a 1-g flame is small compared with the 0-g 1D flame results due to a thin flame thickness caused by a relatively high local strain rate.

At low strain rates in Regime A, the coupled effects of the heat release and the high local strain rate weaken the flame at the outer edge of the 1-g flame. Flame extinction initiates from the weak outer flame edge even though the region near the centerline is still strong enough to sustain combustion. The extinction limit of the $1-\mathrm{g}$ flame is much lower than that of the 0 -g 1D flame at low strain rates due to the multi-dimensional flame extinction mechanism at Regime A. The extinction characteristics of 1-g flames can be explained through consideration of the specific local maximum heat release rate.

\section{Acknowledgements}

This research was supported by the NASA Microgravity Research Division through Contract No. NNC04CB07C with Dr. Sandra L. Olsson serving as Technical Monitor.

\section{References}

[1] Tsuji H 1982 Prog. Energy. Combust. Sci. 8 93-119

[2] Puri I K and Seshadri K 1986 Combust. Flame 65 137-150

[3] Peters N and Kee R J 1987 Combust. Flame 68 17-29

[4] Seshadri K and Kee R J 1988 Combust. Flame 73 23-44

[5] Maruta K, Yoshida M, Guo H, Ju Y and Niioka T 1998 Combust. Flame 112 181-187

[6] Lutz A E, Kee R J, Grcar J F and Rupley, F M 1997 Sandia Report SAND96-8243

[7] Sohrab S H, Liñan A and Williams F A 1982 Combust. Sci. Technol. 27143

[8] Bundy M, Hamins A, Lee K Y 2003 Combust. Flame 133 299-310

[9] Han B, Ibarreta A F, Sung C J and T'ien J S 2004 Proc. Combust. Inst. 30 527-535.

[10] Bundy M, Park J, Oh C B, Hamins A, "Extinction and Temperature Measurements in Nonpremixed Methane Flames in Microgravity," in preparation, 2005.

[11] Seshadri K and Williams F A 1978 Int. J. Heat Mass Transfer 21 251-253

[12] McMrutry P A, Jou W H, Riley J J and Metcalfe R W 1986 AIAA J. 28 962-970 
[13] Kee R J, Dixon-Lewis D, Warnatz J, Coltrin M E and Miller J A 1986 Sandia Report SAND86-8246

[14] Leonard B P 1979 Comput. Meth. Appl. Mech. Eng. 19 59-98

[15] Najm H N and Wyckoff P S 1997 Combust. Flame 110 92-112

[16] Hirt C W and Cook J L 1972 J. Comput. Phys. 10 324-340

[17] Kee R J, Rupley F M and Miller J A 1989 Sandia Report SAND89-8009B

[18] Oh C B, Lee C E and Park J 2004 Combust. Flame 138 225-241

[19] Oh C B, Hwang C H and Lee C E 2006 submitted to J. Comput. Appl. Math

[20] Dryer F L and Glassman I 1972 Proc. Combust. Inst. 14 987-1003

[21] Ju Y, Guo H, Maruta K and Liu F 1997 J. Fluid Mech. 342 315-334

[22] Bowman C T, Hanson R K, Davidson D F, Gardiner W C, Lissianski V, Smith G. P, Golden D M, Frenklach M and Goldenburg M 1999 http://www.me.berkeley.edu/gri_mech/

[23] T'ien J S 1986 Combust. Flame 65 31-34

[24] Sung C J, Liu J B and Law C K 1995 Combust. Flame 102 481-492

[25] Chelliah H K, Law C K, Ueda T, Smooke M D and Williams F A 1990 Proc. Combust.

Inst. 23 503-511

[26] Poinsot T and Veynante D 2001 Theoretical and Numerical Combustion (Edwards)

p.50 


\section{List of Tables}

Table 1. Calculated (2D) specific maximum heat release rate as a function of radial location in 1-g flames.

Table 2. Local strain rate $\left(\mathrm{a}_{l}\right)$ and flame thickness of 0 -g and 1-g flames at select global strain rate conditions.

\section{List of Figures}

Figure 1. Schematic drawing of the burner geometry and computational domain.

Figure 2. Photos (upper) and computed flame shapes (lower) of 1 -g counterflow nonpremixed flame for (a) $\mathrm{a}_{\mathrm{g}}=15 \mathrm{~s}^{-1}$ and $\mathrm{Vr}=4$, (b) $\mathrm{a}_{\mathrm{g}}=20 \mathrm{~s}^{-1}$ and $\mathrm{Vr}=3$, (c) $\mathrm{a}_{\mathrm{g}}=30 \mathrm{~s}^{-1}$ and $\mathrm{Vr}=3$, and (d) $a_{\mathrm{g}}=50 \mathrm{~s}^{-1}$ and $\mathrm{Vr}=1$. Ca is 0.79 for all flames. Temperature is shown on left-hand side of the computed results and the heat release rate and stream lines are shown on the right-hand side of the computed results.

Figure 3. Measured and computed temperature profiles for $\mathrm{a}_{\mathrm{g}}=20 \mathrm{~s}^{-1}$ with $\mathrm{Ca}=0.81$ and $\mathrm{Vr}=1$. Figure 4. Computed axial velocity profiles at the centerline for $\mathrm{a}_{\mathrm{g}}=20 \mathrm{~s}^{-1}$ with $\mathrm{Ca}=0.81$ and $\mathrm{Vr}=1$.

Figure 5. Measured and computed extinction limits and combustion regimes of $1-\mathrm{g}$ and $0 \mathrm{-g}$ counterflow nonpremixed flames.

Figure 6. Computed extinction process of 1-g counterflow nonpremixed flame for $a_{\mathrm{g}}=60 \mathrm{~s}^{-1}$ and $\mathrm{Vr}=1$ while $\mathrm{Ca}$ increases from 0.79 to 0.825 at time equal to $0 \mathrm{~s}$. The flame temperature is shown on the left-hand side, and heat release rate and stream lines are shown on the righthand side. (a) $0 \mathrm{~s}$; (b) $0.06 \mathrm{~s}$; (c) $0.09 \mathrm{~s}$.

Figure 7. Photos of extinction process of a 1-g counterflow nonpremixed flame for $\mathrm{a}_{\mathrm{g}}=60 \mathrm{~s}^{-1}$ and $\mathrm{Vr}=1$, with $\mathrm{Ca}$ increasing from 0.79 to 0.825 .

Figure 8. Computed extinction process of 1 -g counterflow nonpremixed flame for $a_{\mathrm{g}}=20 \mathrm{~s}^{-1}$ and $\mathrm{Vr}=3$ while $\mathrm{Ca}$ increases from 0.79 to 0.825 at time equal to $0 \mathrm{~s}$. Flame temperature is shown on the left-hand side, and heat release rate and stream lines are shown on the righthand side. (a) $0 \mathrm{~s}$; (b) $0.30 \mathrm{~s}$; (c) $0.34 \mathrm{~s}$.

Figure 9. Photos of extinction process of a 1-g counterflow nonpremixed flame for $\mathrm{a}_{\mathrm{g}}=20 \mathrm{~s}^{-1}$ and $\mathrm{Vr}=3$, with $\mathrm{Ca}$ increasing from 0.79 to 0.825 .

Figure 10. Computed fuel $\left(\mathrm{CH}_{4}\right)$ and oxidizer $\left(\mathrm{O}_{2}\right)$ volume fraction distributions in a 1-g counterflow nonpremixed flame for (a) $\mathrm{a}_{\mathrm{g}}=60 \mathrm{~s}^{-1}, \mathrm{Vr}=1$ and $\mathrm{Ca}=0.79$ and (b) $\mathrm{a}_{\mathrm{g}}=20 \mathrm{~s}^{-1}, \mathrm{Vr}=3$ and $\mathrm{Ca}=0.79$. Fuel flows from the lower duct and oxidizer flows from the upper duct. Stream lines are shown on the right-hand side.

Figure 11. Computed flame temperature, reactant $\left(\mathrm{CH}_{4}\right.$ and $\left.\mathrm{O}_{2}\right)$ concentrations, and heat release rate in coordinates normal to the flame surface at three locations for a 1-g counterflow nonpremixed flame with $\mathrm{a}_{\mathrm{g}}=60 \mathrm{~s}^{-1}$ and $\mathrm{Vr}=1$. (symbol : location $\mathrm{A}$; line : location $\mathrm{B}$; dashed line : location C; See Fig. 10 for locations).

Figure 12. Computed normal component of velocity to the flame surface and local strain rate in the coordinates normal to the flame surface at three locations of 1 -g counterflow nonpremixed flame for $\mathrm{a}_{\mathrm{g}}=60 \mathrm{~s}^{-1}$ and $\mathrm{Vr}=1$. (symbol : location $\mathrm{A}$; line : location $\mathrm{B}$; dashed line : location C; See Fig. 10 for locations).

Figure 13. Computed flame temperature, reactants $\left(\mathrm{CH}_{4}\right.$ and $\left.\mathrm{O}_{2}\right)$ concentrations, and heat release rate in the coordinates normal to the flame surface at three locations of $1-\mathrm{g}$ counterflow nonpremixed flame for $\mathrm{ag}_{\mathrm{g}}=20 \mathrm{~s}^{-1}$ and $\mathrm{Vr}=3$. (symbol : location A; line : location B; dashed line : location C; See Fig. 10 for locations).

Figure 14. Computed normal component of velocity to the flame surface and local strain rate in the coordinates normal to the flame surface at three locations of 1 -g counterflow nonpremixed flame for $\mathrm{a}_{\mathrm{g}}=20 \mathrm{~s}^{-1}$ and $\mathrm{Vr}=3$. (symbol : location $\mathrm{A}$; line : location $\mathrm{B}$; dashed line : location C; See Fig. 10 for locations). 
Figure 15. Computed fractional contribution by each term in the energy equation (Eq. 16) to the heat release of 0 -g and $1-\mathrm{g}$ flames with $\mathrm{Ca}=0.79$ as a function of the global strain rate along the flow field centerline. 


\section{Tables}

Table 1. Calculated (2D) specific maximum heat release rate as a function of radial location in 1-g flames.

\begin{tabular}{|c|c|c|c|c|}
\hline Location & $\mathrm{r} / \mathrm{R} *$ & $\begin{array}{c}\text { Maximum HRR } \\
\left(\mathrm{J} / \mathrm{cm}^{3}-\mathrm{s}\right)\end{array}$ & $\begin{array}{c}\text { Local strain rate } \\
\left(\mathrm{s}^{-1}\right)\end{array}$ & $\begin{array}{c}\text { SMHRR } \\
\left(\mathrm{J} / \mathrm{cm}^{3}\right)\end{array}$ \\
\hline \multicolumn{5}{|c|}{$\mathrm{ag}_{\mathrm{g}}=20 \mathrm{~s}^{-1}, \mathrm{Vr}=3, \mathrm{Ca}=0.79$} \\
\hline $\mathrm{A}$ & 0 & 156 & 60 & 2.6 \\
\hline $\mathrm{B}$ & 0.5 & 150 & 61 & 2.5 \\
\hline $\mathrm{C} * *$ & 1.1 & 73 & 95 & 0.8 \\
\hline \multicolumn{7}{|c|}{$\mathrm{a}_{\mathrm{g}}=60 \mathrm{~s}^{-1}, \mathrm{Vr}=1, \mathrm{Ca}=0.79$} \\
\hline $\mathrm{A}$ & 0 & 229 & 105 & 2.2 \\
\hline $\mathrm{B}$ & 0.8 & 228 & 107 & 2.1 \\
\hline $\mathrm{C} * *$ & 1.6 & 116 & 40 & 2.7 \\
\hline
\end{tabular}

* where $\mathrm{R}$ is the burner inner radius and $\mathrm{r} / \mathrm{R}=0$ is at the center of the flow field.

** outer flame edge region has about half the value of the centerline heat release rate.

Table 2. Local strain rate $\left(\mathrm{a}_{l}\right)$ and flame thickness of 0 -g and 1-g flames at select global strain rate conditions.

\begin{tabular}{|c|c|c|c|c|c|}
\hline \multicolumn{2}{|c|}{} & \multicolumn{4}{|c|}{ Global strain rate, $\mathrm{a}_{\mathrm{g}}\left(\mathrm{s}^{-1}\right)$} \\
\cline { 3 - 6 } & 15 & 20 & 40 & 60 \\
\hline $\begin{array}{c}0-\mathrm{g} \\
\text { flame }\end{array}$ & $\begin{array}{c}\text { Local strain rate, } \\
\mathrm{a}_{l}\left(\mathrm{~s}^{-1}\right)\end{array}$ & 27 & 35 & 67 & 97 \\
\cline { 2 - 6 } & $\begin{array}{c}\text { Flame thickness, } \\
\mathrm{w}_{f}^{*}(\mathrm{~mm})\end{array}$ & 10.4 & 9.1 & 6.7 & 5.6 \\
\hline $\begin{array}{c}1-\mathrm{g} \\
\text { flame }\end{array}$ & $\begin{array}{c}\text { Local strain rate, } \\
\mathrm{a}_{l}\left(\mathrm{~s}^{-1}\right)\end{array}$ & 55 & 60 & 73 & 105 \\
\cline { 2 - 6 } & $\begin{array}{c}\text { Flame thickness, } \\
\mathrm{w}_{f}^{*}(\mathrm{~mm})\end{array}$ & 8.0 & 7.5 & 6.5 & 5.3 \\
\hline
\end{tabular}

* The flame width, $\mathrm{w}_{f}$, is defined as the full width at $5 \%$ of the maximum flame temperature. 


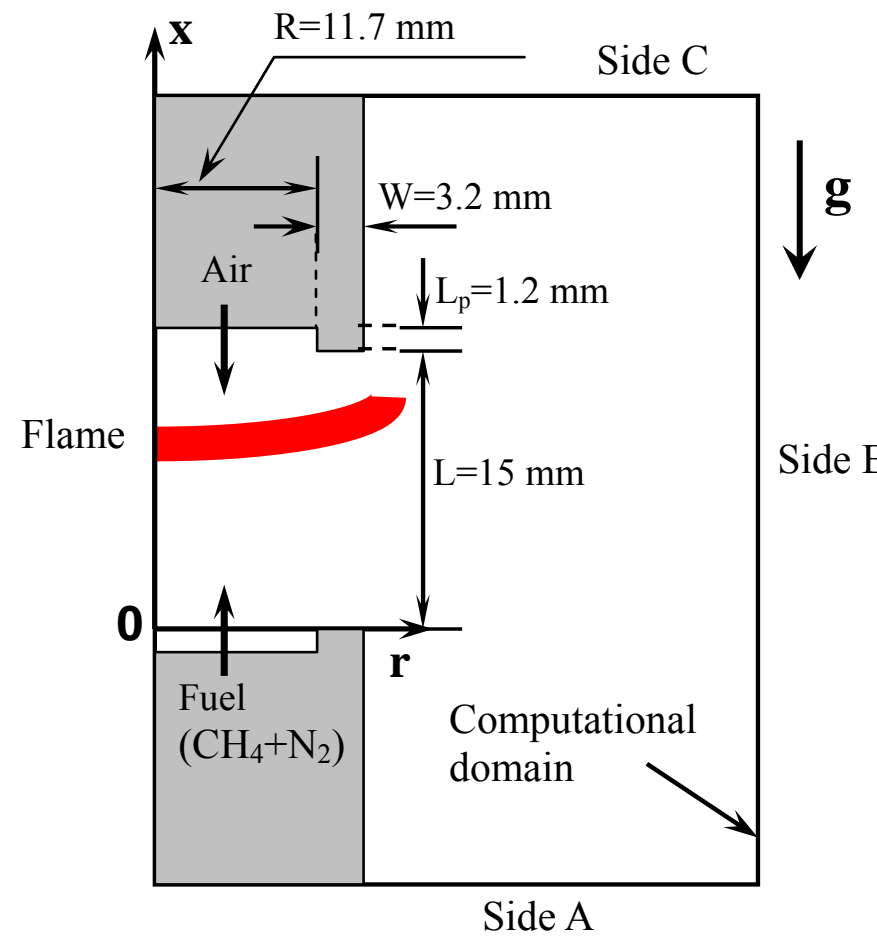

Figure 1. Schematic drawing of the burner geometry and computational domain. 


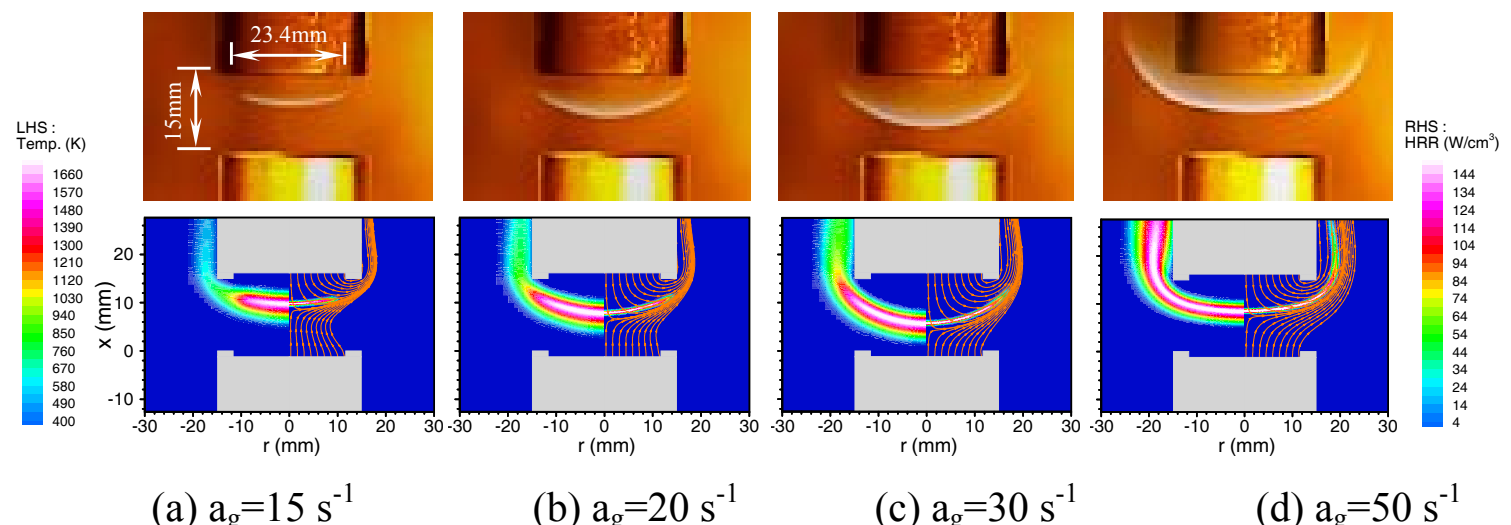

Figure 2. Photos (upper) and computed flame shapes (lower) of 1-g counterflow nonpremixed flame for (a) $\mathrm{a}_{\mathrm{g}}=15 \mathrm{~s}^{-1}$ and $\mathrm{Vr}=4$, (b) $\mathrm{a}_{\mathrm{g}}=20 \mathrm{~s}^{-1}$ and $\mathrm{Vr}=3$, (c) $\mathrm{a}_{\mathrm{g}}=30 \mathrm{~s}^{-1}$ and $\mathrm{Vr}=3$, and (d) $a_{\mathrm{g}}=50 \mathrm{~s}^{-1}$ and $\mathrm{Vr}=1$. Ca is 0.79 for all flames. Temperature is shown on left-hand side of the computed results and the heat release rate and streamlines are shown on the right-hand side of the computed results. 


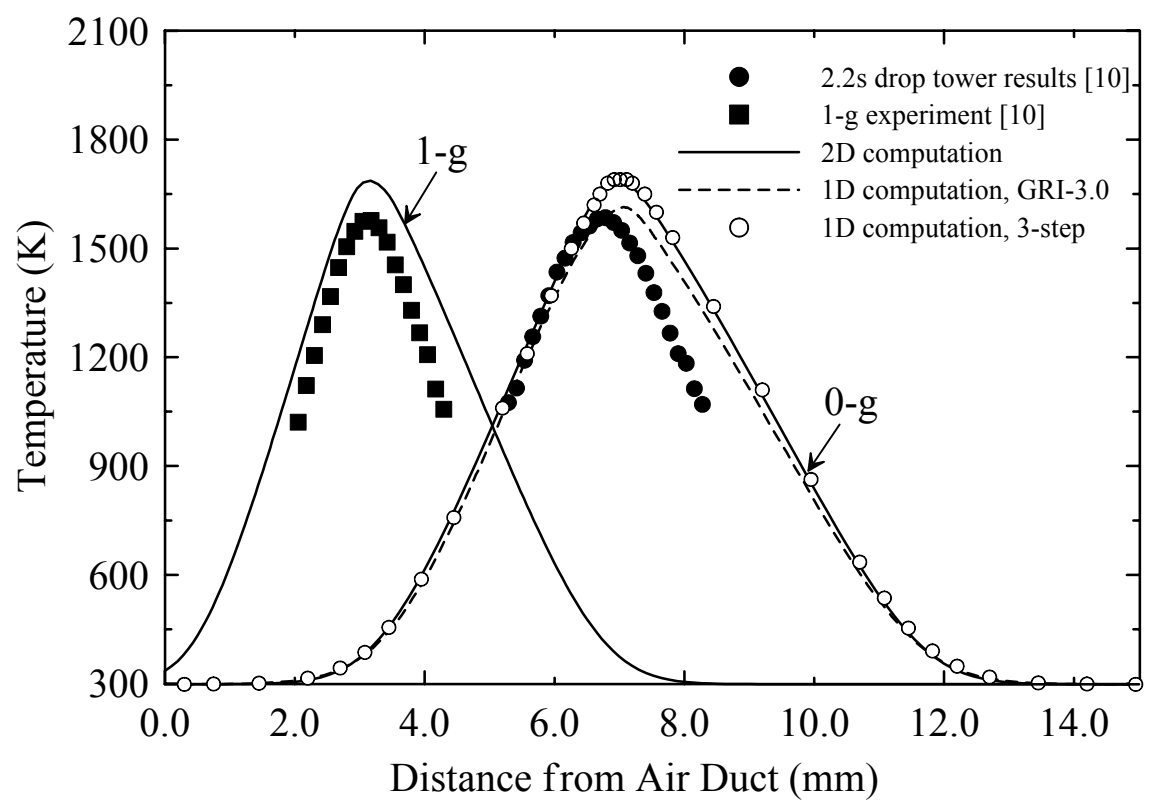

Figure 3. Measured and computed temperature profiles for $\mathrm{a}_{\mathrm{g}}=20 \mathrm{~s}^{-1}$ with $\mathrm{Ca}=0.81$ and $\mathrm{Vr}=1$. 


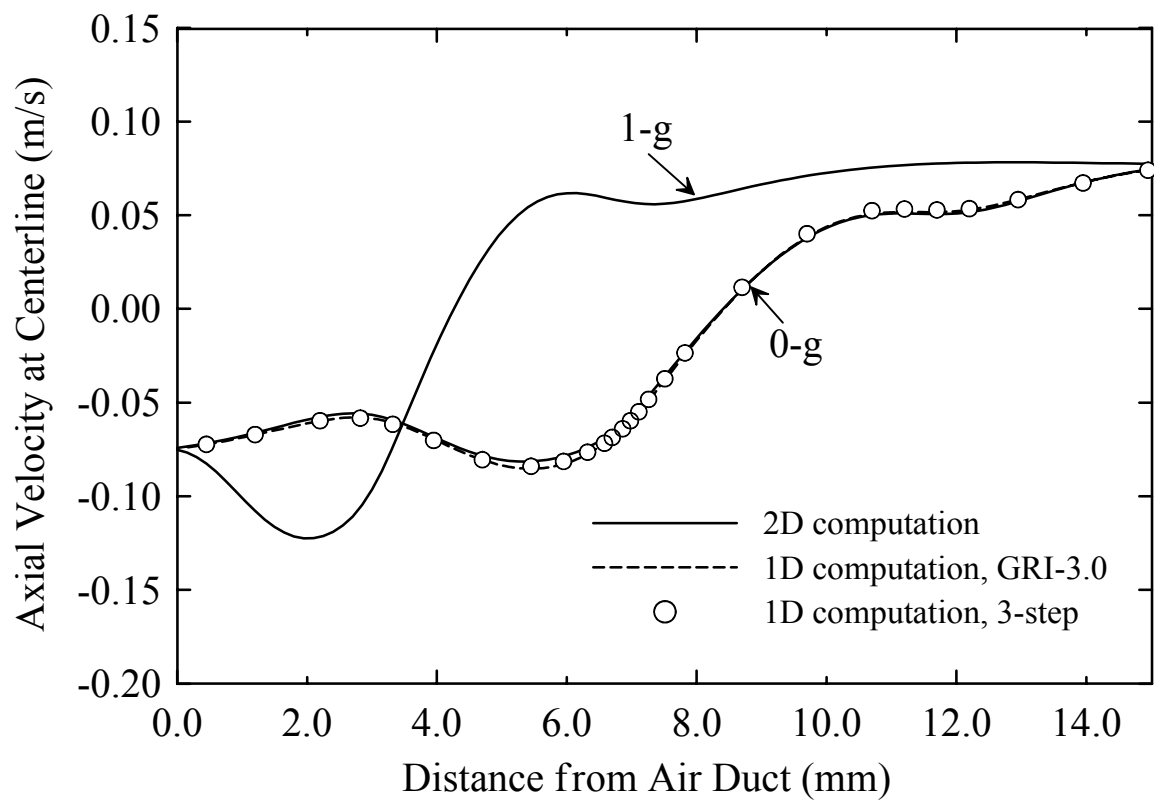

Figure 4. Computed axial velocity profiles at the centerline for $\mathrm{a}_{\mathrm{g}}=20 \mathrm{~s}^{-1}$ with $\mathrm{Ca}=0.81$ and $\mathrm{Vr}=1$. 


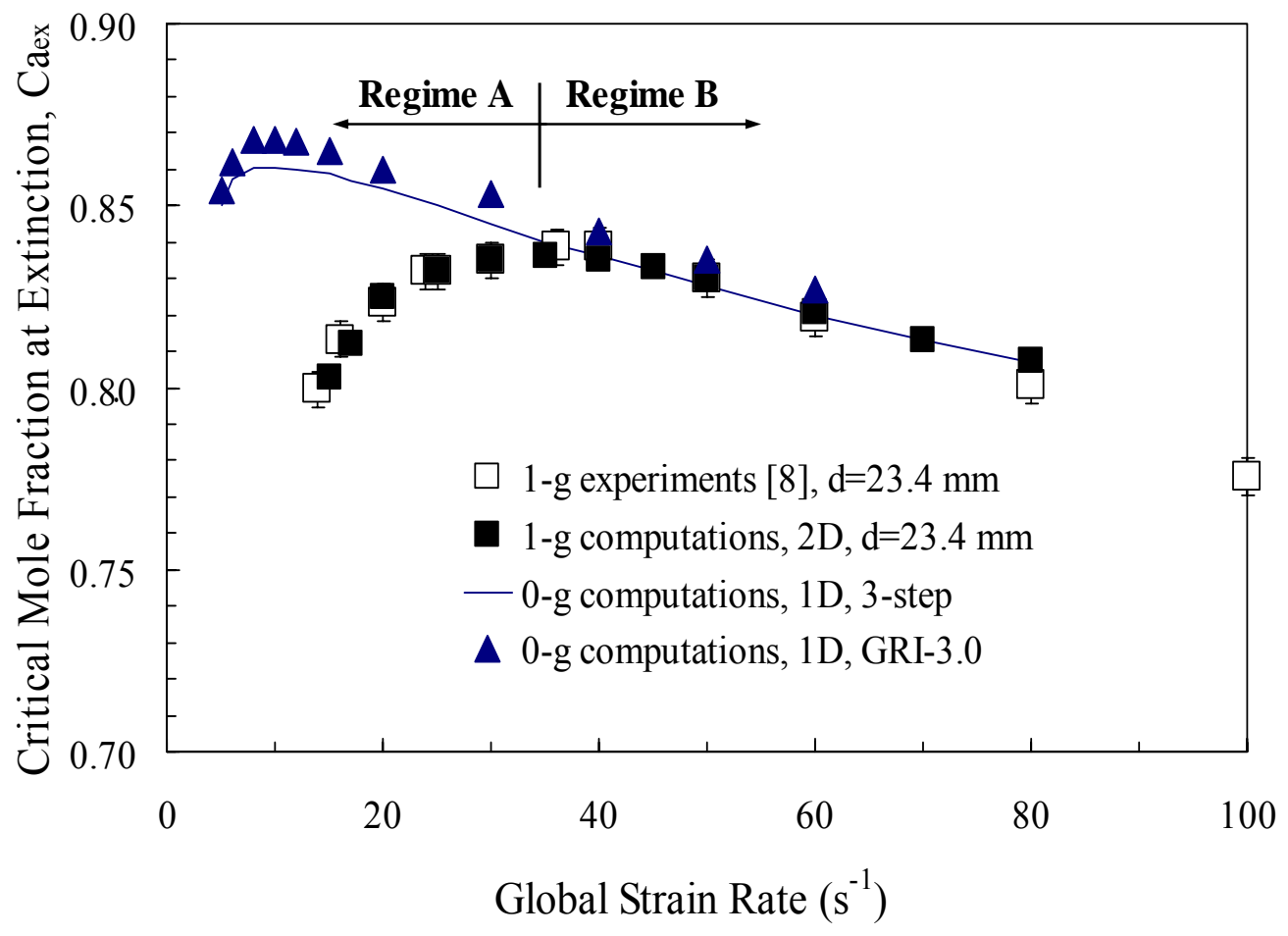

Figure 5. Measured and computed extinction limits and combustion regimes of $1-\mathrm{g}$ and $0-\mathrm{g}$ counterflow nonpremixed flames. 


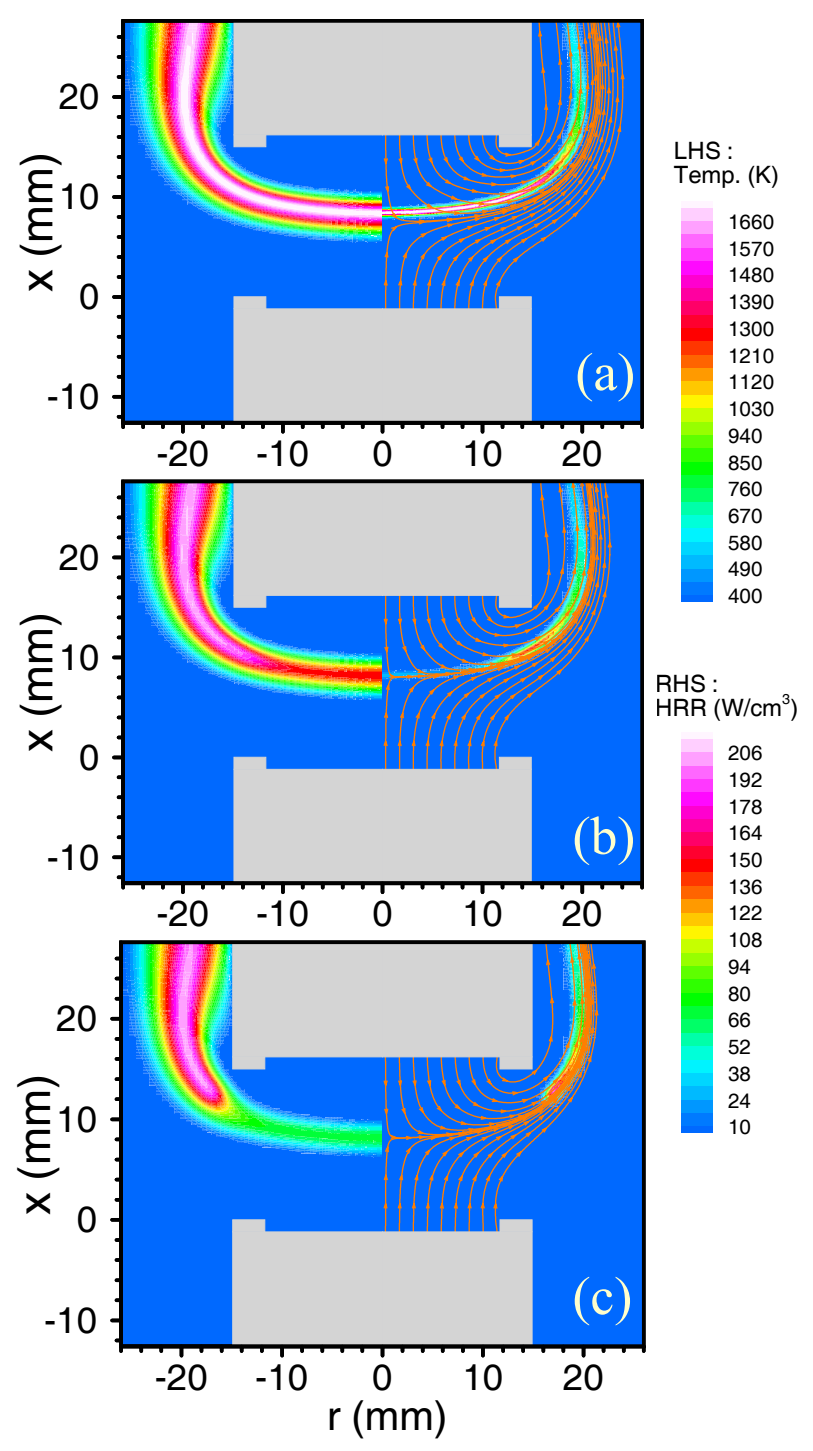

Figure 6. Computed extinction process of 1 -g counterflow nonpremixed flame for $a_{\mathrm{g}}=60 \mathrm{~s}^{-1}$ and $\mathrm{Vr}=1$ while $\mathrm{Ca}$ increases from 0.79 to 0.825 at time equal to $0 \mathrm{~s}$. The flame temperature is shown on the left-hand side, and heat release rate and stream lines are shown on the righthand side. (a) $0 \mathrm{~s}$; (b) $0.06 \mathrm{~s}$; (c) $0.09 \mathrm{~s}$. 

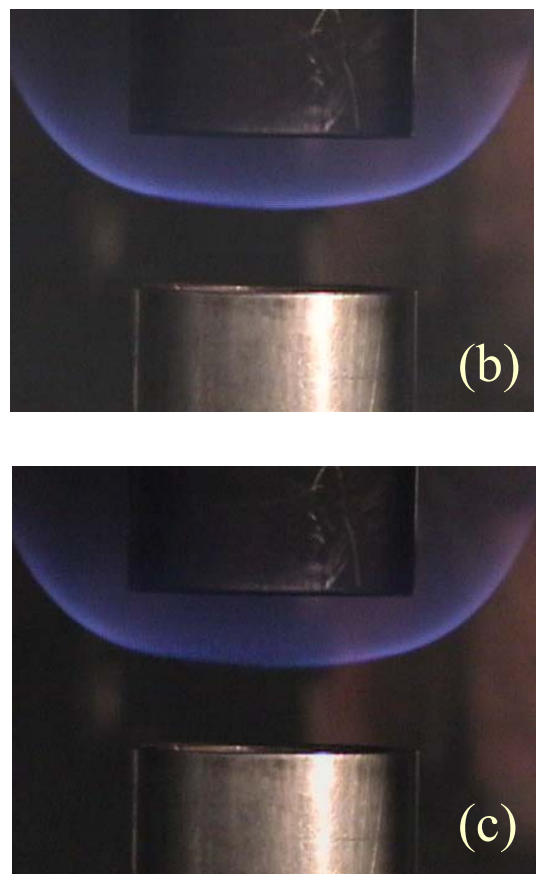

Figure 7. Photos of extinction process of a 1-g counterflow nonpremixed flame for $\mathrm{a}_{\mathrm{g}}=60 \mathrm{~s}^{-1}$ and $\mathrm{Vr}=1$, with $\mathrm{Ca}$ increasing from 0.79 to 0.825 . 


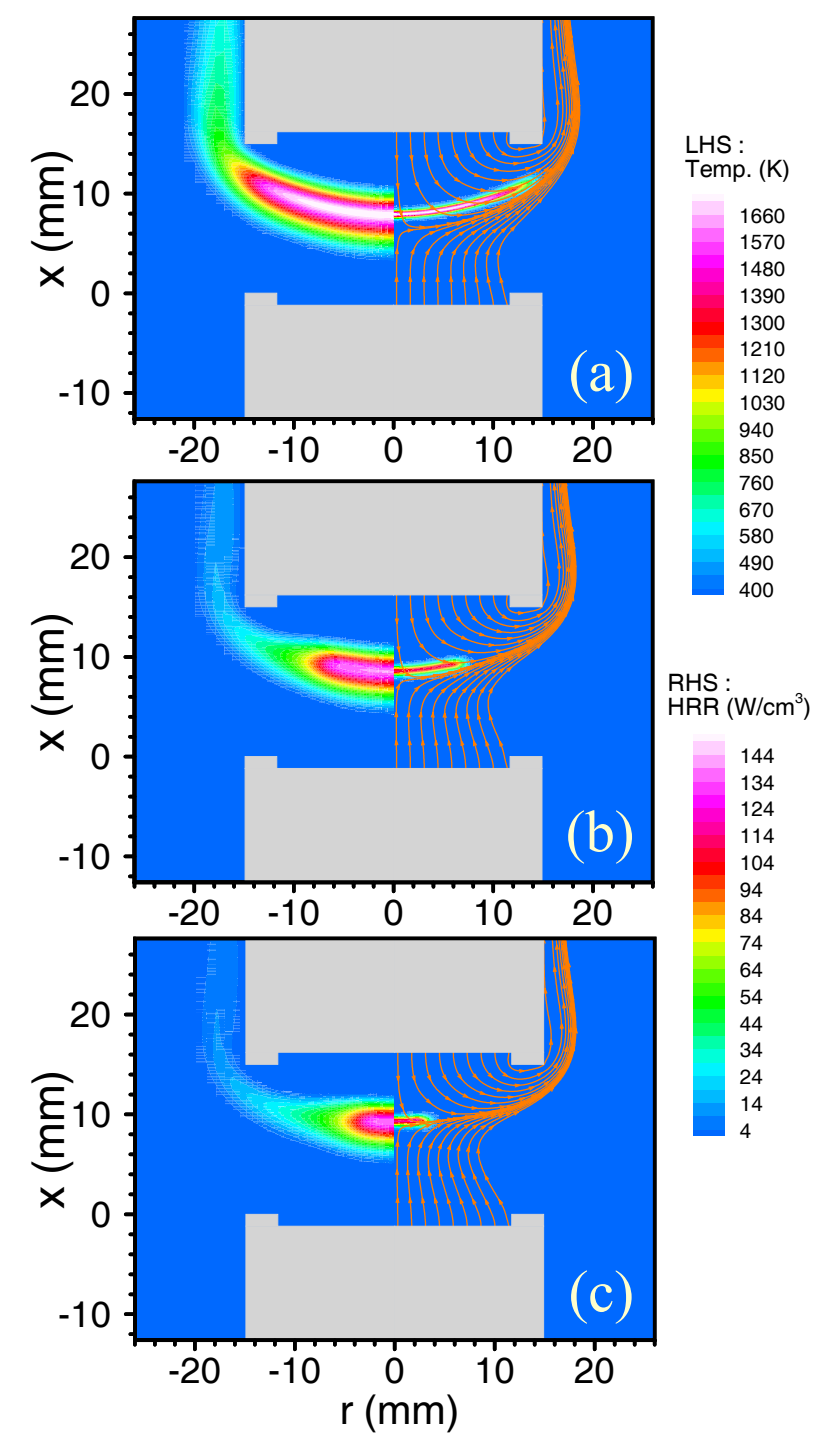

Figure 8. Computed extinction process of 1 -g counterflow nonpremixed flame for $\mathrm{a}_{\mathrm{g}}=20 \mathrm{~s}^{-1}$ and $\mathrm{Vr}=3$ while $\mathrm{Ca}$ increases from 0.79 to 0.825 at time equal to $0 \mathrm{~s}$. Flame temperature is shown on the left-hand side, and heat release rate and stream lines are shown on the righthand side. (a) $0 \mathrm{~s}$; (b) $0.30 \mathrm{~s}$; (c) $0.34 \mathrm{~s}$. 

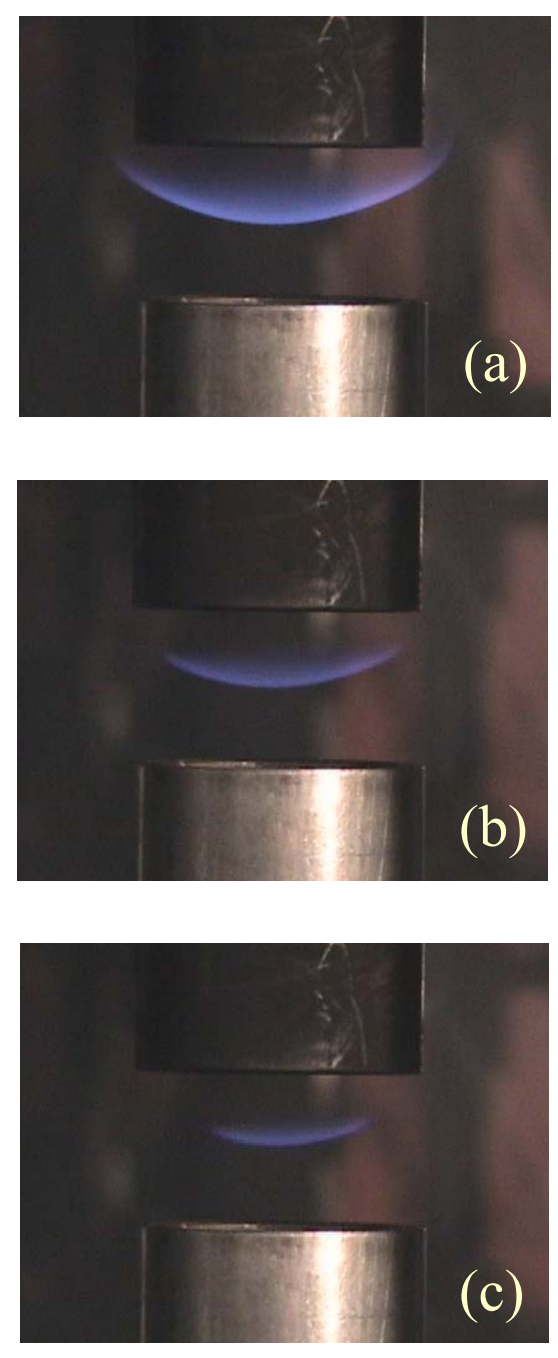

Figure 9. Photos of extinction process of a 1-g counterflow nonpremixed flame for $\mathrm{a}_{\mathrm{g}}=20 \mathrm{~s}^{-1}$ and $\mathrm{Vr}=3$, with $\mathrm{Ca}$ increasing from 0.79 to 0.825 . 


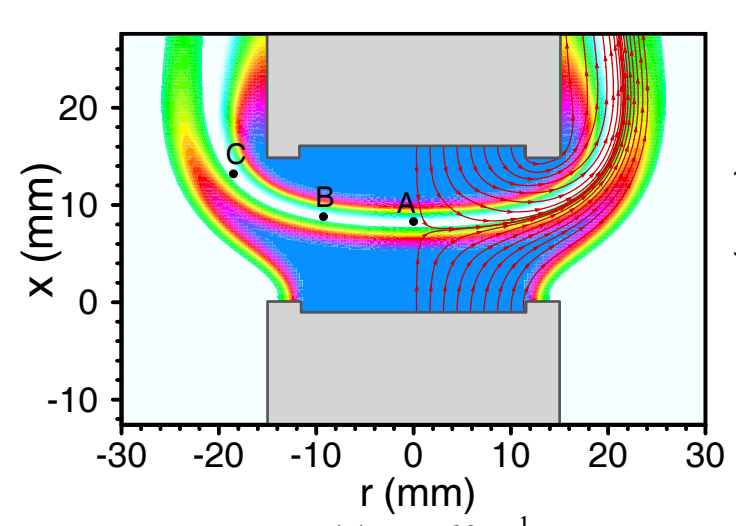

(a) $\mathrm{a}_{\mathrm{g}}=60 \mathrm{~s}^{-1}$,

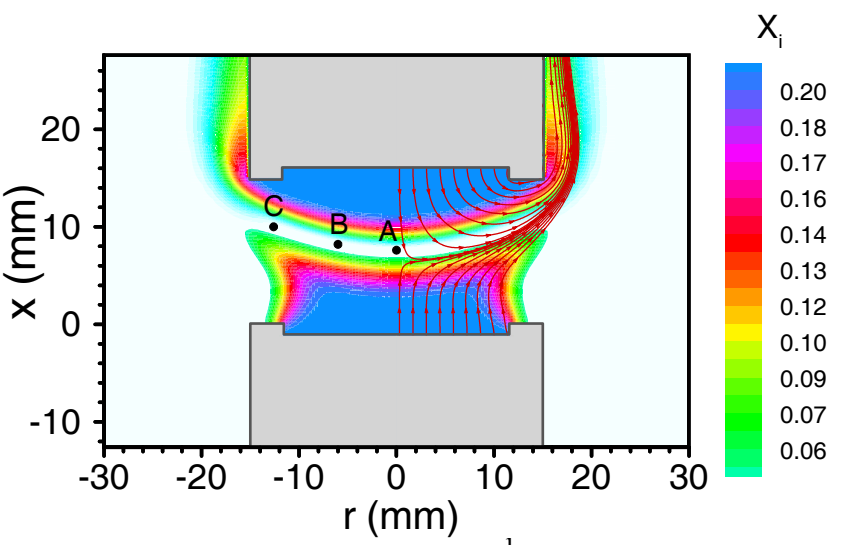

(b) $\mathrm{a}_{\mathrm{g}}=20 \mathrm{~s}^{-1}$

Figure 10. Computed fuel $\left(\mathrm{CH}_{4}\right)$ and oxidizer $\left(\mathrm{O}_{2}\right)$ volume fraction distributions in a 1-g counterflow nonpremixed flame for (a) $a_{\mathrm{g}}=60 \mathrm{~s}^{-1}, \mathrm{Vr}=1$ and $\mathrm{Ca}=0.79$ and (b) $\mathrm{ag}_{\mathrm{g}}=20 \mathrm{~s}^{-1}, \mathrm{Vr}=3$ and $\mathrm{Ca}=0.79$. Fuel flows from the lower duct and oxidizer flows from the upper duct. Streamlines are shown on the right-hand side. 


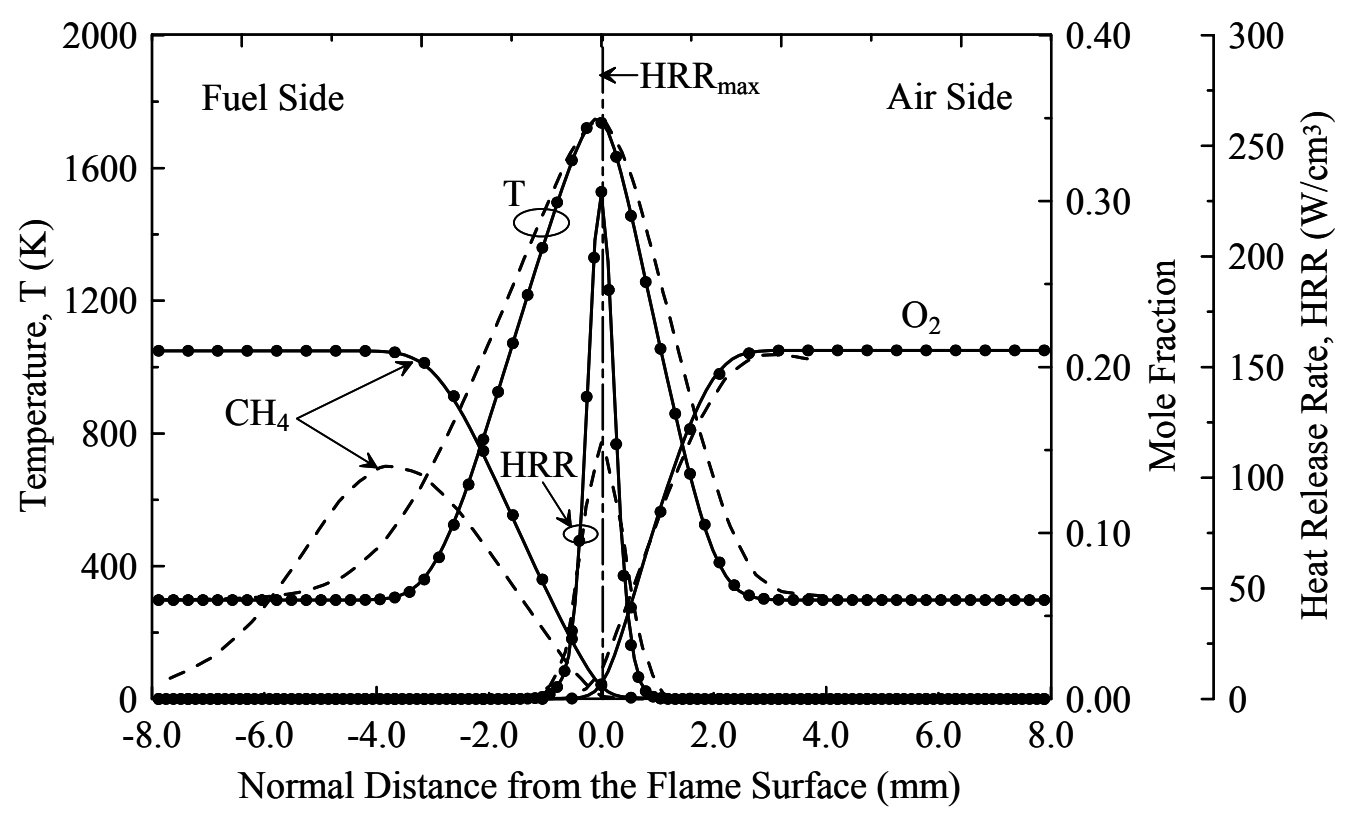

Figure 11. Computed flame temperature, reactant $\left(\mathrm{CH}_{4}\right.$ and $\left.\mathrm{O}_{2}\right)$ concentrations, and heat release rate in coordinates normal to the flame surface at three locations for a 1-g counterflow nonpremixed flame with $\mathrm{a}_{\mathrm{g}}=60 \mathrm{~s}^{-1}$ and $\mathrm{Vr}=1$. ( $\bullet$ : location $\mathrm{A}$; - : location $\mathrm{B}$; --- : location $\mathrm{C}$; see Fig. 10 for location of points A, B, and C). 


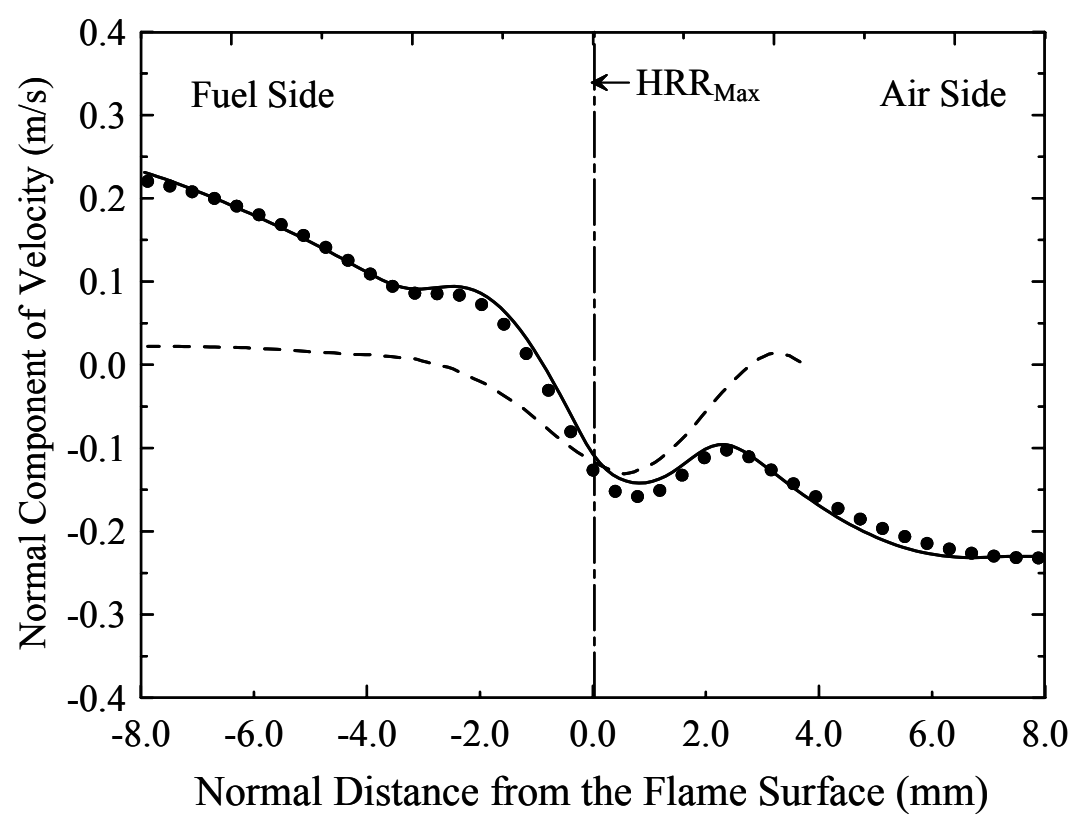

(a) normal component of velocity to the flame surface

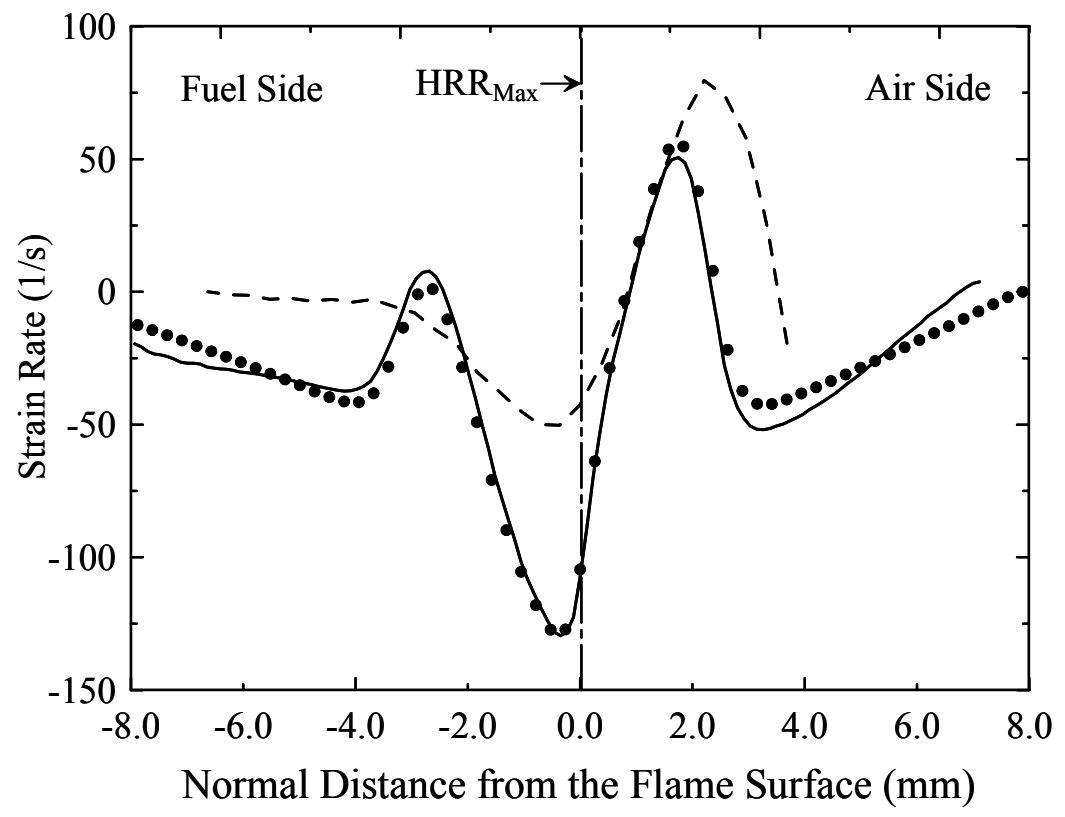

(b) local strain rate

Figure 12. Computed normal component of velocity to the flame surface and local strain rate in the coordinates normal to the flame surface at three locations of 1 -g counterflow nonpremixed flame for $\mathrm{a}_{\mathrm{g}}=60 \mathrm{~s}^{-1}$ and $\mathrm{Vr}=1$. ( $\bullet$ : location $\mathrm{A},-$ : location $\mathrm{B}$, --- : location $\mathrm{C}$; see Fig. 10 for location of points A, B, and C). 


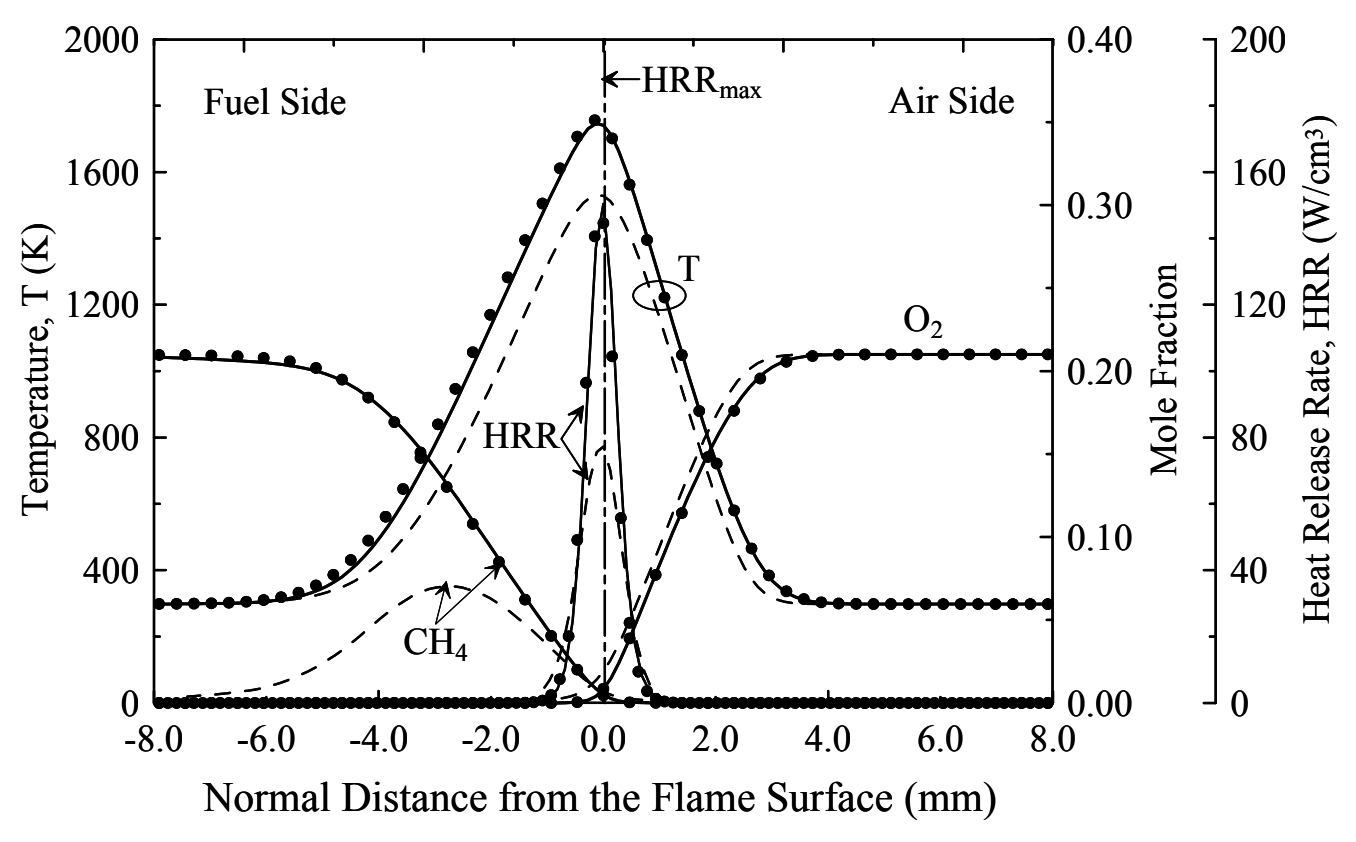

Figure 13. Computed flame temperature, reactants $\left(\mathrm{CH}_{4}\right.$ and $\left.\mathrm{O}_{2}\right)$ concentrations, and heat release rate in the coordinates normal to the flame surface at three locations of $1-\mathrm{g}$ counterflow nonpremixed flame for $\mathrm{a}_{\mathrm{g}}=20 \mathrm{~s}^{-1}$ and $\mathrm{Vr}=3$. ( $\bullet$ : location $\mathrm{A},-$ : location $\mathrm{B},---$ : location C; see Fig. 10 for location of points A, B, and C). 


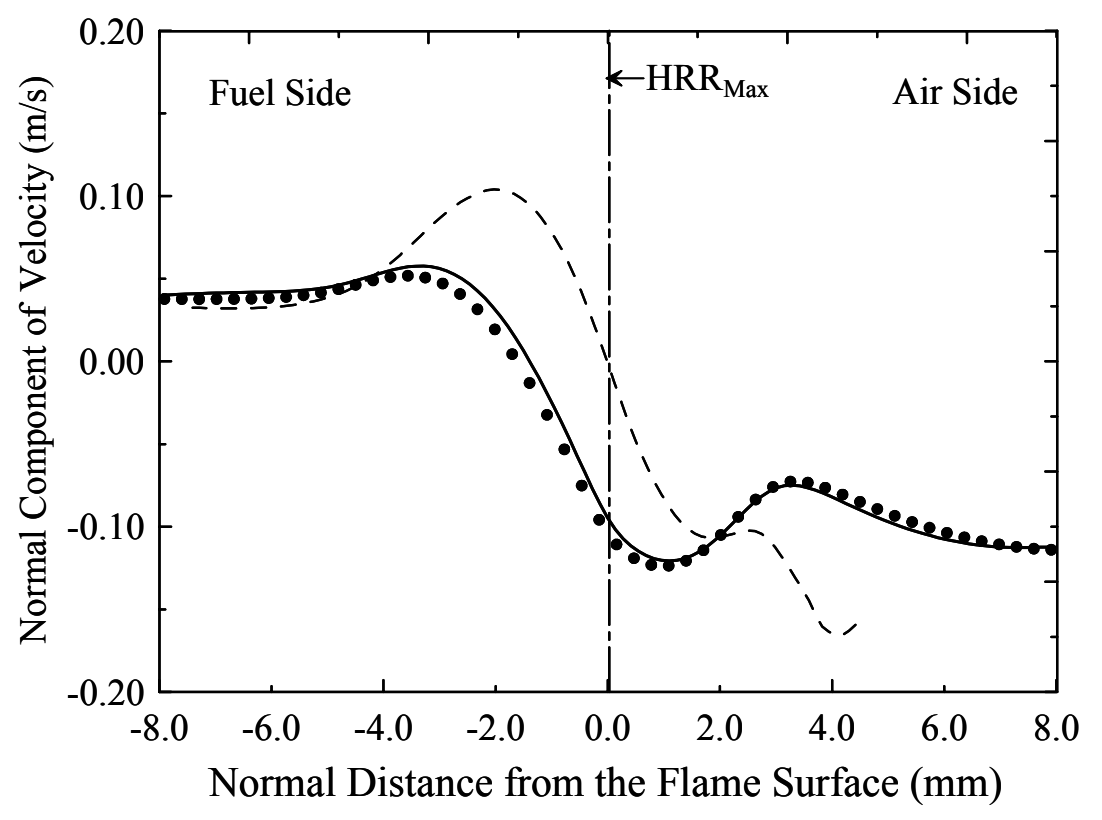

(a) normal component of velocity to the flame surface

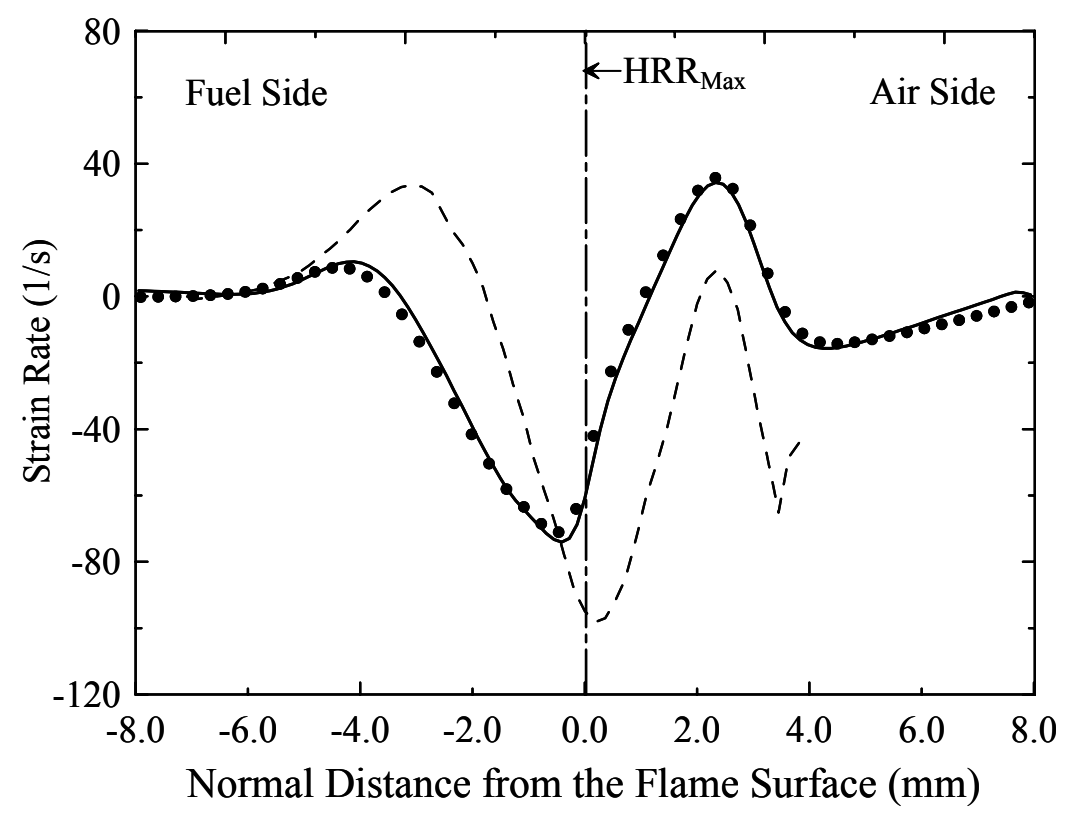

(b) local strain rate

Figure 14. Computed normal component of velocity to the flame surface and local strain rate in the coordinates normal to the flame surface at three locations of 1 -g counterflow nonpremixed flame for $\mathrm{a}_{\mathrm{g}}=20 \mathrm{~s}^{-1}$ and $\mathrm{Vr}=3$. ( $\bullet$ : location $\mathrm{A},-$ : location $\mathrm{B}$, --- : location $\mathrm{C}$; see Fig. 10 for location of points A, B, and C). 


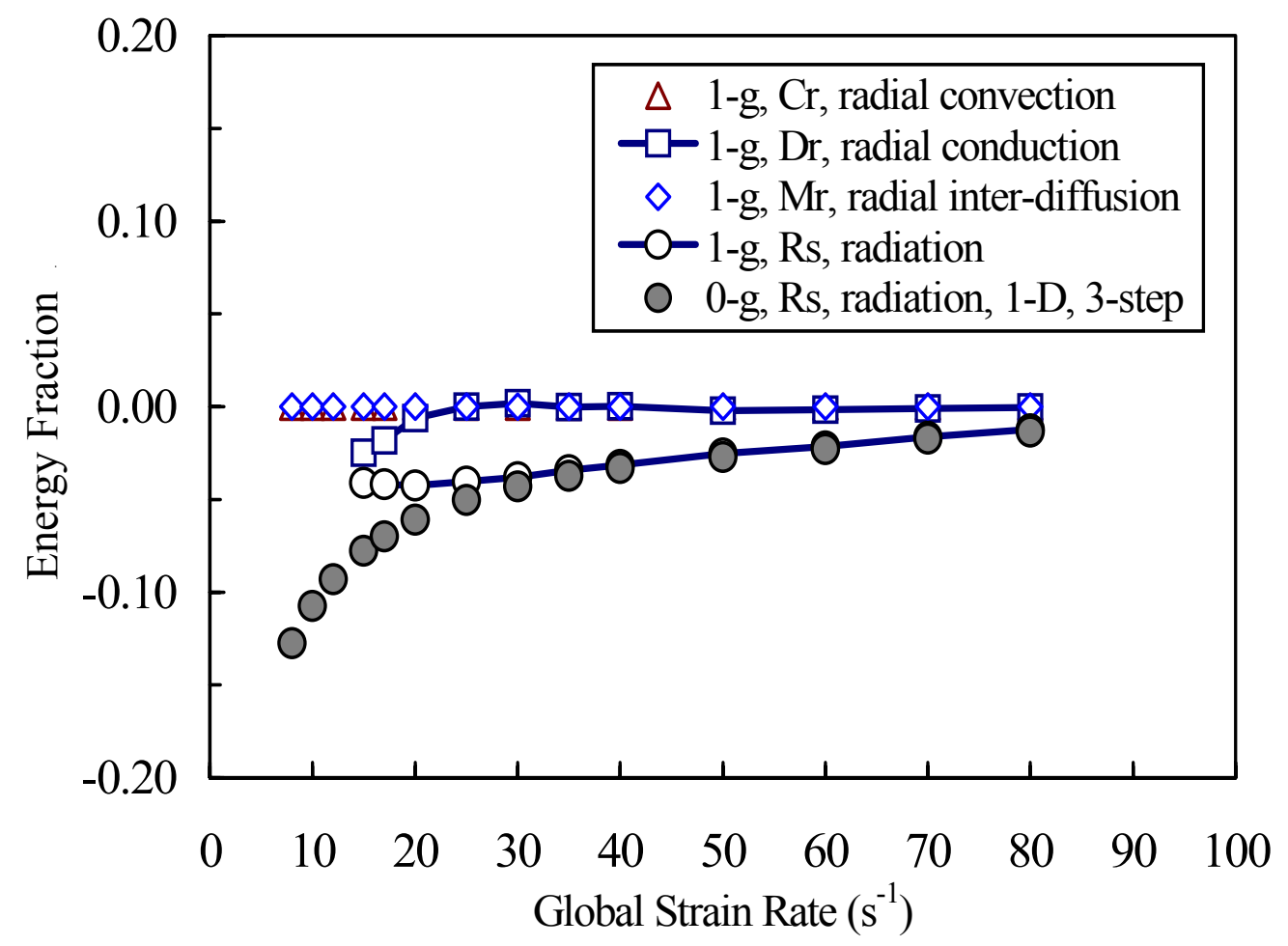

Figure 15. Computed fractional contribution by each term in the energy equation (Eq. 16) to the heat release of $0-\mathrm{g}$ and $1-\mathrm{g}$ flames with $\mathrm{Ca}=0.79$ as a function of the global strain rate along the flow field centerline. 


\title{
Appendix 2
}

\section{Effect of Buoyancy on the Radiative Extinction Limit of Low Strain Rate}

\author{
Non-Premixed Methane-Air Flames
}

\begin{abstract}
The structure and extinction of non-premixed flames were investigated through comparison of experiments and calculations using a counterflow configuration. Experiments were conducted at the NASA Glenn Research Center's $2.2 \mathrm{~s}$ drop tower to attain suppression and temperature measurements in low-strain non-premixed methane-air microgravity flames. Suppression measurements using nitrogen added to the fuel stream were performed for global strain rates from $7 \mathrm{~s}^{-1}$ to $50 \mathrm{~s}^{-1}$. Judicious hardware selection and an optimized experimental procedure facilitated rapid, controllable, and repeatable flame extinction measurements. The minimum nitrogen volume fraction in the fuel stream needed to assure suppression for all strain rates in microgravity was measured to be $0.855 \pm 0.016$, associated with the turning point, which occurred at a global strain rate of $15 \mathrm{~s}^{-1}$. This value was larger than the analogous value in normal gravity. Flame temperature measurements were attained in the high temperature region of the flame $(\mathrm{T}>1200 \mathrm{~K})$ using visible emission from a $\mathrm{SiC}$ filament positioned axially along the burner centerline. The suppression and temperature measurements were used to validate a two-dimensional flame simulation developed here, which included buoyancy effects and finite rate kinetics. The simulations yielded insight into the differences between microgravity and normal gravity suppression results, and also explained the inadequacy of the one-dimensional model results to explain the microgravity suppression results.
\end{abstract}




\section{INTRODUCTION}

Unwanted fires typically occur due to non-premixed combustion. The agent concentration required to achieve the suppression (or extinction) of non-premixed flames is an important consideration for design of fire protection systems as engineers rely on suppression data to estimate suppressant mass requirements for total flooding applications. Information regarding critical suppressant concentrations in the high strain rate regime is less important than in the low strain rate regime, because low strain rate conditions typically require higher agent concentrations and fire protection design must be based on worst-case conditions. The initial stage of an unwanted fire in a microgravity environment, such as an orbiting space platform, will likely occur at a low strain rate. The actual value of the strain rate will depend on the combustion configuration and local environmental conditions such as air currents generated by the fire itself and any forced ventilation.

A review of the literature indicates that there has been little work on low $\left(<30 \mathrm{~s}^{-1}\right)$ strain rate flame suppression by an agent, and practically none on the suppression of low strain rate adiabatic flames in microgravity. Related studies include Refs. [1-10]. Maruta et al. [1] conducted the first comprehensive suppression measurements of very low strain non-premixed flames in microgravity using the Japan Microgravity Center (JAMIC) $10 \mathrm{~s}$ drop tower. In their study, the suppression of methane-air diffusion flames with $\mathrm{N}_{2}$ added to the fuel stream was measured under microgravity conditions. The minimum methane concentration required to sustain combustion was measured to decrease as the strain rate decreased until a critical value was observed. As the global strain rate was further reduced, the required methane concentration increased. This behavior was denoted as a "turning point" and was attributed to the enhanced importance of radiative loss in low strain rate flames. In terms of fire safety, the turning point agent concentration represents a fundamental limit for nonpremixed flames, assuring suppression for all flow conditions. Bundy et al. [2] observed similar extinction behavior in low strain rate normal gravity flames. Zhang et. al. [3] studied extinction of premixed flames in microgravity 
using a $2.2 \mathrm{~s}$ drop tower. Ronney [4] examined the effect of $\mathrm{CF}_{3} \mathrm{Br}$ on the burning velocities, flammability limits and minimum ignition energies of alkane/air mixtures and determined that flame propagation occurred over a wider range of conditions at normal gravity than in microgravity. VanDerWege et al. [5] reported on the shape and the visual character of methane jets $(\mathrm{Re}=100)$ flowing into a quiescent agent laden environment. Other investigators have examined extinction of diffusion flames through conductive losses to walls [6] or transient twophase diffusion effects in flames burning alcohol fuels [7]. Olson and T'ien [8] reported on the structure of low stretch PMMA diffusion flames burning in normal gravity.

Experimental observations under microgravity conditions show that counterflow flames appear to be nearly flat [1]. Under normal gravity conditions, high strain rate flames are also flat as buoyancy is overwhelmed by convection. As the strain rate decreases in normal gravity, buoyancy forces become relatively more important and the flames are clearly curved. Onedimensional flame codes such as OPPDIF [9] are based on a similarity solution that neglects buoyancy. These one-dimensional steady state simulations fail to describe the multi-dimensional structure of low strain rate normal gravity flames, nor do they capture the dynamics of a flame during the transition from normal to microgravity. To gain physical insight, a numerical method is needed that is capable of simulating flames under the influence of buoyancy, and to better understand the effects of finite burner size on the detailed flame structure. Frouzakis et al. [10] developed a two dimensional (2D) direct numerical simulation that considered potential problems arising from the use of a 1D similarity solution along the flow field centerline to represent the character of 2D counterflow flames [10]. In their study, the structure of low strain rate counterflow $\mathrm{H}_{2}$-air flames was investigated.

The objective of this study was to investigate the structure and suppression of low strain rate counterflow non-premixed flames in both normal gravity and microgravity through measurements and numerical simulations. The suppression effectiveness of a suppressant $\left(\mathrm{N}_{2}\right)$ 
added to the fuel stream of low strain rate methane-air diffusion flames was measured. Flame temperature measurements were attained in the high temperature region of the flame by radiative emission from a thin filament positioned axially along the burner centerline. A two-dimensional (2D) flame simulation, including buoyancy effects was developed, and was validated with the flame suppression and the temperature profile measurements.

As mentioned above, microgravity suppression measurements similar to those reported here were previously conducted [1]. Figure 1 replots the results presented in Fig. 4 of Ref. [1], which shows a comparison of the previous microgravity measurements with their calculations based on a 1D similarity solution. In this study (and in Figure 1), the global strain rate $\left(\mathrm{a}_{\mathrm{g}}\right)$ was defined [11] as:

$$
a_{g}=\frac{2 V_{a}}{L}\left(1+\frac{V_{f} \sqrt{\rho_{f}}}{V_{a} \sqrt{\rho_{a}}}\right)
$$

where the parameters $V$ and $\rho$ denote the mean velocity and density of the reactant streams at the duct boundaries, $L$ is the duct separation distance, and the subscripts $a$ and $f$ represent the air and fuel streams, respectively. The definition of the global strain rate used here is larger than the definition used in Ref. [1] by a factor of two. While there are similarities in the gross trends between the measurements and the simulation results in Fig. 1, some interesting differences are evident, particularly in the very low strain rate regime, where the calculations overpredict the critical agent concentration in the fuel stream at extinction. The differences between the model and the experimental results could be associated with a number of issues. Reference [1] reports that the location of mesh screens in the exits of the burner ducts was varied for each of the experimental conditions. The location of the mesh screens provides a well-defined boundary condition on the flow field within the duct, which impacts the flow boundary conditions and possibly comparison of the suppression results with the model. In addition, the combustion test chamber in Ref. [1] was filled with air, rather than an inert, non-reactive gas such as nitrogen. 
Experiments conducted in normal gravity show that use of an air ambient in the combustion chamber impacts the extinction results [2]. For these reasons, the work reported here revisits the previous microgravity suppression measurements. In addition, this study extends the previous experimental work by investigating the detailed flame structure of the near extinction flames through measurements of the local temperature. This information was useful for validation of a 2D numerical code developed here and subsequently used to investigate the mechanisms of flame extinction under normal and microgravity conditions.

Like the measurements, there are also a number of questions related to the application of the 1D similarity model to the previous experimental measurements [1]. At low strain rates, the flames are rather thick, and the flame diameter/flame thickness ratio was not very large. Only when this ratio is large enough, can the flame be classified as one-dimensional. In this case, lateral heat and diffusion losses may be significant, and neglect of these terms through use of a 1D similarity model may be problematic. The 2D model developed here attempts to address these issues.

Han et al. [12] recently reported on the structure of ultra low-stretch $\left(\sim 2 \mathrm{~s}^{-1}\right)$ methane nonpremixed flames. Their study considered radiation effects and extinction in curved flames established in normal gravity by flowing diluted fuel in a downward direction through a porous spherically symmetric burner with a large radius of curvature. Heat losses to the burner were characterized and the computational results were found to be consistent with experimental observations.

In this study, conductive heat losses to the burner were avoided, which impacted the range of strain rates investigated, because flame thickness increases as the strain rate decreases. Here, the global strain rate $\left(\mathrm{a}_{\mathrm{g}}\right)$ was varied from $7 \mathrm{~s}^{-1}$ to $50 \mathrm{~s}^{-1}$ in microgravity flames and from $14 \mathrm{~s}^{-1}$ to $50 \mathrm{~s}^{-1}$ in normal gravity flames to avoid conductive heat losses to 
the burner - as determined through consideration of the profile of temperature near the burner boundaries To maximize the range of strain rates considered in the normal gravity flames considered here, the approach used by Ref. 2 was applied in which the velocity ratio of the air stream to the fuel stream $\left(V_{a} / V_{f}\right.$ in Eq. 1$)$ was adjusted such that the flame location was forced towards the center of the flowfield, away from the burner ducts.

\section{EXPERIMENTAL METHOD} Experimental Apparatus

Microgravity experiments were conducted at the NASA Glenn Research Center $2.2 \mathrm{~s}$ drop tower. A $15 \mathrm{~mm}$ diameter stainless steel counter-flow burner was enclosed in a $25 \mathrm{~L}$ cylindrical chamber. The experimental hardware was mounted in a standard NASA drop rig. A schematic of the burner and flow system is shown in Fig. 2. To control each gas flow (air, $\mathrm{CH}_{4}$, and $\mathrm{N}_{2}$ added to the fuel stream), a pressure transducer, solenoid valve, pressure regulator, and a fast response time $(\approx 50 \mathrm{~ms})$ pressure controller were placed upstream of a critical flow orifice. The burner was designed to have minimal dead volume as glass beads and a series of fine mesh steel screens were used to impose a near plug-flow velocity profile. The duct separation distance, L, was $15 \mathrm{~mm}$ (see Fig. 2) and the wire mesh screens were positioned $\approx 1 \mathrm{~mm}$ into each of the ducts. This exact geometry was considered in the 2D numerical model developed here. The reactants were stored in pressurized $500 \mathrm{~cm}^{3}$ stainless steel cylinders. The oxygen content in the bottled air was measured to be $(20.93 \pm 0.04) \%$ using a paramagnetic analyzer [13]. The fuel was research grade methane (99.99\% purity). Flow control and data acquisition were performed using a PC104 microprocessor with $320 \mathrm{MB}$ of flash memory and a 16 bit data acquisition board sampling at $200 \mathrm{~Hz}$. 


\section{Suppression Measurements}

Attaining accurate suppression measurements in $2.2 \mathrm{~s}$ of microgravity was achieved by judicious hardware selection $(50 \mathrm{~ms}$ time response pressure transducers, associated critical flow orifices, and a small dead-volume flow system) and development of an optimized experimental procedure in which microgravity conditions were initiated at near-extinction (normal gravity) flame conditions. The combustion chamber was evacuated and filled to $101 \mathrm{kPa}$ with $\mathrm{N}_{2}$ in contrast to the previous measurements [1]. The flow configuration used for these experiments used air from the top duct and methane diluted with nitrogen from the bottom duct. The initial $\mathrm{N}_{2}$ volume fraction was set as close to normal gravity suppression conditions as possible. Ignition was accomplished by positioning and energizing a $0.25 \mathrm{~mm}$ diameter $(6 \mathrm{~cm}$ long $)$ coiled $\mathrm{Pt}+$ $30 \% \mathrm{Rh}$ wire between the ducts after the reactant flows were initiated. Upon ignition, the ignition wire was simultaneously de-energized and slowly retracted from the flame at a rate of $2 \mathrm{~cm} / \mathrm{s}$ to minimize convective disturbances. About $5 \mathrm{~s}$ later, after the flame had stabilized, microgravity conditions were initiated by releasing the drop package. From this point on, the extinction experiments were automated.

Flame suppression was achieved by increasing the agent flow and simultaneously decreasing the fuel flow, while maintaining a constant global strain rate, until a critical agent volume fraction in the fuel stream was attained. For each experiment, the onboard computer recorded the transient strain rate, nitrogen concentration in the fuel stream, the chamber pressure, the start and end of the drop period, the flow meter flows, and the signal from a photodetector inside the chamber. Acceleration levels during the drop were measured as less than $10^{-3} \mathrm{~m} / \mathrm{s}^{2}$. The photodetector signal dropped abruptly when the flame was extinguished and the time of suppression was independently confirmed from inspection of a digital video recording. The 
suppression concentration was inferred by determining the $\mathrm{N}_{2}$ concentration based on the time of flame suppression and the delay time of the system.

The experimental method is illustrated in Figure 3, which shows the measured nitrogen volume fraction in the fuel stream of a $15 \mathrm{~s}^{-1}$ methane-air flame as a function of time after drop initiation. The photodetector signal is also shown, which indicated the time of flame extinction when its value rapidly decreased. The critical $\mathrm{N}_{2}$ concentration at extinction was inferred from the concentration-time data through consideration of the system delay time, which was the time of travel from the fuel/ $\mathrm{N}_{2}$ mixing tee (see component number 7 in Fig. 2) to the flame zone, at the middle of the flow field. The delay time was calculated through consideration of the system volume and the gas flows. The calculation was verified by performing extinction experiments for different $\mathrm{N}_{2}$ "ramping" rates during the experimental drop for the same flame conditions, with the ramping rates varying about $20 \%$ to $30 \%$. These experiments resulted in determination of the values of the critical $\mathrm{N}_{2}$ volume fraction at extinction to within $0.1 \%$, verifying the estimates of the system delay times. Experiments in normal gravity also showed that the critical $\mathrm{N}_{2}$ suppression volume fraction was independent of the $\mathrm{N}_{2}$ ramping rate, for the rates considered here. Since the $\mathrm{N}_{2}$ volume fraction at the beginning of the experimental drop was very close to the extinction concentration (within $2 \%$, see Fig. 3), uncertainty in the delay time was not a significant contributor to the uncertainty in the $\mathrm{N}_{2}$ volume fraction. The expanded relative uncertainty in the $\mathrm{N}_{2}$ volume fraction was $2 \%$, dominated by uncertainty in the flows, based on a propagation of error analysis and repeat measurements. For all measurements reported here, the expanded uncertainty is presented with a coverage factor of two, i.e., an uncertainty of $2 \sigma$ representing a $95 \%$ confidence interval.

The time for the flame to make the transition to microgravity was determined from observation of video images in experiments in which the $\mathrm{N}_{2}$ concentration was held constant. 
The longest transition time, at $7 \mathrm{~s}^{-1}$, was about $0.2 \mathrm{~s}$, which was less than $10 \%$ of the total microgravity time available.

\section{Temperature Measurements}

Measurement of the visible emission intensity from a $12.5( \pm 0.5) \mu \mathrm{m} \beta$-SiC filament placed along the burner centerline allowed determination of flame temperatures for $\mathrm{T}>1200 \mathrm{~K}$. Below this temperature, the signal to noise ratio was inadequate. Radiation emitted by the filament was recorded using a digital CCD camera with a close-up lens such that the spatial resolution of the image was $0.07 \mathrm{~mm} /$ pixel. The camera exposure was adjusted to prevent image saturation (overexposure) at the maximum flame temperature. Flame emission intensity was insignificant compared to the filament intensity.

The total emissive power from a surface can be expressed using Plank's Law integrated over all wavelengths as $\mathrm{E}=\varepsilon \sigma \mathrm{T}^{4}$. The fraction of the total radiance captured by the detector is a function the spectral sensitivity of the detector, the transmissivity of the optics of the detector, and the solid angle. Because the spectral response curve of the detector and the transmissivity of the optics are not constant (and are unknown), a linear relationship between the detector signal and $\mathrm{T}^{4}$ could not be assumed. A calibration source was required to find the relationship between signal intensity and filament temperature.

The intensity measurements were calibrated using the one-dimensional OPPDIF flame code [9], following Ravikrishna and Laurendeau [14]. In order to equate the fiber luminescence to a fiber temperature, the profiles of the flame temperature and the emitted intensity along the length of the fiber for a given set of flame conditions was required. The correlation was based on a comparison of centerline counterflow flame measurements with OPPDIF calculations for a microgravity moderately-strained 
methane-air diffusion flame with a $\mathrm{N}_{2}$ concentration of $81 \%$ by volume in the fuel stream. The OPPDIF predicted gas temperature profile was corrected to the predicted fiber temperature based on heat transfer to the fiber. The fiber temperature was then compared to the measured fiber luminosity and a correlation was determined with luminosity taken as proportional to the fiber temperature to the fifth power. The expanded uncertainty in the temperature measurement was typically $60 \mathrm{~K}$, based on repeat measurements. Because the conductivity along the filament is negligible [15], the energy balance becomes:

$$
h P\left(T-T_{f}\right)=\sigma \varepsilon \mathrm{P} \mathrm{T}_{\mathrm{f}}^{4}
$$

where $\mathrm{h}$ is the convection coefficient, $\mathrm{T}$ is the gas temperature, $\mathrm{T}_{\mathrm{f}}$ is the filament temperature, $\mathrm{P}$ is the perimeter of the filament, $\sigma$ is the Stefan-Boltzman constant, and $\varepsilon$ is the filament emissivity. Solving Eq. 2 for T, a radiative correction for the gas temperature results:

$$
\mathrm{T}=\mathrm{T}_{\mathrm{f}}+\sigma \varepsilon \mathrm{T}_{\mathrm{f}}^{4} / \mathrm{h}
$$

The convection coefficient was found by using a numerical correlation for low velocity cross flow over a cylinder [16]. Experiments compared the filament intensity with the filament oriented horizontally and vertically in the counterflow flame to determine if there was a significant difference caused by filament orientation. The difference between the two orientations was $15 \mathrm{~K}$, which was within experimental error, so the cross flow assumption for the convection coefficient was considered acceptable. Extinction measurements, performed with and without the filament present, showed that the filament had a negligible effect $(<0.1 \%$ difference $)$ on the agent concentration required for extinction. Using an optical microscope, inspection of the filament after flame exposure revealed that there was no observable change in the diameter or other degradation in these relatively low temperature short-duration experiments. 


\section{NUMERICAL METHOD}

The present computation employed a time-dependent axisymmetric configuration to treat counterflow diffusion flames formed between two opposed circular ducts. A coupled set of model-free equations with a low Mach number approximation was used following Ref. [17]. QUICK [18] and second-order central difference schemes were used to discretize the convective and diffusive terms. A predictor-corrector scheme nearly identical to that of Najm et al. [19] was used for time integration of the governing equations. Efficient algebraic relaxation for the velocity-pressure correction was performed using the HSMAC method [20]. CHEMKIN-II [21] and TRANFIT [22] were adopted for calculation of thermodynamic and transport properties. The computational domain in the axial direction was taken to be $40 \mathrm{~mm}$. In the radial direction, domains of $70 \mathrm{~mm}$ and $50 \mathrm{~mm}$ were used for the zero and normal gravity conditions, respectively. In addition, $268 \times 70$ grids were used for the zero gravity simulation and $268 \times 65$ grids for normal gravity. A uniform grid spacing of $0.15 \mathrm{~mm}$ was used in the axial direction. Radially, non-uniform grids with a minimum spacing of $0.3 \mathrm{~mm}$ were clustered near the centerline. A grid sensitivity study confirmed that the calculated extinction limit and the temperature maximum was unchanged when a finer grid $(0.10 \mathrm{~mm}$ in the axial direction) was used, indicating that the heat release rate zone was adequately resolved.

The inflow temperature boundary condition for the reactant streams was 298 K. Uniform axial velocity was imposed at the mesh screens, which were positioned about $1.2 \mathrm{~mm}$ into each of the ducts. This condition is appropriate for global strain rates in $0 \mathrm{G}$ and $1 \mathrm{G}$ above about $7 \mathrm{~s}^{-1}$ and $15 \mathrm{~s}^{-1}$, respectively, as exemplified by the temperature gradient, which is nominally flat under those conditions. Sides A and B shown in Fig. 2 were treated as outflow boundary conditions for the normal gravity and zero gravity calculations, respectively. A no slip condition was applied on the burner walls and the wall temperature was taken as $298 \mathrm{~K}$. A no mass flux condition was applied at all boundaries. The oxidizer stream was composed of undiluted air composed of $21 \%$ oxygen and $79 \%$ nitrogen by volume, and the fuel was methane diluted by 
nitrogen. The ambient gas was set to pure nitrogen, as in the experiment, to prevent secondary combustion of fuel.

\section{Chemical reaction mechanism and radiation model}

A 3-step irreversible reaction mechanism [23] for methane oxidation was used. Use of a larger, more comprehensive chemical mechanism was precluded due to practical reasons associated with computational cost. The 3 step chemical model is adequate, as this paper focuses on the energetics associated with flame suppression, and not detailed reaction pathways. The detailed mechanism and reaction rates were taken as [23]:

$$
\begin{aligned}
& \mathrm{CH}_{4}+(3 / 2) \mathrm{O}_{2} \rightarrow \mathrm{CO}+2 \mathrm{H}_{2} \mathrm{O} \\
& \mathrm{CO}+(1 / 2) \mathrm{O}_{2} \rightarrow \mathrm{CO}_{2} \\
& \mathrm{CO}_{2} \rightarrow \mathrm{CO}+(1 / 2) \mathrm{O}_{2} \\
& -\mathrm{d}\left[\mathrm{CH}_{4}\right] / \mathrm{dt}=10^{11.68} \exp (-23500 / \mathrm{T})\left[\mathrm{CH}_{4}\right]^{0.7}\left[\mathrm{O}_{2}\right]^{0.8} \\
& -\mathrm{d}[\mathrm{CO}] / \mathrm{dt}=10^{12.35} \exp (-19200 / \mathrm{T})[\mathrm{CO}]^{1.0}\left[\mathrm{H}_{2} \mathrm{O}\right]^{0.5}\left[\mathrm{O}_{2}\right]^{0.25} \\
& \left.-\mathrm{d}\left[\mathrm{CO}_{2}\right] / \mathrm{dt}=10^{12.50} \exp (-20500 / \mathrm{T})\right)[\mathrm{CO}]^{1.0}\left[\mathrm{H}_{2} \mathrm{O}\right]^{0.5}\left[\mathrm{O}_{2}\right]^{0.25}
\end{aligned}
$$

with reactions rates in kmole- $\mathrm{m}^{-3}-\mathrm{s}^{-1}$.

The viability of the 3 step global mechanism was demonstrated by performing low strain rate flame calculations using OPPDIF [24] and by comparing the calculations to flame measurements (see the discussion of Figs. 5 and 7 below). OPPDIF calculations using the GRI3.0 mechanism yielded very similar agent extinction requirements as OPPDIF calculations using the 3-step mechanism, while the temperature peak using the 3-step mechanism was less than 100 K larger than that obtained using GRI-3.0. Although detailed chemical reactions are not included in the 3-step mechanism, it was considered appropriate to predict the extinction limits of $\mathrm{N}_{2}$ diluted methane flames, because Nitrogen is known to extinguish a flame mainly by physical influences, such as heat capacity and dilution effects, rather than through chemical effects. An optically-thin radiation sub-model [26] was implemented, which considered heat loss from $\mathrm{CH}_{4}$, 
$\mathrm{CO}_{2}, \mathrm{H}_{2} \mathrm{O}$, and $\mathrm{CO}$. Soot was not considered in these thin blue flames (see Fig. 4). The volumetric rate of radiative heat loss in the energy equation can be written as:

$$
\dot{q}_{r}=-4 \sigma K_{p}\left(T^{4}-T_{\infty}^{4}\right)
$$

where $T$ and $T_{\infty}$ are the local and the ambient temperature, respectively. $K_{p}$ is the Plank mean absorption coefficient of the mixture, which is expressed as:

$$
K_{p}=P_{\mathrm{CH}_{4}} K_{\mathrm{CH}_{4}}+P_{\mathrm{CO}_{2}} K_{\mathrm{CO}_{2}}+P_{\mathrm{H}_{2} \mathrm{O}} K_{\mathrm{H}_{2} \mathrm{O}}+P_{\mathrm{CO}} K_{\mathrm{CO}}
$$

where $P_{i}$ and $K_{i}$ denote the partial pressure and Plank mean absorption coefficient of species $i$, respectively, with $K_{p}$ taken from Ref. [26].

\section{RESULTS AND DISCUSSION}

Temperature profiles were measured along the burner axis and comparisons were made between the microgravity and normal gravity results. As the flame transitioned into microgravity, the maximum flame temperature location shifted towards the center of the flowfield and the flame width increased. Figure 5 compares the measured axial temperature profiles in normal and microgravity for $\mathrm{a}_{\mathrm{g}}=20 \mathrm{~s}^{-1}$ and an $\mathrm{N}_{2}$ volume fraction in the fuel stream equal to 0.80 . The measured microgravity peak temperature was essentially the same as in normal gravity. The predicted (2D model) peak temperatures in the 0 -g and $1-\mathrm{g}$ flames were in agreement with the measured peaks to within experimental uncertainty $(60 \mathrm{~K})$, while the locations of the peaks were within about $0.3 \mathrm{~mm}$ of the measurements. The computed temperature fields are also shown in Fig. 6, which shows that the microgravity flame is thicker along the axis and over the entire flow field consistent with the flame images seen in Figs. 4 and the calculated results shown in Fig. 5. The simulated flames appear to be similar in shape to the experimentally-observed visible flame shapes, but there is a tendency for the model to over-predict the fuel-side temperature. This is likely due to the limitations associated with the simplified global chemical model, which does not 
address real kinetic effects such as dissociation, recombination, chain branching, etc. Near the edge of the burner, even the microgravity flames are not simply one-dimensional in shape.

Figure 7 shows measurements, and one-dimensional (1D) and two-dimensional (2D) model calculations of the critical $\mathrm{N}_{2}$ volume fraction in the fuel stream required to extinguish the methane-air diffusion flames as a function of the global strain rate. The figure compares the microgravity suppression measurements conducted here with the normal gravity results reported by Bundy et al. [2]. For the normal gravity flames, the air/fuel velocity ratio was adjusted, such that the flame was positioned away from the burner duct so that heat loss to the burner was negligible. The extinction data for normal gravity and microgravity collapse into one curve for moderate global strain rates $\left(\mathrm{a}_{\mathrm{g}}>40 \mathrm{~s}^{-1}\right)$ as convective forces begin to dominate the effects of buoyancy. Figure 7 also shows the microgravity suppression measurements of Maruta et al. [1], which are in agreement with the microgravity results presented here. The one-dimensional (1D) calculations of flame extinction (reported in [1] and confirmed in this study) failed to quantitatively reproduce the experimentally determined microgravity extinction results determined here and in Ref. [1]. This is attributed to the importance of lateral heat losses associated with radial conduction in the energy equation, which are neglected in the 1D similarity solution, but are considered in the 2D model calculation. The 2D modeling results shown in Fig. 7 appear to be adequate, showing agreement with the microgravity experiments to within experimental uncertainty, despite the use of simplified chemistry and radiation submodels. For the very lowest strain rates $\left(10 \mathrm{~s}^{-1}\right)$, the $2 \mathrm{D}$ model somewhat underpredicts the critical agent concentration, due perhaps to the use of the optically thin radiation sub-model, which tends to overpredict radiative heat loss, especially in the relatively thick lower strain rate flames.

The $\mathrm{N}_{2}$ volume fraction in the fuel stream at the turning point represents the minimum agent needed to assure suppression regardless of strain rate. Its value in microgravity was measured as $0.855 \pm 0.016$ at a global strain rate of $15 \mathrm{~s}^{-1} \pm 5 \mathrm{~s}^{-1}$. This value was larger than the analogous value in 1-g. Figure 7 shows that the microgravity suppression measurements and the $2 \mathrm{D}$ model 
suppression results drop sharply for strain rates lower than the turning point. The 'turning point' in normal gravity occurred at a higher global strain rate than in microgravity for both the simulations and the measurements.

At low strain rates, the extinction process is very different in normal gravity and microgravity, due to differences in flame structure. In this regard, it is helpful to consider the specific maximum heat release rate per unit volume divided by the local strain rate (SMHRR), which represents the flame strength along a flame surface as introduced by Sung et al. [27]. Calculations show that there is no effective difference between using the peak versus integrated reaction rates in comparing flame strength. Smaller values of SMHRR imply that the flame is weak and easier to extinguish. Table 1 compares the flame strength at three locations for flames with global strain rates of $10 \mathrm{~s}^{-1}(0-\mathrm{g})$ and $20 \mathrm{~s}^{-1}(0-\mathrm{g}$ and $1-\mathrm{g})$, and an agent fuel stream volume fraction of 0.79 . Table 1 lists the calculated ( $2 \mathrm{D}$ model) maximum heat release rate $\left(\mathrm{HRR}_{\max }\right)$, the local strain rate $\left(a_{1}\right)$, and the specific maximum heat release rate (SMHRR). as a function of radial location in the normal gravity and microgravity flames. The table shows that SMHRR at

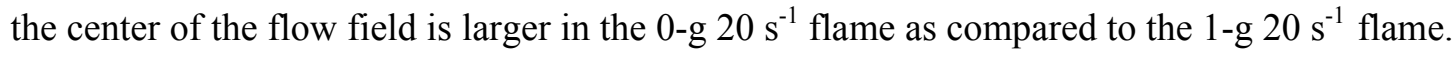
This is consistent with the results shown in Fig. 7 in which the normal gravity flame requires less agent to extinguish than the 0 -g flame, both at $20 \mathrm{~s}^{-1}$. The calculated value of the SMHRR in 1-g is nearly constant near the center of the flow field, but decreases by $1 / 3$ of this value near the edge of the burner (at a radial distance, $r$, equal to the radius of the burner duct, $\mathrm{R}$ ). This is consistent with the observation that the 1-g low strain rate flame extinguishes from the outer edge first. The SMHRR of the 0 -g flame is also constant near the center, but increases towards the flame edge. Unlike the 1-g flame, the microgravity flame under these conditions abruptly and simultaneously extinguishes over the entire flame surface. For the same global strain rate (see Eq. 1), the local strain rate along the flame axis in the 0 -g flame $\left(=36 \mathrm{~s}^{-1}\right)$ is about $1 / 2$ the value of the local strain rate in the normal gravity flame $\left(=62 \mathrm{~s}^{-1}\right)$. In $1-\mathrm{g}$, buoyancy tends to enhance the local strain rate as hot gases are "pulled" above the burner (see Fig. 6). The table also shows that the SMHRR 
value at the edge of the 0 -g flames is smaller in the $10 \mathrm{~s}^{-1}$ flame than in the $20 \mathrm{~s}^{-1}$ flame (both in 0 -g). This is consistent with the results shown in Fig. 7 in which the $10 \mathrm{~s}^{-1}$ flame requires somewhat less agent to extinguish than the $20 \mathrm{~s}^{-1}$ flame (both at $0-\mathrm{g}$ ).

Figure 8 shows the 2D model results of the local fractional energy loss contributed by key terms in the energy equation (and normalized by the heat release rate) along the flowfield centerline of $0-\mathrm{g}$ and $1 \mathrm{-g}$ flames with $0.79 \mathrm{~N}_{2}$ volume fraction in the fuel stream as a function of the global strain rate. The figure also shows the radiative loss fraction determined in this study using the $1 \mathrm{D}$ model. The calculations show that axial conduction and diffusion are by far the largest heat loss mechanisms. The $2 \mathrm{D}$ model results indicate that radiative heat transfer is a significant energy loss mechanism in the 0 -g flames, becoming larger as the strain rate decreases. Radiative heat loss is not negligible even at moderate strain rates in near-extinction 0-g flames, nor is it zero in 1-g flames. Radial diffusion is found to be a relatively small contributor to energy loss for global strain rates above about $20 \mathrm{~s}^{-1}$ in both the 0 -g and 1 -g flames. As the strain rate

decreases below $15 \mathrm{~s}^{-1}$. Its magnitude is about $1 / 2$ that of the radiative loss term for a global strain rate of $10 \mathrm{~s}^{-1}$ in the 0 -g flames. The combination of these loss mechanisms becomes larger as the strain rate decreases below the turning point at $15 \mathrm{~s}^{-1}$, consistent with the observed decrease in agent concentration requirements presented in Fig. 7. Figure 8 shows that the radiative loss terms in the2D and 1D models were similar in magnitude.

\section{SUMMARY AND CONCLUSIONS}

A fundamental study of the structure and suppression of low strain nonpremixed flames was conducted using experiments and numerical computations. For the first time, temperature profiles were determined in near extinction diffusion flames in microgravity. The temperature profile measurements, along with measurements of the critical agent suppression requirements, were used to validate the $2 \mathrm{D}$ flame code. The $2 \mathrm{D}$ model calculations also showed agreement with experimental observation of flame curvature. 
Analysis, using flame simulations, allows insight of the heat transfer processes that control flame structure and extinction. At low strain rates, the flames are rather thick and lateral heat and diffusion losses are not negligible. For finite size burners, the simulations confirm that low strain rate counterflowing nonpremixed flames cannot be assumed to be purely onedimensional in normal gravity or even microgravity. The commonly used one-dimensional flame codes do not provide a full picture of the multi-dimensional counterflow structure for experiments involving low strain normal gravity or microgravity flames. By providing physical insight, twodimensional simulations are a useful tool for guiding the interpretation of counterflow flame experiments.

\section{ACKNOWLEDGEMENTS}

This research was partially supported by the NASA Microgravity Research Division through Contract No. C-32066-T with Dr. Sandra Olson serving as Technical Monitor. The authors are grateful to Drs. K. Maruta, K.Y. Lee, J. Logue, W.C. Park, J. Park, and I.K.Puri for helpful discussions. 


\section{REFERENCES}

[1] K. Maruta, M. Yoshida, H. Guo, Y. Ju, T. Niioka, T., Combust. Flame, 112 (1998) 181 186.

[2] M. Bundy, A. Hamins, K.Y. Lee, Combust. Flame, 103 (2003) 299-306.

[3] H. Zhang, F.N. Egolfopoulos, Proc Combust. Inst. 28 (2000) 1875-1882.

[4] P.D. Ronney, Acta Astronautica, 12 (1985) 915.

[5] B.A. VanDerWege, M.T. Bush, S. Hochgreb, Effect of $\mathrm{CF}_{3} \mathrm{H}$ and $\mathrm{CF}_{3} \mathrm{Br}$ on Laminar Diffusion Flame in Normal and Microgravity, Proc Fourth Int Microgravity Combust Workshop, NASA Conf Pub 10174, 1995, 369-374.

[6] J. Sutula, J. Jones, J.L. Torero, J. Borlik, O.A. Ezekoye, "Diffusion Flame Extinction in Low Strain Flow", Proceedings of the Fourth International Microgravity Combustion Workshop, NASA Conference Publication 10194, 1997, 87-92.

[7] F.A. Williams, "Influences of Water on Methanol Droplet Burning and Extinction," Proceedings of the Fourth International Microgravity Combustion Workshop, NASA Conference Publication 10174, 1997, 449-454.

[8] S.L. Olsen J.S. T'ien, Combust. Flame, 121 (2000) 439-452.

[9] A. Lutz, R.J. Kee, J. Grcar, J., F.M. Rupley, “A Fortran Program Computing Opposed Flow Diffusion Flames", SAND96-8243, Sandia National Labs, Livermore (1997).

[10] C.E. Frouzakis, J. Lee, A. G. Tomboulides, K. Boulouchos, Proc. Combust. Inst., 27 (1998) 571-577.

[11] K. Seshadri, F.A.Williams, Int. J. Heat Mass Transfer, 21 (1978) 251.

[12] B. Han A.F. Ibarreta, C.J. Sung, J. T'ien, Combust. Flame, 149 (2007) 173-190.

[13] M. Kelly, NIST, Report of paramagnetic analyzer test results, personal communication, March 20, 2000.

[14] R.V. Ravikrishna, N.M. Laurendeau, Combust. Flame, 120 (2000) 372-382.

[15] V. Vilimpoc, L.PGross, Proc. Combust. Inst., 22 (1988) 1907-1914

[16] A. Zhukauskas, Ziugzda, J. Heat Transfer of a Cylinder in Cross Flow,_Hemisphere Pub., New York, 1985.

[17] C.B. Oh, C.E. Lee, J. Park, Combust. Flame, 138 (2004) 225-241.

[18] B.P. Leonard, Comput. Meth. Appl. Mech. Eng., 19 (1979) 59-98.

[19] H.N. Najm, P.S. Wyckoff, Combust. Flame, 110 (1997) 92-112.

[20] C.W. Hirt, J.L. Cook, J. Comput. Phys., 10 (1972) 324-340.

[21] R.J. Kee, F.M. Rupley, J.A. Miller, CHEMKIN-II: A Fortran Chemical Kinetics Package for the Analysis of Gas Phase Chemical Kinetics, Report No. SAND89-8009B, Sandia National Laboratories, 1989.

[22] R.J. Kee, G. Dixon-Lewis, J. Warnatz, M.E. Coltrin, J.A. Miller, A Fortran Computer Code Package for the Evaluation of Gas-phase Multicomponent Transport Properties, Report No. SAND86-8246, Sandia National Laboratories, 1986.

[23] F.L. Dryer, I. Glassman, Proc. Combust. Inst., 14 (1972) 987-1003.

[24] C.B. Oh, A. Hamins, M. Bundy, J. Park, Combust. Theory Model., (2006) submitted.

[25] Smith, G. P., Golden, D. M., Frenklach, M., Moriatry, N. W., Eiteneer, B., Goldenberg, M, Bowman, C. T., Hanson, R. K., Song, S., Gardiner, W. C., Lissianski, V., Qin, Z., http://www.me.berkeley.edu/gri_mech/.

[26] Y. Ju, H. Guo, K, Maruta, F, Liu, J. Fluid Mech., 342 (1994) 315-334.

[27] C.J. Sung, J.B. Liu, C.K. Law, Combust. Flame, 102 (1995) 481-492. 
Table 1. The computed (2D) local maximum heat release rate $\left(H R R_{\max }\right)$, the local strain rate $\left(\mathrm{a}_{1}\right)$, and the specific maximum heat release rate (SMHRR) as a function of radial location in 0 -g and 1-g flames at $\mathrm{a}_{\mathrm{g}}=10 \mathrm{~s}^{-1}$ and $20 \mathrm{~s}^{-1}$ for an agent fuel stream volume fraction of 0.79 .

\begin{tabular}{l|c|c|c|}
\hline Location $^{\mathrm{a}}$ & $\begin{array}{c}\mathrm{HRR}_{\max } \\
\left(\mathrm{J} / \mathrm{cm}^{3} \mathrm{~s}\right)\end{array}$ & $\begin{array}{c}\mathrm{a}_{1} \\
\left(\mathrm{~s}^{-1}\right)\end{array}$ & $\begin{array}{c}\text { SMHRR } \\
\left(\mathrm{J} / \mathrm{cm}^{3}\right)\end{array}$ \\
\hline $\mathrm{r} / \mathrm{R}=0.0$ & 58.7 & 19 & 3.1 \\
\hline $\mathrm{r} / \mathrm{R}=0.5$ & 53.9 & 17 & 3.3 \\
\hline $\mathrm{r} / \mathrm{R}=1.0$ & 37.4 & 10 & 3.8 \\
\hline \multicolumn{5}{|c|}{$0 \mathrm{~g} ; \mathrm{a}_{\mathrm{g}}=20 \mathrm{~s}^{-1}$} \\
\hline $\mathrm{r} / \mathrm{R}=0.0$ & 110 & 36 & 3.1 \\
\hline $\mathrm{r} / \mathrm{R}=0.5$ & 107 & 33 & 3.2 \\
\hline $\mathrm{r} / \mathrm{R}=1.0$ & 82 & 19 & 4.3 \\
\hline \multicolumn{5}{|c|}{$1 \mathrm{~g} ; \mathrm{a}_{\mathrm{g}}=20 \mathrm{~s}^{-1}$} \\
\hline $\mathrm{r} / \mathrm{R}=0.0$ & 165 & 62 & 2.7 \\
\hline $\mathrm{r} / \mathrm{R}=0.5$ & 164 & 67 & 2.4 \\
\hline $\mathrm{r} / \mathrm{R}=1.0$ & 147 & 84 & 1.8 \\
$\mathrm{a} . \mathrm{R}$ is the inner duct radius; $\mathrm{r} / \mathrm{R}=0$ is on the central axis. \\
\hline
\end{tabular}




\section{List of Captions for the Figures}

Figure 1. Computed (1D model) and previous measurements of the critical nitrogen volume fraction in the fuel stream for suppression of $\mathrm{CH}_{4}$ flames in microgravity [1].

Figure 2. Schematic of counterflow system including (1) gas cylinders, (2) pressure transducers, (3) solenoid valves, (4) pressure regulators, (5) pressure controllers, (6) critical flow orifices, (7) mixing tee, (8) burner, and (9) glass beads and metal screens.

Figure 3. Measured nitrogen model fraction in the fuel stream of a $15 \mathrm{~s}^{-1}$ flame as a function of time. The photodetector signal is also shown, which indicates the time of flame extinction.

Figure 4. Flames in normal gravity (left) and microgravity for $\mathrm{a}_{\mathrm{g}}=20 \mathrm{~s}^{-1}$ and the fuel stream $\mathrm{N}_{2}$ volume fraction $=0.80$.

Figure 5. Computed (2D model) and measured temperature profiles in normal gravity and microgravity for $20 \mathrm{~s}^{-1}$ methane-air flames with $0.80 \mathrm{~N}_{2}$ volume fraction in the fuel stream.

Figure 6. Computed 2D temperature distributions of steady $\mathrm{a}_{\mathrm{g}}=20 \mathrm{~s}^{-1}$ near suppression methaneair flames in (a) normal gravity and (b) zero gravity.

Figure 7. Computed and measured critical nitrogen volume fraction in the fuel stream for suppression of $\mathrm{CH}_{4}$ flames in microgravity and normal gravity.

Figure 8. Results of 2D model calculations of the fractional contribution by axial convection, axial diffusion, radial diffusion, and radiation in the energy equation (normalized by the heat release rate) in 0 -g (lines) and 1-g flames (symbols) along the flow field centerline with $0.79 \mathrm{~N}_{2}$ volume fraction in the fuel stream as a function of the global strain rate. The radiative loss fraction determined using the $1 \mathrm{D}$ calculation is also shown. 


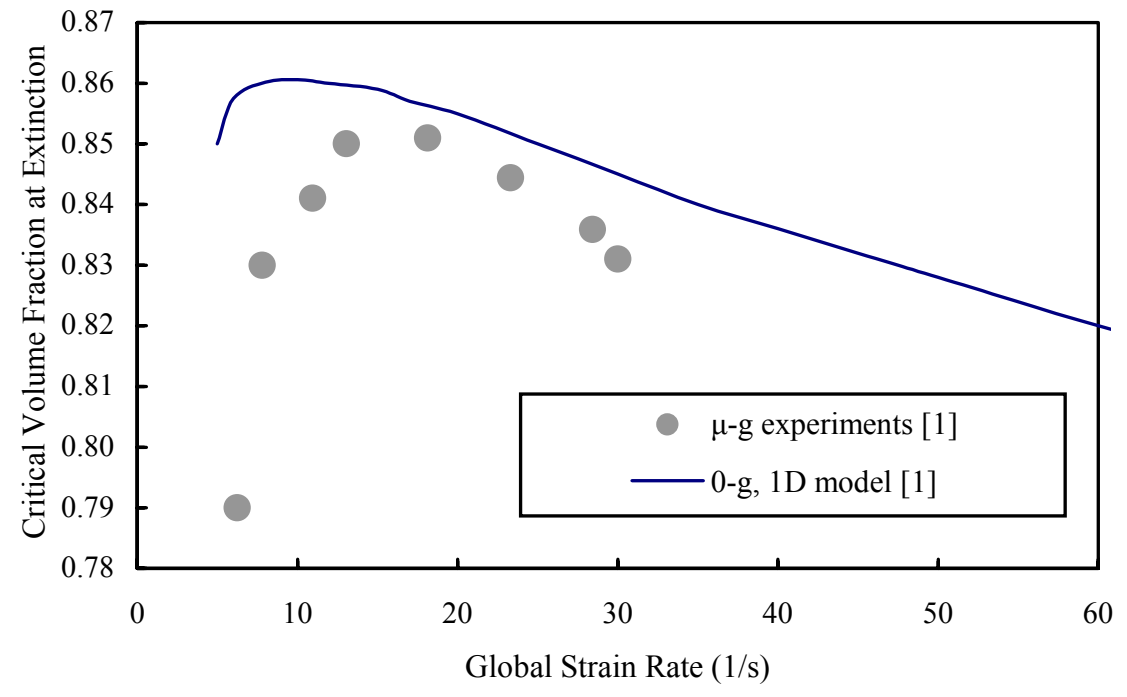

Figure 1. Previously computed (1D model) and measured critical nitrogen volume fraction in the fuel stream for suppression of $\mathrm{CH}_{4}$ flames in microgravity [1]. 


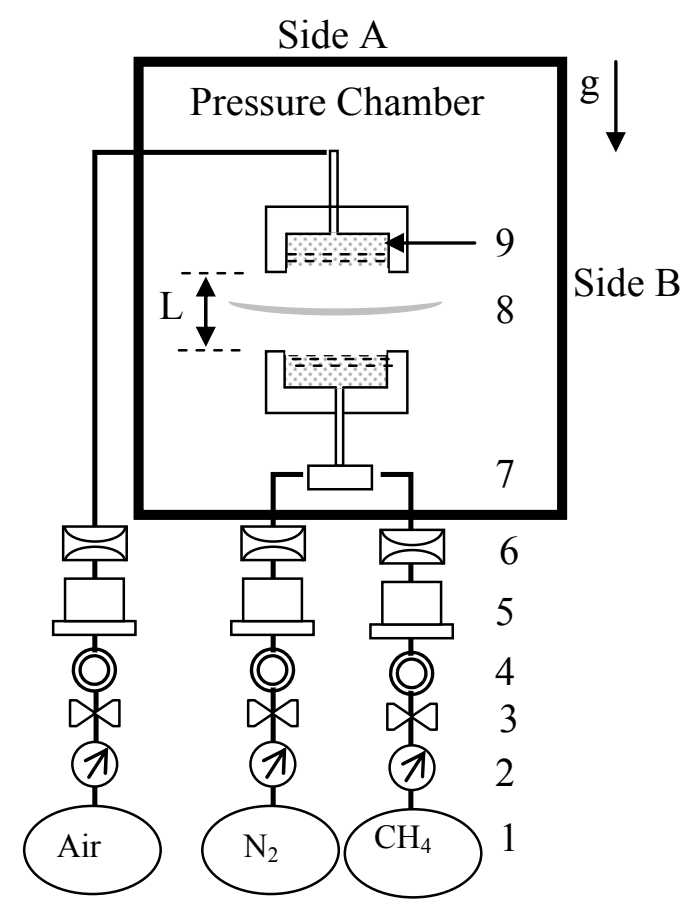

Figure 2. Schematic of counterflow system including (1) gas cylinders, (2) pressure transducers, (3) solenoid valves, (4) pressure regulators, (5) pressure controllers, (6) critical flow orifices, (7) mixing tee, (8) burner, and (9) glass beads and metal screens.

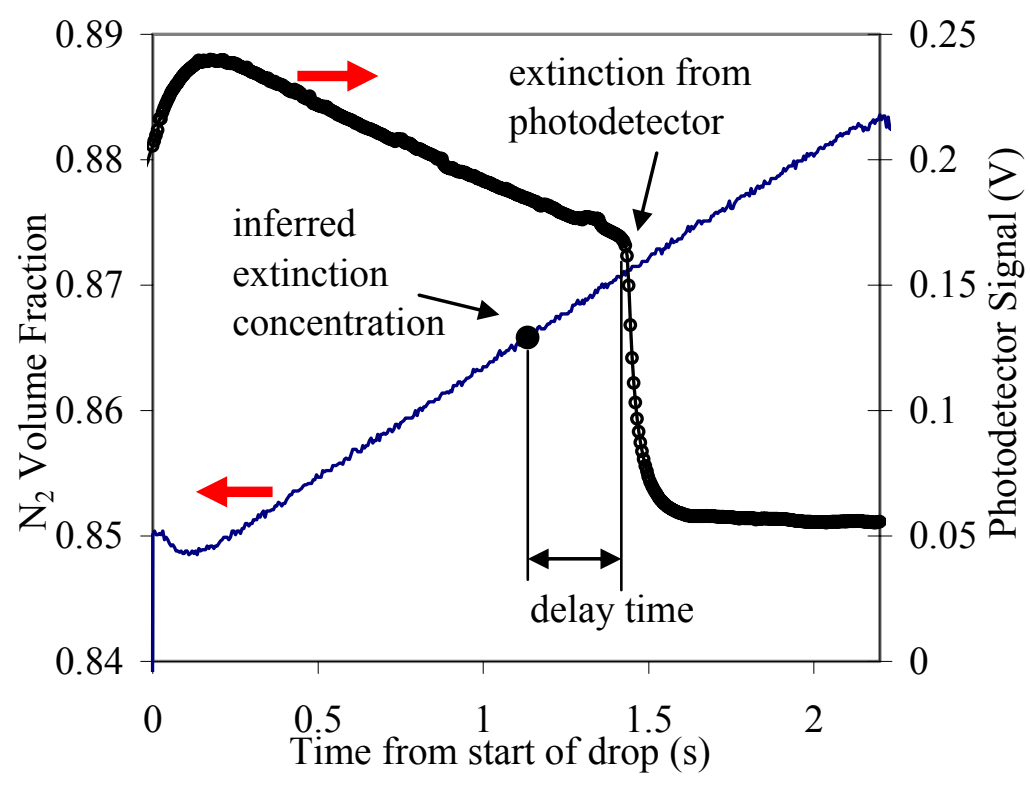

Figure 3. Measured nitrogen volume fraction in the fuel stream of a $15 \mathrm{~s}^{-1}$ methane-air flame as a function of time. The photodetector signal is also shown, indicating the time of flame extinction. 

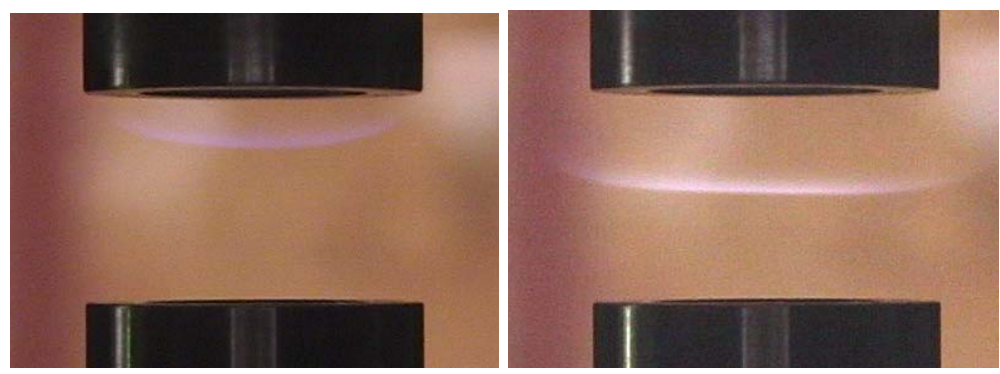

Figure 4. Flames in normal gravity (left) and microgravity for $a_{g}=20 \mathrm{~s}^{-1}$ and a fuel stream $\mathrm{N}_{2}$ volume fraction of 0.80 .

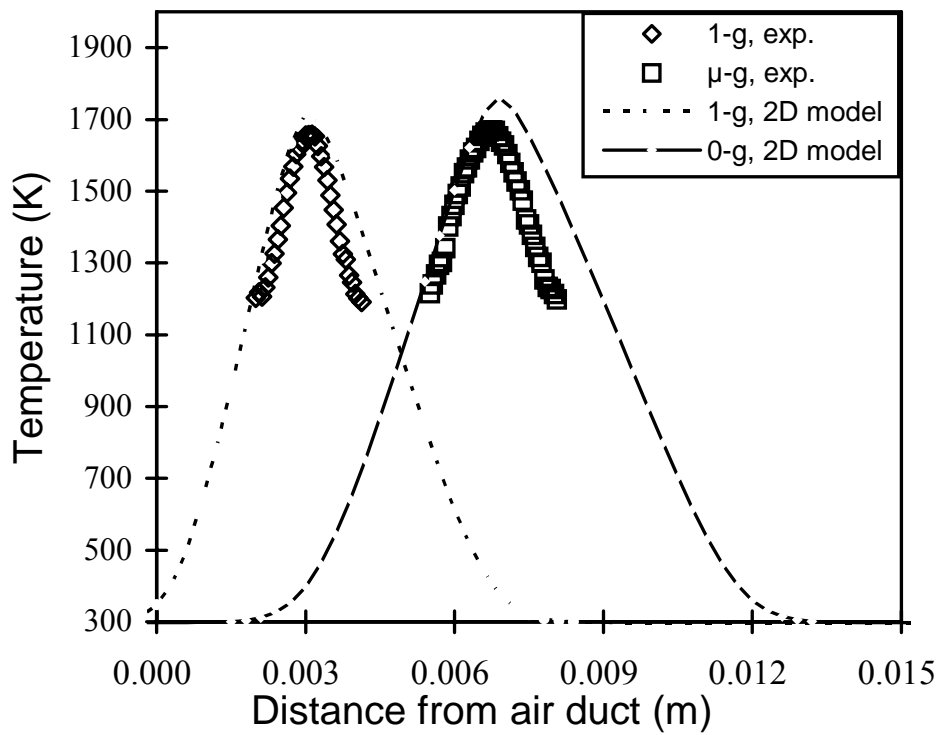

Figure 5. Computed (2D model) and measured temperature profiles in normal gravity and microgravity for $20 \mathrm{~s}^{-1}$ methane-air flames with $0.80 \mathrm{~N}_{2}$ volume fraction in the fuel stream. The expanded uncertainty in the temperature measurement was estimated as $60 \mathrm{~K}$. 

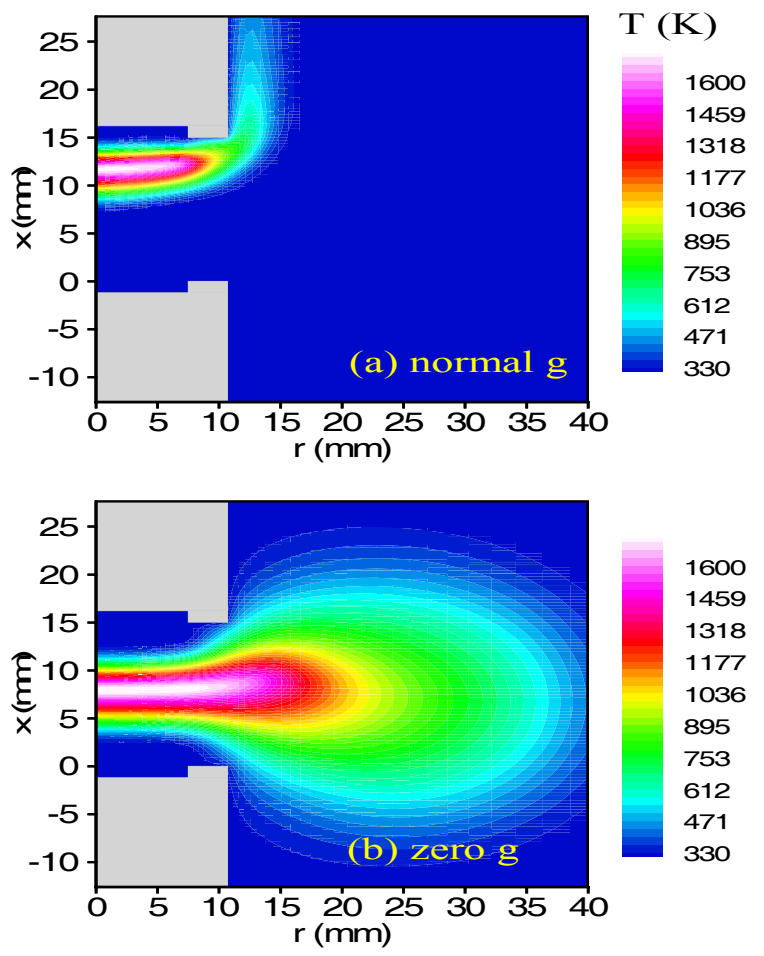

Figure 6. Computed 2D temperature distributions of steady $\mathrm{a}_{\mathrm{g}}=20 \mathrm{~s}^{-1}$ near suppression methane-air flames in (a) normal gravity and (b) zero gravity. 


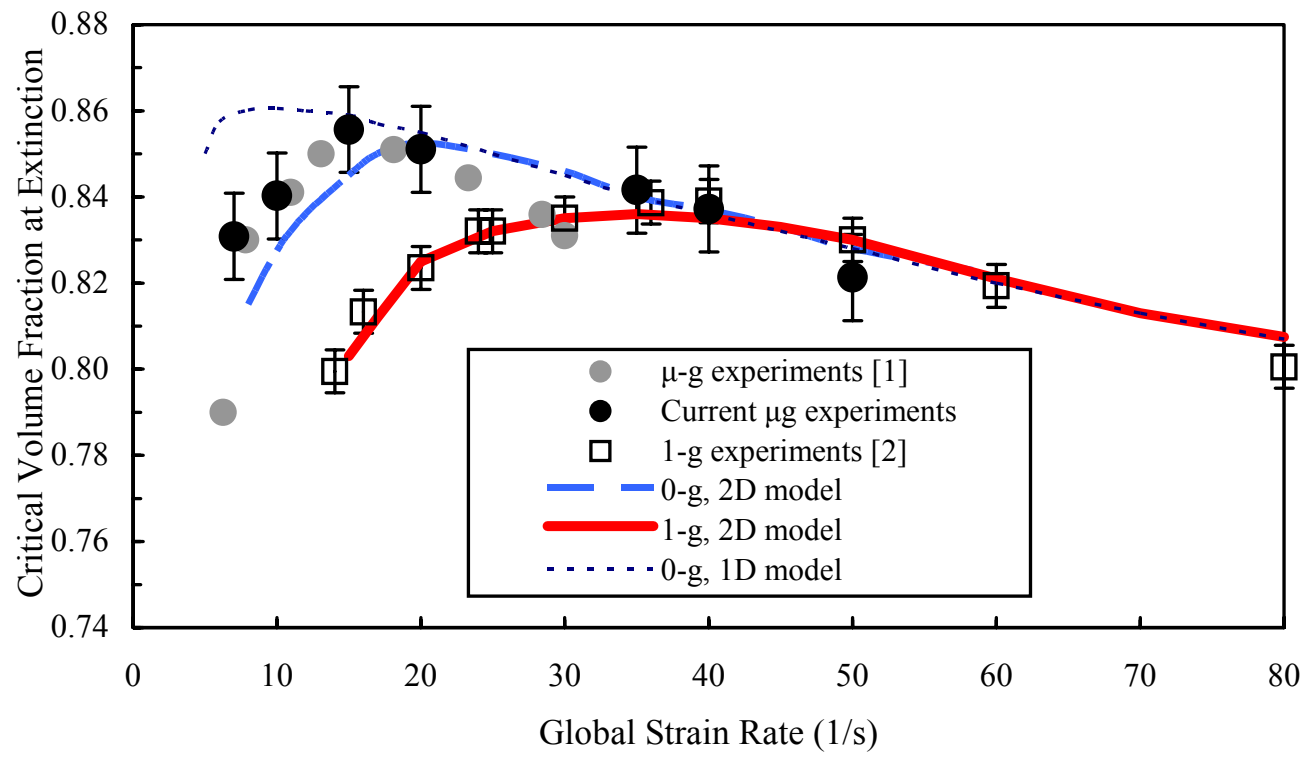

Figure 7. Computed and measured critical nitrogen volume fraction in the fuel stream for suppression of $\mathrm{CH}_{4}$ flames in microgravity and normal gravity. 

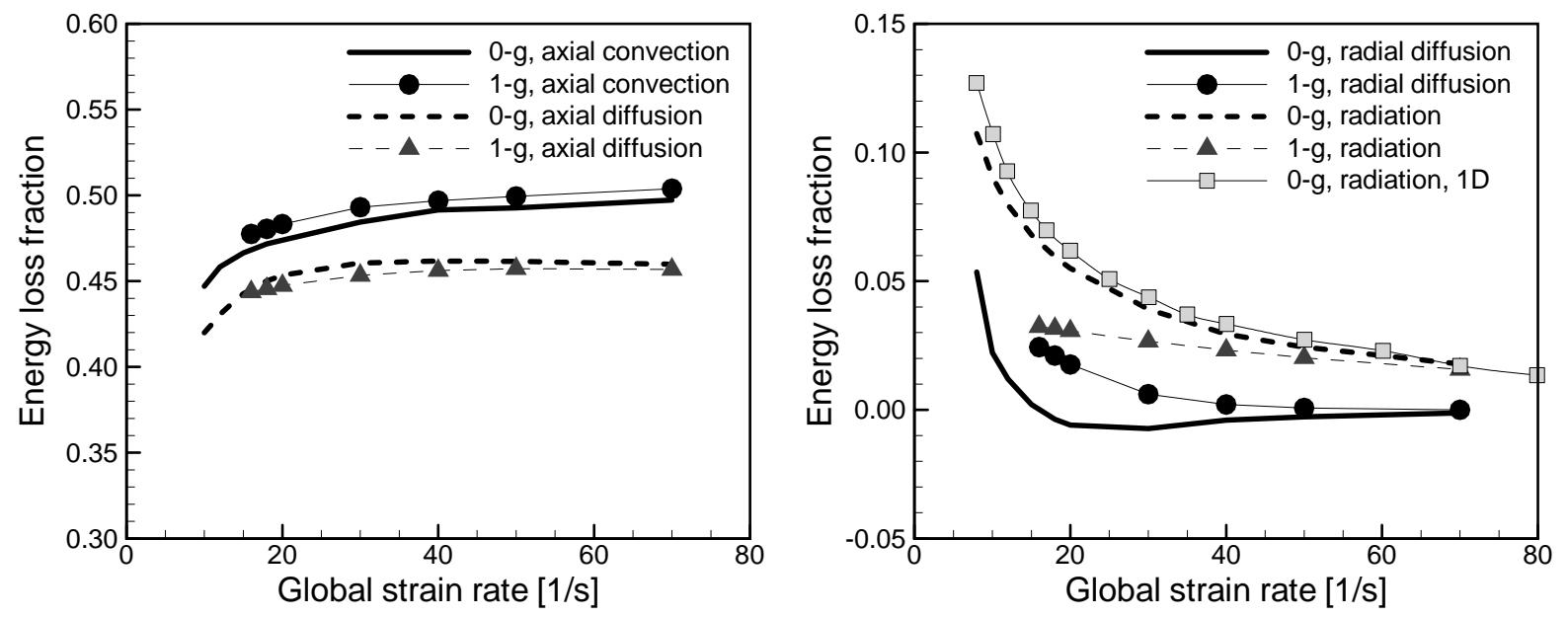

Figure 8. Results of 2D model calculations of the fractional contribution by axial convection, axial diffusion, radial diffusion, and radiation in the energy equation (normalized by the heat release rate) in 0-g (lines) and 1-g flames (symbols) along the flow field centerline with $0.79 \mathrm{~N}_{2}$ volume fraction in the fuel stream as a function of the global strain rate. The radiative loss fraction determined using the $1 \mathrm{D}$ calculation is also shown. 


\title{
Appendix 3
}

\section{Numerical Study of the Suppression of Methane-Air Flames with Carbon Dioxide in Normal Gravity and Microgravity}

\begin{abstract}
The structure and extinction of non-premixed flames was investigated through comparison of experiments and calculations in a methane-air counterflow flame with $\mathrm{CO}_{2}$ added to the fuel stream. Flames with low global strain rates $\left(20 \mathrm{~s}^{-1}\right.$ to $\left.120 \mathrm{~s}^{-1}\right)$ are considered. Axisymmetric flame simulations yield insight into the superior effectiveness of $\mathrm{CO}_{2}$ as an agent as compared to $\mathrm{N}_{2}$. Differences in radiative exchange when $\mathrm{CO}_{2}$ rather than $\mathrm{N}_{2}$ is used as a suppressant are highlighted. In addition, a comparison of differences in the structure and extinction of microgravity and normal gravity flames are also considered. Measurements and computations of the maximum flame temperature near the flow field centerline for near-extinction normal gravity methane-air flames diluted by $\mathrm{CO}_{2}$ show behavior analogous to $\mathrm{N}_{2}$ diluted flames in which the maximum temperature has a minimum value between strain rates of $20 \mathrm{~s}^{-1}$ to $30 \mathrm{~s}^{-1}$. By providing physical insight, two-dimensional simulations are a useful tool for guiding the interpretation of counterflow flame experiments. The analysis, using flame simulations, allows insight of the heat transfer processes that control flame structure and extinction.
\end{abstract}




\section{INTRODUCTION}

A series of measurements and calculations have been undertaken in an effort to improve the understanding of the suppression of low strain rate flames by an agent in microgravity. The current study extends previous work by developing a two-dimensional numerical simulation of flame structure and extinction in micro-gravity and normal gravity for methane-air non-premixed flames with carbon dioxide as a suppressant added to the fuel stream.

The investigation is relevant from both a fire safety and a fundamental perspective. Unwanted fires typically occur due to non-premixed combustion. The initial stage of an unwanted fire in a microgravity environment, such as an orbiting space platform, will likely occur at a low strain rate. A primary motivation of this work is to characterize the agent concentration required to achieve extinction of counterflowing non-premixed (or diffusion) flames at low strain rates. The agent concentration required to achieve the suppression of non-premixed flames is an important consideration in design of total flooding fire protection systems. Carbon dioxide is of interest because it is currently used as the suppressant of choice on-board orbiting space platforms.

The counterflow flame geometry is a convenient configuration for control of the flow field strain rate as well as the flame position [1]. From an experimental perspective, the counterflow configuration has been used to acquire well-defined data on the structure and extinction behavior of flames. Furthermore, the counterflow configuration is amenable to mathematical and numerical analysis, and has provided useful insight into local "flamelet" structure [1-4].

It is common engineering practice to develop and apply models that are as simple as possible, while maintaining the salient physics. Viewed as a flamelet, the counterflow flame is typically modeled as one-dimensional (1D). Experimental observations under microgravity conditions have confirmed that counterflow flames are nearly flat [5]. Under normal gravity conditions, high strain rate flames are also flat near the flow field centerline as buoyancy is dominated by convection. As the strain rate decreases in normal gravity, however, buoyancy forces become relatively more important and counterflow flames are clearly curved. Onedimensional flame codes such as OPPDIF [6], which are based on a similarity solution that neglects buoyancy fail to describe the multi-dimensional structure of low strain rate normal gravity flames, nor do they capture the dynamics of a flame during the transition from normal gravity to microgravity. To gain physical insight, a numerical method is needed that is capable of simulating realistic flames that are multidimensional due to the influence of buoyancy. The price 
of using a multidimensional modeling approach is simplification of the complex flame chemistry, such that the duration of a computation is practical. Such approximations are acceptable provided that the most significant observables are adequately represented.

There have been many studies on the structure and extinction of moderately strained counterflow nonpremixed flames [1-4, 7]. Relatively few studies, however, have considered low strain rate flames. Maruta et al. [5] conducted the first comprehensive extinction measurements of very low strain nonpremixed flames in microgravity using the $10 \mathrm{~s}$ JAMIC drop tower in Japan.

In that study, the extinction of methane-air diffusion flames with $\mathrm{N}_{2}$ added to the fuel stream was measured under microgravity conditions. The minimum methane concentration required to sustain combustion was measured to decrease as the strain rate decreased until a critical value was observed. As the global strain rate was further reduced, the required methane concentration increased. This behavior was denoted as a "turning point" and was attributed to the enhanced importance of radiative loss in low strain rate flames. In terms of fire safety, the turning point agent concentration represents a fundamental limit for nonpremixed flames, assuring suppression for all flow conditions. Bundy et al. [8] observed similar behavior in low strain rate normal gravity flames. Recently, the extinction behavior of ultra low-stretch, buoyant counterflowing nonpremixed flames established in a large Tsuji-type burner was investigated [9]. In that study, information about the extinction limit was not provided, although multi-dimensional effects on flame extinction were discussed.

The objective of this study is to investigate the structure and extinction characteristics of low strain rate counterflowing methane-air nonpremixed flames using carbon dioxide as the agent. An axisymmetric 2D computational model, including buoyancy effects and radiative heat transfer was developed. The model was validated through comparison of the 2D model with experiments and $1 \mathrm{D}$ computational results for counterflow nonpremixed flames diluted by nitrogen. Once validated, the calculation was used in this study to explore the near-extinction flame structure for flame suppressed by $\mathrm{CO}_{2}$.

\section{EXPERIMENTS}

The calculation results were validated by comparison to experimental measurements with $\mathrm{N}_{2}$ and $\mathrm{CO}_{2}$ as the suppressant using a burner system that is shown in Figure 1. Experimental methods were described previously [1]. The inner burner duct diameter $(D)$ was $23.4 \pm 0.1 \mathrm{~mm}$ 
and the duct separation distance $(L)$ was set to $25.0 \pm 0.1 \mathrm{~mm}$. Four 200 mesh stainless steel screens were positioned $1.6 \pm 0.1 \mathrm{~mm}$ from the duct exits and at $1.6 \mathrm{~mm}$ intervals to impose a tophat velocity profile. A water-cooled jacket about the top burner duct prevented heating of the metal burner and preheating of the supplied reactants. The reactant flows were controlled using mass flow controllers that were calibrated using a dry cell primary flow meter with an uncertainty of $1 \%$. Flame temperature measurements were conducted using thin filament pyrometry [2]. The details of the measurement and calibration methods are given in Refs. [1, 2].

Still flame images were taken with a camera using a $1 \mathrm{~s}$ shutter opening and an $\mathrm{f}$ stop of 2.8 to compare the steady flame shapes with the computations. Images of flame extinction was recorded with a digital video camera to clarify the difference between modes of extinction at low and high strain rates. The calculation results for the extinction limits as a function of a global strain rate for normal gravity (1-g) counterflow flames was compared with previous measurements given in Ref [1].

Counterflow flame conditions were defined by the global strain rate and the concentration of agent $\left(\mathrm{N}_{2}\right.$ or $\left.\mathrm{CO}_{2}\right)$ in the methane fuel stream. The fractional amount of agent in the fuel stream was denoted as $\mathrm{Ca}$. For a given global strain rate, the flame extinguished for a critical value of $\mathrm{Ca}$. The global strain rate, $\mathrm{a}_{g}$, is used to characterize the flow field in a counterflow flame. Its definition is [3]:

$$
\mathrm{a}_{g}=\frac{2 V_{O}}{L}\left(1+\frac{V_{F} \sqrt{\rho_{F}}}{V_{O} \sqrt{\rho_{O}}}\right)=\frac{2 V_{r} V_{F}}{L}\left(1+\frac{\sqrt{\rho_{F}}}{V_{r} \sqrt{\rho_{O}}}\right)
$$

where the parameters $V$ denotes the velocity and $\rho$ the density of the reactant streams at the duct boundaries, $L$ is the duct separation distance, and the subscripts $\mathrm{O}$ and $\mathrm{F}$ represent the air and fuel streams, respectively. The velocity ratio, $V_{r}$, is defined as equal to $V_{O} / V_{F}$. The global strain rate concept allows quantification of a characteristic flame residence time or flow time.

\section{NUMERICAL METHOD}

The present study computation employed a time-dependent axisymmetric configuration to treat counterflow diffusion flames formed between two opposed circular ducts. A coupled set of model-free equations with a low Mach number approximation was used following Ref. [4]. QUICK [5] and second-order central difference schemes were used to discretize the convective and diffusive terms. A predictor-corrector scheme nearly identical to that of Najm et al. [6] was 
used for time integration of the governing equations. Efficient algebraic relaxation for the velocity-pressure correction was performed using the HSMAC method [7]. CHEMKIN-II [8] and TRANFIT [9] were adopted for calculation of thermodynamic and transport properties.

The computational domain in the axial direction and radial direction was taken to be 40 $\mathrm{mm}$ and $70 \mathrm{~mm}$ respectively. In addition, $268 \times 70$ grids were used for the zero gravity simulation and $268 \times 65$ grids for normal gravity. A uniform grid spacing of $0.15 \mathrm{~mm}$ was used in the axial direction. Radially, non-uniform grids with a minimum spacing of $0.3 \mathrm{~mm}$ were clustered near the centerline. A grid sensitivity study confirmed that the calculated extinction limit and the temperature maximum was unchanged when a finer grid $(0.10 \mathrm{~mm}$ in the axial direction) was used, indicating that the heat release rate zone was adequately resolved.

The inflow temperature boundary condition for the reactant streams was $298 \mathrm{~K}$. Uniform axial velocity was imposed at the mesh screens, which were positioned about $1.2 \mathrm{~mm}$ into each of the ducts. This condition is appropriate for global strain rates in $0 \mathrm{G}$ and $1 \mathrm{G}$ above about $7 \mathrm{~s}^{-1}$ and $15 \mathrm{~s}^{-1}$, respectively, as exemplified by the temperature gradient, which is nominally flat under those conditions. The computational geometry is shown in Fig. 2. Sides A and B in Fig. 2 were treated as outflow boundary conditions. A no slip condition was applied on the burner walls and the wall temperature was taken as $298 \mathrm{~K}$. A no mass flux condition was applied at all boundaries. The oxidizer stream was composed of undiluted air composed of $21 \%$ oxygen and $79 \%$ nitrogen by volume, and the fuel was methane diluted by suppressants. The ambient gas was set to pure nitrogen, as in the experiment, to prevent secondary combustion of fuel.

\subsection{Chemical reaction mechanism and radiation model}

A 3-step irreversible reaction mechanism [10] for methane oxidation was used. Use of a larger, more comprehensive chemical mechanism was precluded due to practical reasons associated with computational cost. The 3 -step chemical model is adequate, as this paper focuses on the energetics associated with flame suppression, and not kinetic minutiae. The detailed mechanism and reaction rates were taken as [10]:

$$
\begin{aligned}
& \mathrm{CH}_{4}+3 / 2 \mathrm{O}_{2} \rightarrow \mathrm{CO}+2 \mathrm{H}_{2} \mathrm{O} \\
& \mathrm{CO}+1 / 2 \mathrm{O}_{2} \rightarrow \mathrm{CO}_{2} \\
& \mathrm{CO}_{2} \rightarrow \mathrm{CO}+1 / 2 \mathrm{O}_{2}
\end{aligned}
$$

and the associated reaction rates were:

$$
-\mathrm{d}\left[\mathrm{CH}_{4}\right] / \mathrm{dt}=10^{11.68} \exp (-23500 / \mathrm{T})\left[\mathrm{CH}_{4}\right]^{0.7}\left[\mathrm{O}_{2}\right]^{0.8}
$$




$$
\begin{aligned}
& -\mathrm{d}[\mathrm{CO}] / \mathrm{dt}=10^{12.35} \exp (-19200 / \mathrm{T})[\mathrm{CO}]^{1.0}\left[\mathrm{H}_{2} \mathrm{O}\right]^{0.5}\left[\mathrm{O}_{2}\right]^{0.25} \\
& \left.-\mathrm{d}\left[\mathrm{CO}_{2}\right] / \mathrm{dt}=10^{12.50} \exp (-20500 / \mathrm{T})\right)[\mathrm{CO}]^{1.0}\left[\mathrm{H}_{2} \mathrm{O}\right]^{0.5}\left[\mathrm{O}_{2}\right]^{0.25}
\end{aligned}
$$

with reaction rates in units of kmole- $\mathrm{m}^{-3}-\mathrm{s}^{-1}$.

The viability of the 3 step global mechanism was demonstrated by performing low strain rate flame calculations using OPPDIF [11]. The calculations showed that the GRI-3.0 mechanism [12] and the 3-step mechanism yielded nearly the same extinction and flame temperature profile results. An optically-thin radiation sub-model [13] was implemented, which considered heat loss from $\mathrm{CH}_{4}, \mathrm{CO}_{2}, \mathrm{H}_{2} \mathrm{O}$, and $\mathrm{CO}$. Soot was not considered in these thin blue flames. The volumetric rate of radiative heat loss in the energy equation can be written as:

$$
\dot{q}_{r}=-4 \sigma K_{p}\left(T^{4}-T_{\infty}^{4}\right)
$$

where $T$ and $T_{\infty}$ are the local and the ambient temperature, respectively. $K_{p}$ is the Plank mean absorption coefficient of the mixture, which is expressed as:

$$
K_{p}=P_{\mathrm{CH}_{4}} K_{\mathrm{CH}_{4}}+P_{\mathrm{CO}_{2}} K_{\mathrm{CO}_{2}}+P_{\mathrm{H}_{2} \mathrm{O}} K_{\mathrm{H}_{2} \mathrm{O}}+P_{\mathrm{CO}} K_{\mathrm{CO}}
$$

where, $P_{i}$ and $K_{i}$ denote the partial pressure and Plank mean absorption coefficient of species $i$, respectively, with $K_{p}$ taken from Ref. [13].

$$
\begin{aligned}
& \rho c_{p}\left(\frac{\partial T}{\partial t}\right)=-\rho c_{p} u \frac{\partial T}{\partial x}-\rho c_{p} v \frac{\partial T}{\partial r}+\frac{\partial}{\partial x}\left(\lambda \frac{\partial T}{\partial x}\right)+\frac{1}{r} \frac{\partial}{\partial r}\left(r \lambda \frac{\partial T}{\partial r}\right) \\
& +\sum_{i=1}^{N} \rho c_{p i} D_{i m} \frac{\partial Y_{i}}{\partial x} \frac{\partial T}{\partial x}+\sum_{i=1}^{N} \rho c_{p i} D_{i m} \frac{\partial Y_{i}}{\partial r} \frac{\partial T}{\partial r}+\dot{q}_{r}-\sum_{i=1}^{N} W_{i} h_{i}^{0} \dot{\omega}_{i}
\end{aligned}
$$

\section{Results and discussion}

\subsection{Validation of the computational results}

The computed flame shape was compared with measurements to validate the $2 \mathrm{D}$ model. Figure 3 compares photographs of the thin non-luminous flame and computed flame shapes using the $2 \mathrm{D}$ model for $20 \mathrm{~s}^{-1}$ in both $0-\mathrm{g}$ and $1-\mathrm{g}$, the flames were near extinction with $\mathrm{N}_{2}$ dilution in the fuel stream.

The high heat release rate region represents the high temperature zone and the peak heat release rate can be considered to be near the flame surface. The computed flame shape and the flame surface location by photographs were similar as show in Figure 3. The photographs in Figure 3 show that the flame size, the shape, and the flame surface location of the 1-g flames 
were reasonably well predicted by the $2 \mathrm{D}$ computations for a variety of global strain rate and velocity ratio conditions.

Figure 4 compares the calculated temperature profiles with measurements in a nearextinction 1-g methane-air nonpremixed counterflow flame with $\mathrm{a}_{\mathrm{g}}=20 \mathrm{~s}^{-1}$ with the fuel stream diluted by $\mathrm{N}_{2}(\mathrm{Ca}=0.81)$. Extinction occurs for $\mathrm{Ca}=0.84$. The temperature profile computed by the $2 \mathrm{D}$ model was in good agreement with previous measurements obtained using thin filament pyrometry. The flame location was also reasonably predicted by the $2 \mathrm{D}$ model. The $2 \mathrm{D}$ model developed here provides a more complete description of the flame physics as seen in the flame

structure, including the flame size, the shape, the flame surface location and the flame temperature for a variety of global strain rate and velocity ratio conditions.

\subsection{Extinction limits and suppression characteristics of $\mathrm{CO}_{2}$ addition in fuel stream}

Figure 5 shows a comparison between the measured and computed extinction limits of the critical $\mathrm{CO}_{2}$ volume fraction in the fuel stream to extinguish the methane-air diffusion flame as a function of the global strain rate for equal fuel and oxidizer flow velocities $\left(\mathrm{V}_{\mathrm{r}}=1\right)$. The flame extinction curve has a turning point in which the critical $\mathrm{CO}_{2}$ volume fraction increased as the strain rate decreased, until the volume fraction reached a maximum value near $\mathrm{a}_{\mathrm{g}}=30 \mathrm{~s}^{-1}$ and then decreased as the global strain rate increased. The measured critical agent volume fraction of $\mathrm{CO}_{2}$ in the methane fuel stream assuring suppression for all global strain rates was $0.773 \pm 0.009$, and that of $2 \mathrm{D}$ model was 0.76 which is raged in the error bar. The $2 \mathrm{D}$ model under-predicted for smaller $a_{g}$ of 30 , and over-predicted for higher $a_{g}$ of 30 .

Figure 6 shows the computed flame shamp of 1 -g counterflow for $\mathrm{a}_{\mathrm{g}}=20$ with different dilution volume fractions of $\mathrm{CO}_{2}$. For the case of $\mathrm{Ca}=60$, the edge of the computed flame reached to the outer lip of the burner, but increasing of $\mathrm{Ca}$ made to decrease the flame size. Near the extinction limit $(\mathrm{Ca}=66)$, the flame zone was located near the center axis of the burner.

Figure 7 show the temperature profile along the center axis of the counterflow flame for different $\mathrm{CO}_{2}$ volume fraction in the fuel stream. The maximum temperature decreased and the flame position moved up to air duct as the volume fraction of $\mathrm{CO}_{2}$ increased. But, the flame thickness and overall flow structure was not significantly varied with increasing of Ca even if the flame size and temperature field was changed.

Table 1 represent the computed fractional contribution to the heat release rate by key terms in the energy equation along the flow field centerline for the $\mathrm{a}_{\mathrm{g}}=20$. As the volume fraction of $\mathrm{CO}_{2}$ increased, the contribution of radiation and axial convection term increased while that of axial 
conduction decreased. The results indicate that axial convection is the largest contribution of the heat loss mechanism near the extinction limit.

Table 1. The computed fractional contribution by each term in the energy equation to the heat release rate of $1-g, a_{g}=20$.

\begin{tabular}{|c|c|c|c|}
\hline $\mathrm{Ca}$ & axial convection & axial conduction & radiation \\
\hline 60 & 0.4532 & 0.4502 & 0.0928 \\
\hline 65 & 0.4627 & 0.4296 & 0.1042 \\
\hline 66 & 0.4640 & 0.4225 & 0.1071 \\
\hline
\end{tabular}

Figure 8 shows the computed flame shape using 2D model for the fuel stream diluted with $\mathrm{CO}_{2}$. The flame was wider with increasing the global strain rate, and the flame apart from the burner tube of air incoming. The flame thickness and curvature decreased as the global strain rate increased. As an increase in global strain rate tend to increase the distance between flow stagnation point and flame surface at the centerline of the burner.

For the case of low strain rate, some of the mixture of fuel and $\mathrm{CO}_{2}$ did not rise up to flame surface and dispersed out near lower burner tube. This was probably because the inertia of the fuel and $\mathrm{CO}_{2}$ mixture is low. But for the case of $\mathrm{a}_{\mathrm{g}}=40$, most of incoming flow rose toward the flame surface.

Figure 9 shows the computed local strain rate and the position of maximum heat release rate at the centerline of the burner for $\mathrm{CO}_{2}$ volume fraction of 65 . The negative maximum value of local strain rate is further from the air duct as the global strain rate increased. The flame surface location defined by the maximum heat release rate was also moved down as shown in Figure 8 . The position of the maximum heat release rate was just above the maximum negative local strain rate.

Figure 10 represents the computed fractional contribution of axial convection and diffusion term in the energy equation to the heat release for $0.65 \mathrm{CO}_{2}$ as function of the global strain rate along the centerline. The contribution of axial convection fraction increased with increasing the global strain rate. The contribution of the axial diffusion fraction is linearly 
increased with increasing the global strain rate until $\mathrm{a}_{\mathrm{g}}=35$. But it was nearly constant in the higher global strain rate of $\mathrm{a}_{\mathrm{g}}=80$.

Figure 11 shows the computed fractional contribution of radiative term in the energy equation to the heat release rate as function of global strain rate near the extinction limit of $\mathrm{N}_{2}$ and $\mathrm{CO}_{2}$ suppression. The conditions are $\mathrm{Ca}=65$ for $\mathrm{CO}_{2}$ suppression and $\mathrm{Ca}=79$ for $\mathrm{N}_{2}$ suppression. The results show that the radiative energy loss mechanism becoming larger as the global strain rate decreases.

As expected, the fractional contribution of radiative energy loss of $\mathrm{CO}_{2}$ suppression is almost twice times higher than that of the $\mathrm{N}_{2}$ suppression. $\mathrm{N} 2$ is radiatively inactive gas while $\mathrm{CO}_{2}$ is a strong absorber. Some radiation energy emitted near the flame surface can not be absorbed by the reactant when the fuel is diluted with $\mathrm{CO}_{2}$. Therefore, the radiative heat loss may affect on the difference of extinction limit between $\mathrm{CO}_{2}$ and $\mathrm{N}_{2}$ suppression.

Figure 12 indicate the maximum temperature at the centerline of the burner as function of Ca for global strain rate of 20,30, and 60 . The maximum temperature decreased with increasing $\mathrm{Ca}$, it has the minimum value at the extinction limits. The maximum temperature near the extinction limit has the minimum value around the global strain rate of 30 .

Figure 13 shows the maximum flame temperature near the flame extinction with $2 \mathrm{D}$ computation and measurements. 2D computation in microgravity shows similar trends with experiments in the maximum temperature along the centerline of the burner. For the nitrogen agent in microgravity, the maximum centerline temperature had a minimum value near the global strain rate of $20 \mathrm{~s}-1$. For the CO2 agent in normal gravity, the trend was similar with $\mathrm{N} 2$ in microgravity except the turning point slightly moved to global strain rate of $30 \mathrm{~s}-1$.

SMHRR(Specific Maximum Heat Release Rate) considered to investigate the order of flame strength with the volume fraction of $\mathrm{CO} 2$. Figure 14 shows the computed maximum heat release rate and local strain rate as function of $\mathrm{Ca}$. The maximum heat release rate decreased with increasing volume fraction of $\mathrm{CO} 2$ while the local strain rate in which the maximum heat release rate occurred was almost constant. Accordingly, the SMHRR decreased as the volume fraction of $\mathrm{CO} 2$ increased. The value of SMHRR for ag=60 was about 2.0 near the extinction limit.

Figure 15 shows the computed SMHRR with maximum heat release rate and local strain rate as function of the global strain rate near the extinction limits. The maximum heat release rate and local strain rate had the minimum value around the global strain rate of 30 near the extinction limit of $\mathrm{CO}_{2}$ volume fraction. For the higher global strain rate than 30, the maximum heat release rate and local strain rate linearly increased as the global strain rate increased. Except the case of $\mathrm{a}_{\mathrm{g}}=20$, the flame was extinguished under 2.0 of SMHRR. 
Figure 16 shows the maximum temperature and heat release rate at the centerline of the burner near the extinction limit at $\mathrm{a}_{\mathrm{g}}=20$ for the $\mathrm{N}_{2}$ and $\mathrm{CO}_{2}$, respectively. The maximum heat release rate, the maximum temperature and flame location for the $\mathrm{CO}_{2}$ flame suppression were similar with that of the $\mathrm{N}_{2}$, but the flame thickness of the $\mathrm{CO}_{2}$ suppression is thinner than that of the $\mathrm{N}_{2}$ suppression.

Figure 17 shows the computed results of the temporal evolution of 1 -g flame extinction at $\mathrm{a}_{\mathrm{g}}=30$ and $\mathrm{V}_{\mathrm{r}}=1$. The $\mathrm{CO}_{2}$ volume fraction in the fuel stream of 1-g flame was increased at time equal zero from an initial steady value of 0.74 to 0.78 , its value at the extinction limit. The right hand side of the computational results shows the computed temperature field, while the left hand side shows the computed heat release rate and streamlines. Figure 6 (b) shows that the extinction of the 1-g flame initiate near the centerline as the increased $\mathrm{CO}_{2}$ volume fraction in the fuel stream reaches the flame surface. The flame zone around the centerline becomes weak as the heat release rate decreases and the entire flame abruptly extinguishes.

\section{Conclusions}

The structure and extinction of non-premixed flames was investigated through comparison of experiments and calculations in a methane-air counterflow flame with $\mathrm{CO}_{2}$ added to the fuel stream. The simulations yielded insight into the effectiveness of $\mathrm{CO}_{2}$ as an agent, highlighting differences in the radiative loss when $\mathrm{CO}_{2}$ rather than $\mathrm{N}_{2}$ is used as a suppressant. The differences between microgravity and normal gravity suppression results were modeled. Measurements and computations of the maximum flame temperature near the flow field centerline for near-extinction methane-air flames diluted by $\mathrm{CO}_{2}$ show behavior analogous to $\mathrm{N}_{2}$ diluted flames in which the maximum temperature has a minimum value between strain rates of $20 \mathrm{~s}^{-1}$ and $30 \mathrm{~s}^{-1}$.

The analysis, using flame simulations, allows insight of the heat transfer processes that control flame structure and extinction. At low strain rates, the flames are rather thick and lateral heat and diffusion losses are not negligible. By providing physical insight, two-dimensional simulations are a useful tool for guiding the interpretation of counterflow flame experiments. 


\section{References}

[1] Bundy M, Hamins A, Lee K Y 2003 Combust. Flame 133 299-310

[2] Bundy M, Park J, Oh C B, Hamins A, "Extinction and Temperature Measurements in

Nonpremixed Methane Flames in Microgravity," submitted to Combustion Theory and Modeling, 2006.

[3] Seshadri K and Williams F A 1978 Int. J. Heat Mass Transfer 21 251-253

[4] C.B. Oh, C.E. Lee, J. Park, Combust. Flame, 138 (2004) 225-241.

[5] B.P. Leonard, Comput. Meth. Appl. Mech. Eng.,, 19 (1979) 59-98.

[6] H.N. Najm, P.S. Wyckoff, Combust. Flame, 110 (1997) 92-112.

[7] C.W. Hirt and J.L. Cook, J. Comput. Phys., 10 (1972) 324-340.

[8] R.J. Kee, F.M. Rupley, J.A. Miller, CHEMKIN-II: A Fortran Chemical Kinetics Package for the Analysis of Gas Phase Chemical Kinetics, Report No. SAND89-8009B, Sandia National Laboratories, 1989.

[9] R.J. Kee, G. Dixon-Lewis, J. Warnatz, M.E. Coltrin, J.A. Miller, A Fortran Computer Code Package for the Evaluation of Gas-phase Multicomponent Transport Properties, Report No.

SAND86-8246, Sandia National Laboratories, 1986.

[10] F.L. Dryer, I. Glassman, Proc. Combust. Inst., 14 (1972) 987-1003.

[11] A. Lutz, R.J. Kee, J. Grcar, J., F.M. Rupley, "A Fortran Program Computing Opposed Flow Diffusion Flames", SAND96-8243, Sandia National Labs, Livermore (1997).

[12] Smith, G. P., Golden, D. M., Frenklach, M., Moriatry, N. W., Eiteneer, B., Goldenberg, M, Bowman, C. T., Hanson, R. K., Song, S., Gardiner, W. C., Lissianski, V. and Qin, Z., http://www.me.berkeley.edu/gri mech/.

[13] Y. Ju, H. Guo, K, Maruta, F, Liu, J. Fluid Mech., 342 (1994) 315-334. 


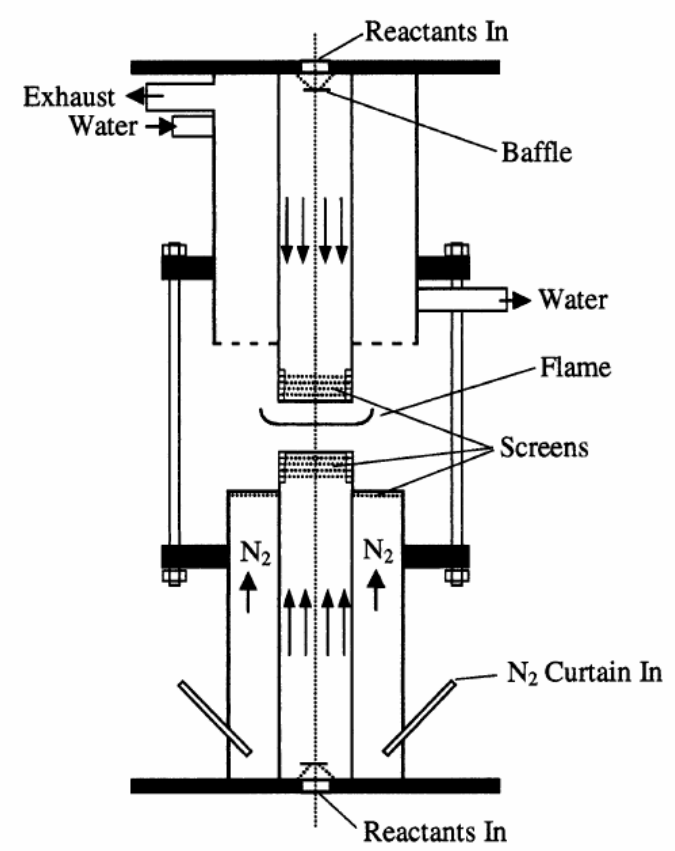

Figure 1. Schematic drawing of counterflow burner.

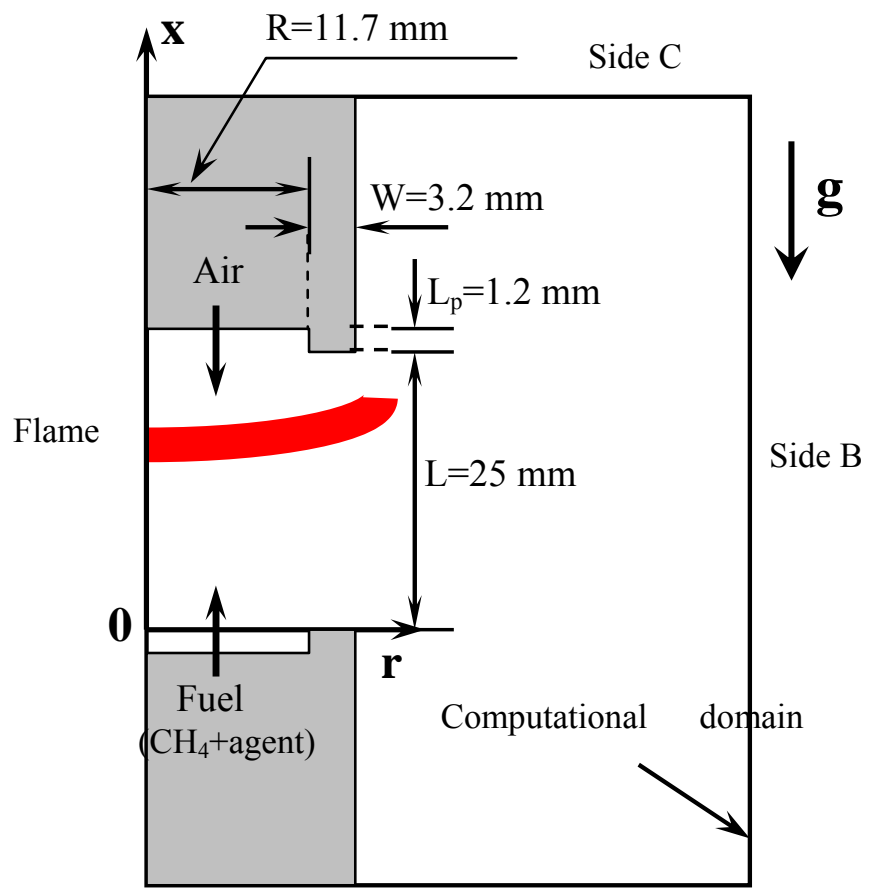

Side A

Figure 2. Schematic the computational domain. 


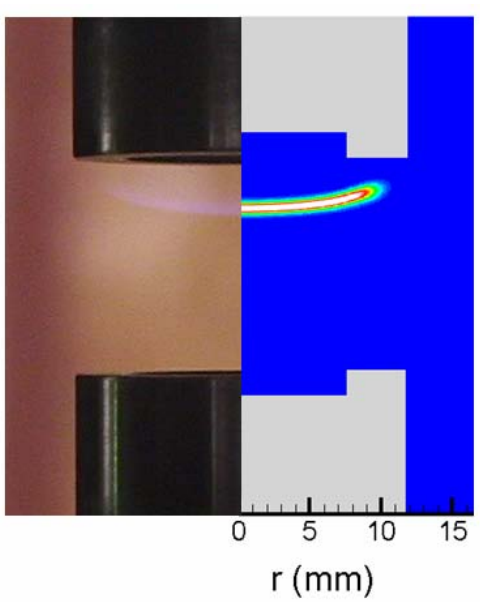

(a) 1 -g

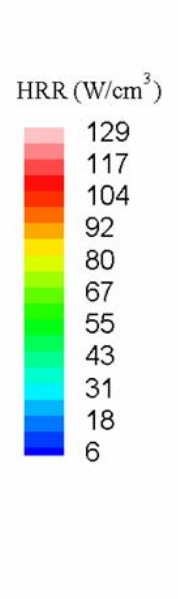

Figure 3. Comparison of flame shape in normal gravity and microgravity for methane-air nonpremixed flames at $\mathrm{a}_{\mathrm{g}}=20 \mathrm{~s}^{-1}$ and a fuel stream $\mathrm{N}_{2}$ volume fraction of 0.80 . The left hand sides are photographs, while the right hand sides are simulation results.

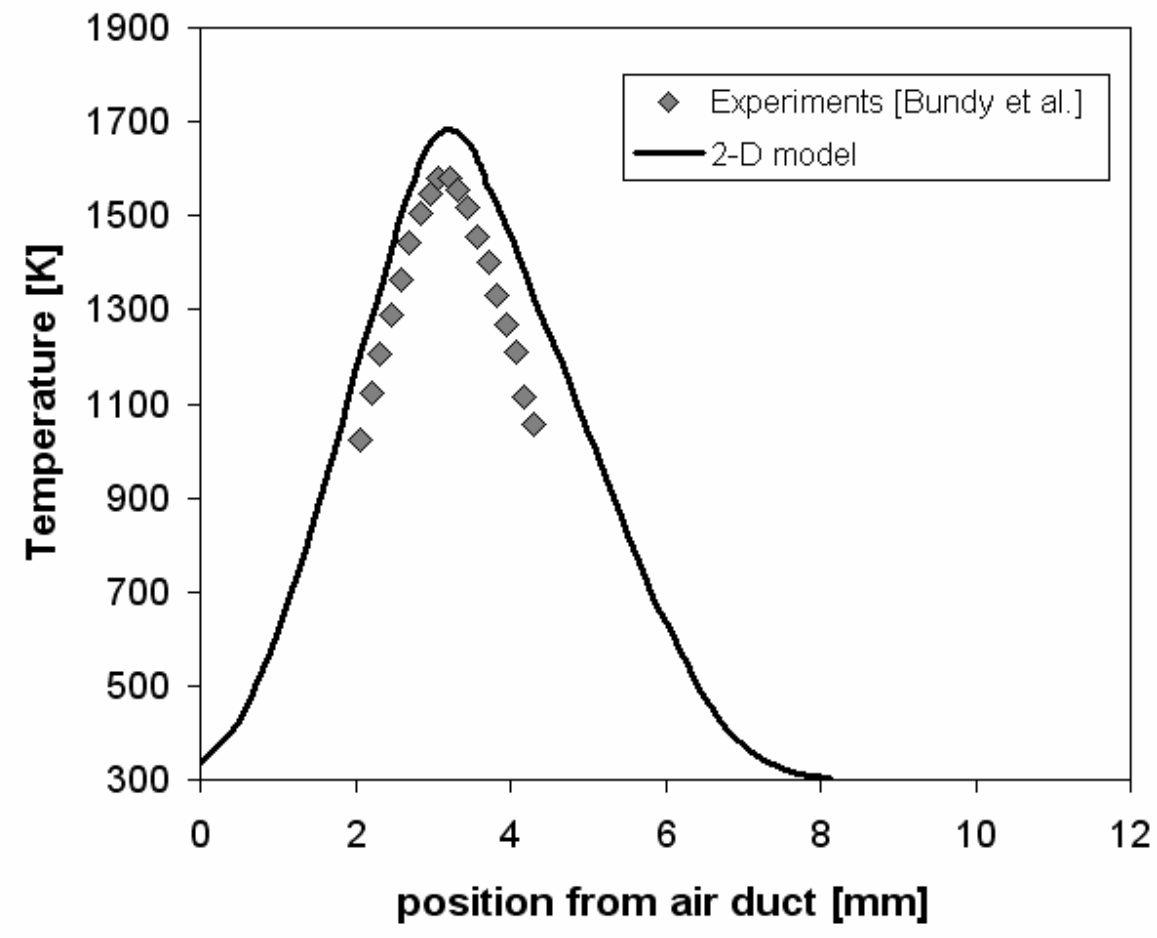

Figure 4. Measured and computed temperature profiles for $\mathrm{a}_{\mathrm{g}}=20 \mathrm{~s}^{-1}$ with 0.81 volume fraction of $\mathrm{CO} 2$ in the fuel stream and $\mathrm{Vr}=1$. 


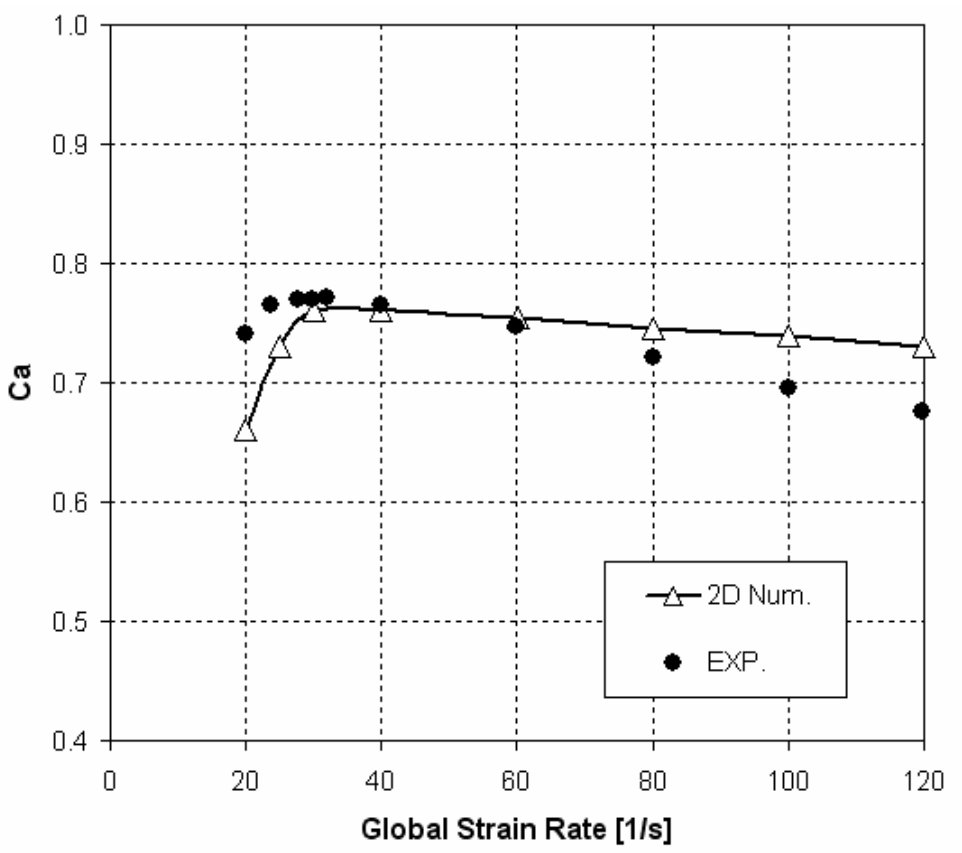

Figure 5. Computed and measured critical $\mathrm{CO}_{2}$ volume fraction in the fuel stream $(\mathrm{Ca})$ as a function of the global strain rate for suppression of $\mathrm{CH}_{4}$ flames in normal gravity. 


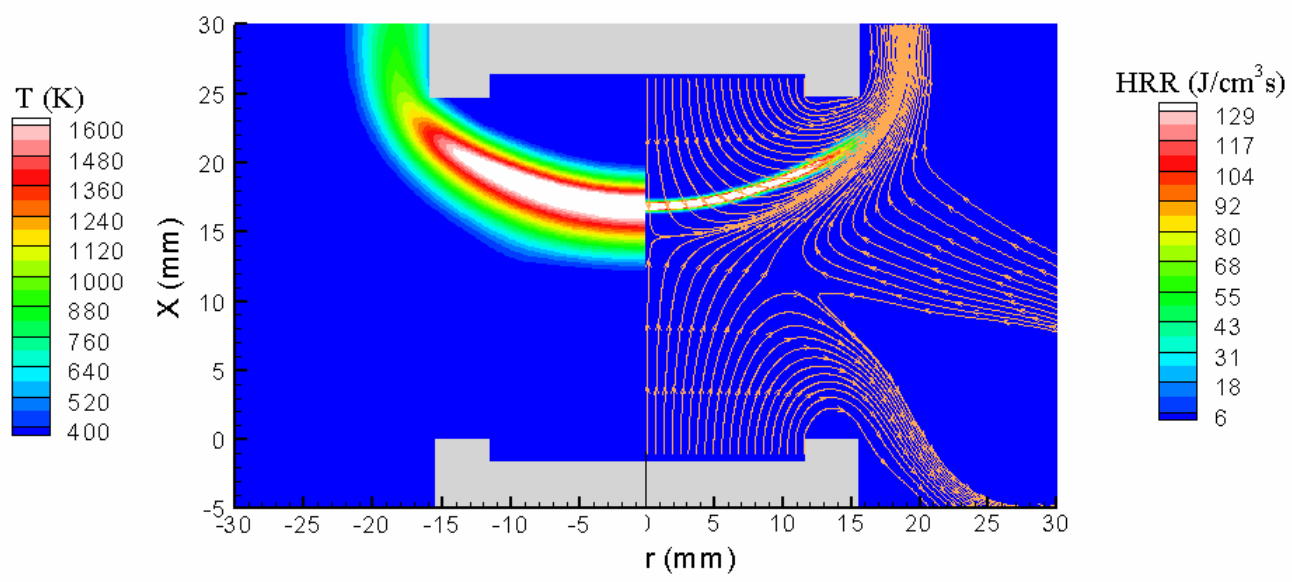

(a) $\mathrm{Ca}=0.60$

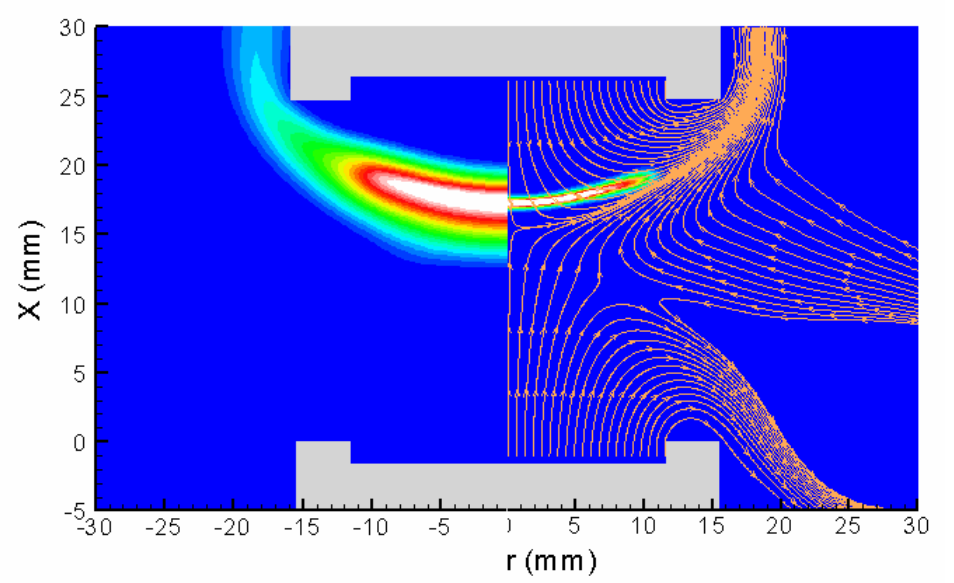

(b) $\mathrm{Ca}=0.65$

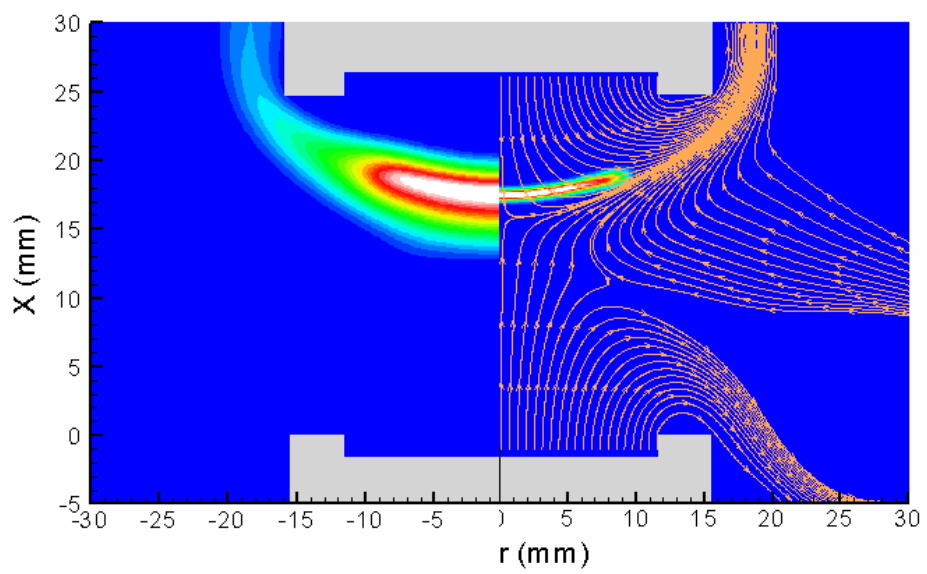

(c) $\mathrm{Ca}=0.66$

Figure 6. Computations of a normal gravity counterflow nonpremixed flame diluted with $\mathrm{CO}_{2}$ in the fuel stream for the global strain rate of $20 \mathrm{~s}^{-1}$. Calculated temperatures are shown on the left-hand side of the figures and the heat release rate and streamlines are shown on the right-hand side. 


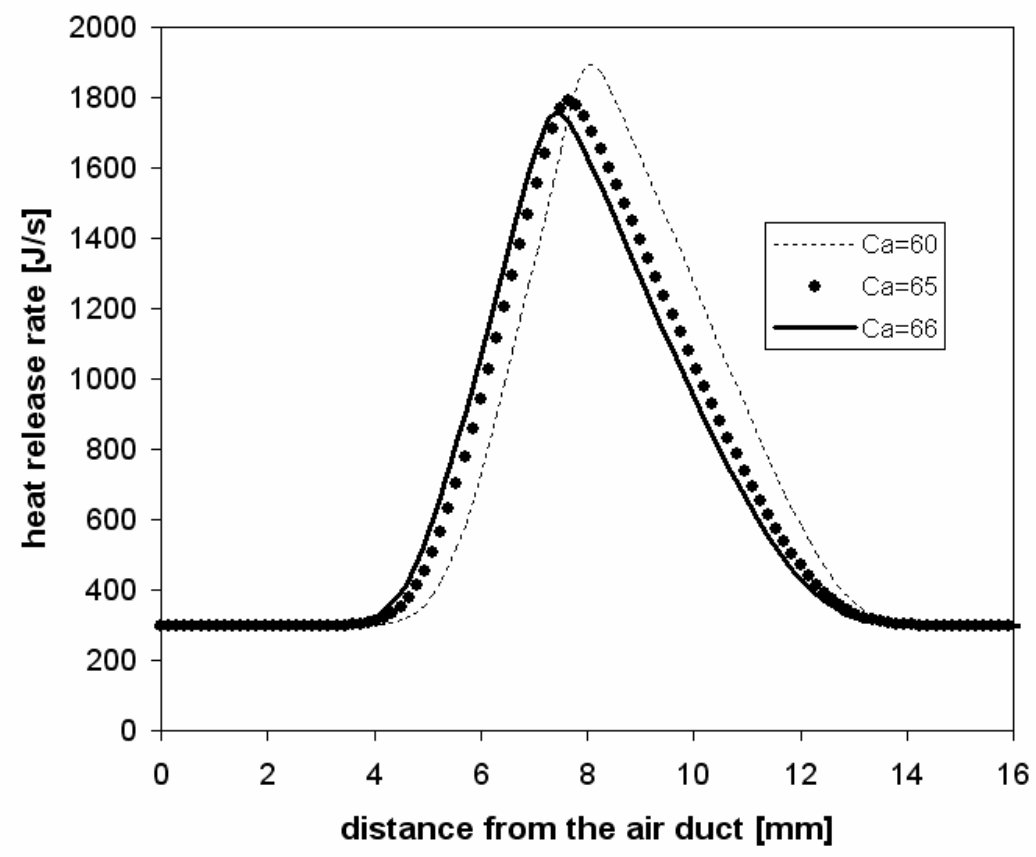

Figure 7. The computed local heat release rate for different $\mathrm{CO}_{2}$ volume fractions in the fuel stream $(0.60$, 0.65 , and 0.66 ) at a global strain rate of $\mathrm{a}_{\mathrm{g}}=20 \mathrm{~s}^{-1}$. 


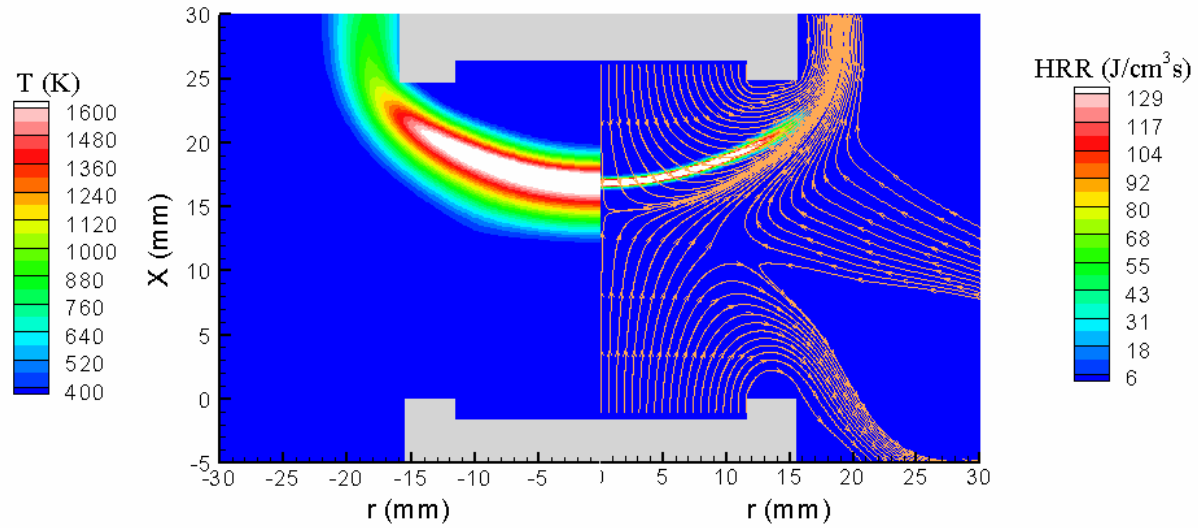

a) $a_{\mathrm{g}}=20 \mathrm{~s}^{-1}$

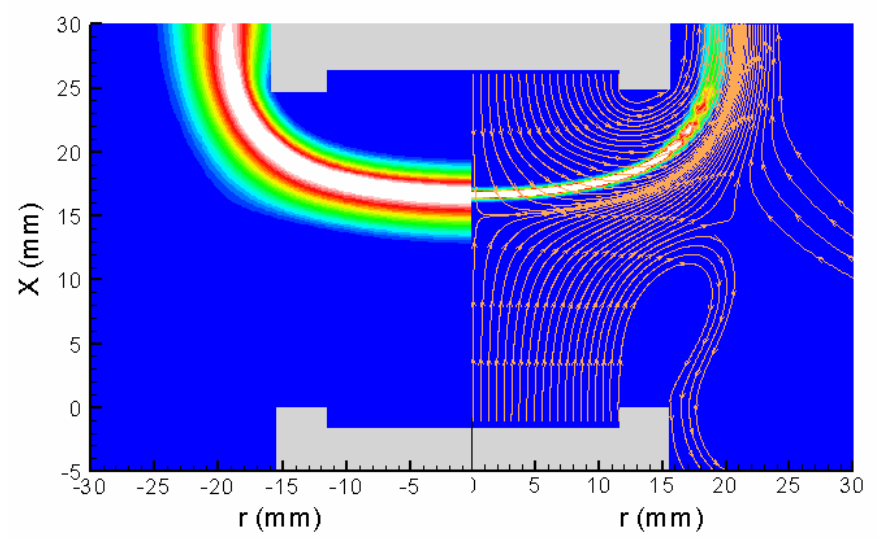

(b) $\mathrm{a}_{\mathrm{g}}=30 \mathrm{~s}^{-1}$

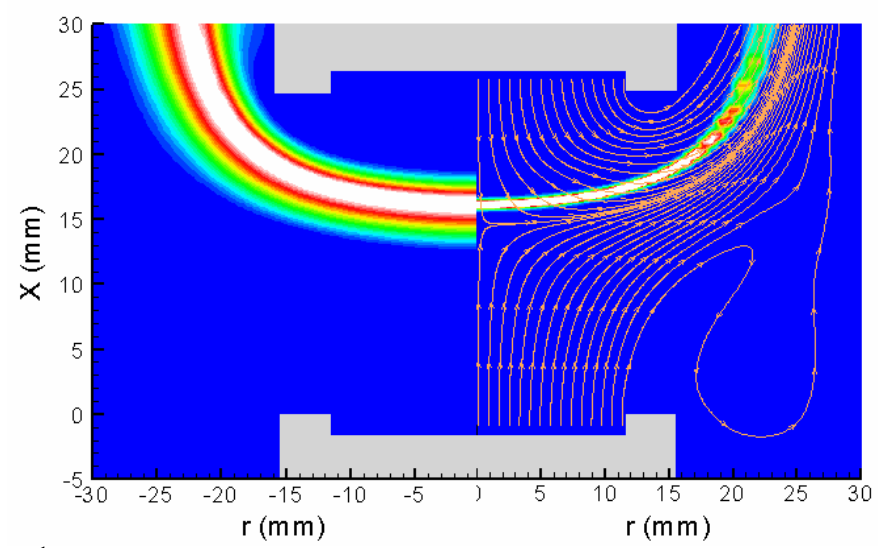

(c) $\mathrm{a}_{\mathrm{g}}=40 \mathrm{~s}^{-1}$

Figure 8. The calculated structure of a normal gravity counterflow nonpremixed flame with a $\mathrm{CO}_{2}$ volume fraction of 0.65 . The temperature is shown on left-hand side of the figure; the local heat release rate and streamlines are shown on the right-hand side. 


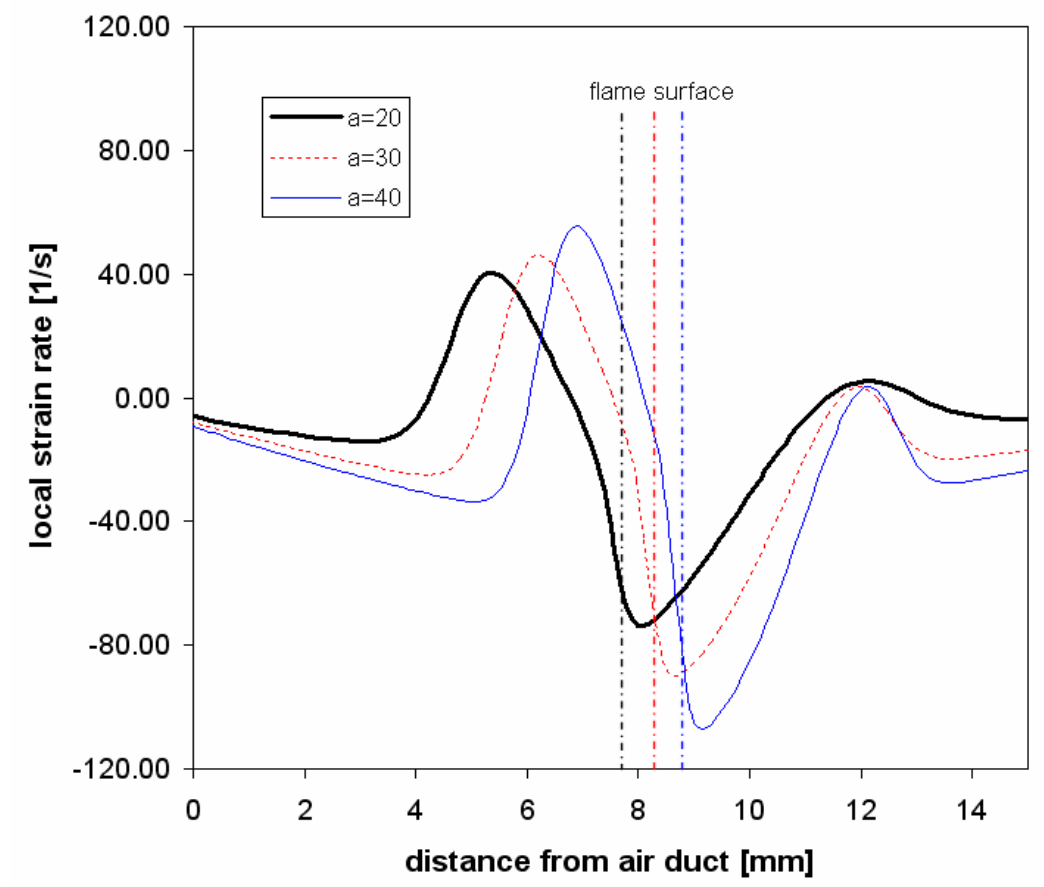

Figure 9. Computed local strain rate along the centerline for a $\mathrm{CO}_{2}$ volume fraction of 0.65 in the fuel stream with $\mathrm{V}_{\mathrm{r}}=1$ and global strain rates of $20 \mathrm{~s}^{-1}, 30 \mathrm{~s}^{-1}$, and $40 \mathrm{~s}^{-1}$.

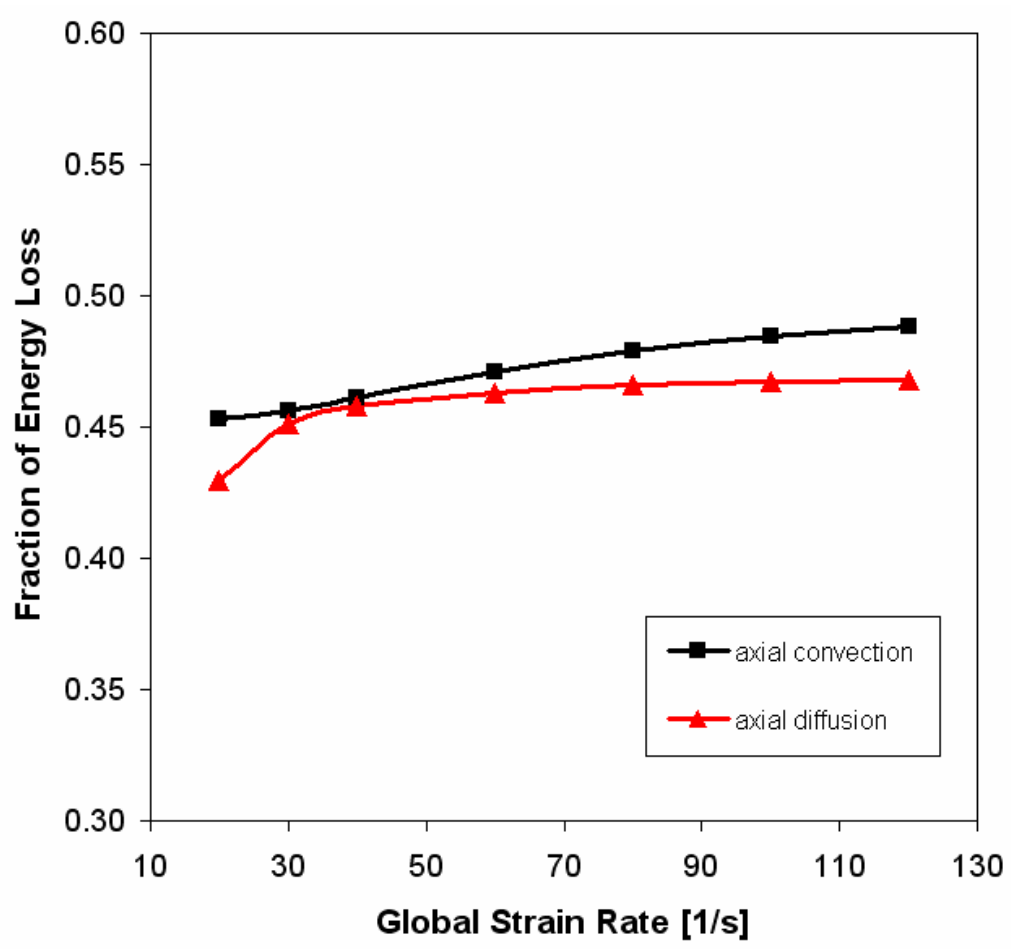

Figure 10. Computed fractional contribution by each term in the energy equation to the heat release of a 1$\mathrm{g}$ flame with $\mathrm{Ca}=0.65$ (agent $=\mathrm{CO}_{2}$ ) as a function of the global strain rate along the flow field centerline. 


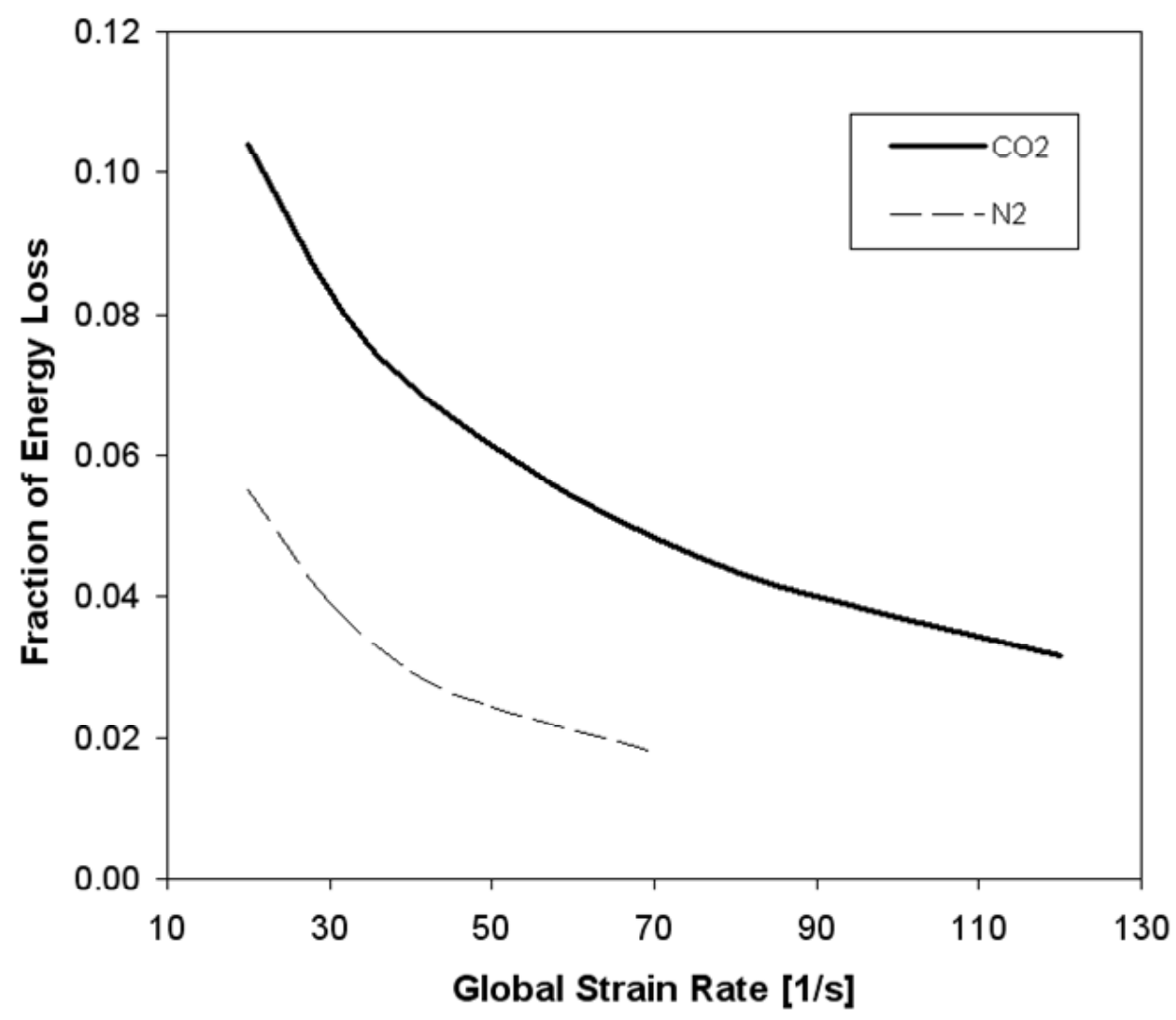

Figure 11. Comparisons of computed radiative fraction for $\mathrm{N}_{2}$ and $\mathrm{CO}_{2}$ for near-extinction 1-g flames as a function of the global strain rate along the flow field centerline. $\left(\mathrm{Ca}=0.65\right.$ for $\mathrm{CO}_{2}$ and $\mathrm{Ca}=0.79$ for $\left.\mathrm{N}_{2}\right)$

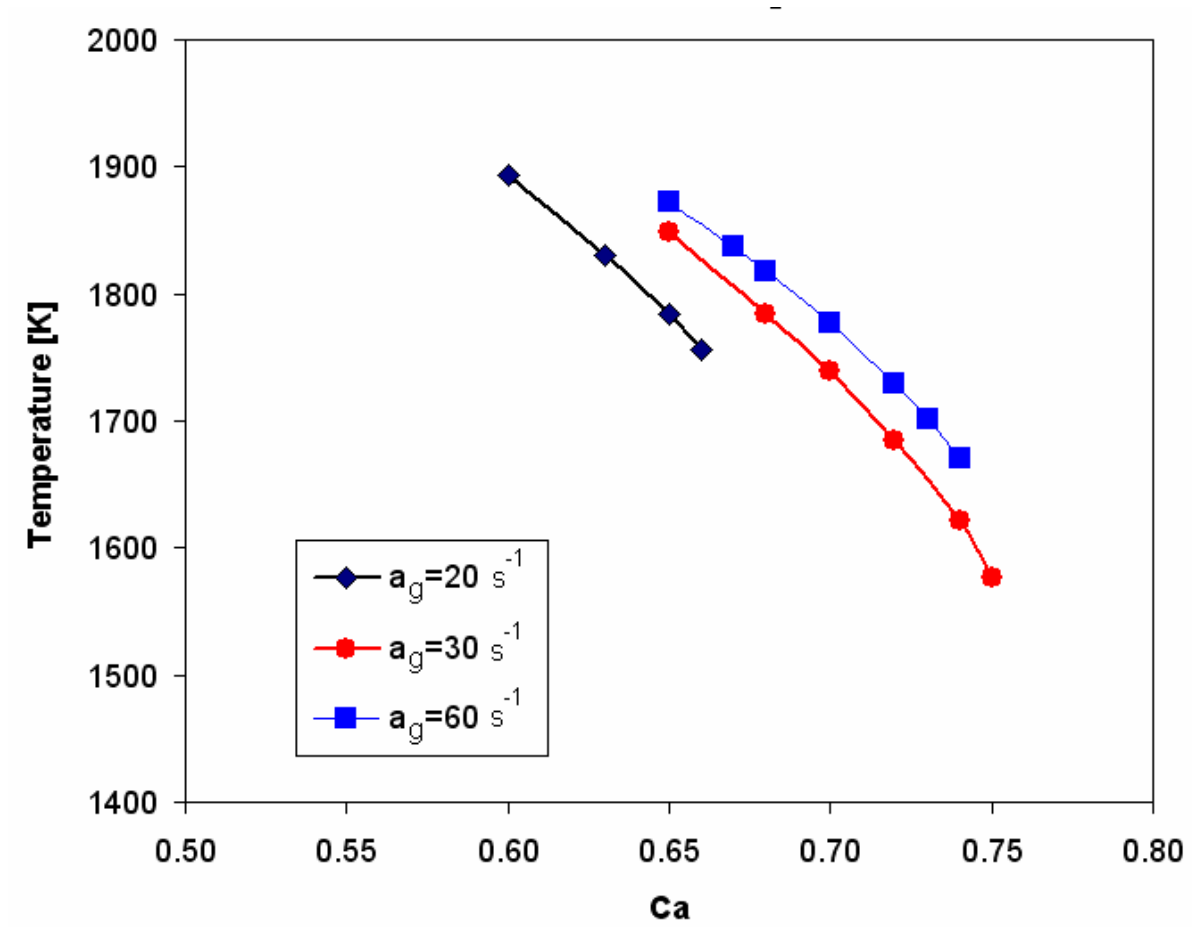

Figure 12. Maximum temperature along the flow field centerline as a function of the $\mathrm{CO}_{2}$ volume fraction in the fuel stream. 


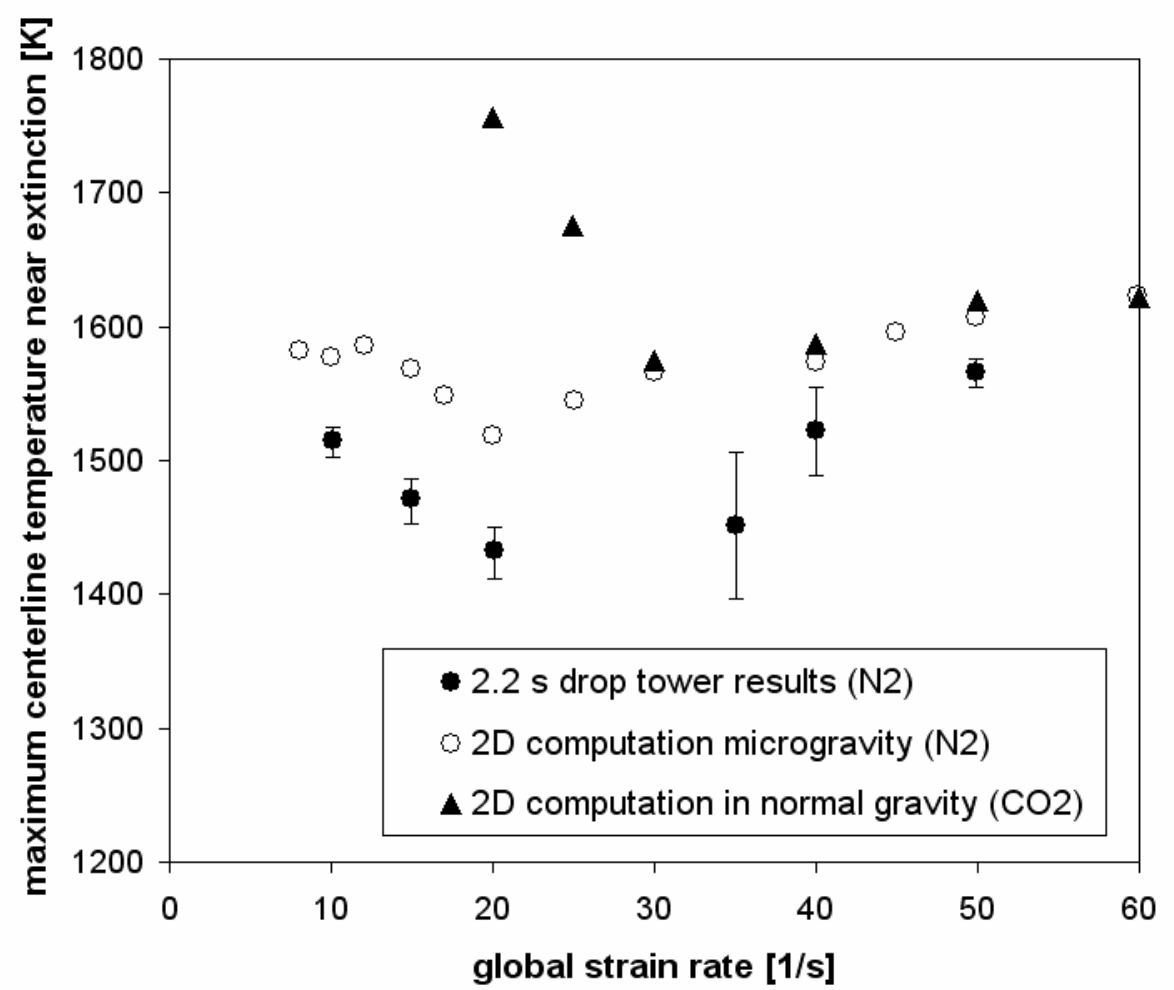

Figure 13. Measured and computed maximum flame temperature near the flow field centerline as a function of the global strain rate for near-extinction methane-air flames diluted by $\mathrm{N}_{2}$ and $\mathrm{CO}_{2}$.

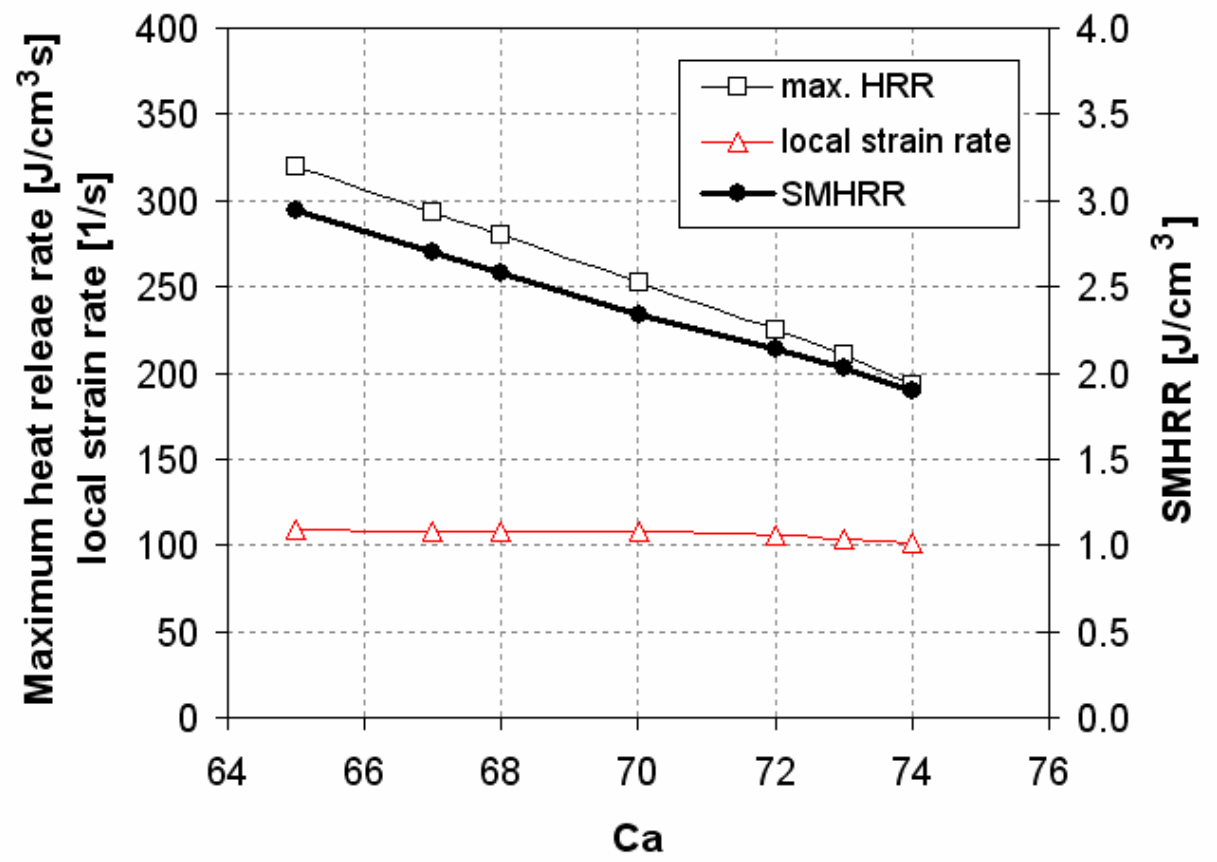

Figure 14. Computed maximum heat release rate, the local strain rate, and the specific maximum heat release rate (SMHRR) as a function of volume fraction of $\mathrm{CO} 2$ in the fuel stream for $\mathrm{a}_{\mathrm{g}}=60$. 


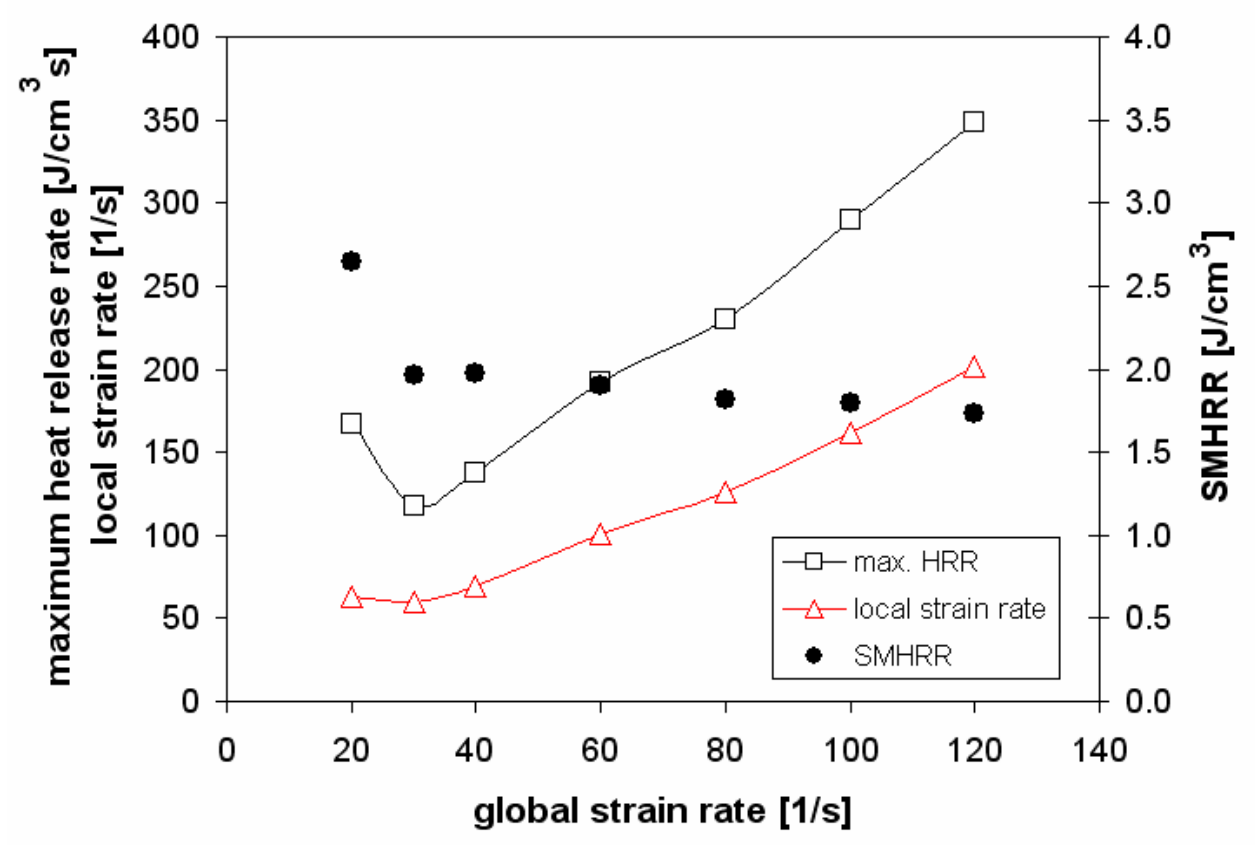

Figure 15. Computed maximum heat release rate, the local strain rate, and the specific maximum heat release rate (SMHRR) as function of global strain rate near the extinction limits $\left(\mathrm{a}_{\mathrm{g}}=20, \mathrm{Ca}=0.66, \mathrm{a}_{\mathrm{g}}=30\right.$, $\mathrm{Ca}=0.75, \mathrm{a}_{\mathrm{g}}=40, \mathrm{Ca}=0.75, \mathrm{a}_{\mathrm{g}}=60, \mathrm{Ca}=0.74, \mathrm{a}_{\mathrm{g}}=80 \mathrm{Ca}=0.74, \mathrm{a}_{\mathrm{g}}=100, \mathrm{Ca}=0.73, \mathrm{a}_{\mathrm{g}}=120, \mathrm{Ca}=0.72$ )

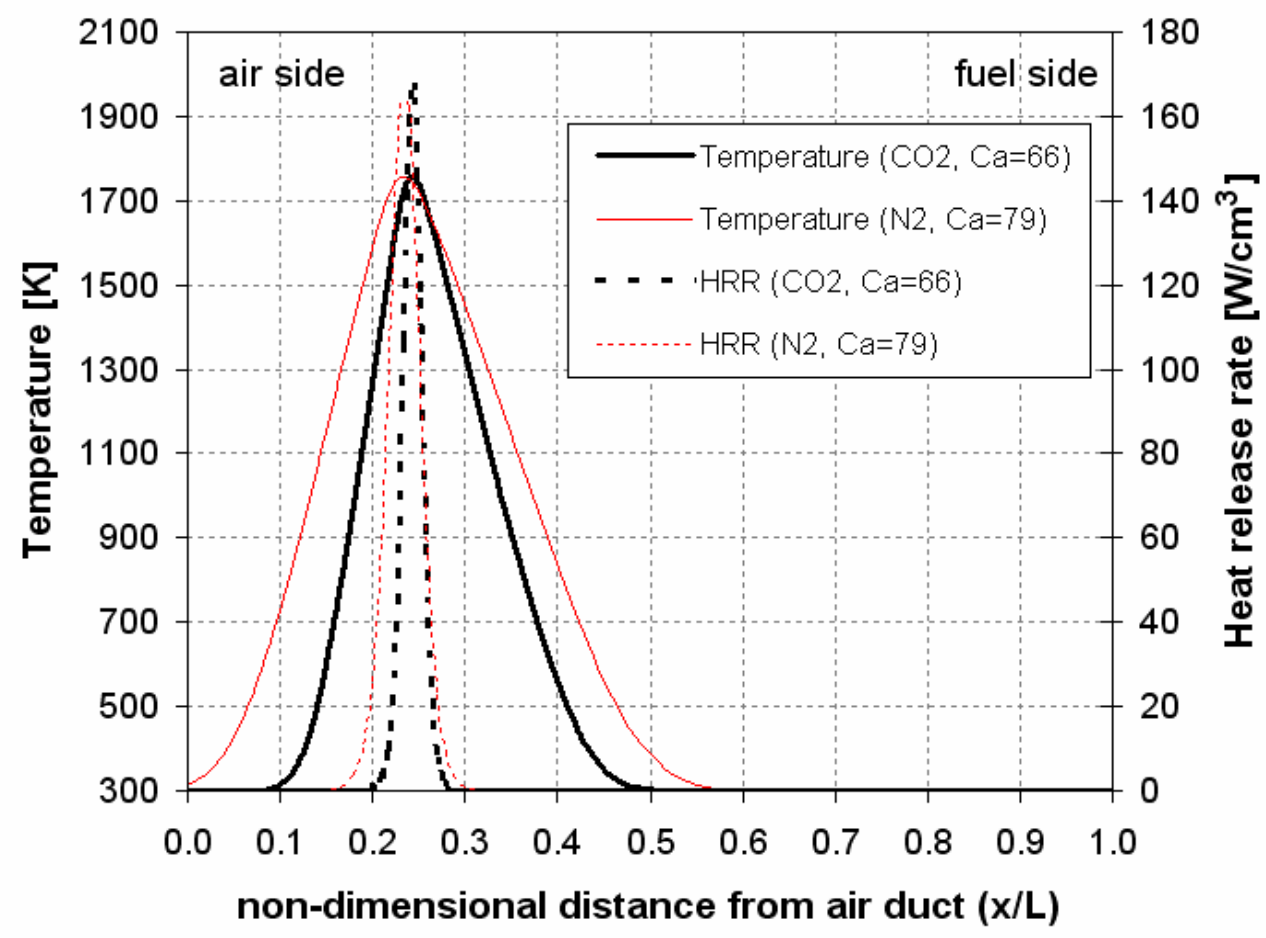

Figure 16. Comparison of centerline temperature and heat release rate between $\mathrm{N}_{2}$ and $\mathrm{CO}_{2}$ suppression near the extinction limits at $\mathrm{a}_{\mathrm{g}}=20 \mathrm{~s}^{-1}$. 


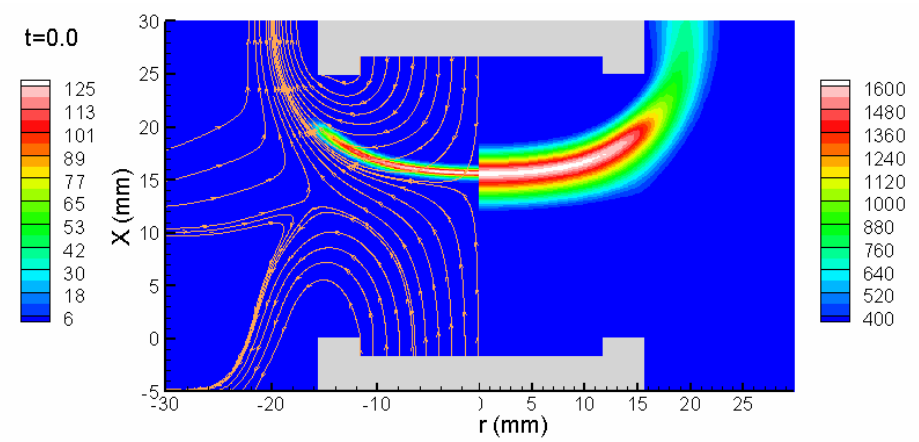

(a) $\mathrm{t}=0.0 \mathrm{~s}$

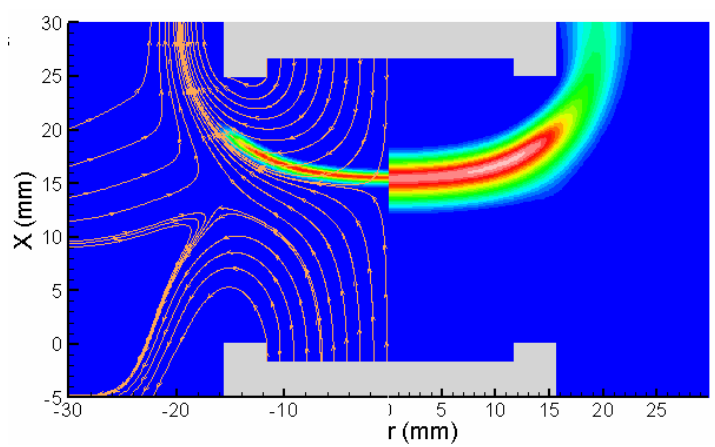

(b) $t=0.14 \mathrm{~s}$

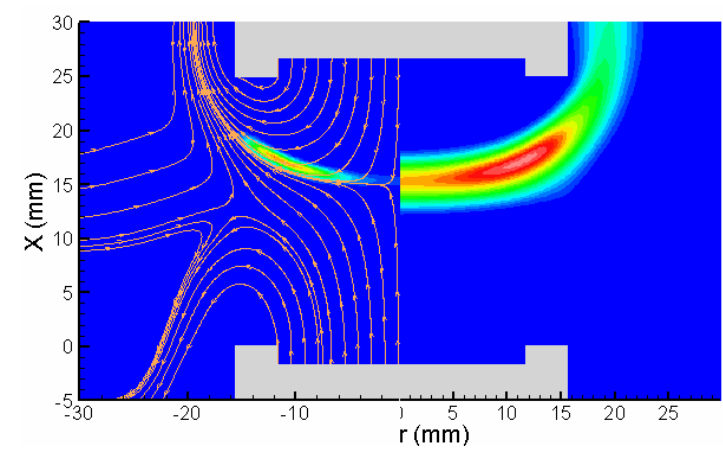

(c) $\mathrm{t}=0.15 \mathrm{~s}$

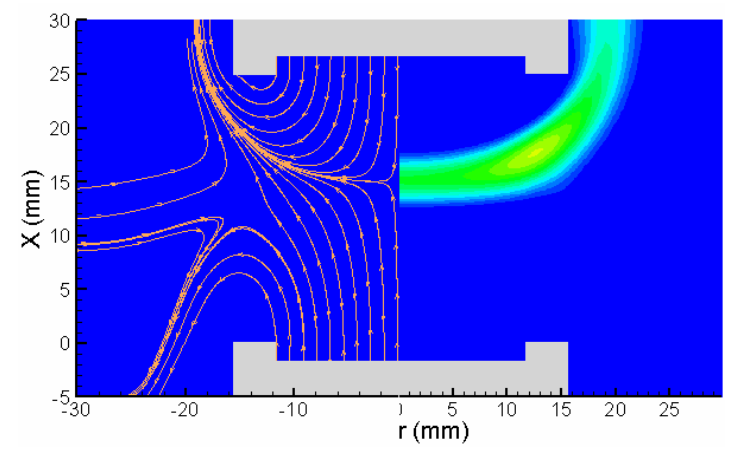

(d) $\mathrm{t}=0.16 \mathrm{~s}$

Figure 17. Computed transient extinction of a normal gravity counterflow nonpremixed flame diluted by $\mathrm{CO}_{2}$ in the fuel stream for $\mathrm{a}_{\mathrm{g}}=30 \mathrm{~s}^{-1}$ and $\mathrm{V}_{\mathrm{r}}=1$ with $\mathrm{Ca}$ increasing from 0.74 to 0.78 . The flame temperature is shown on the right-hand side and the heat release rate and streamlines are shown on the left-hand side. 


\title{
Appendix 4
}

\section{Suppression Limits of Low Strain Rate 1G Non-Premixed Propane Flames}

\begin{abstract}
The suppression of low strain rate non-premixed normal gravity propane flames was investigated experimentally in a counterflow configuration. Conductive heat losses were minimized by varying the velocity ratio of fuel to oxidizer to adjust the flame position such that conductive losses to the burner were reduced. This was confirmed by temperature measurements using thermocouples $\left(0.05 \mathrm{~mm}\right.$ wire diameter) near the reactant ducts. The critical concentration of $\mathrm{N}_{2}$, $\mathrm{CO}_{2}$, and $\mathrm{CF}_{3} \mathrm{Br}$ added to the fuel and the critical concentration of $\mathrm{N}_{2}$ added to the oxidizer stream required to obtain extinction of propane-air non-premixed flames was measured as a function of the global strain rate. In agreement with previous measurements performed with methane-air diffusion flames, limiting non-premixed flame extinction behavior in which the agent concentration obtained a value that insures suppression for all global strain rates was observed.

A series of extinction measurements varying the air: fuel velocity ratio showed that the critical $\mathrm{N}_{2}$ concentration was invariant with this ratio, unless conductive losses were present. In terms of fire safety, the measurements confirm the existence of a fundamental limit for suppressant requirements in normal gravity flames as was previously seen in methane-air flames. This can be thought of as analogous to agent flammability limits in premixed flames. The critical agent volume fraction in the propane fuel stream assuring suppression for all global strain rates was measured to be $.923 \pm 0.003$ for $\mathrm{N}_{2}, 0.879 \pm 0.004$ for $\mathrm{CO}_{2}$, and $0.517 \pm 0.01$ for $\mathrm{CF}_{3} \mathrm{Br}$. These results were distinct from the methane results. The critical agent volume fraction in the oxidizer stream assuring suppression for all global strain rates in the propane flames was measured as $0.354 \pm 0.003$ for $\mathrm{N}_{2 .}$.
\end{abstract}

Measurements using thin filament pyrometry measures flame temperatures for diluted propane-air flame near extinction for several different strain rates. Insight was gained into the near extinction flame temperatures as a function of strain rate. 


\section{INTRODUCTION}

The agent concentration required to achieve the suppression of low strain rate non-premixed flames is an important consideration for fire protection applications as engineers rely on suppression data to estimate suppressant mass requirements for total flooding applications. Information regarding critical suppressant concentrations in the high strain rate regime is less important than in the low strain rate regime, because low strain rate conditions typically require higher agent concentrations and fire protection design must be based on worst-case conditions. Currently, there is a scarcity of experimental data on the effectiveness of suppressants in low strain rate non-premixed flames.

Low strain rate agent suppression requirements in counterflow flames are also of interest because they correspond to agent suppression requirements in buoyancydominated flames, such as cup burner flames [1]. The burner of choice for testing agent suppression effectiveness has traditionally been the cup burner. In that burner, the flame strain rate is not controlled and preheating of the fuel cup can lead to flame stabilization. A study comparing inert and halocarbon suppressant effectiveness in the counterflow and cup burner geometries was performed by Saso et al. [2]. Their results confirmed the results of Hamins et al. [1], showing a correspondence in flame extinguishment concentration between the cup burner and the counterflow burner at a global strain rate of $30 \mathrm{~s}^{-1}$.

The counterflow geometry is a convenient configuration for direct control of the strain rate and flame position [3]. The effect of flame position on suppressant requirements has been considered in a number of counterflow flame suppression studies. 
In some counterflow studies, the fuel and oxidizer reactant streams were adjusted such that the flame position is maintained [4]. Flame position has been shown to effect suppressant requirements if the flame is too close to the reactant ducts, which was attributed to conductive rather than convective heat losses.

The effectiveness of chemically acting inhibitors on methane-air counterflow diffusion flames was investigated by Vora et al. [5] and Siow et al. [6]. In each of these studies the suppressant effectiveness was related to the measured $\mathrm{OH}$ concentration in flames with a global strain rate of $20 \mathrm{~s}^{-1}$.

The first comprehensive extinction measurements of very low strain nonpremixed flames were reported by Maruta et al. [7], who performed the experiments under micro-gravity conditions. In that study, the extinction of methane-air flames with $\mathrm{N}_{2}$ added to the fuel stream was investigated using the JAMIC $10 \mathrm{~s}$ drop tower. The fuel stream nitrogen concentration required to achieve extinction was measured to increase as the strain rate decreased, until a critical value was obtained. As the global strain rate was further reduced, the required $\mathrm{N}_{2}$ concentration decreased. This behavior was denoted as a "turning point" and was attributed to the enhanced importance of radiative losses at low strain rates. Numerical calculations were performed to quantify the radiative heat loss effects. The fraction of radiative heat loss to total flame enthalpy was found to be greater than $10 \%$ for near extinction flames with a global strain rate less than $4 \mathrm{~s}^{-1}$. Several other works to date have established the importance of radiative heat loss on the stability of weakly strained diffusion flames [8-10].

Recent work at the National Institute of Standards and Technology studied the extinction characteristics of methane-air diffusion flames at low strain rates in 1-g. The 
turning point phenomenon was observed for $1-\mathrm{g}$ methane flames as well as the $\mu \mathrm{g}$

methane flames. With the exception of the previous work performed by Bundy et al [11], the studies that have considered suppression by an agent in normal gravity counterflow flames have not carefully investigated the low strain rate region (see Ref. [1] for example). There are experimental difficulties associated with establishing steady flames at low strain rates in the laboratory including flame instabilities associated with ambient currents and forced exhaust.

The objective of this work was to study the suppression of low strain rate nonpremixed propane flames in normal gravity through the establishment of steady flames free from significant conductive losses to the burner ducts. In the experiments described here, gaseous $\mathrm{N}_{2}$ was used as a suppressant added to both the oxidizer and fuel streams to investigate whether turning point behavior occurs in suppression of normal gravity propane flames, as previously observed in normal gravity methane flames [11]. In addition, the suppression effectiveness of $\mathrm{CO}_{2}$ and $\mathrm{CF}_{3} \mathrm{Br}$ are also reported for flames with agent added to the fuel streams of propane-air diffusion flames.

\section{EXPERIMENTAL METHOD}

Experiments were conducted using the counterflow burner shown in Figure 1. The inner diameter of the reactant ducts was $(23.4 \pm 0.1) \mathrm{mm}$ and the duct separation distance (L) was set to $(25.0 \pm 0.1) \mathrm{mm}$. Four 200 mesh stainless steel screens were positioned $(1.6 \pm 0.1) \mathrm{mm}$ from the duct exits and at $1.6 \mathrm{~mm}$ intervals to impose a tophat velocity profile. A water-cooled jacket about the top reactant duct prevented heating of the metal burner and preheating of the reactants. The reactants were air and research 
grade propane (99\% purity), which were stored in pressurized cylinders. The oxygen content in the bottled air was measured to be $(20.93 \pm 0.04) \%$ using a paramagnetic analyzer [12]. The reactant flows were controlled using mass flow controllers that were calibrated using a dry cell primary flow meter with an uncertainty of $1 \%$. The central axis of the burner was aligned vertically with gravity.

The burner was fitted with a concentric tube (64 $\mathrm{mm}$ o.d.) about the bottom duct for flow of an inert gas to shield the reactants from ambient air. Experiments were performed using the "curtain" flow of nitrogen to isolate the reactants from the ambient environment. The average velocity of the curtain was tuned to approximately match the fuel flow from the lower duct; however the magnitude of the curtain flow rate had a negligible effect on the extinction results for curtain flows in the range of $20 \mathrm{~cm}^{3} / \mathrm{s}$ to 80 $\mathrm{cm}^{3} / \mathrm{s}$. Several studies have explored the impact of the composition of the ambient environment on flame stability as exemplified by the concentration of suppressant required to achieve extinction on flame stability as exemplified by the concentration of suppressant required to achieve extinction. Some studies have used an air ambient [7], whereas others have used an inert environment [12]. In previous work done on 1-g methane extinction [11] it was shown that as the curtain composition was varied from pure $\mathrm{N} 2$ to pure air, the $\mathrm{N} 2$ concentration in the fuel stream required to achieve extinction increased significantly. This suggested that the enhanced stability associated with the air curtain was due to excess fuel reacting with the oxygen in the curtain flow; therefore tall measurements were performed using a pure $\mathrm{N} 2$ curtain.

A number of previous studies investigating the structure and extinction of gaseous diffusion flames applied a flow of nitrogen $[13,14]$ about one of the reactant streams (i.e., 
a "curtain" of nitrogen), while applying suction through an exhaust section about the opposing reactant stream. Use of a forced exhaust was found to create turbulence in low strain rate flames. Instead, the burner was isolated from ambient disturbances by placing it in a nearly closed compartment $(0.5 \mathrm{~m} \times 0.5 \mathrm{~m} \times 0.6 \mathrm{~m})$ with a round $10 \mathrm{~cm}$ diameter exhaust port at its top. The compartment was placed inside a chemical hood, allowing controlled removal of combustion byproducts through buoyancy-driven ventilation. The annular top exhaust section of the burner was not used for these experiments.

In the experiments described here, the global strain rate $\left(\mathrm{ag}_{\mathrm{g}}\right)$ was varied from $12 \mathrm{~s}^{-}$ ${ }^{1}$ to $70 \mathrm{~s}^{-1}$. The global strain rate concept allows quantification of a characteristic flame residence time or flow time. Suppression measurements were performed by incrementally increasing the agent flow, while maintaining a constant global strain rate. This was accomplished by simultaneously reducing the air or fuel flow. The global strain rate is defined as:

$$
\mathrm{a}_{\mathrm{g}}=\frac{2 \mathrm{~V}_{\mathrm{a}}}{\mathrm{L}}\left(1+\frac{\mathrm{V}_{\mathrm{f}} \sqrt{P_{\mathrm{f}}}}{\mathrm{V}_{\mathrm{a}} \sqrt{\mathrm{P}_{\mathrm{a}}}}\right)=\frac{2 \mathrm{~V}_{\mathrm{r}} \mathrm{V}_{\mathrm{f}}}{\mathrm{L}}\left(1+\frac{\sqrt{\rho_{\mathrm{f}}}}{\mathrm{V}_{\mathrm{a}} \sqrt{P_{\mathrm{a}}}}\right),
$$

which is a factor of two larger than the definition used by Maruta et al. [7] or Puri and Seshadri [14]. The parameters $\mathrm{V}$ and $\rho$ denote the velocity and density of the reactant streams at the duct boundaries, $\mathrm{L}$ is the duct separation distance, and the subscripts a and F represent the oxidizer and fuel streams, respectively. The parameter $V_{r}$ is defined as equal to $V_{a} / V_{F}$. The expression given by Eq. (1) was derived by Seshadri and Williams [15] to describe global strain rate for counterflow flames. Chelliah et al. [16] used Eq. (1) to compare global and local oxidizer strain rates for undiluted propane-air flames near extinction. Pogliani et al. [17] performed a numerical investigation of flame stretch and 
radiation on flame extinction at low strain rates. Their calculations showed that there is a proportional relationship between the global and oxidizer side strain rates. Zegers et al. [18] used LDV measurements to determine local strain rates in non-premixed methane/air and methane/air flames. Their results also show a linear relationship between the maximum velocity gradient on the oxidizer side of the flame and the global strain rate defined by Eq. 1.

The flame extinction measurements conducted here were repeated at least four times. Experiments were preformed with velocity ratios of $\mathrm{V}_{\mathrm{r}}=1 / 2, \mathrm{~V}_{\mathrm{r}}=1, \mathrm{~V}_{\mathrm{r}}=2$ and $\mathrm{V}_{\mathrm{r}}=$ 3. The $V_{r}=1 / 2$ and $V_{r}=1$ tests where performed with the fuel jet from the top burner duct and the air jet from the bottom burner duct and the $V_{r}=2$ and 3 cases were tested with the opposite orientation. The mean value of the relative expanded standard uncertainty in the agent extinction concentration was typically $0.8 \%$ based on repeat measurements and a propagation of uncertainty analysis. All uncertainties reported here are for a coverage factor of one, which is the combined standard uncertainty [19]. Measurement repeatability typically accounted for approximately one-quarter of the uncertainty.

Changing the velocity of the reactant streams led to changes in flame position and flame shape. Flame shape was characterized in terms of flame curvature through the use of digital photography and image analysis. The curvature was defined as the reciprocal of the average radius of a circle associated with the luminous flame in the cylindrical zone between the ducts. The analysis of curvature was based on three points defined by the intersection of the lower edge of the luminous flame with (1) the central axis and (2) the segments connecting the inner walls of the top and bottom burner ducts. 
Temperature measurements were conducted along the centerline near the burner ducts using thermocouples. Heat transfer from the flame to the burner is indicated by the temperature gradient near the burner ducts. The temperature measurements were conducted using small thermocouples with the wires aligned horizontally along an isotherm to minimize conductive losses. Measurements were made using $0.05 \mathrm{~mm}(0.002$ in) diameter $(\mathrm{Pt} / \mathrm{Pt}+10 \% \mathrm{Rh}) \mathrm{S}$-type thermocouples. Strain rates at which significant conductive losses were found were removed from the final results.

Temperature measurements were performed for $\mathrm{T} \geq 1250 \mathrm{~K}$ by measuring the luminous intensity of a thin filament positioned in the flame. This technique was originally developed by Vilimpoc et al. [20] and is detailed in several publications on laminar diffusion flames [21,22]. A $(12.5 \pm 2)$ micron SiC filament was aligned axially between the burner ducts at various radial locations. The radiative energy emitted from the filament was digitally recorded using a CCD camera and close-up lens. The spatial resolution of the image was $0.047 \mathrm{~mm}$. The image luminous intensity was digitized to 8 bit resolution, this represents a $2^{\circ} \mathrm{K}$ resolution. The exposure setting on the camera was adjusted so that the image was not saturated (over-exposed) at the maximum flame temperature. Image processing software was used to acquire the fiber intensity data from the digital image. The emission intensity at each axial location was found by subtracting the background intensity from all pixels and integrating the radial intensities across the fiber.

For a specific set of flame conditions the measured fiber intensity profile was compared to the calculated fiber temperature profile to determine the relationship between fiber emissions and fiber temperature following the method of Vilimpoc et al. 
[20] OPPDIF provided the calculated gas temperature profile for a given set of conditions. The OPPDIF code uses multi-step chemistry and a narrowband radiation model and has been validated for predicting temperatures in counterflow flames. The radiation model is described in detail by Pogliani et al. [17]. The OPPDIF gas temperature profile was used to calculate the heat transfer to the fiber and the fiber temperature profile given the material properties of the fiber. The fiber temperature was then compared to the measured fiber luminosity and a correlation was determined with luminosity being proportional to the fiber temperature to the fifth power. The relationship between fiber temperature and illuminosity was recalibrated for each set of tests to take into account any changes in the camera settings or fiber position.

The SiC fiber was used because it has a known emissivity of 0.88 over a wide range of wavelengths [20] and a low conductivity allowing point measurements along the entire length of the fiber. [23] Since the conductivity is low, it can be neglected and the energy balance becomes

$$
h P\left(\mathrm{~T}_{\mathrm{g}}-\mathrm{T}_{\mathrm{f}}\right)=\sigma \varepsilon \mathrm{P} \mathrm{T}_{\mathrm{f}}{ }^{4}
$$

where $\mathrm{h}$ is the convection coefficient, $\mathrm{T}_{\mathrm{g}}$ is the gas temperature, $\mathrm{T}_{\mathrm{f}}$ is the fiber temperature, $\mathrm{P}$ is the perimeter of the fiber, $\sigma$ is the Stefan-Boltzman constant, and $\varepsilon$ is the fiber emissivity. Solving for $\mathrm{T}_{\mathrm{g}}$ a simple radiative correction for the fiber results:

$$
\mathrm{T}_{\mathrm{g}}=\mathrm{T}_{\mathrm{f}}+\sigma \varepsilon \mathrm{T}_{\mathrm{f}}{ }^{4} / \mathrm{h}
$$

The convection coefficient was found by using a numerical correlation for low velocity cross flow over a cylinder. [17] Experiments compared the filament intensity with the fiber oriented horizontally and vertically at several locations in the flow field to 
determine if there was a significant difference caused by fiber orientation [24]. The differences found between the two orientations were within experimental error and showed that the crossflow assumption for the convection coefficient was adequate.

\section{Results and Discussion}

\section{Observations}

The flames were laminar, steady and the suppression measurements were highly repeatable for strain rates as low as $15 \mathrm{~s}^{-1}$ depending on the agent type and configuration. Below that value, the conductive losses from the flame to the burner become significant. Undiluted, low strain rate counterflow propane-air flames are yellowish in color. As $\mathrm{N}_{2}$ and $\mathrm{CO}_{2}$ were added to either the fuel or oxidizer streams, flame luminosity decreased until flame emission was entirely blue in color near extinction. This was not the case when $\mathrm{CF}_{3} \mathrm{Br}$ was added to the flames. In that case, the flames became increasingly luminous as more agent was added. These flames were highly luminous near extinction and large amounts of soot were observed to escape from the flame. This is similar to observations made in methane/air flames [11].

Figure 2 shows the measured position of the central axis of the luminous flame zone as a function of the global strain rate for several values of the velocity ratio $\left(V_{r}\right)$ when the air stream was flowing from the top duct. In these experiments, the fuel side jet contained $98 \%$ of the extinction value of $\mathrm{N}_{2}$ in the flow for a given strain. The results in 
Fig. 2 show that the flames were lifted towards the top duct as the global strain rate was decreased due to the effects of buoyancy. When the propane was injected form the top jet, $V_{r}=1 / 2$ and $V_{r}=1$, the curvature appears to reach a maximum in the ag $=20-25 \mathrm{~s}^{-1}$ range at a curvature of roughly $0.4 \mathrm{~cm}^{-1}$. When the fuel was injected from the bottom jet the curvature appeared to increase linearly with decreasing strain rate. At higher strains the curvature decreases with increasing strain rate. The magnitude of the difference in the curvature between velocity ratios seems to increase with increasing strain rate. The flame position also increased linearly with increasing strain rate. Increasing the velocity of the top jet compared to the bottom jet pushed the flame further from the top duct. The results also showed that as $\mathrm{V}_{\mathrm{r}}$ was increased from 1 to 3 , the luminous flame shifted away from the top duct and the flame curvature generally decreased. Through adjustment of the value of $\mathrm{V}_{\mathrm{r}}$, the suppression measurements reported here are for flames that were sufficiently far from the ducts such that conductive heat losses were negligible.

\section{Conductive Heat Losses to the Burner}

Thermocouple measurements were conducted to characterize the temperature field near the top reactant duct as $\mathrm{V}_{\mathrm{r}}$ was varied. The most problematic conditions in terms of conductive losses are the lowest strain rate flames, which have the broadest temperature profiles and are located closest to the top duct as seen in Fig. 2. To determine the losses to the burner for the 1-g tests for different velocity ratios and global strain rates, the temperature was measured along the centerline near the burner ducts using thermocouples as conductive heat transfer from the flame to the burner is indicated by the temperature gradient near the burner ducts. The results are shown in figures 4 and 
5. Measurements were made using $0.050 \mathrm{~mm}(0.002 \mathrm{in})$ diameter $(\mathrm{Pt} / \mathrm{Pt}+10 \% \mathrm{Rh}) \mathrm{S}$ type thermocouples. The distance from the thermocouple to the orifice was determined by taking an image of the thermocouple at each measurement location and finding the pixel distance from the thermocouple to the duct and the distance per pixel for the camera. The rate of energy lost to the duct ring due to conductivity was estimated. In order to decide if the losses were significant, the energy loss per unit time due to conduction to the rig was equated to the uncertainties in the flow rate. The uncertainty in the flow rate of the diluent corresponds to an uncertainty in the energy loss from the flame. The uncertainty in the energy loss from the flame is equal to the energy it would take to raise the volume of diluent that represents the possible error in the flow to the flame temperature. This value was calculated and compared to the conductive losses for each strain rate. If the conductive losses were less then the energy loss rate uncertainties due to the uncertainties in the flow rates, then it was assumed that the conductive losses were negligible, if not then the data point was removed from this analysis. The conductive losses were considered significant for $a_{g} \leq 17 \mathrm{~s}^{-1}$ when $\mathrm{Vr}=1$ and for $a_{g}<13$ $\mathrm{s}^{-1}$ when $\mathrm{Vr}=2,0.5,3$, and 0.3 .

\section{Flame Temperature Measurements}

Flame temperatures were attained by measuring the luminous emission from a 12.5 micron $\mathrm{SiC}$ filament place axially between the burner ducts. Low strain rate flames near extinction were established to observe the effects of curvature and air-fuel velocity 
ratio on flame structure. Previous work showed that the flame position, but not the flame temperatures, changed with the fiber distance from the centerline. [11] This suggests that even though the flames are curved by buoyancy, the local agent concentration required for suppression will not differ significantly along the flame sheet. Further evidence that the flame curvature does not significantly affect the stability of these flames is given by the extinction results described below. Previous work also indicated that the flame structure is not significantly impacted as the velocity ratio is varied over the small range of velocity ratios used in this study. [11]

Temperature measurements were taken for a certain percentage of the extinction diluent concentration present in the flow. The temperature data presented here is for the nitrogen-diluted flames only. Temperature data was taken for $\mathrm{V}_{\mathrm{a}} / \mathrm{V}_{\mathrm{f}}=1$ at $98 \%$ and $99.5 \%$ of extinction and for $\mathrm{V}_{\mathrm{a}} / \mathrm{V}_{\mathrm{f}}=2$ at $98 \%$ of extinction. The maximum temperature for each strain rate and flow condition is shown in figure 5. The same trend can be seen for all conditions. At higher strain rates the near extinction temperature decreases with decreasing strain rate until a minimum extinction temperature is reached, then as strain rate decreases, near extinction temperatures increase. When comparing the graph to the extinction data, it is seen that the minimum temperature correlates with the maximum diluent concentration. The flame is most stable at the turning point and this is when flames can be stabilized at the lowest temperatures. As the percentage of extinction diluent in the flow is increased, the flame temperature decreases but the shape of the curve remains the same. When comparing the different velocity ratios it can be seen that shapes of the curves are similar but the temperatures at $98 \%$ of extinction for the $\mathrm{V}_{\mathrm{a}} / \mathrm{V}_{\mathrm{f}}=$ 2 case are slightly lower then the temperatures for the $\mathrm{V}_{\mathrm{a}} / \mathrm{V}_{\mathrm{f}}=1$ case. The $\mathrm{V}_{\mathrm{a}} / \mathrm{V}_{\mathrm{f}}=2$ 
case has a fuel jet exit velocity that is less then the $V_{a} / V_{f}=1$ case and the air jet velocity is two times larger than the fuel velocity. The changes in these parameters affect the reaction rate and the thermal and mass diffusivities at the flame surface. When the velocity ratio is equal to one it appears that there is slightly more heat generation then for a velocity ratio of two. The differences in the extinction measurements taken for the two velocity ratios are insignificant, but the different flow configurations do apparently have an effect on the energy production due to combustion.

\section{Flame Extinction Measurements}

Previous work has shown the $\mathrm{V}_{\mathrm{r}}$ can be treated as an independent variable that does not have a large effect on the amount of diluent needed for extinction in a given strain rate methane-air non-premixed flame. [11] Extinction measurements done in this study also confirm that $\mathrm{V}_{\mathrm{r}}$ can be treated as an independent variable for low strain rate propane-air non-premixed flames. Figure 7 shows the measured $\mathrm{N}_{2}$ volume fraction in the fuel stream required for extinction as a function of the global strain rate for a number of values of $\mathrm{V}_{\mathrm{r}}$ and two different burner orientations for flames without significant conductive heat losses. Conditions below the data points represent stable flames, whereas conditions on and above the data represent flames that have been extinguished. Error bars representing the expanded combined standard uncertainty are shown for all points. Turning point behavior was exhibited, in which the critical suppressant concentration increased as the strain rate decreased, until the concentrations reached a maximum value near $\mathrm{a}_{\mathrm{g}}=30 \mathrm{~s}^{-1}$ and then decreased as the global strain rate further 
decreased. For a particular value of the global strain rate, the agent suppression concentration did not significantly change as the velocity ratio was varied.

Flame curvature can affect flame stability, although in counterflow diffusion flames the radius of curvature must be extremely small before there is a noticeable effect. Finke and Grunefeld [25] found measurable differences in the extinction strain rate of hydrogen diffusion flames with a radius of curvature less than $10 \mathrm{~mm}$. The smallest radius of curvature of the flames in this study was $18 \mathrm{~mm}$. Figure 2 shows that the largest absolute difference in flame curvature as $\mathrm{V}_{\mathrm{r}}$ was varied from $1 / 2$ to 3 was observed for a global strain rate of approximately $40 \mathrm{~s}^{-1}$. The measurements in Fig. 7 show negligible differences in $\mathrm{N}_{2}$ suppression requirements at $\mathrm{a}_{\mathrm{g}}=40 \mathrm{~s}^{-1}$ as the velocity ratio was varied from $\mathrm{Vr}=1 / 2$ to $\mathrm{Vr}=3$, suggesting that differences in flame curvature had a negligible effect on agent extinction requirements and flame stability for the flames considered in this study.

Figure 8 shows the comparison of the 1-g methane extinction curve [11] and the 1-g propane extinction curve. In the 1-g tests the turning point occurred at lower strain rates for the propane then for the methane. The curve of the turning point behavior of the nitrogen extinction of propane was also much shallower then that of the nitrogen extinction of methane as can be seen in figure 8 . The reason for the differences in turning point locations for the two fuels is most likely due to differences in flame structure and radiative emissions. The main cause for heat loss from the flame in 1-g is convective and radiative losses. Different fuel masses cause different exit momentums from the jets affecting the convective heat transfer and the relative importance of the losses due to buoyancy. The conductivity of the gases passing through the flame front also affects the 
convective heat transfer and the flame temperature based on the fuel chemistry affects the buoyancy forces and the radiative losses. These effects all play a role in determining the location of the turning point. For the propane, the conductive losses appear to be more significant then the radiative losses at lower global strain rates then for the methane.

Figure 9 shows suppression measurements of the critical $\mathrm{CO}_{2}$, and $\mathrm{CF}_{3} \mathrm{Br}$ concentration in the fuel stream of non-premixed $\mathrm{C}_{3} \mathrm{H}_{8}$-air flames as a function of the global strain rate. The averaged results for $\mathrm{N}_{2}$ from Figure 7 are included in this figure. As expected, the most effective suppressant was $\mathrm{CF}_{3} \mathrm{Br}$, followed by $\mathrm{CO}_{2}$ and then $\mathrm{N}_{2}$. The critical suppressant concentration increased as the strain rate decreased, with its value leveling off near $30 \mathrm{~s}^{-1}$, except for $\mathrm{CF}_{3} \mathrm{Br}$, which flattened near $40 \mathrm{~s}^{-1}$. The results demonstrate the existence of turning point behavior for both inert and chemically active agents in normal gravity diffusion flames when agent is added to the fuel stream. The turning point occurs at lower values of $\mathrm{ag}_{\mathrm{g}}$ than in the $1 \mathrm{~g}$ methane measurements [11].

Figure 10 shows measurements of the $\mathrm{N}_{2}$ volume fraction in the oxidizer stream required to achieve extinction as a function of the global strain rate. Similar to the results for agent added to the fuel stream (Fig. 8), these measurements also show turning point behavior. The turning point occurs within the same range of global strain rates, at values between $30 \mathrm{~s}^{-1}$ to $35 \mathrm{~s}^{-1}$.

Masri et al. [26] suggest that the relevant parameter when comparing agent effectiveness in fuel-side and air-side dilution should be the effective mass fraction. The effective mass fraction is defined as the agent mass fraction that would exist at the theoretical stoichiometric flame sheet location in cold flow, neglecting preferential diffusion. 
For a propane-air flame, the effective mass fraction is given by, $\mathrm{Y}_{\mathrm{eff}, \mathrm{st}}=\mathrm{Y}_{\mathrm{a}, \mathrm{f}}+$ $\left(\mathrm{Y}_{\mathrm{a}, \mathrm{o}}-\mathrm{Y}_{\mathrm{a}, \mathrm{f}}\right) \xi_{\mathrm{st}}$, where $\xi_{\mathrm{st}}=\left[1+3.636 \mathrm{Y}_{\mathrm{C} 3 \mathrm{H} 8, \mathrm{f}} / \mathrm{Y}_{\mathrm{O} 2, \mathrm{o}}\right]^{-1}$. $\mathrm{Y}_{\mathrm{eff}, \mathrm{st}}$ at extinction for both air and fuel stream dilution is shown in Figure 10. The fuel-side dilution extinction experiments from Figure 9 are represented by the closed symbols in Figure 11 and the air-side dilution extinction experiments from Figure 10 correspond to the open symbols in Figure 10. For each of the three different agents, the air-stream agent addition required a greater amount of agent by mass for extinction than for fuel-stream agent addition. Trees et al. [27] attribute differences in air-stream and fuel-stream agent effectiveness to flame structure and preferential diffusion effects.

\section{SUMMARY AND CONCLUSIONS}

In summary, the range of global strain rates typically investigated in normal gravity was extended by isolating the burner in order to reduce disturbances by ambient currents and by varying the velocity ratio of fuel and oxidizer to reduce conductive losses to the burner. By treating $\mathrm{V}_{\mathrm{r}}\left(=\mathrm{V}_{\mathrm{a}} / \mathrm{V}_{\mathrm{f}}\right)$ in Equation 1 as an independent experimental variable, it is possible to adjust the flame location and thereby minimize conductive heat losses from the flame to the burner. A flame free of conductive losses is relatively more stable than a flame with conductive losses. Such a flame will require larger agent suppression requirements. Whereas flame position and the location of the stagnation point may change as the parameter $\mathrm{V}_{\mathrm{r}}$ is varied in these flames, the suppression and maximum flame temperature measurement results suggest that flame stability is essentially unchanged. 
The critical concentration of $\mathrm{N}_{2}, \mathrm{CO}_{2}$, and $\mathrm{CF}_{3} \mathrm{Br}$ added to the fuel stream and the critical concentration of $\mathrm{N}_{2}$ added to the oxidizer stream required to obtain extinction of propane-air non-premixed flames was measured as a function of the global strain rate. In terms of fire safety, the measurements demonstrate the existence of a fundamental limit in the suppressant requirements in normal gravity diffusion flames, analogous to agent flammability limits in premixed flames. A fundamental distinction between premixed flammability limits and non-premixed flame suppression limits is that the value of the limiting concentration in a diffusion flame will obtain different values depending on whether the suppressant is added to the oxidizer stream or the fuel stream. The consideration of configuration does not arise in a premixed flame. The critical agent volume fraction in the propane fuel stream assuring suppression for all global strain rates was measured to be $0.923 \pm 0.003$ for $\mathrm{N}_{2}, 0.879 \pm 0.004$ for $\mathrm{CO}_{2}$, and $0.517 \pm 0.001$ for $\mathrm{CF}_{3} \mathrm{Br}$. The critical agent volume fraction in the oxidizer stream assuring suppression for all global strain rates was measured as $0.354 \pm 0.003$ for $\mathrm{N}_{2}$.

The structure of normal and micro gravity flames at moderate strain rates can be expected to be similar, as buoyancy effects are relatively unimportant for momentum dominated flames. At low strain rates, however, significant differences in flame structure are anticipated. The ability to work with low strain rate flames in normal gravity enables experimentation at reduced cost as compared to microgravity flames. Further work is ongoing to determine the differences in the structure of low strain rate non-premixed flames under normal and microgravity conditions. 


\section{ACKNOWLEDGEMENTS}

This research was partially supported by the NASA Microgravity Research Division through Contract No. C-32066-T (NIST) with Dr. Sandra L. Olson serving as Technical Monitor. The authors are grateful to Professor I.K. Puri of the University of Chicago at Illinois for helpful discussions. 


\section{REFERENCES}

1. Hamins, A., Trees, D., Seshadri, K., \& Chelliah, H., Combust. Flame, 99:221 (1994).

2. Saso, Y., Saito, N., Chihong, L., and Ogawa, Y., Fire Safety Journal, 26:303 (1996).

3. Tsuji, H., Prog. Ener. Combust. Sci. 8:93-119(1982).

4. Macdonald, M.A., Jayaweera, T.M., Fisher, E.M, and Gouldin, F.C., Combust. Flame 116:166-176 (1999).

5. Vora, N., Siow, J.E., and Laurendeau, N.M., Combust. Flame 126:1393 (2001).

6. Siow, J.E., and Laurendeau, N.M., Combust. Sci. Technol. 174:91(2002).

7. Maruta, K., Yoshida, M., Guo, H., Ju, Y., \& Niioka, T., Combust. Flame, 112:181 (1998).

8. Liu, F., Smallwood, G.J., Gülder, Ö.L., and Ju, Y., Combust. Flame, 121:275 (2000).

9. T'ien, J.S., Combust. Flame, 65:31 (1986).

10. Olsen, S.L., T’ien, J.S., Combust. Flame, 121:439 (2000).

11. Bundy, M.,Hamins, A., Lee, K.Y., Combustion and Flame, 103:299 (2003)

12. Kelly, M., NIST, Report of paramagnetic analyzer test results, personal communication, March 20, 2000.

13. Yang, M.H., Hamins, A. \& Puri, I.K., Combust. Flame 98:107-122 (1994).

14. Puri, I.K., \& Seshadri, K., Combust. Flame, 65:137-150 (1986).

15. Seshadri, K., \& Williams, F.A., Int. J. Heat Mass Transfer, 21:251 (1978).

16. Chelliah, H.K., Law, C.K., Ueda, T., Smooke, M.D., and Williams, F.A., Proceedings of the Twenty-Third Symposium (International) on Combustion, The Combustion Institute, Pittsburgh, 1990, 503-511.

17. Pogliani, B., Bundy, M., Hamins, A., Puri, I.K. Proceedings of the Second Joint Meeting of the US Sections of the Combustion Institute, Oakland, 2001.

18. Zegers, E.J.P., Williams, B.A., Fisher, E. M., Fleming, J.W., and Sheinson, R.S., Combust. Flame, 121:471 (2000).

19. International Organization of Standardization, Guide to the Expression of Uncertainty in Measurement, Geneve, Switzerland, 1993.

20. Vilimpoc, V., Goss, L.P., and Sarka, B., Opt. Lett. 13:93-95 (1988).

21. Ravikrishna, R.V., and Laurendeau, N.M., Combust. Flame., 120:372-382 (2000).

22. Pitts, W.M., Proceedings of the Twenty-Sixth Symposium (International) on Combustion, The Combustion Institute, Pittsburgh, 1996, 1171-1179.

23. Gross, Larry P., Weaver, William, L., and Trump, Darryl D. Thin Filament Velocimetry and Pyrometry Innovative Scientific Solutions Inc. 
24. Logue, J.: "Characteristics of Low Strain Near Extinciton Flames in mg and 1-g"; Master's Thesis, University of Maryland, Department of Fire Protection Engineering (2003)

25. Finke, H., \& Grunefeld, G., Proceedings of the Combustion Institute, 28:2133 (2000).

26. Masri, A.R., Combust. Sci. Technol. 96:189(1994).

27. Trees, D., Grudno, A., Seshadri, K., Combust. Sci. Technol. 124:311(1997).

28. Pogliani, B., Puri, I.K., and Hamins, A., "Effect of Thermal Radiation on the Extinction of Diluted Counterflow Nonpremixed Flames," presented at the Western States Section Technical Meeting of the Combustion Institute, Salt Lake City, Utah, October 15-16, 2001.

29. Pandya, T.P., and Srivastava, N.K., Combust. Sci. Technol. 11:165(1975).

30. Sheinson, R.S., Penner-Hahn, J.E., and Indritz, D., "The Physical and Chemical Action of Fire Suppressants," Fire Safety Journal 15, 43 (1989). 


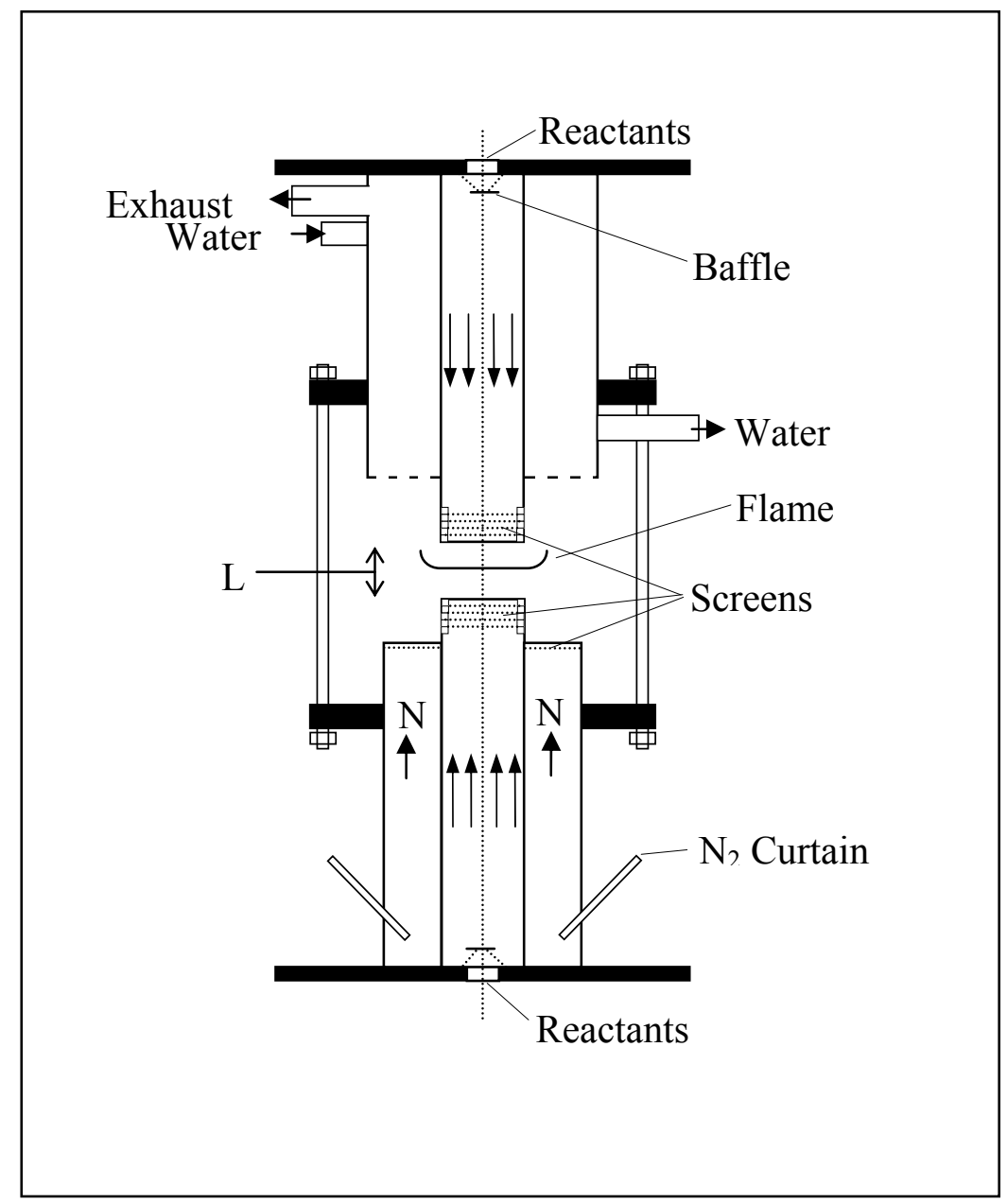

Figure 1 Schematic drawing of counterflow burner. 


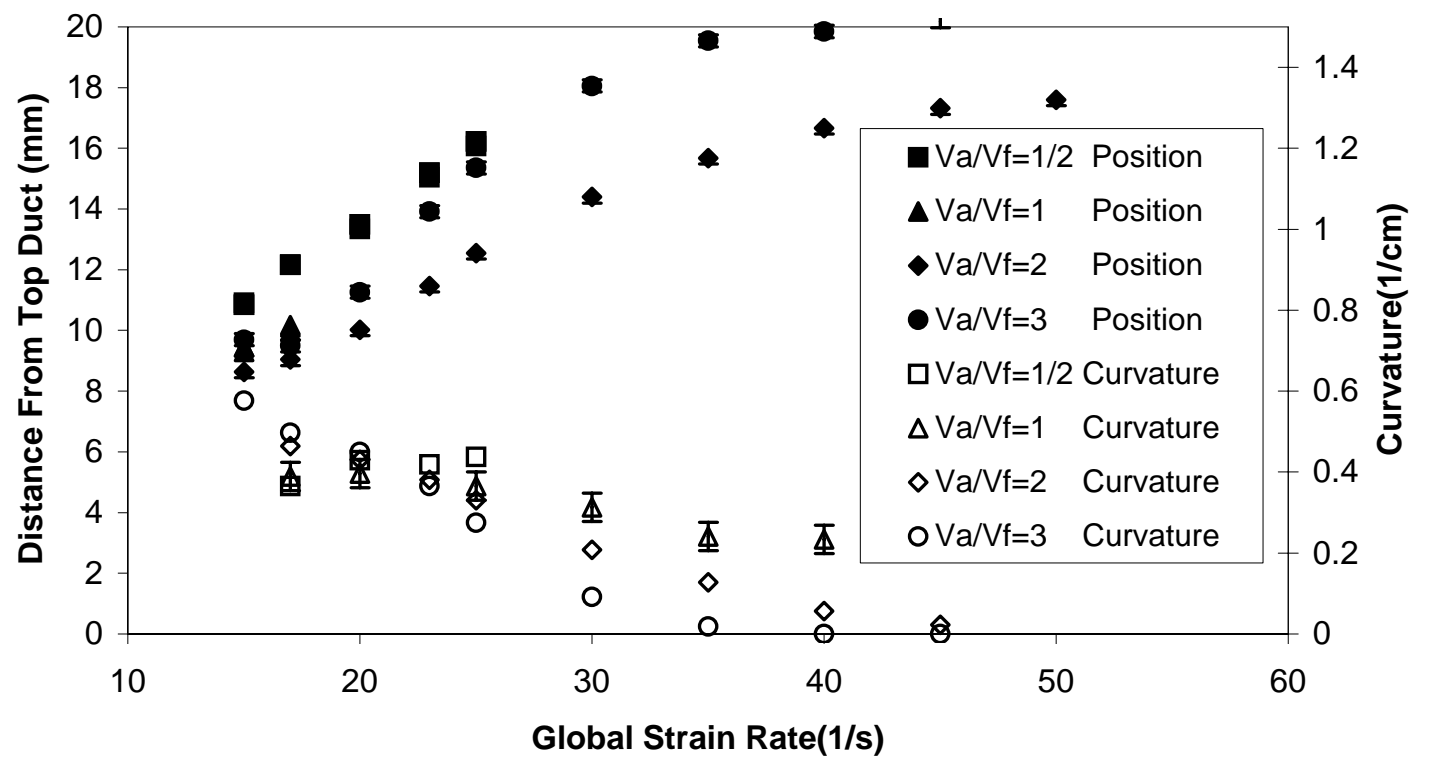

Figure 2 The position of the luminous flame zone and the flame curvature as a function of the global strain rate for various ratios of the velocity of the air stream to the velocity of the fuel stream $\left(\mathrm{V}_{\mathrm{r}}\right)$.

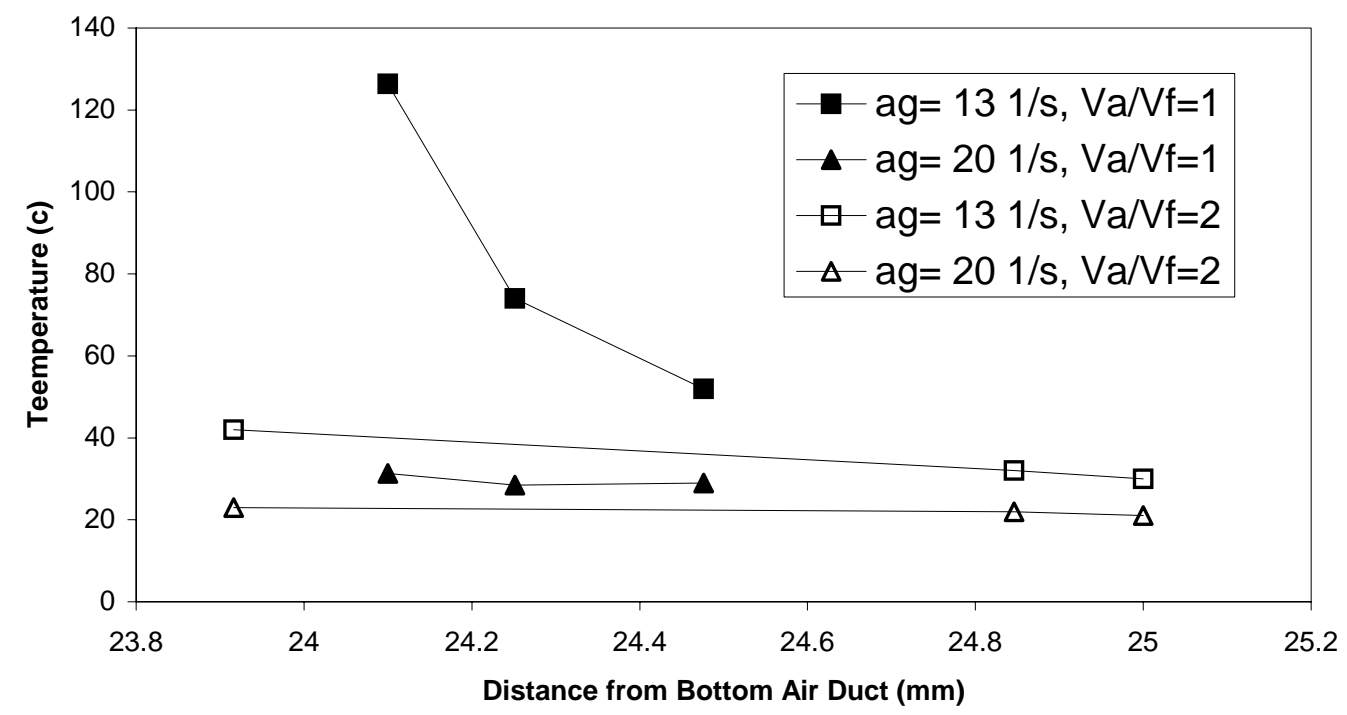

Figure 3 The measured temperature as a function of location near the fuel (upper) duct for four near-extinction propane-air flames with $\mathrm{N}_{2}$ added to the fuel stream wit two different velocity ratios. 


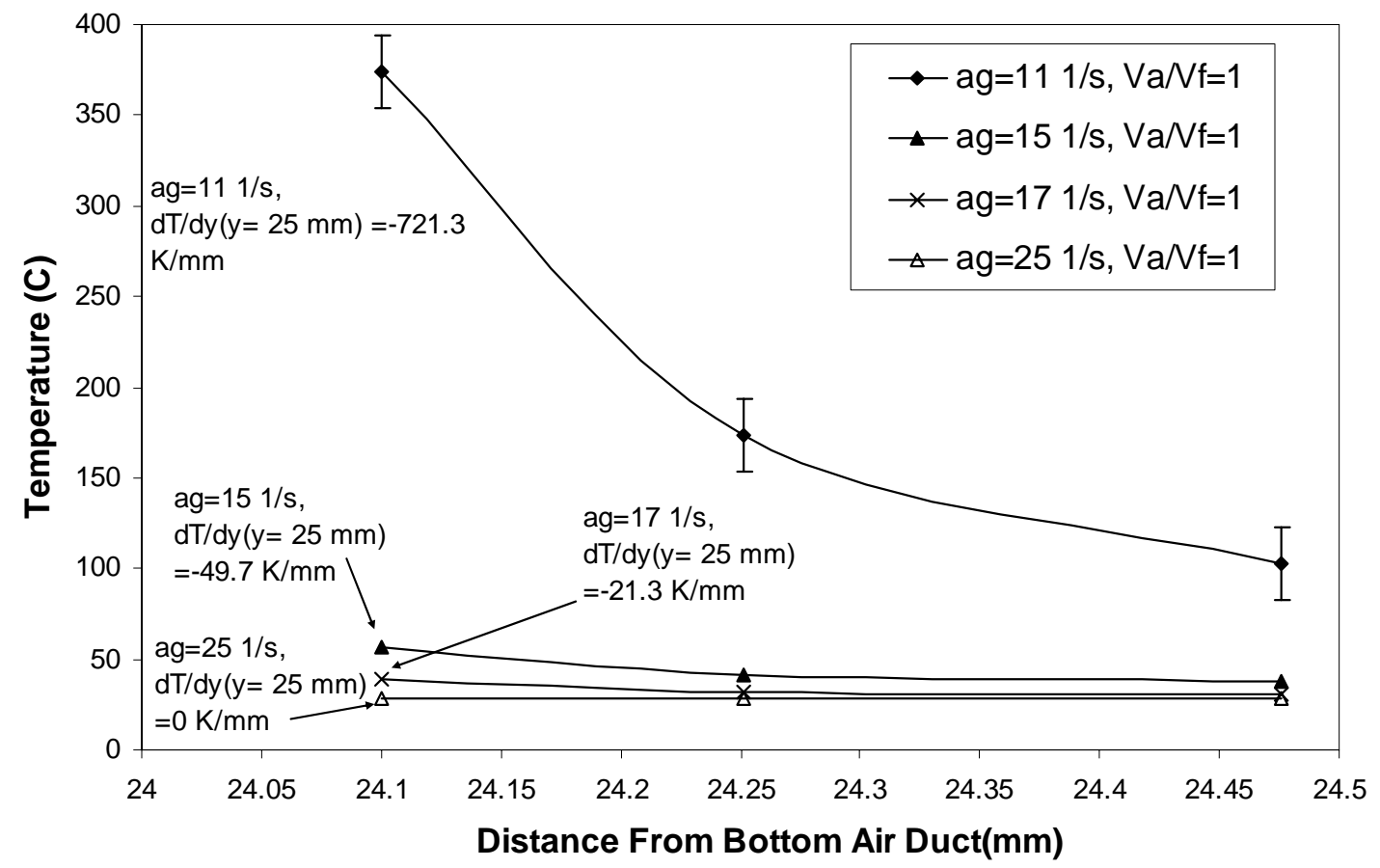

Figure 4 The measured temperature as a function of location near the fuel (upper) duct for four near-extinction propane air flames with $\mathrm{N}_{2}$ added to the fuel stream under conditions of a constant velocity ratio for various values of the global strain rate. 


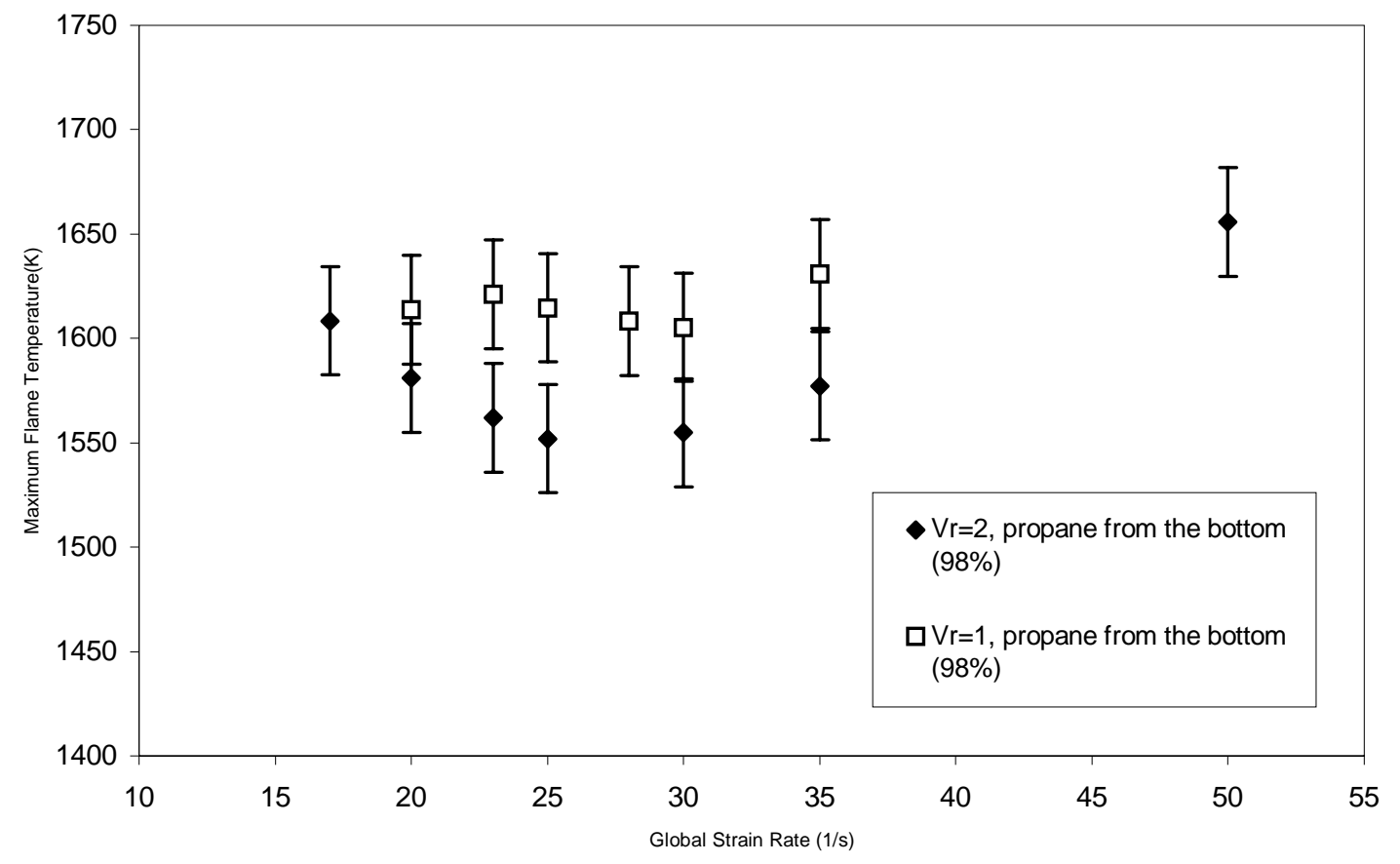

Figure 5 Maximum temperatures as a function of strain rate for different velocity ratios and percentages of extinction.

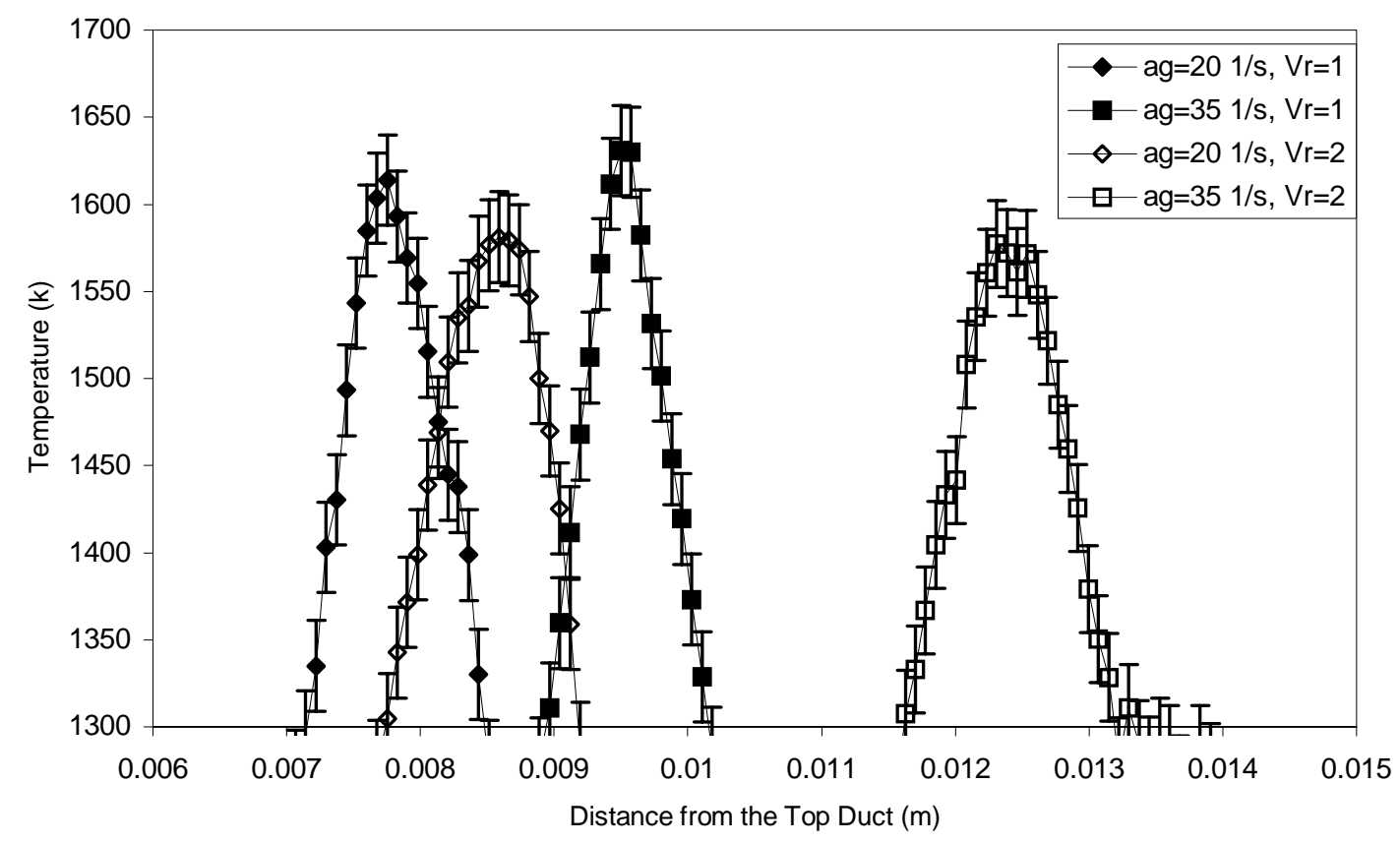

Figure 6 Temperature profiles for $a_{g}=20 \mathrm{~s}^{-1}$ and $a_{g}=35 \mathrm{~s}^{-1}$ for diluent concentrations of $98 \%$ and $99.5 \%$ of the volumetric extinction concentration and $\mathrm{V}_{\mathrm{r}} /=1$ and 2 . 


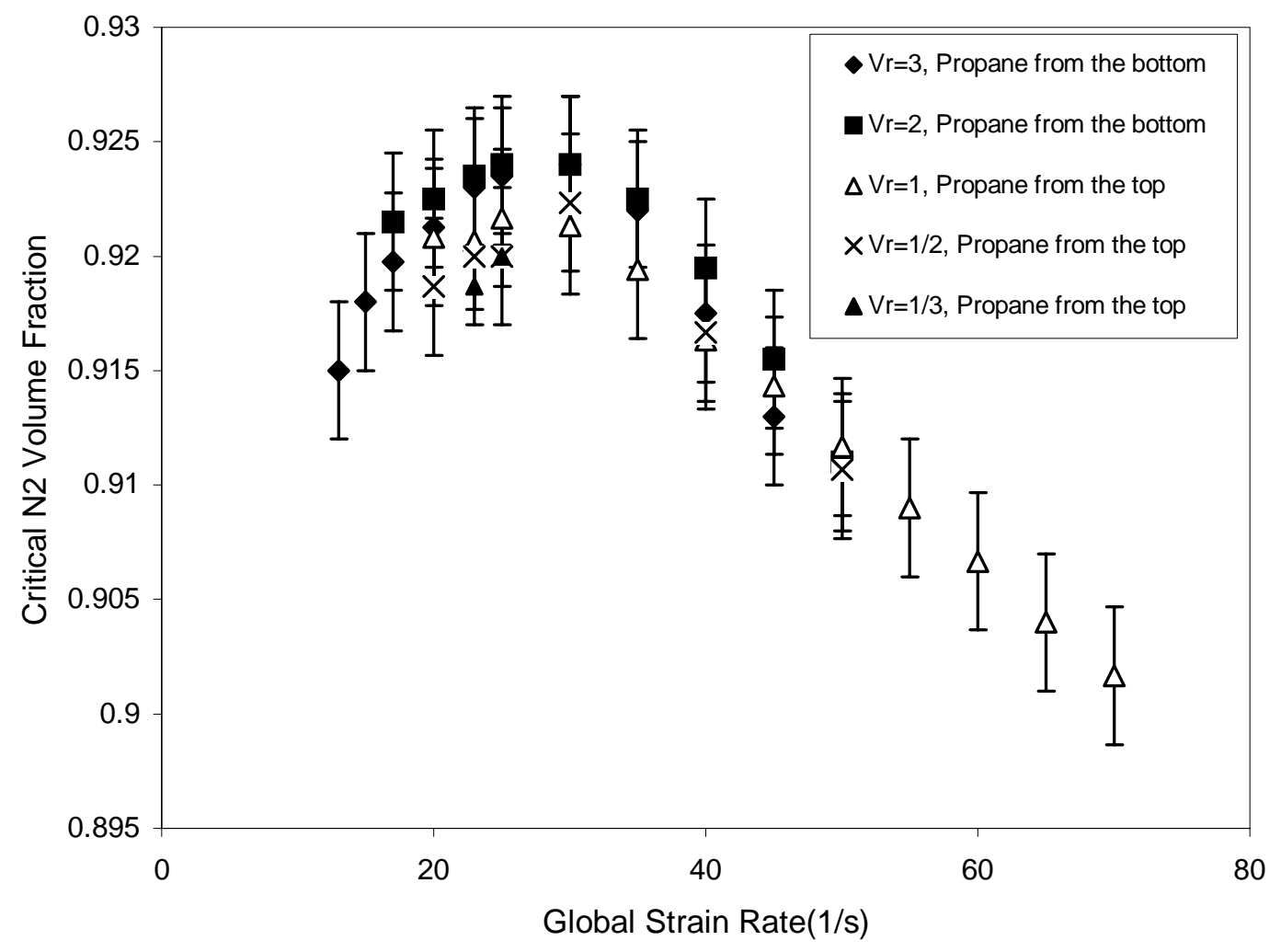

Figure 7 The measured N2 volume fraction in the fuel stream required for suppression in flames free of conductive losses as a function of the global strain rate $\left(\mathrm{a}_{\mathrm{g}}\right)$ for a number of air:fuel velocity ratios $\left(\mathrm{V}_{\mathrm{r}}\right)$ and two different rig orientations, with the fuel injected from the bottom and the top jets, in the presence of an $\mathrm{N}_{2}$ curtain. 


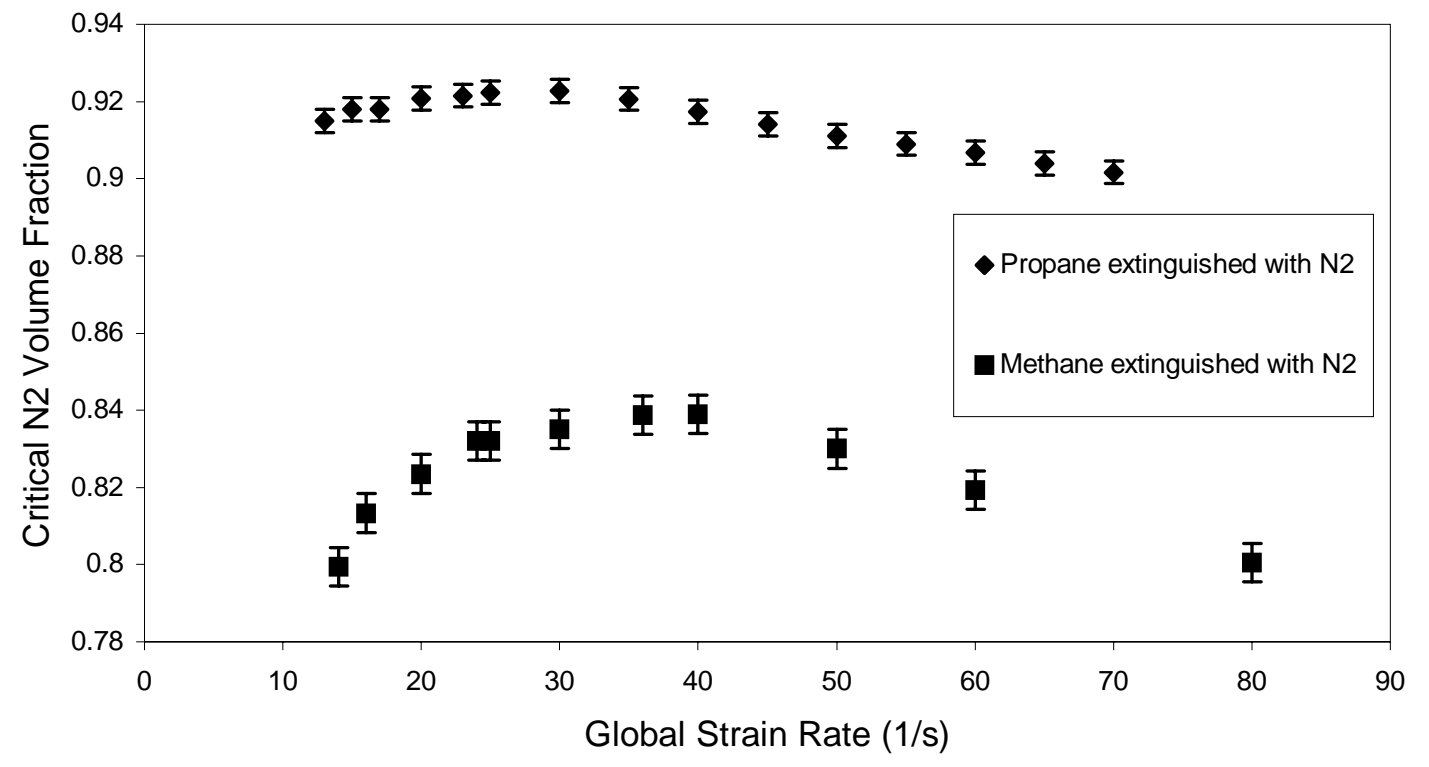

Figure 8 Comparison of extinction curves for propane and methane air diffusion flames diluted with $\mathrm{N} 2$ from the fuel side.

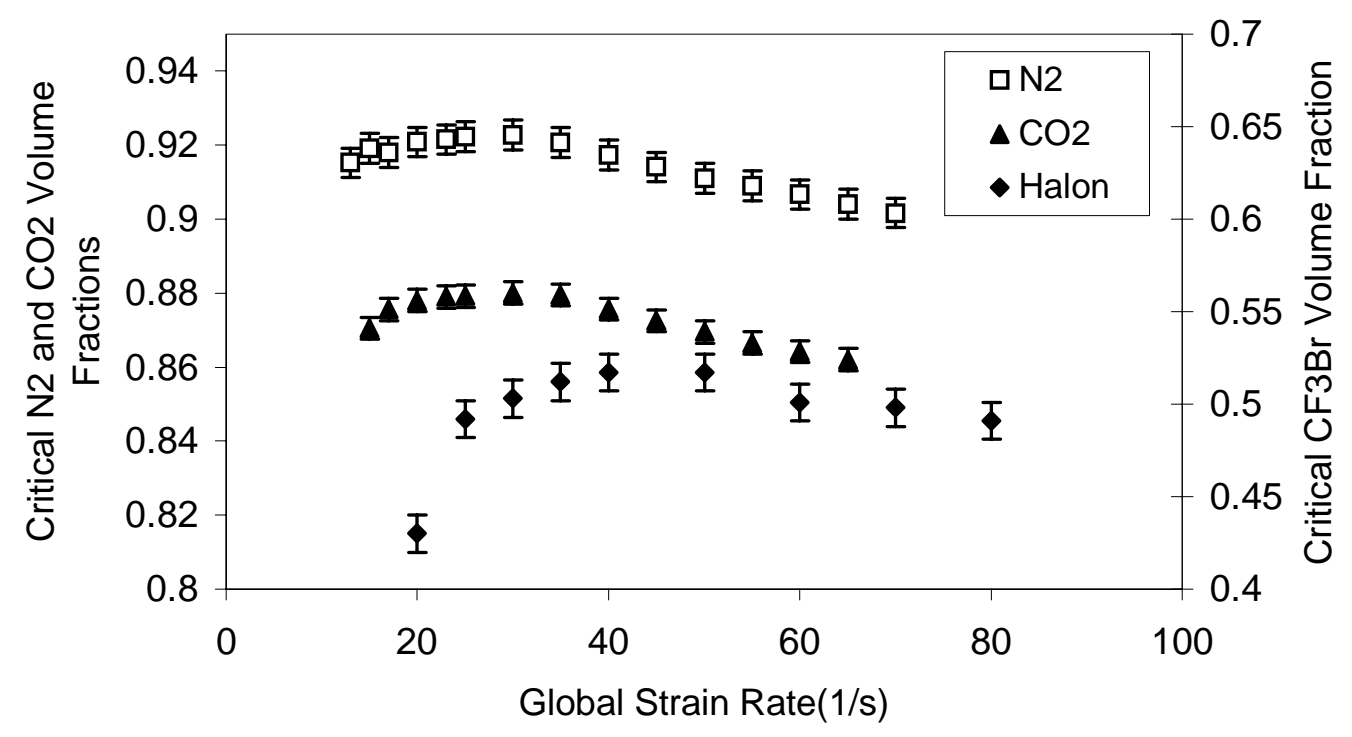

Figure 9 The critical agent concentration in the fuel stream required for suppression of propane-air diffusion flames as a function of global strain rate. 


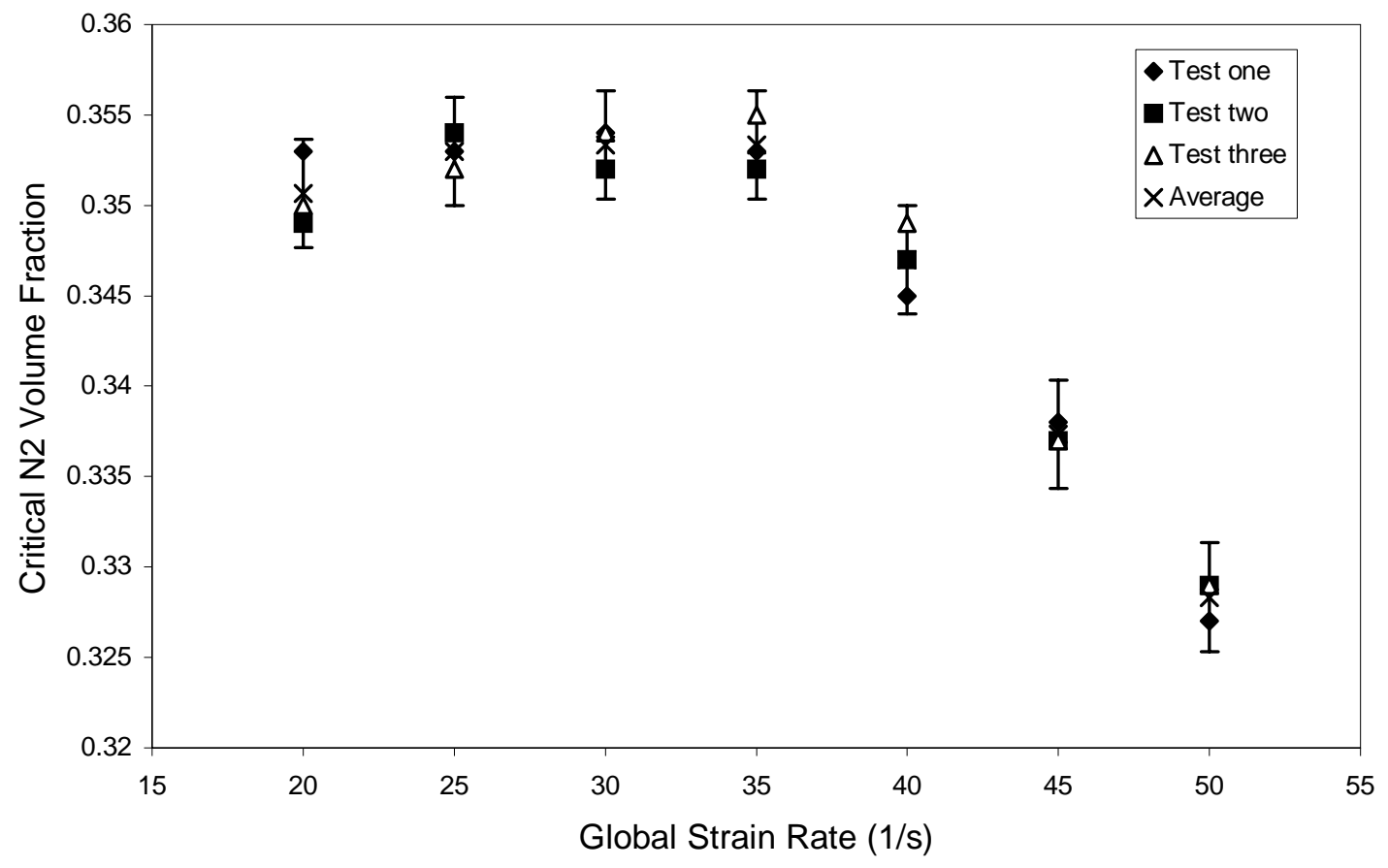

Figure 10 The critical concentration of $\mathrm{N} 2$ in the oxidizer stream required for suppression of propane-air diffusion flames as a function of global strain rate. 


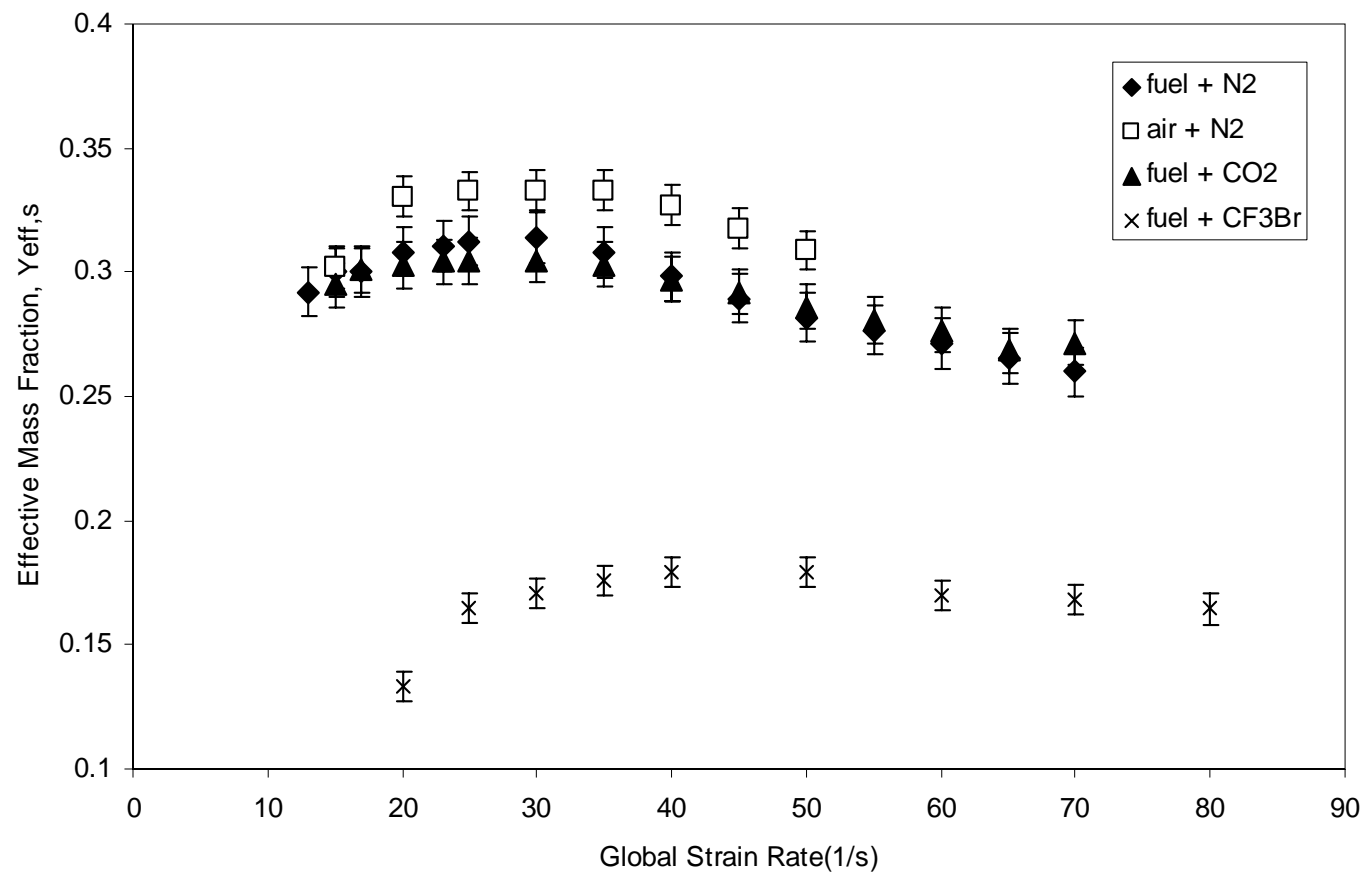

Figure 11 The critical effective mass fraction required for extinction of propane-air diffusion flames as a function of global strain rate. 


\title{
Appendix 5
}

\section{A Technique for Extrapolating Absorption Coefficient Measurements to High Temperatures}

\begin{abstract}
An extrapolation technique that provides semi-quantitative estimates for the infrared absorption coefficients of gaseous fuels at temperatures beyond those for which measurements are generally practical $(>700 \mathrm{~K})$ is presented. The new method is based on a simplified expression for molecular line intensities consisting of three fitting parameters and two variables (temperature and frequency). The accuracy of the extrapolations was tested first by comparing predictions of absorption coefficients for $\mathrm{CO}, \mathrm{CO}_{2}$, and $\mathrm{H}_{2} \mathrm{O}$ vapor to the corresponding values obtained directly from the HITEMP molecular database. Finally, in order to establish the practical utility of the method, the spectrum of propane at $1000 \mathrm{~K}$ obtained from the extrapolation technique was compared to actual experimental measurements.
\end{abstract}




\section{Introduction}

The transfer of thermal energy between the flames and fuel in a combusting system is mediated by the absorption and emission of infrared radiation (IR). Thus, to accurately model fires or incinerators, the spectroscopic properties of the gas phase combustion intermediates must be known. This information can be obtained from non-intrusive measurements of the attenuation in the intensity of IR radiation from an external source, such as from a Fourier Transform Infrared (FTIR) spectrometer. Whether the objective is combustion modeling or diagnostics, calibration spectra corresponding to the gases of interest at elevated temperatures must be available. This poses a problem because it is difficult to measure calibration quality spectra at temperatures above $700 \mathrm{~K}$. Furthermore, since the IR spectra of gas phase molecules undergo dramatic changes with increasing temperature, the common strategy of using spectra measured at room temperature to approximate high temperature absorption coefficients [1] yields unacceptable errors. Much attention has been focused on radiation from combustion products $\left(\mathrm{H} 2 \mathrm{O}, \mathrm{CO}_{2}, \mathrm{CO}\right.$, and soot) in flames. However, relatively little is known about absorption properties of large hydrocarbon molecules near the fuel source. DeRis [2] performed experiments measured radiative feedback to the fuel surface in PMMA pool fires. His work has motivated several recent studies on fuel absorption at elevated temperatures [3-8]. The focus of this investigation was to develop a semi-quantitative method to extrapolate absorption coefficients, obtained for temperatures up to $700 \mathrm{~K}$, to the higher temperatures $(1000 \mathrm{~K})$ that are required to describe the transfer of radiation between a flame and its fuel-rich core.

\section{Extrapolation Technique}

According to the Beer Lambert law, the absorption coefficient, $\kappa v$, at any wavenumber, $v$, can be expressed in terms in terms of measurable quantities as

$$
\kappa_{v}=\frac{-\ln \left(\tau_{v}\right)}{p L}
$$

where $\tau_{v}$ is the spectral transmittance, $\mathrm{p}$ is the partial pressure of the absorbing specie $(\mathrm{Pa})$, and $\mathrm{L}$ is the measurement path length $(\mathrm{m})$. From a more fundamental perspective [9], the absorption coefficient is the product of line intensity $(S)$, line shape $\left(g\left(v-v_{0}\right)\right)$ and the number of absorbing molecules per unit volume and pressure:

$$
\kappa_{v}=S \cdot g\left(v-v_{0}\right) \cdot N_{t} \cdot\left(\frac{296}{T}\right)
$$

where $v_{\mathrm{o}}$ is the center of an absorbing line in wavenumbers and $\mathrm{N}_{\mathrm{L}}$ is Loschmidts' number $\left(\mathrm{N}_{\mathrm{L}}=2.447 \cdot 10^{17}\right.$ molecules $/ \mathrm{cm}^{3} / \mathrm{kPa}$ at $\left.296 \mathrm{~K}\right)$. The line intensity $(\mathrm{S})$ corresponds to the product of the quantum mechanical probability for the transition and the population difference between the initial (absorption) and final (emission) states [11]: 


$$
S=\frac{\left\{\frac{8 \cdot \pi^{3}}{3 h c}\right\} \cdot v \cdot\left\{\frac{\mid k^{2}}{g_{t}}\right\} \cdot g_{i} \cdot I_{i} \cdot\left[1-\exp \left(-\frac{h c v}{k T}\right)\right] \cdot g_{i} \cdot \exp \left(-\frac{E}{k T}\right)}{Q \cdot 10^{36}}
$$

Here, $\mathrm{h}$ and $\mathrm{k}$ are the Planck and Boltzmann constants, respectively, $\mathrm{c}$ is the speed of light, $\mathrm{E}^{\prime}$ is the energy of the lower state, $r$ is the transition dipole moment, and hov is the difference in energy between the upper and lower states. The second bracketed term is the quantum mechanical transition probability, where $\mathrm{g}_{1}$ is the degeneracy of the lower state. Finally, $\mathrm{I}_{\mathrm{a}}$ is the isotope fraction, $\mathrm{g}_{\mathrm{i}}$ is the nuclear spin degeneracy, and $\mathrm{Q}$ is the rotational partition sum. Substituting $S$ from eqn. (3) and the (pressure broadened) Lorentzian line shape for $g\left(v-v_{0}\right)$ [9] in eqn. (2) gives:

$$
k_{v}=\frac{\left\{\frac{8 \cdot \pi^{3}}{3 h c}\right\} v\left\{\frac{\mid \underline{H}^{2}}{g_{i}}\right\} g_{i} I_{a}\left[1-\exp \left(-\frac{h c v}{k T}\right)\right] g_{t} \exp \left(-\frac{E}{k T}\right) \frac{g}{\pi}\left(\frac{296}{T}\right)^{n} P_{t} N_{t}\left(\frac{296}{T}\right)}{Q \cdot 10^{36} \cdot\left[\left(v-v_{0}\right)^{2}+\left(g \cdot\left(\frac{296}{T}\right)^{n} P_{t}\right)^{2}\right]}
$$

where $\mathrm{P}_{\mathrm{t}}$ is the total pressure and $\mathrm{g}$ is a broadening parameter $\left(\mathrm{cm}^{-1} / \mathrm{kPa}\right)$.

The approach taken in this study was to simplify this expression to a form suitable for fitting the absorption coefficients measured over a range of temperatures. This was achieved by reducing eqn. (4) to an expression containing three fit parameters $\left(\mathrm{S}_{0}, \mathrm{E}^{\prime}\right.$, and $p)$ and two variables ( $v$ and $T)$. The values of the absorption coefficients at higher temperatures, which are difficult to measure, can then be estimated by extrapolation. The terms with negligible temperature or frequency dependence were consolidated into $\mathrm{S}_{0}$ as indicated in eqn. (5). This includes everything in the numerator with the exception of the wavenumber, $v$, the exponentials, and explicit temperatures. In the denominator, it includes all but $\mathrm{T}^{\mathrm{n}}$ and the temperature dependence of the partition sum $\mathrm{Q}$.

$$
S_{0}=\frac{\left\{\frac{8 \pi^{2}}{3 h c}\right\}\left[\frac{\mid I^{2}}{g_{i}}\right\} g_{i} I_{a} g_{i} N_{L}}{296^{n-1} 10^{36} g \cdot P_{t}\left(\frac{Q}{T^{\frac{m}{2}}}\right)}
$$

The rotational partition function is presumed to be proportional to $\mathrm{T}(\mathrm{m}=2$ rotational degrees of freedom) in a linear molecule and $\mathrm{T}^{3 / 2}(\mathrm{~m}=3)$ in a nonlinear molecule. With this in mind, all powers of $\mathrm{T}$ that were not contained in the exponential terms were included in the temperature exponent, p. As a first approximation, we also ignored the 
explicit contributions from overlapping rotational lines (i.e., we set $v=v_{0}$ ) so that the

effects of the Lorentzian line shape functions are effectively subsumed into the $\mathrm{S}_{0}$ and $\mathrm{T}^{\mathrm{p}}$ terms. Since the temperature dependence of each rotational transition is unique, this approximation is likely to result in larger errors when the resolution of the measurements is not sufficient to differentiate between the individual lines. After substituting $E^{\prime}=h c v_{r}=$ $1.439 v_{r}$ for the energy of the lower state, eqn. (4) becomes:

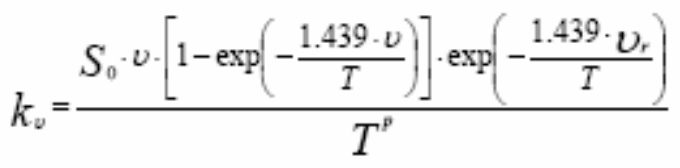

In this expression temperature, $\mathrm{T}(\mathrm{K})$, and wavenumber, $v\left(\mathrm{~cm}^{-1}\right)$, are independent variables and the parameters $\mathrm{S}_{0}, v_{\mathrm{r}}$, and $\mathrm{p}$ were fit over a range of temperatures at each wavenumber.

\section{Extrapolation data processing}

\section{HITEMP Database (Carbon monoxide, Carbon Dioxide, and Water Vapor)}

Absorption data for $\mathrm{CO}, \mathrm{CO}_{2}$ and $\mathrm{H}_{2} \mathrm{O}$ were obtained from the HITEMP database [10]. HITEMP is the high temperature analog of the HITRAN database, which is an extensive compilation of molecular line absorption data for 36 species [11]. The accuracy of the spectra derived from the HITEMP database for applications to combusting systems at temperatures exceeding $1000 \mathrm{~K}$ has already been examined by others [12]. Parameters $\left(\mathrm{S}_{\mathrm{o}}, v_{\mathrm{r}}, \mathrm{p}\right)$ were fit to eqn. (6) for absorption coefficients obtained from the database at $300,400,450,500$ and $600 \mathrm{~K}$. Using these parameters, an extrapolation was performed to $1000 \mathrm{~K}$ and comparisons were made to absorption coefficients calculated from spectra generated directly from the HITEMP database at $1000 \mathrm{~K}$.

\section{Experiment}

A Mattson Galaxy 7020 FTIR spectrometer was modified so that the IR beam from a globar source passes through the interferometer but is then diverted outside the spectrometer, bypassing the standard sample compartment and detector. The IR beam travels along the axis of a quartz flow cell, which is located inside a tube furnace, and onto an external Mercury Cadmium Telluride (MCT) detector (MI0465, Graseby Infrared). A diagram of our experimental setup is shown in Figure 1. The entire optical path, including the spectrometer and external detector chamber was purged with $\mathrm{N}_{2}$ (99.5\% Super Dry) to eliminate absorption from ambient water vapor and $\mathrm{CO}_{2}$. The interferometer is equipped with corner-cube optics. This arrangement minimizes the effect of sample emission on the transmission measurements [13]. This was confirmed by measuring the emissions (with the source blocked) from the heated (1000 K) cell containing propane gas, which was found to be negligible. The furnace (Lindberg/Blue M 
HTF53347C with CC58434C-1 controller) has three heating zones designed to maintain a uniform temperature over the full length $(31.75 \pm 0.01 \mathrm{~cm})$ of the cell (inner diameter $=$ $2.54 \mathrm{~cm}$ ). The gas temperatures were measured with K-type thermocouples at the inlet and outlet of the cell. The temperature difference between two thermocouples was typically about $5 \mathrm{~K}$, which was considered acceptable for the purposes of this investigation. The ends of the quartz cell were sealed with Zinc Selenide ( $\mathrm{ZnSe})$ laser grade windows $(0.3 \mathrm{~cm}$ thickness $)$. The temperature of the windows was kept below 700 $\mathrm{K}$ to prevent oxidation of the $\mathrm{ZnSe}$. This was accomplished by directing a jet of $\mathrm{N}_{2}$ on the outside of the windows as seen in Figure 1. The pressure inside of the cell was monitored and regulated to maintain $101.3 \mathrm{kPa}$ during the measurements. Mixtures containing 1000 $\pm 20 \mathrm{ppm}, 2500 \pm 50 \mathrm{ppm}$, and $4000 \pm 80 \mathrm{ppm}$ of propane (CP Grade, Matheson) in $\mathrm{N}_{2}$ (99.5\% Super Dry) were made by regulating the flow of these gases into the cell using mass flow controllers $\left(20 \mathrm{sccm}\right.$ for propane and $200 \mathrm{sccm}$ for $\mathrm{N}_{2}$ ).

Comparisons of our extrapolation technique to experimental measurements were performed for propane at $800 \mathrm{~K}$ and $1000 \mathrm{~K}$ based on fits determined from measurements made at temperatures of $300,400,450,500$ and $600 \mathrm{~K}$. The absorption spectra were measured at $1 \mathrm{~cm}-1$ resolution and signal averaged over 128 scans.

\section{Accuracy assessment}

In assessing the accuracy of our extrapolations, integrated absorption coefficients

$$
\int_{n_{n}}^{v_{v}} \kappa_{v} d v=\frac{-\int_{n_{3}}^{v_{s}} \ln \left(\tau_{v}\right) d v}{p L}
$$

from the extrapolated spectra are compared to the corresponding values from the experimental (or HITEMP) spectra. In this equation, $v_{1}$ and $v_{2}$ are the frequencies corresponding to the band limits. In the case of propane, an average integrated absorption coefficient from spectra of the three (1000 ppm, $2500 \mathrm{ppm}$, and $4000 \mathrm{ppm})$ gas mixtures was obtained. The accuracies of the extrapolations are assessed on the basis of relative errors computed by taking the ratios of the differences between the integrated absorption coefficients obtained from the extrapolations and the "actual" values obtained either from the HITEMP (for $\mathrm{CO}, \mathrm{H}_{2} \mathrm{O}$, and $\mathrm{CO}_{2}$ ) or experimental spectra (for $\mathrm{C}_{3} \mathrm{H}_{8}$ ) and dividing by the "actual" values.

\section{Extrapolation Results}

As a first attempt, the accuracy of the extrapolation procedure was examined without introducing complications due to experimental errors. Extrapolations of the spectra for $\mathrm{CO}, \mathrm{CO}_{2}$ and $\mathrm{H}_{2} \mathrm{O}$ (based on parameters determined by fitting eqn. (6) to HITEMP spectra over temperatures $300,400,450,500$ and $600 \mathrm{~K}$ ) were compared to the corresponding spectra at $1000 \mathrm{~K}$ generated directly from the HITEMP database. This exercise provides an estimate of the magnitude of the errors resulting from the simplifications introduced in representing eqn. (4) by eqn. (6). The practical utility of 
using our methodology in conjunction with experimental measurements is demonstrated by comparing predictions (based on fits of spectra measured at lower temperatures) for the absorption of IR radiation by the $\mathrm{C}-\mathrm{H}$ stretching region in propane (extending from $2700 \mathrm{~cm}^{-1}$ to $3200 \mathrm{~cm}^{-1}$ ) at $800 \mathrm{~K}$ and $1000 \mathrm{~K}$.

\section{Carbon Monoxide}

Parameters were fit for the $\mathrm{R}$ branch of the $4.7 \mu \mathrm{m}$ CO band, over the range from $2150 \mathrm{~cm}^{-1}$ to $2270 \mathrm{~cm}^{-1}$. The data were generated at a resolution of $1 \mathrm{~cm}^{-1}$, resulting in an average spacing of $0.482 \mathrm{~cm}^{-1}$. This was sufficiently high that the individual lines in the band were resolved. Figure 2 (a) is a comparison of extrapolated absorption coefficient from eqn. (6) to the one from HITEMP at $300 \mathrm{~K}$. The difference in the integrated absorption between the original and fit data, obtained from eqn. (6), is less than $-0.1 \%$. The small error is expected because the reference spectrum was included in the training set. In Figure 2 (b), however, the extrapolated absorption coefficients are compared to the HITEMP data at $1000 \mathrm{~K}$, which is $400 \mathrm{~K}$ above the highest temperature spectrum used in the fitting procedure. The difference in the integrated absorbance at this temperature is still only $3.6 \%$. While this agreement may be a little misleading because there is clearly a cancellation of errors, the magnitudes of the residuals (Figure 3) are on average at least an order of magnitude smaller than the absorbance values.

The spectra of heavier molecules are not as well resolved at elevated temperatures as is the CO spectrum shown in Figure 2. Closely spaced broadened lines will, in effect, smear out distinguishable line structure. Since this is the case for many fuels, it is important to investigate the effect of reducing the resolution on the accuracy of the extrapolations. Figure 4 (a) and (b) compare the extrapolated absorption coefficients and HITEMP data at $1000 \mathrm{~K}$ and $4 \mathrm{~cm}^{-1}$. At $4 \mathrm{~cm}^{-1}$ resolution, the CO line structure is gone and the band appears as a continuous absorption. The fit procedure was carried out using these data with similar results as the higher resolution case. The integrated absorbance at $1000 \mathrm{~K}$ using the fit parameters differed from the HITEMP data by only $-0.28 \%$. The errors in the temperature extrapolations for $\mathrm{CO}$ appear to remain tractable upon de-resolving the spectrum even though the contributions from overlapping rotational lines were not explicitly accounted for in the derivation of eqn. (6).

\section{Water Vapor}

Parameters were fit to lines in the $2.7 \mu \mathrm{m}$ water band, over the range between $3500 \mathrm{~cm}^{-1}$ $4000 \mathrm{~cm}^{-1}$. The temperatures used were the same as those in the CO case. The water absorption data was generated from the HITEMP database at a resolution of $4 \mathrm{~cm}-1$, resulting in an average data spacing of $1.93 \mathrm{~cm}-1$. At this resolution, most of the line structure was still visible in this band. Figure 5 (a) is a comparison of extrapolated absorption coefficient from eqn. (6) to the one from HITEMP at $300 \mathrm{~K}$, using the parameters generated in the fit. The results of this comparison were comparable to those from the $\mathrm{CO}$ fit at $300 \mathrm{~K}$. The difference in the integrated absorbance was $-0.02 \%$. Again, we anticipated a small error because the parameters were fit to data at this temperature. However, the comparison is still favorable at $1000 \mathrm{~K}$, where the difference in the integrated absorbance is only $3.6 \%$. This result is shown in Figure 5 (b). The residuals are shown as a function of wavenumber in Figure 6. 


\section{Carbon Dioxide}

The accuracy of the extrapolation method for the $4.3 \mu \mathrm{m}$ band in $\mathrm{CO}_{2}$ over the spectral range $2250 \mathrm{~cm}^{-1}$ to $2350 \mathrm{~cm}^{-1}$ (P branch) was also examined. The procedure was carried out using data at two resolutions: $0.5 \mathrm{~cm}^{-1}$ and $4 \mathrm{~cm}^{-1}$, resulting in average data spacing of $0.241 \mathrm{~cm}-1$ and $1.93 \mathrm{~cm}-1$, respectively. The HITEMP and fit data at T $=300 \mathrm{~K}$ and 0.5 $\mathrm{cm}-1$ resolution are compared in Figure 7a. In this case the difference in the integrated absorption coefficient was $-2.1 \%$, compared with $-1.1 \%$ at $4 \mathrm{~cm}^{-1}$ resolution. At $1000 \mathrm{~K}$, the difference at $0.5 \mathrm{~cm}^{-1}$ resolution was only $-0.7 \%$. The HITEMP and fitted spectra are compared in shown in Figure 7 (b). While the error in the integrated absorbance is small, a frequency resolved comparison, as indicated by the residual spectrum in Figure 8, does reveal a small, but noticeable systematic error between $2270 \mathrm{~cm}^{-1}$ and $2300 \mathrm{~cm}^{-1}$. At 4 $\mathrm{cm}^{-1}$ resolution (and $1000 \mathrm{~K}$ ) the difference in the integrated absorption coefficient at $1000 \mathrm{~K}$ is $1.3 \%$. The discrepancies are apparent in the comparison shown in Figure 9. A summary of the integrated and residual RMS errors for the extrapolations of the HITEMP data is presented in Table 1. Chu et al. [14] report uncertainties on the order of $2 \%-3 \%$ for the measurement of absorption coefficients in the NIST Quantitative Infrared Database. Additionally, their study reports that line intensity variations on the order of \pm $10 \%$ can frequently be found in comparisons of quantitative reference spectra. Although the cancellation of positive and negative errors makes it difficult to discern a pattern in the discrepancies between the integrated absorption coefficients obtained from direct calculation and the extrapolation, it does appear that the RMS errors grow more rapidly with temperature in the extrapolations from the lower resolution spectra. However, in either case, the errors in the extrapolations are comparable to the experimental uncertainties reported by Chu.

\section{Propane $\left(\mathrm{C}_{3} \mathrm{H}_{8}\right)$}

Figure 10 shows how the absorption coefficients for propane vary with temperature. The band broadens with increasing temperature as higher energy rotational states become populated. Furthermore, the peak absorption drops by more than an order of magnitude from $300 \mathrm{~K}$ to $1000 \mathrm{~K}$. These changes in the shape and intensity of the absorption band are captured in the extrapolations.

The extrapolated absorption coefficients at $800 \mathrm{~K}$ (a) and $1000 \mathrm{~K}$ (b) are compared to the corresponding experimental values in Figure 11. Although there is at least qualitative agreement, a more detailed comparison reveals that the extrapolations exhibit more structure and underestimate the absorbance at the wings of the bands. The fine structure apparent in the extrapolations is presumably an artifact resulting from the retention of the higher resolution inherent at lower temperatures. The discrepancy at the band wings is probably due to the inability of the extrapolations to capture the effects of "hot bands", corresponding to vibrational transitions that are not populated at the lower temperatures used in determining the fitting parameters. Despite these deficiencies, the errors in the integrated absorption coefficients are only about $10 \%$ to $20 \%$ at $800 \mathrm{~K}$ and $1000 \mathrm{~K}$. The accuracy of the extrapolations is better for frequencies in the vicinity of the band center and become less accurate at the wings (Table 2). The residuals are shown as a function of wavenumber in Figure 12. 


\section{Summary and Conclusions}

The variations in the IR absorption coefficients for three combustion products $\left(\mathrm{CO}, \mathrm{CO}_{2}\right.$, and $\left.\mathrm{H}_{2} \mathrm{O}\right)$ and one fuel $\left(\mathrm{C}_{3} \mathrm{H}_{8}\right)$ were examined as functions of temperature from $300 \mathrm{~K}$ to $1000 \mathrm{~K}$. As expected, the intensities and shapes of the absorption bands of these molecules undergo dramatic changes over this temperature range, becoming broader and less intense (by as much as an order of magnitude) with the increasing population of higher energy rotational states. On this basis, it is concluded that this temperature dependence must be considered to accurately model the transfer of IR radiation and to measure the concentrations of hot gases in fires and incinerators by transmission spectroscopy. With this in mind, an extrapolation technique was developed to extend the range of molecular absorption coefficients to temperatures beyond the range for which measurements are routinely available. Experimental measurements of propane indicate that errors in the extrapolation are about $10-20 \%$ over the temperature range of interest. Thus, by employing this extrapolation procedure, the accuracy of absorption coefficients used in models of radiative transfer and in combustion diagnostics can be improved by as much as an order of magnitude over what would otherwise be obtained using values measured at lower temperatures.

\section{Acknowledgements}

This work was partially supported by the National Research Council Postdoctoral Associate Program, the NASA Microgravity Program (Contract \#C32066T; Dr. Sandra Olson, scientific officer), and the Fire Research Grants Program (Contract \# 60NANB1D0075). The authors acknowledge helpful discussions with Professors Jungho Kim and Greg Jackson of the Department of Mechanical Engineering of the University of Maryland. 


\section{References}

1. Modest, M.F., Bharadwaj, S. P., JQSRT 73 (2002) 329-338.

2. DeRis, J., Proc. Combust. Inst. 17 (1979) 1003-1015.

3. Fuss, S.P., Ezekoye, O.A., Hall, M.J., ASME J. Heat Transfer, 118 (1996) 918-923.

4. Fuss, S.P., Hall, M. J., Ezekoye, O. A., Applied Optics, 38 (1999) 2895-2904.

5. Brosmer, M.A., and Tien, C. L., JQSRT, 33 (1985) 521-532.

6. Brosmer, M.A., and Tien, C. L., ASME J. Heat Transfer, 107 (1985) 943-948.

7. Brosmer, M.A., and Tien, C. L., Combust. Sci. Tech., 48 (1986) 163-175.

8. Park, S., H., Stretton, A. J., and Tien, C. L., Combust. Sci. Tech., 62 (1988) 257-271.

9. Gross, L.A., Griffiths, P.R., and Sun, J.N.-P., in: J. Wormhoudt (Ed.), Infrared

Measurements for Gaseous Measurements, Marcel Decker: New York. 1985, p. 81-132.

10. Rothman, L.S., Camy-Peyret, C., Flaud, J-M., Gamache, R., Goldman, A., Goorvitch, D., Hawkins, R., Schroeder, J., Selby, J., Wattson, R., JQSRT, being prepared.

11. Rothman, L.S., Rinsland, C.P., Goldman, A., Massie, S.T., Edwards, D.P., Flaud, J.M., Perrin, A., Camy-Peyret, C., Dana, V., Mandin, J.Y., Schroeder, J., McCann, A., Gamache, R.R., Wattson, R.B., Yoshino, K., Chance, K.V., Jucks, K.W., Brown, L.R., Nemtchinov, V., and Varanasi, P., JQSRT, 60 (1998) 665-710.

12. Fleckl, T., Jager, H., and Obernberger, I., J. Physics. D: Applied Phys., 35 (2002) 3138-3144.

13. Tripp, C.P., and McFarlane, R. A., Applied Spectroscopy, 48 (1994) 1138-1142.

14. Chu, P.M., Guenther, F. M., Rhoderick, G., C., and Lafferty, W. J., J. Research National Inst. St. Tech., 104 (1999) 59-81. 
Table 1

Summary of errors in the HITEMP extrapolations.

\begin{tabular}{|c|c|c|c|c|c|}
\hline \multirow{3}{*}{$\begin{array}{l}\text { Molecule } \\
\left(\text { Res, } \mathrm{cm}^{-1}\right)\end{array}$} & \multirow{3}{*}{ Integration Range $\left(\mathrm{cm}^{-1}\right)$} & \multicolumn{2}{|c|}{ Error in integrated values $(\%)$} & \multicolumn{2}{|c|}{ RMS of the residual } \\
\hline & & \multicolumn{4}{|c|}{ Temperature $(\mathrm{K})$} \\
\hline & & 300 & 1000 & 300 & 1000 \\
\hline CO (1) & 2150-2270 & -0.1 & 3.6 & $1.33 \mathrm{E}^{-3}$ & $1.11 \mathrm{E}^{-3}$ \\
\hline CO (4) & $2150-2270$ & 0.3 & -0.3 & $2.04 \mathrm{E}^{-4}$ & $1.10 \mathrm{E}^{-3}$ \\
\hline $\mathrm{H}_{2} \mathrm{O}(4)$ & $3500-4000$ & -0.02 & 3.6 & $2.09 \mathrm{E}^{-3}$ & $4.85 \mathrm{E}^{-3}$ \\
\hline & $2250-2350$ & -2.1 & -0.7 & $3.06 \mathrm{E}^{-2}$ & $1.45 \mathrm{E}^{-2}$ \\
\hline $\mathrm{CO}_{2}(4)$ & $2250-2350$ & -1.1 & 1.3 & $1.36 \mathrm{E}^{-2}$ & $1.18 \mathrm{E}^{-}$ \\
\hline
\end{tabular}

Table 2

Errors in the integrated absorption coefficients for propane at $1 \mathrm{~cm}^{-1}$ resolution.

\begin{tabular}{|c|c|c|c|c|c|c|}
\hline \multirow[t]{3}{*}{$\begin{array}{c}\text { Integration } \\
\text { Range } \\
\left(\mathrm{cm}^{-1}\right)\end{array}$} & \multicolumn{3}{|c|}{$\begin{array}{l}\text { Integrated Absorption } \\
\text { Coefficient }_{\left(\mathrm{Pa}^{-1} \mathrm{~m}^{-1}\right)} \\
\text { Upper: Extrapolation } \\
\text { Lower: Experiment }\end{array}$} & \multicolumn{3}{|c|}{$\begin{array}{c}\text { Error in integrated values } \\
(\%)\end{array}$} \\
\hline & \multicolumn{6}{|c|}{ Temperature (K) } \\
\hline & 300 & 800 & 1000 & 300 & 800 & 1000 \\
\hline $\begin{array}{l}2700-2850 \\
\text { Right Wing }\end{array}$ & 0.030 & 0.022 & 0.020 & 3.5 & -41.1 & -40.8 \\
\hline & 0.029 & 0.037 & 0.033 & & & \\
\hline $\begin{array}{l}2850-3050 \\
\text { Band Center }\end{array}$ & 1.064 & 0.324 & 0.244 & -1.9 & -15.9 & -4.3 \\
\hline & 1.084 & 0.385 & 0.255 & & & \\
\hline $\begin{array}{c}3050-3200 \\
\text { Left Wing }\end{array}$ & 0.014 & 0.013 & 0.011 & 167 & -537 & -590 \\
\hline & 0.012 & 0.027 & 0.026 & & & \\
\hline
\end{tabular}




\section{List of Captions}

Figure 1: Diagram of experiment setup

Figure 2: Comparison of $\mathrm{CO}$ spectral absorption coefficient between HITEMP and data calculated using eqn. (7) with fit parameters at $1 \mathrm{~cm}^{-1}$ resolution: (a) $300 \mathrm{~K}$, (b) $1000 \mathrm{~K}$. The CO partial pressure is $0.101 \mathrm{kPa}$ and the path length is $0.32 \mathrm{~m}$.

Figure 3: Residual ( $\left.\kappa_{\mathrm{Fit}}-\kappa_{\mathrm{Hitemp}}\right)$ for $\mathrm{CO}$ at $1000 \mathrm{~K}$. This represents the difference between the data sets shown in Figure 2.

Figure 4: Comparison of CO spectral absorption coefficient between HITEMP and data calculated using eqn. (7) with fit parameter at $4 \mathrm{~cm}^{-1}$ resolution: (a) $300 \mathrm{~K}$, (b) $1000 \mathrm{~K}$. The CO partial pressure is $0.101 \mathrm{kPa}$ and the path length is $0.32 \mathrm{~m}$.

Figure 5: Comparison of water vapor spectral absorption coefficient between HITEMP and data calculated using eqn. (7) with fit parameters at $1 \mathrm{~cm}^{-1}$ resolution: (a) $300 \mathrm{~K}$, (b) $1000 \mathrm{~K}$. The $\mathrm{H}_{2} \mathrm{O}$ partial pressure is $1.01 \mathrm{kPa}$ and the path length is $0.32 \mathrm{~m}$.

Figure 6: Residual $\left(\kappa_{\text {Fit }}-\kappa_{\text {Hitemp }}\right.$ ) for $\mathrm{H}_{2} \mathrm{O}$ at $1000 \mathrm{~K}$. This represents the difference between the data sets shown in Figure 5.

Figure 7: Comparison of $\mathrm{CO}_{2}$ spectral absorption coefficient at $300 \mathrm{~K}$ between HITEMP and data calculated using eqn. (7) with fit parameters at $0.5 \mathrm{~cm}^{-1}$ resolution: (a) $300 \mathrm{~K}$, (b) $1000 \mathrm{~K}$. The $\mathrm{CO}_{2}$ partial pressure is $0.341 \mathrm{kPa}$ and the path length is $0.32 \mathrm{~m}$.

Figure 8: Residual $\left(\kappa_{\mathrm{Fit}}-\kappa_{\mathrm{Hitemp}}\right)$ for $\mathrm{CO}_{2}$ at $1000 \mathrm{~K}$. This represents the difference between the data sets shown in Figure 7.

Figure 9: Comparison of $\mathrm{CO}_{2}$ spectral absorption coefficient at $1000 \mathrm{~K}$ between HITEMP and data calculated using eqn. (7) with fit parameters at $4 \mathrm{~cm}^{-1}$ resolution: (a) $300 \mathrm{~K}$, (b) $1000 \mathrm{~K}$. The $\mathrm{CO}_{2}$ partial pressure is $0.341 \mathrm{kPa}$ and the path length is $0.32 \mathrm{~m}$.

Figure 10: Comparison of $\mathrm{C}_{3} \mathrm{H}_{8}$ mean spectral absorption coefficient at $1000 \mathrm{~K}$ between Experiment and data calculated using eqn. (7) with fit parameters at $1 \mathrm{~cm}^{-1}$ resolution: (a) Extrapolation, (b) Experiment. The temperature is from $300 \mathrm{~K}$ to $1000 \mathrm{~K}$, and the path length is $0.32 \mathrm{~m}$.

Figure 11: Comparison of $\mathrm{C}_{3} \mathrm{H}_{8}$ mean spectral absorption coefficient between Experiment and data calculated using eqn. (7) with fit parameters at $1 \mathrm{~cm}^{-1}$ resolution: (a) $800 \mathrm{~K}$, (b) $1000 \mathrm{~K}$. The path length is $0.32 \mathrm{~m}$.

Figure 12: Residual ( $\kappa_{\text {extrapolation }}-\kappa_{\text {experiment }}$ ) for $\mathrm{C}_{3} \mathrm{H}_{8}$ at $1000 \mathrm{~K}$. This represents the difference between the data sets shown in Figure 11. 


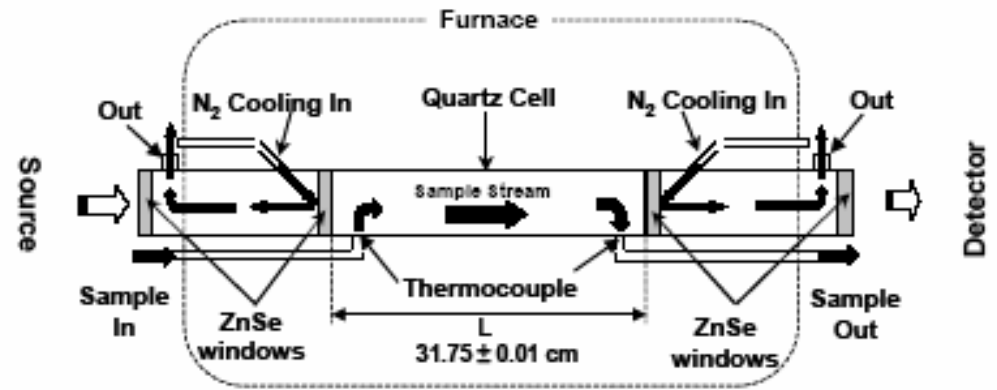

Figure 1: Diagram of experiment setup 

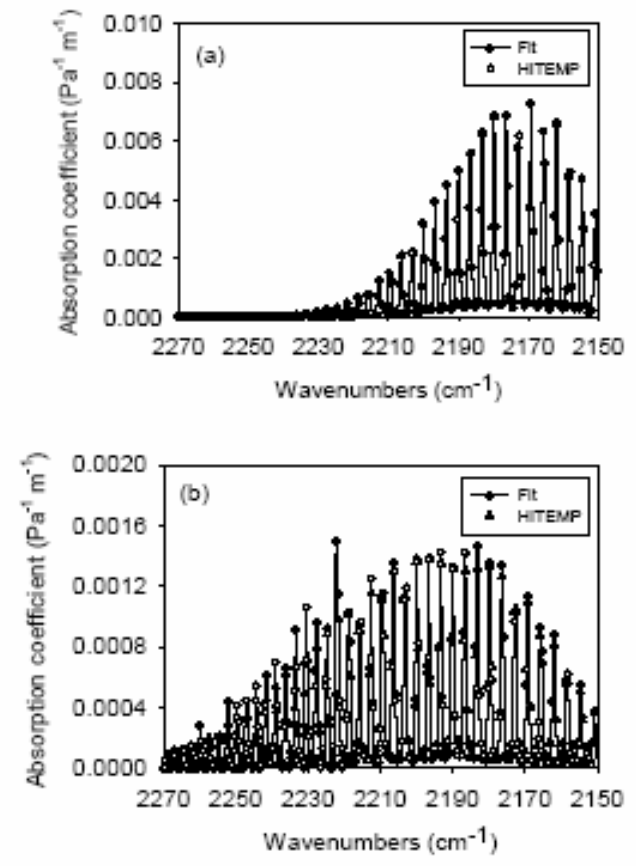

Figure 2: Comparison of $\mathrm{CO}$ spectral absorption coefficient between HITEMP and data calculated using equ. (7) with fit parameters at $1 \mathrm{~cm}^{-1}$ resolution: (a) $300 \mathrm{~K}$, (b) $1000 \mathrm{~K}$. The $\mathrm{CO}$ partial pressure is $0.101 \mathrm{kPa}$ and the path length is $0.32 \mathrm{~m}$. 


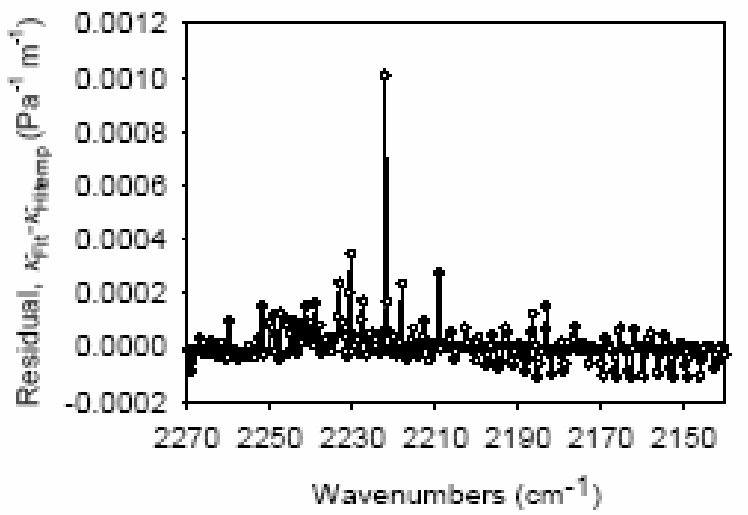

Figure 3: Residual ( $\left.\kappa_{F z}-\kappa_{\text {Filater }}\right)$ for $\mathrm{CO}$ at $1000 \mathrm{~K}$

This represents the difference between the data sets shown in Figure 2 . 

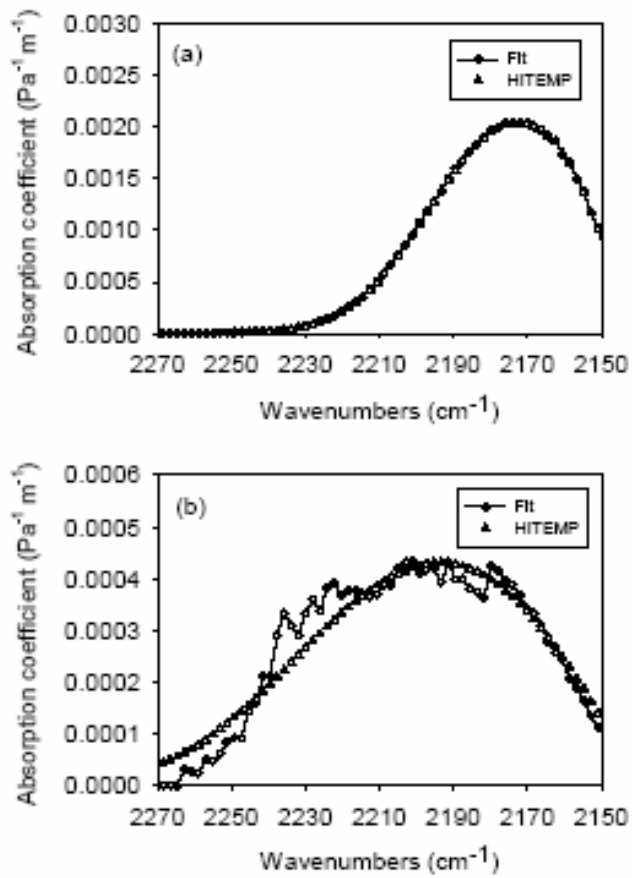

Figure 4: Comparison of $\mathrm{CO}$ spectral absorption coefficient between HITEMP and data calculated using equ. (7) with fit parameter at $4 \mathrm{~cm}^{-1}$ resolution: (a) $300 \mathrm{~K}$, (b) $1000 \mathrm{~K}$. The $C O$ partial pressure is $0.101 \mathrm{kPa}$ and the path length is $0.32 \mathrm{~m}$. 

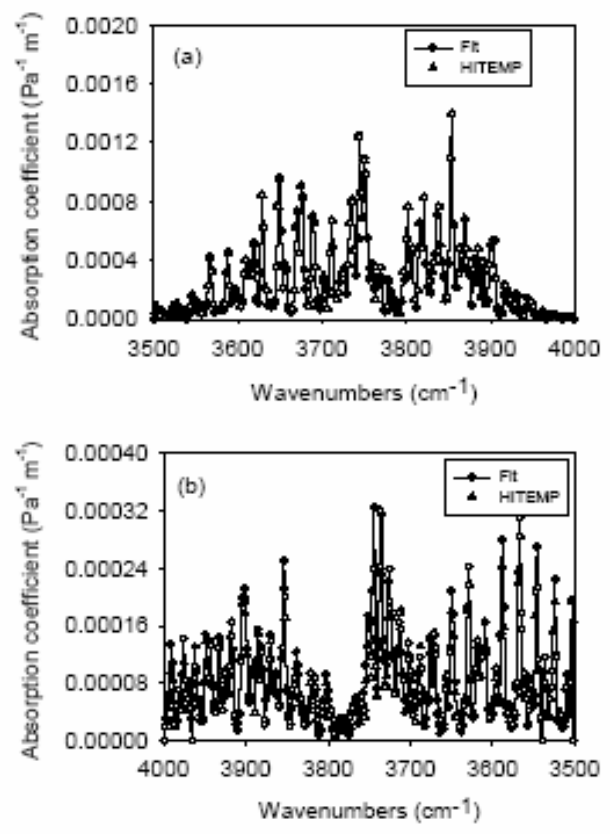

Figure 5: Comparison of water vapor spectral absorption coefficient between HITEMP and data calculated using eqn. (7) with fit parameters at lem- resolution: (a) $300 \mathrm{~K}$, (b) $1000 \mathrm{~K}$. The $\mathrm{H}_{2} \mathrm{O}$ partial pressure is $1.01 \mathrm{kPa}$ and the path length is $0.32 \mathrm{~m}$. 


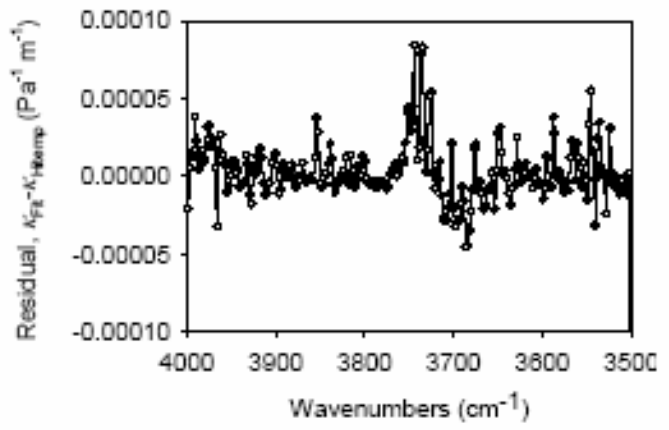

Figure 6: Residual ( $\kappa_{\text {prt }}-\mathrm{N}_{\text {hitapip }}$ ) for $\mathrm{H}_{2} \mathrm{O}$ at $1000 \mathrm{~K}$. This represents the difference between the data sets shown in Figure 5 . 

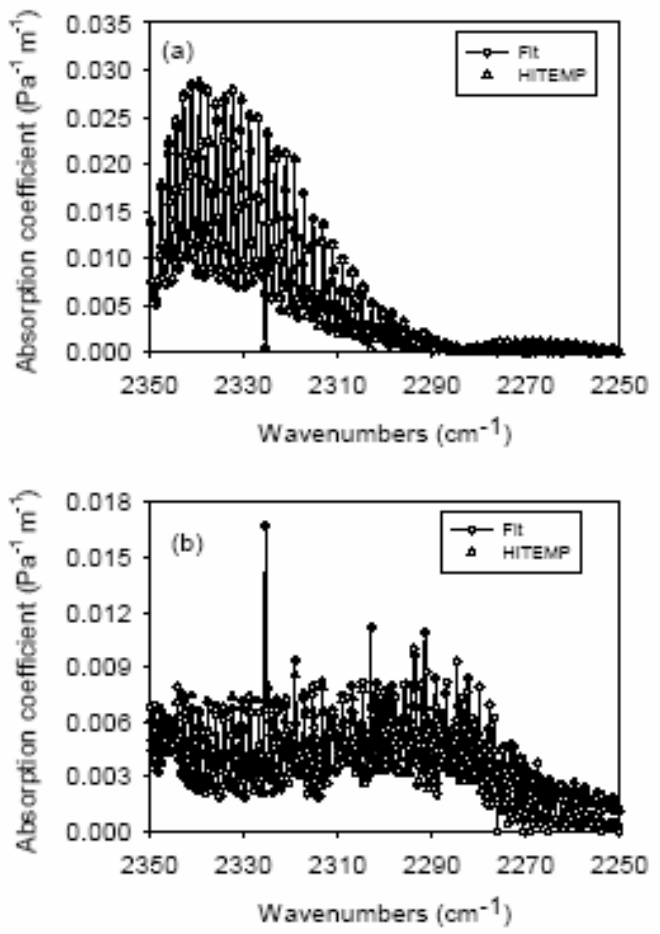

Figure 7: Comparison of $\mathrm{CO}_{2}$ spectral absorption coefficient at $300 \mathrm{~K}$ between HITEMP and data calculated using egn. (7) with fit parameters at $0.5 \mathrm{~cm}^{-1}$ resolution: (a) $300 \mathrm{~K}$, (b) $1000 \mathrm{~K}$. The $\mathrm{CO}_{2}$ partial pressure is $0.341 \mathrm{kPa}$ and the path length is $0.32 \mathrm{~m}$ 


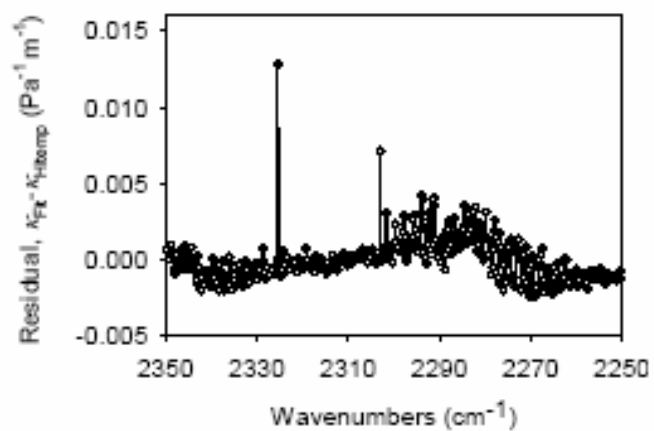

Figure 8: Residual ( $\kappa_{\overline{7 t}}-\kappa_{\text {fritemp }}$ ) for $\mathrm{CO}_{2}$ at $1000 \mathrm{~K}$. This represents the difference between the data sets shown in Figure 7. 

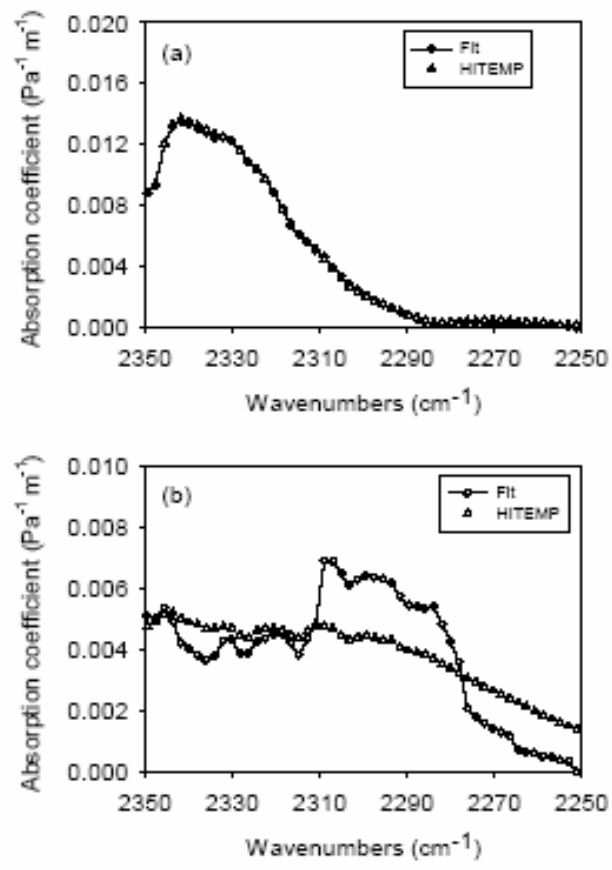

Figure 9: Comparison of $\mathrm{CO}_{2}$ spectral absorption coefficient at $1000 \mathrm{~K}$ between HITEMP and data calculated using eon (7) with fit parameters at $4 \mathrm{~cm}^{-1}$ resolution: (a) $300 \mathrm{~K}$, (b) $1000 \mathrm{~K}$. The $\mathrm{CO}_{2}$ partial pressure is $0.341 \mathrm{kPa}$ and the path length is $0.32 \mathrm{~m}$ 

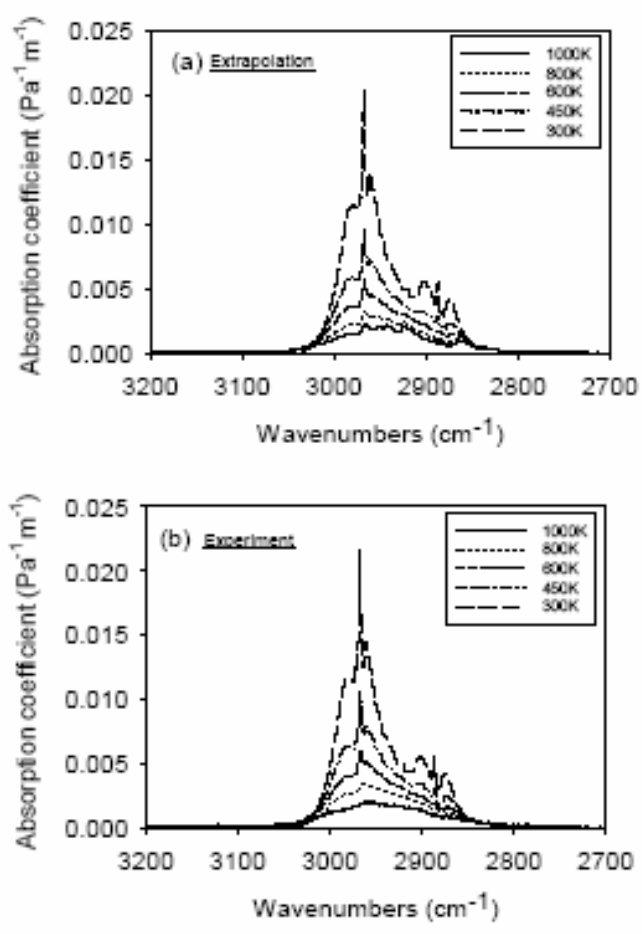

Figure 10: Comparison of $\mathrm{C}_{3} \mathrm{H}_{8}$ mean spectral absorption coefficient at $1000 \mathrm{~K}$ between experiment and data calculated using equ. (7) with fit parameters at $\mathrm{l} \mathrm{cm}^{-1}$ resolution: (a) Extrapolation, (b) Experiment. The temperature is from $300 \mathrm{~K}$ to $1000 \mathrm{~K}$, and the path length is $0.32 \mathrm{~m}$ 

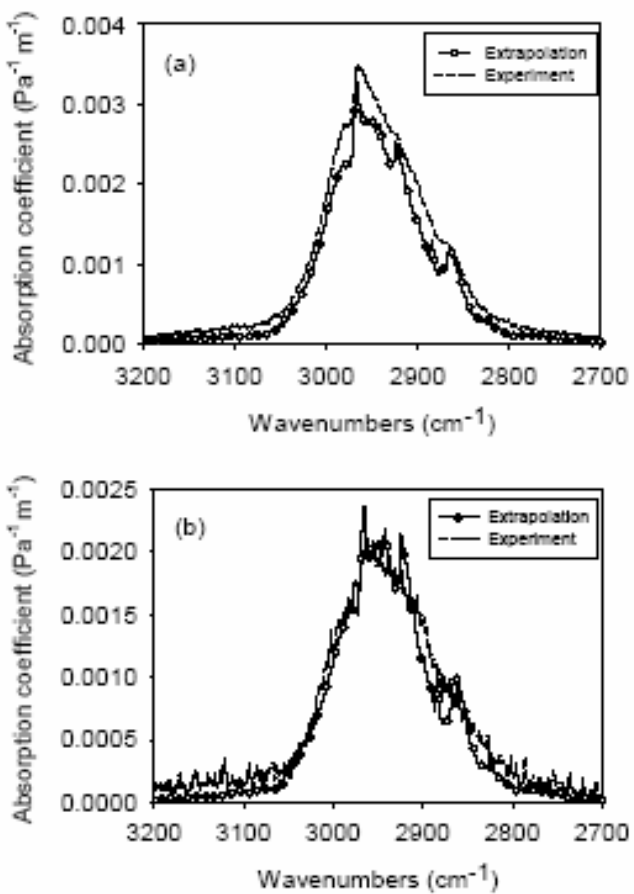

Figure 11: Comparison of $\mathrm{C}_{2} \mathrm{H}_{8}$ mean spectral absorption coefficient between experiment and data calculated using eqn. (7) with fit parameters at $1 \mathrm{~cm}^{-1}$ resolution: (a) $800 \mathrm{~K}$, (b) $1000 \mathrm{~K}$. The path length is $0.32 \mathrm{~m}$. 


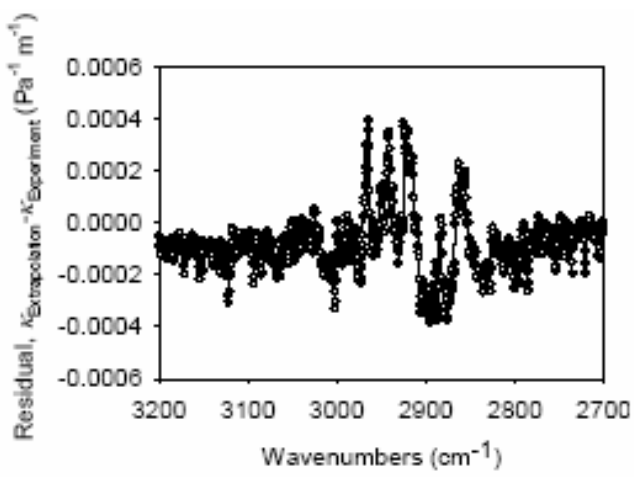

Figure 12: Residual ( $\kappa_{\text {expositian }}-\kappa_{\text {experinan }}$ ) for $\mathrm{C}_{3} \mathrm{H}_{8}$ at $1000 \mathrm{~K}$. This represents the difference between the data sets shown in Figure 11. 


\title{
Appendix 6 \\ Determination of Planck Mean Absorption Coefficients for $\mathrm{CF}_{3} \mathrm{Br}$
}

\begin{abstract}
The Planck mean absorption coefficient, $\mathrm{a}_{\mathrm{p}}$, has been calculated for $\mathrm{CF}_{3} \mathrm{Br}$ over a temperature range from $295 \mathrm{~K}-675 \mathrm{~K}$ using data obtained through measurements. A plot of $\mathrm{a}_{\mathrm{p}}$ vs. temperature showed monotonically decreasing behavior over this temperature range. The magnitude of the $\mathrm{a}_{\mathrm{p}}$ values suggests that $\mathrm{CF}_{3} \mathrm{Br}$ can significantly impact calculations of radiative transfer in flames containing this species. Consideration of conditions in an inhibited heptane flame are consistent with this conclusion.
\end{abstract}

\section{Nomenclature}

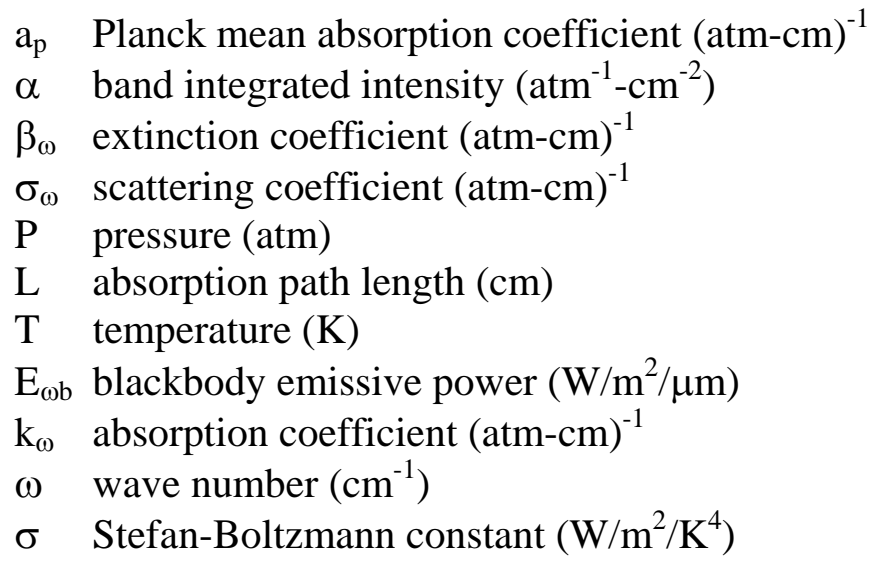




\section{Introduction}

In large-scale fires, radiation is the dominant mode of heat transfer [1]. In nonsooting and moderately sooting fires, the participation of heated gases and soot, through absorption and emission of infrared radiation, plays a significant role in radiative exchange. The Planck mean absorption coefficient, $\mathrm{a}_{\mathrm{p}}$, characterizes radiative emission in the source term of the generalized energy equation for an absorbing/emitting (nonscattering) medium [2]. Because it is a function only of the local temperature, $a_{p}$ can be conveniently tabulated and efficiently used in complex radiative heat transfer calculations, avoiding consideration of wavelength dependence. The Planck mean absorption coefficient, $\mathrm{a}_{\mathrm{p}}$, is defined as:

$$
a_{p}=\frac{\int_{\Delta \omega} \kappa_{\omega} E_{\omega, b} d \omega}{\sigma T^{4}}
$$

To calculate $a_{p}$ from Eq. (1), the spectral absorption coefficient, $\kappa_{\omega}$, for a gas or gas mixture, is needed as a function of temperature. In the more general case of a scattering medium the absorption coefficient is replaced by the extinction coefficient, $\beta_{\omega}$ :

$$
\beta_{\omega}=\kappa_{\omega}+\sigma_{\omega}
$$

where $\sigma_{\omega}$ is the scattering coefficient. However, for a gas, scattering is typically neglected and the extinction coefficient is equivalent to the absorption coefficient. The radiative properties, including $\kappa_{\omega}$, of molecular combustion species such as $\mathrm{H}_{2} \mathrm{O}, \mathrm{CO}_{2}$, and CO have been relatively well characterized. A narrow band model (RADCAL) was developed which evaluates Eq. (1) for relevant combustion species including $\mathrm{CO}_{2}, \mathrm{H}_{2} \mathrm{O}$, $\mathrm{CO}, \mathrm{CH}_{4}$ and soot [3]. 
Alternatively, Abu-Romia and Tien [4] presented a method for calculating $\mathrm{a}_{\mathrm{p}}$ that is based on a simplified narrow band approach. This approach utilizes the integrated intensity of individual gas bands that can be determined independently and tabulated. According to this method $\mathrm{a}_{\mathrm{p}}$ can be calculated from:

$$
a_{p}=\frac{\int_{0}^{\infty} \kappa_{\omega} E_{\omega, b} d \omega}{\sigma T^{4}}=\sum_{j} \frac{\overline{E_{b, j}} \alpha_{j}}{\sigma T^{4}} .
$$

In this expression, the summation is over any bands that make a significant contribution to the absorption coefficient. The approximation is made that the blackbody emissive power varies linearly across each absorption band so that the value evaluated at the band center, $\left(\overline{E_{b, j}}\right)$, can be used. The only required parameter is the temperature dependent integrated intensity, $\alpha_{\mathrm{j}}$, which characterizes absorption for each band. This method has the advantage that it is easily implemented for cases in which the integrated intensity is a known function of temperature. Tien [5] presented results based on this model for $\mathrm{CO}_{2}$, $\mathrm{H}_{2} \mathrm{O}, \mathrm{N}_{2} \mathrm{O}, \mathrm{NH}_{3}, \mathrm{SO}_{2}, \mathrm{CH}_{4}, \mathrm{CO}$ and NO. Grosshandler and Thurlow [6] extended this method to derive an expression for $a_{p}$ based on the equivalence ratio for flames burning $\mathrm{H}_{2}$, $\mathrm{CO}, \mathrm{CH}_{3} \mathrm{OH}$ and $\mathrm{CH}_{4}$ in air, and lean regions of other generic flames.

Although the production of $\mathrm{CF}_{3} \mathrm{Br}$ (Halon 1301) has been halted due to its adverse effects on stratospheric ozone, it is still widely used as a fire suppressant. This agent inhibits flames primarily through chemical effects. Heat loss to the surroundings by radiative emission, however, can also influence extinction. Radiation can be particularly significant in weakly strained flames [7]. Therefore, it is important to characterize the 
radiative properties of $\mathrm{HF}$ and $\mathrm{HBr}$ so that flame emission can be modeled more accurately.

Radiative transfer involving species such as $\mathrm{CF}_{3} \mathrm{Br}$ has not been studied extensively, although results for $\mathrm{HBr}$ and $\mathrm{HF}$ are available [8]. $\mathrm{HBr}$ and $\mathrm{HF}$ are prevalent in flames and fires inhibited by $\mathrm{CF}_{3} \mathrm{Br}$ (and related halogenated compounds). They may also be present in incinerators. These are difficult species to study experimentally due to their corrosive nature. Halogenated compounds such as $\mathrm{CF}_{3} \mathrm{Br}$ are widely used as fire suppression agents. Measurements have shown that the local $\mathrm{CF}_{3} \mathrm{Br}$ volume fraction in near-extinction $\mathrm{CF}_{3} \mathrm{Br}$-inhibited heptane/air counterflow flames can be significant, even in the high temperature reaction zone [9]. Seshadri, for example, measured volume fractions larger than 0.02 in such flames.

The Planck mean absorption coefficient can be used to characterize radiative emission from gases of any optical thickness [2] and is thus a useful parameter, particularly since it can be determined a priori. The aim of this study was to calculate $a_{p}$ for $\mathrm{CF}_{3} \mathrm{Br}$ for use in simplified flame models [e.g., 10] using spectral data determined at NIST.

\section{Experiment}

A FTIR spectrometer was modified so that the IR beam from a globar source passes through the interferometer but is then diverted outside the spectrometer, bypassing the standard sample compartment and detector. The IR beam travels along the axis of a quartz flow cell, which is located inside a tube furnace, and onto an external Mercury Cadmium Telluride (MCT) detector. A diagram of the experimental setup is shown in 
Figure 1. The entire optical path, including the spectrometer and external detector chamber was purged with $\mathrm{N}_{2}(99.5 \%$ Super Dry) to eliminate absorption from ambient water vapor and $\mathrm{CO}_{2}$. The interferometer is equipped with corner-cube optics. This arrangement minimizes the effect of sample emission on the transmission measurements. This was confirmed by measuring negligible emission (with the source blocked) from the cell heated to $1000 \mathrm{~K}$ and filled with propane gas. The furnace has three heating zones designed to maintain a uniform temperature over the full length $(31.75 \pm 0.01 \mathrm{~cm})$ of the cell (inner diameter $=2.54 \mathrm{~cm}$ ). The gas temperatures were measured with K-type thermocouples at the inlet and outlet of the cell. The temperature difference between two thermocouples was typically about $5 \mathrm{~K}$, which was considered acceptable for the purposes of this investigation. The ends of the quartz cell were sealed with Zinc Selenide (ZnSe) laser grade windows $(0.3 \mathrm{~cm}$ thickness). The temperature of the windows was kept below $700 \mathrm{~K}$ to prevent oxidation of the ZnSe. The pressure inside of the cell was monitored and regulated to maintain $101.3 \mathrm{kPa}$ during the measurements. Mixtures of $\mathrm{CF}_{3} \mathrm{Br}$ (CP Grade, Matheson) in $\mathrm{N}_{2}(99.5 \%$ Super Dry) were made by regulating the flow of these gases into the cell using mass flow controllers (20 sccm for $\mathrm{CF}_{3} \mathrm{Br}$ and 1000 sccm for $\mathrm{N}_{2}$ ). Experimental measurements were performed at ambient temperature (295 K), 375 K, 475 K, 575 K and 675 K. The measurements were limited to temperatures below $700 \mathrm{~K}$ because of thermal restrictions on the windows. The absorption spectra were measured at $4 \mathrm{~cm}^{-1}$ and $16 \mathrm{~cm}^{-1}$ resolution and signal averaged over 128 or 256 scans. 


\section{Methodology}

Planck mean absorption coefficients were calculated according to Eqn. (3). The integrated intensity, $\alpha$, was determined by integrating the spectral absorption coefficient for each band and taking value in the optically thin limit according to:

$$
\alpha=\lim _{p L \rightarrow 0} \int_{\Delta \omega} \boldsymbol{K}_{\omega} d \omega
$$

This procedure was carried out for measurements at $295 \mathrm{~K}, 375 \mathrm{~K}, 475 \mathrm{~K}, 575 \mathrm{~K}$, and $675 \mathrm{~K}$.

\section{Results}

Table 1 shows the Planck mean absorption coefficient for $\mathrm{CF}_{3} \mathrm{Br}$ calculated over a temperature range from $295 \mathrm{~K}-675 \mathrm{~K}$. The values of $\mathrm{a}_{\mathrm{p}}$ are significantly larger than those of $\mathrm{HF}, \mathrm{HBr}$, and $\mathrm{HCl}$ over this temperature range [8], although the general trend of monotonic decrease with increasing temperature is similar to these species. At $295 \mathrm{~K}$, the Planck mean absorption coefficient for $\mathrm{CF}_{3} \mathrm{Br}$ is 2.64 (atm-cm) $)^{-1}$. The values for HF, $\mathrm{HCl}$ and $\mathrm{HBr}$ are, respectively, 0.46, 0.05, and $0.02(\mathrm{~atm}-\mathrm{cm})^{-1}$. The reason for this difference is the relatively large absorption coefficient possessed by $\mathrm{CF}_{3} \mathrm{Br}$ as compared to the other molecules. Figure 2 shows a plot of the spectral transmittance for $\mathrm{CF}_{3} \mathrm{Br}$ for the conditions $\mathrm{T}=295 \mathrm{~K}, \mathrm{pL}=0.031 \mathrm{~atm}-\mathrm{cm}$.

In $\mathrm{CF}_{3} \mathrm{Br}$ inhibited flames, Seshadri [9] and Masri [11] report that the volume fraction of $\mathrm{CF}_{3} \mathrm{Br}$ is comparable to that of $\mathrm{CO}$ in the high temperature reaction zone. For a flame with the $\mathrm{CF}_{3} \mathrm{Br}$ suppressant added to the air stream of a diffusion flame, the 
concentrations of $\mathrm{CO}_{2}, \mathrm{H}_{2} \mathrm{O}$, and $\mathrm{CO}$ will fall as a function of distance from the high temperature reaction zone, and $\mathrm{CF}_{3} \mathrm{Br}$ will be larger than any other species that participates in radiative exchange [9]. In cool flame regions, $\mathrm{CF}_{3} \mathrm{Br}$ may absorb flame radiation, and block its emission to the surroundings. The inclusion of $\mathrm{CF}_{3} \mathrm{Br}$ in radiative emission calculations of $\mathrm{CF}_{3} \mathrm{Br}$ inhibited hydrocarbon flames may be significant and ought to be considered, depending on the combustion configuration.

To estimate the impact of $\mathrm{CF}_{3} \mathrm{Br}$ in the cool flame region, a $\mathrm{CF}_{3} \mathrm{Br}$ inhibited heptane/air counterflow flame [9] was considered. The results showed that, for optically thin conditions, $\mathrm{CF}_{3} \mathrm{Br}$ was found to account for approximately $80 \%$ of the total emission in the region approximately $1.5 \mathrm{~mm}$ from the reaction zone where the temperature is $675 \mathrm{~K}$. In Ref. [9], data are not available for $\mathrm{CF}_{3} \mathrm{Br}$ closer to the reaction zone (corresponding to a temperature of $1300^{\circ} \mathrm{C}$ ). Yet, $\mathrm{a}_{\mathrm{p}}$ values for all relevant species tend to decrease with increasing temperature. While the data in Ref. [9] show that $\mathrm{CF}_{3} \mathrm{Br}$ has a relatively small concentration in the reaction zone, given the magnitude of its Planck coefficient relative to other flame species considered here $\left(\mathrm{CH}_{4}, \mathrm{CO}_{2}, \mathrm{H}_{2} \mathrm{O}\right.$, and $\left.\mathrm{CO}\right)$, it is expected to plays a significant role in the total radiative emission even at higher temperatures.

\section{Conclusions}

Values of the Planck mean absorption coefficient have been calculated for $\mathrm{CF}_{3} \mathrm{Br}$ based on FTIR data over a temperature range from ambient to $700 \mathrm{~K}$. The temperature dependent values of $a_{p}$ fall off with temperature not unlike $\mathrm{HBr}$ and $\mathrm{HF}$. The inclusion of $\mathrm{CF}_{3} \mathrm{Br}, \mathrm{HBr}$ and $\mathrm{HF}$, can significantly contribute to emission calculations for fire suppression or incinerator scenarios where halogenated compounds are present. 


\section{References}

[1] DeRis, J., 1979, “Fire Radiation-A Review,” Proc. 17th Sym (Int) Combust, The Combustion Institute, pp. 1003-1015.

[2] Siegel, R., and Howell, J.R., 1992, Thermal Radiation Heat Transfer, Hemisphere Publishing, Washington.

[3] Grosshandler, W.L., 1993, "RADCAL: A Narrow-Band Model for Radiation Calculations in a Combustion Environment,” NIST Technical Note 1402, National Institute of Standards and Technology, Gaithersburg MD.

[4] Abu-Romia, M.M., and Tien, C.L., 1967, “Appropriate Mean Absorption Coefficients for Infrared Radiation of Gases,” ASME Journal of Heat Transfer, 89, pp. 321-327.

[5] Tien, C.L., 1968, “Thermal Radiation Properties of Gases,” Advances in Heat Transfer, Irvine, T.F., and Hartnett, J.P., eds., Academic Press, New York, 5, pp. 253-324.

[6] Grosshandler, W.L., and Thurlow, E.M., 1992, "Generalized State-Property Relations for Nonluminous Flame Absorption Coefficients,” ASME Journal of Heat Transfer, 114, pp. 243-249.

[7] Maruta, K., Masaharu, Y., Hongsheng, G., Yiguang, J., and Niioka, T., 1998, "Extinction of Low-Stretched Diffusion Flame in Microgravity,” Combust Flame, 112, pp. 181-187.

[8] Fuss, S.P., and Hamins, A., Determination of Planck Mean Absorption Coefficients for HBr, HCl, and HF, ASME J. Heat Transfer, 124, 26-30 (2002).

[9] Seshadri, K. and Williams, F.A., Halogenated Fire Suppressants. ACS Symposium Series 16. April 23-24, 1975, San Antonio, TX, American Chemical Society, Washington DC, (Ed.: R.G. Gann) pp. 149-182, 1975.

[10] Choi, M.Y., Hamins, A., Rushmeier, H., and Kashiwagi, T., "Simultaneous Optical Measurement of Soot Volume Fraction, Temperature, and $\mathrm{CO}_{2}$ in Heptane Pool Fire,” Proc. 25th Sym (Int) Combust, The Combustion Institute, pp. 1471-1480, 1994.

[11] Masri, A.R., 1994, "Chemical Inhibition of Nonpremixed Flames of Hydrocarbon Fuels with $\mathrm{CF}_{3} \mathrm{Br}$,” Combust Sc Tech, 96, pp. 189-212. 
Table 1. Calculated values of Planck mean absorption coefficient for $\mathrm{CF}_{3} \mathrm{Br}$

\begin{tabular}{|l|c|}
\hline $\mathrm{T}(\mathrm{K})$ & $\begin{array}{c}\text { Planck mean } \\
\text { absorption coefficient } \\
\text { (atm-cm) }^{-1}\end{array}$ \\
\hline 295 & 2.64 \\
\hline 375 & 2.59 \\
\hline 475 & 2.18 \\
\hline 575 & 1.80 \\
\hline 675 & 1.43 \\
\hline
\end{tabular}




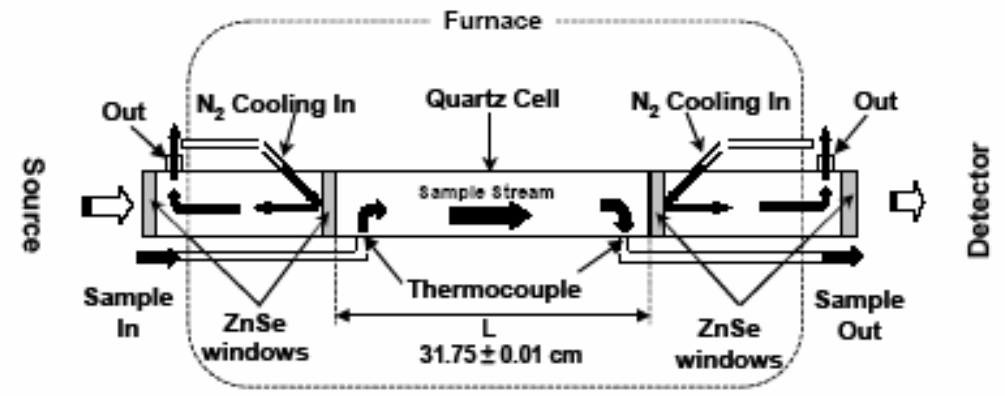

Figure 1: Diagram of experiment setup

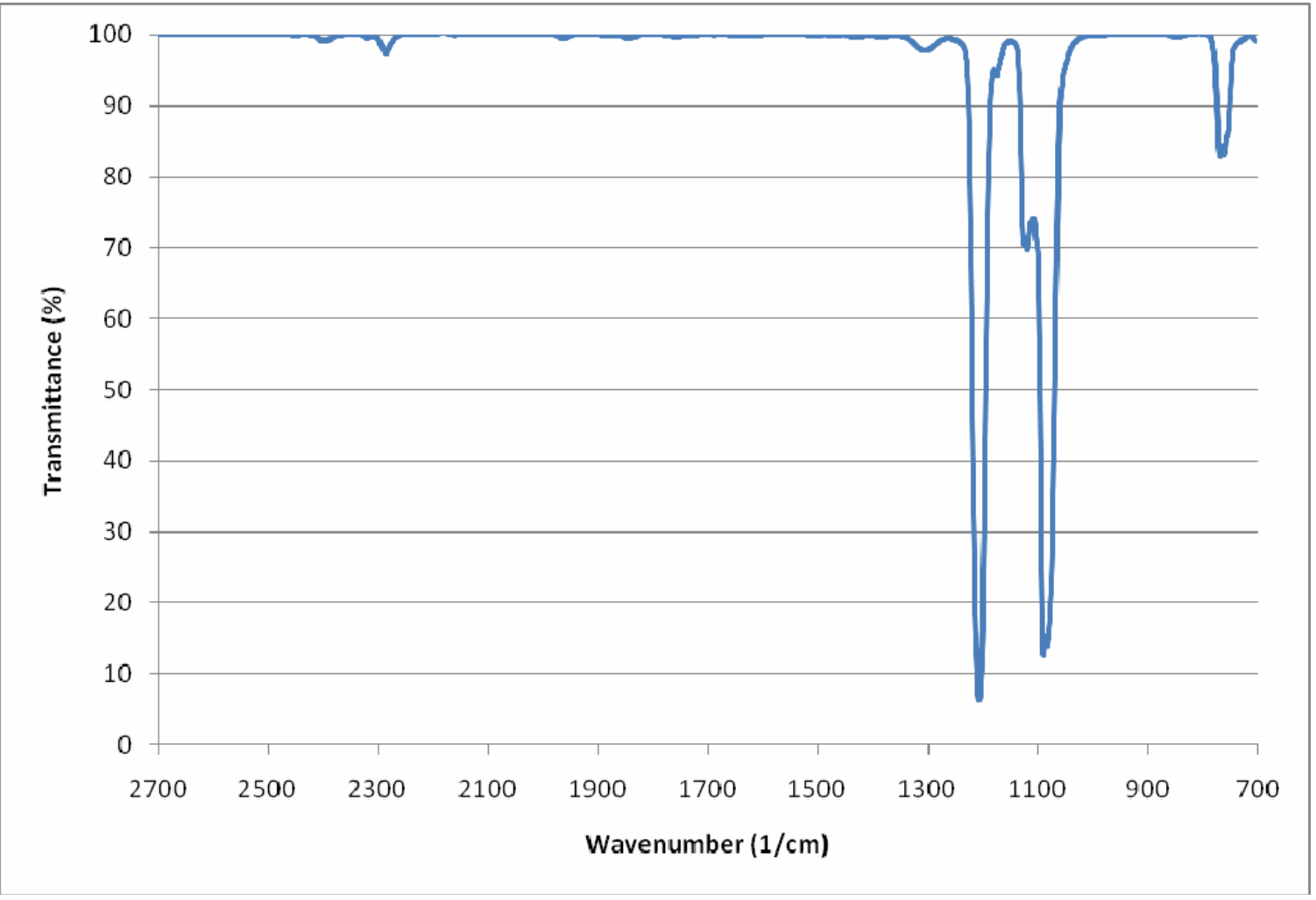

Figure 2: Transmittance spectrum of $\mathrm{CF}_{3} \mathrm{Br}$ at $\mathrm{T}=295 \mathrm{~K}, \mathrm{pL}=0.031 \mathrm{~atm}-\mathrm{cm}$. 


\title{
Appendix 7
}

\section{Determination of Planck Mean Absorption Coefficients for Hydrocarbon Fuels}

\begin{abstract}
Infrared absorption of propane, n-heptane and propylene were measured using Fourier transform infrared spectroscopy (FTIR) for temperatures $\leq 1000 \mathrm{~K}$ to facilitate calculation of absorption coefficients of fuel molecules in non-premixed flames. Spectrally resolved fits of the absorption coefficient data using a semi-empirical quantum-based expression provide a basis for calculating infrared spectra at any temperature. Planck mean absorption coefficients of these fuels and of methane calculated from the HITRAN database are compared since methane absorption has been used to model fuel species absorption in fires. Propane and heptane have similar characteristics over the entire temperature range whereas methane and propylene with their higher proportion of absorption in low frequency bands have peak mean absorption coefficients at lower temperatures where blackbody radiation peaks near the spectral range of these bands. Propylene with low frequency absorption bands associated with the $\mathrm{C}=\mathrm{C}$ bond has the highest Planck mean absorption coefficient at temperatures $<600 \mathrm{~K}$. N-heptane has the largest Planck mean absorption at temperatures $\geq 800 \mathrm{~K}$ where blackbody emissions peak near or above the spectral range of the $\mathrm{C}-\mathrm{H}$ stretching bands. Implications of these results on fuel absorption of radiative heat transfer in large flames are discussed.
\end{abstract}




\section{INTRODUCTION}

The energy required to volatilize solid and liquid fuels in fires is transported by conduction, convection and radiation. With small fires less than $0.1 \mathrm{~m}$ in base diameter, conduction dominates the heat transfer to the fuel source, while convection tends to dominate in fires with diameters between 0.1 and $0.3 \mathrm{~m}$. Above about $0.3 \mathrm{~m}$, radiation heat transfer is typically the largest source of heat feedback to the fuel source (Burgess and Hertzberg 1974). Because of the dominance of radiation for large fires, an accurate assessment of radiation absorption within the fuel rich core of the fire becomes imperative for assessing heat feedback to the fuel source.

For large fires, radiation dominates external heat transfer to the surrounding as well as internal heat transfer to the fuel source. Hamins et al. reported that radiation heat transfer provides $96 \%, 80 \%$, and $55 \%$ of the total heat feedback to the fuel source for $0.3 \mathrm{~m}$ diameter pool fires of toluene, n-heptane and methanol respectively (Hamins et al. 1994). Furthermore, because external heat transfer from large fires is typically dominated by radiation, assessment of fire damage depends on accurate models of radiative heat transfer emitted from fires, which in turn depends on the flame temperature. Flame temperature will be impacted by radiative absorption by both soot and the hydrocarbon-rich core between the fuel surface and the flame. Since the incident radiative heat flux controls fuel volatilization in fires, accurate assessment of the effects of gaseous fuel and fuel-derived molecules on radiative exchange in the fuel-rich core is needed.

In most previous studies, combustion products such as carbon dioxide $\left(\mathrm{CO}_{2}\right)$, water vapor $\left(\mathrm{H}_{2} \mathrm{O}\right)$, carbon monoxide $(\mathrm{CO})$ and soot have been the focus of radiative transport (Buckius and Tien 1977; Lee and Tien 1980; Ludwig et al. 1973). Studies on the radiative absorption of these molecules have provided absorption coefficients over a broad range of temperatures, and one can 
obtain this data through HITRAN (Rothman et al. 2005b). To include contributions of fuels and other fuel decomposition products to radiative transport in fires, absorption coefficients for these molecules must be measured over a broad range of temperatures characteristic of the fuel rich core, from 300 to $1000 \mathrm{~K}$ (Brosmer and Tien 1987; Klassen and Gore 1994).

Many studies incorporating radiative transport in fires or combustion utilize a gray gas assumption to calculate radiation attenuation. The gray gas emissivity approximation is often based on empirical fits to external radiation intensity measurements, e.g., in fires of volatilized plastics (Markstein 1979). The effective emissivity and corresponding absorptivity will vary significantly with flame temperature particularly for sooty flames and will further depend on how close the peak of the broadband flame emissions falls relative to the strong absorption bands of the vaporized fuel molecules (De Ris 1979). To date, only a few studies have attempted to provide data for assessing the temperature dependent absorption coefficients of fuel molecules at temperatures as high as $1000 \mathrm{~K}$. Notable studies in this area include the work of Tien and coworkers on hydrocarbon fuels and methyl-methacrylate (Brosmer and Tien 1985a; Brosmer and Tien 1985b; Brosmer and Tien 1986; Park et al. 1988), and Fuss et al. on paraffin hydrocarbons and acid gases (Fuss et al. 1996; Fuss et al. 1999; Fuss and Hamins 2002). Difficulties in measuring spectrally resolved infrared absorption coefficients at high temperature arise because of the temperature limitations of most infrared window materials and issues associated with high temperature vacuum seals.

This study has been undertaken to build a database for absorption coefficients for several hydrocarbon molecules for temperatures up to $1000 \mathrm{~K}$. Infrared absorption coefficients of the hydrocarbons propane $\left(\mathrm{C}_{3} \mathrm{H}_{8}\right)$, n-heptane $\left(\mathrm{C}_{7} \mathrm{H}_{16}\right)$, and propylene $\left(\mathrm{C}_{3} \mathrm{H}_{6}\right)$ were measured by Fourier transform infrared spectrometer (FTIR) in a unique experimental facility for 
measurements to $1000 \mathrm{~K}$. These measurements are analyzed and compared to existing data for methane $\left(\mathrm{CH}_{4}\right)$ obtained from the HITRAN database (Rothman et al. 2005a).

The intensity of thermal radiation from flames is diminished by absorption and augmented by emission as it travels through the atmosphere of a fire. The emissivity of the participating medium is given in terms of the Planck mean absorption coefficient $\kappa_{P}$ as a function of temperature $T . \kappa_{P}(T)$ is expressed as an integral of the product of the spectral absorption coefficient $\kappa_{\imath}(T)$ and the blackbody Planck function $E_{b \downarrow}(T)$ over all wavenumbers $v$ (Siegel and Howell 1992):

$$
\kappa_{P}(T)=\frac{1}{\sigma T^{4}} \int_{0}^{\infty} \kappa_{v} \frac{C_{1} v^{3}}{\exp \left(\frac{C_{2} v}{T}\right)-1} d v
$$

where $C_{1}, C_{2}$ and $\sigma$ are the first and second radiation constants and the Stefan-Boltzmann constant, respectively. Since $\kappa_{P}$ is a function only of $T$, it can be easily presented in tabular form (Zhang and Modest 2002). Approximate values are obtained by numerical integration and the accuracy increases with the resolution of the spectral measurements. Accurate Planck mean absorption coefficients are important in combustion and fire modeling for solution of radiative transport equation without employing computationally-prohibitive, spectrally-resolved calculations. However, use of the Planck mean absorption coefficient approach is limited by the scarcity of temperature dependent data. In this paper, $\kappa_{P}$ for $n$-heptane, propane, propylene, and methane are calculated for a range of conditions and the impact of hydrocarbon radiative absorption in large-scale fires is discussed.

\section{EXPERIMENTAL APPARATUS}


A Mattson Galaxy $7020^{*}$ FTIR spectrometer was modified such that the IR beam from a globar source passed through the interferometer and was diverted to bypass the standard sample compartment and detector and to travel along the axis of a quartz flow cell. The flow cell was located inside a three-zone tube furnace, and the IR beam passed through the cell into an external Mercury Cadmium Telluride (MCT) detector (MI0465, Graseby Infrared). Absorption spectra were measured at $1 \mathrm{~cm}^{-1}$ resolution with the signal averaged over 128 scans. A diagram of the experimental setup is shown in Figure 1a.

The entire optical path, including the spectrometer and external detector chamber was purged with $\mathrm{N}_{2}\left(99.995 \%\right.$ min. purity) to eliminate absorption from ambient water vapor and $\mathrm{CO}_{2}$. The interferometer was equipped with corner-cube optics which minimized the effect of sample emission on the transmission measurements (Tripp and McFarlane 1994). This was confirmed by measuring the emission with the source blocked from the heated $(1000 \mathrm{~K})$ cell containing propane gas, which was found to be negligible. The furnace (Lindberg/Blue M HTF53347C) had three heating zones designed to maintain a uniform temperature over the full length (31.75 \pm $0.01 \mathrm{~cm})$ of the cell $($ inner diameter $=2.54 \mathrm{~cm})$. Gas temperatures were measured with K-type thermocouples at the inlet and outlet of the cell. The temperature difference between two thermocouples was typically about $5 \mathrm{~K}$, which was considered acceptable for the purposes of this investigation. The ends of the quartz cell were sealed with zinc selenide $(\mathrm{ZnSe})$ laser grade windows $(0.3 \mathrm{~cm}$ thickness $)$. To prevent oxidation of the $\mathrm{ZnSe}$, the temperature of the windows was kept below $700 \mathrm{~K}$ by directing a jet of $\mathrm{N}_{2}$ on the outside of the windows as indicated in Figure 1a. This cooling permitted high-resolution infrared measurement at high temperature

\footnotetext{
${ }^{*}$ Certain commercial equipment, materials, or software are identified in this manuscript to specify adequately the nature of the research. Such identification does not imply recommendation or endorsement by the National Institute of Standards and Technology, nor does it imply that the materials or equipment are necessarily the best available for the purpose.
} 
with many scans. The pressure inside of the cell was monitored and regulated to maintain 101 $\mathrm{kPa} \pm 1 \mathrm{kPa}$ during the measurements. Mixtures containing volume fraction of 1000,2500 , and 4000 ppmv of propane ( $99 \%$ min. purity) in $\mathrm{N}_{2}(99.995 \%$ min. purity), and 5000,10000 , and 15000 ppmv of propylene ( $99 \%$ min. purity) in $\mathrm{N}_{2}(99.995 \%$ min. purity) were passed through the cell using mass flow controllers (MKS 1479A), which had a $\pm 0.5 \%$ uncertainty for the range of flows in the current study.

For n-heptane ( $99.0 \%$ min. purity), a mass flow controller (F.S. $20 \mathrm{~cm}^{3} / \mathrm{min}_{2}$ ) was used to bubble $\mathrm{N}_{2}$ through three liquid heptane baths, assuring a continuous supply of saturated heptane vapor (Figure 1b) at room temperature. The n-heptane concentration was calculated based on the liquid temperature, which was measured by a K-type thermocouple within the last heptane bath. The n-heptane vapor pressure of the saturated stream was obtained using the Antoine equation with parameters obtained from a previous study (Carruth and Kobayashi 1973). Since uncertainty of the thermocouple is $\pm 0.5 \mathrm{~K}$ from our calibration, the uncertainty of the fuel concentration is $\pm 2.7 \%$. A second mass flow controller (F.S. $1000 \mathrm{~cm}^{3} / \mathrm{min}_{2}$ ) was used to dilute the heptane-saturated flow with pure $\mathrm{N}_{2}$ before introduction into the gas cell. Measurements were conducted for three heptane concentrations, which varied as shown in Table 1 due to small variations in the fuel bubbler temperature over time.

\section{METHODOLOGY}

The simplified extrapolation and interpolation technique of absorption coefficient of Wakatsuki et al. (Wakatsuki et al. 2005) was used to determine $\kappa_{v}$ as a function of $T$. This approach involves taking the full quantum expression for $\kappa_{v}$ and simplifying it to the following expression 


$$
\kappa_{v}=\frac{S_{0} v \cdot\left[1-\exp \left(-\frac{1.439 v}{T}\right)\right] \cdot \exp \left(-\frac{1.439 v_{r}}{T}\right)}{T^{n}}
$$

Equation 2 ignores some of the minor temperature dependencies of some terms in the full quantum expression by lumping them into a constant $S_{0}$, but provides a reasonable approximation to the full equation with respect to $T$. The three parameters $S_{0}, v_{r}$, and $n$ are optimized using a least squares approach to fit measured spectral absorption data such that $\kappa_{v}$ can be extrapolated and interpolated for any range of $T$. The fits do very well at capturing the falloff with $T$ of the various absorption band peaks, but have limited accuracy for the wings of strong bands where slight increases in $\kappa_{v}$ with $T$ can arise due to line broadening. However, the wings typically account for very small amounts of the total integrated $\kappa_{P}$ and thus the fitted equations provide sufficiently accurate values for $\kappa_{v}$, and for finding $\kappa_{P}$ as a function of $T$.

In the current study, $\kappa_{P}$ was determined at $50 \mathrm{~K}$ temperature increments using the fits for $S_{0}$, $v_{r}$, and $n$ at $1.0 \mathrm{~cm}^{-1}$ intervals to calculate $\kappa_{v}$ for integration in equation 1 . Infrared spectra were calculated for propane, n-heptane and propylene from 300 to $1400 \mathrm{~K}$ whereas the fits for $S_{0}, v_{r}$, and $n$ were derived from absorption measurements at 300, 400, 450, 500, and $600 \mathrm{~K}$. Earlier studies verified that the error in the integrated absorption coefficient using the extrapolation of the fits for propane to 800 and $1000 \mathrm{~K}$ for propane were $<20 \%$ in comparison to measured values (Wakatsuki et al. 2005). For lower $T$, within the range of measurements, interpolated $\kappa_{P}$ were $<10 \%$ of the measured values. The errors in the extrapolations are comparable to the experimental uncertainties reported elsewhere (Chu et al. 1999). $\kappa_{P}$ for methane was derived using the HITRAN database to obtain $\kappa_{v}$ for the same range of $T$. The same temperatures for the experimental fuels were used for methane as well. 


\section{RESULTS}

Figure 2 shows the absorption coefficient of propane at $296 \mathrm{~K}$, which illustrates typical absorption spectra for a paraffin hydrocarbon. The temperature dependent normalized blackbody spectral emissive power is also plotted as a function of wavenumber to show how characteristic bands of such fuels impact absorption of blackbody radiation at varying temperatures. Propane contains a $\mathrm{CH}_{3}$ - stretching peak centered at $2960 \mathrm{~cm}^{-1}$ and bending peaks at $1460 \mathrm{~cm}^{-1}$ and 1380 $\mathrm{cm}^{-1}$ as well as $-\mathrm{CH}_{2}$ - stretching peaks at $2930 \mathrm{~cm}^{-1}$ and $2850 \mathrm{~cm}^{-1}$, and a bending peak at 1470 $\mathrm{cm}^{-1}$. Figures $3 \mathrm{a}$ ) and $3 \mathrm{~b}$ ) show the spectral absorption coefficient of the propane stretching and bending band regions as a function of $T$. The plots show the characteristic decline with increasing $T$ in absorption coefficients near the band centers and the broadening causing a rise with increasing $T$ in spectral absorption near the edges of the band.

The location of the peak blackbody emission shifts to larger wavenumber (shorter wavelength) as $T$ increases as indicated in Figure 3. The low wavenumber absorption bending bands thus have a larger impact on emission and absorption of blackbody radiation at $\mathrm{T}<800 \mathrm{~K}$. On the other hand for $T \geq 800 \mathrm{~K}$, more characteristic of fire emissions, the higher frequency $\mathrm{C}$ - $\mathrm{H}$ stretching peaks fall nearer to the peaks of blackbody emission and thus play the dominant role in fuel-based radiative absorption.

Figure 4 shows the absorption coefficient of n-heptane at $296 \mathrm{~K}$ and the temperaturedependent normalized blackbody spectral emissive power as a function of wavenumber. As normal alkanes, propane and heptane have similar characteristic band groups $\left(\mathrm{CH}_{3^{-}}\right.$and $\left.-\mathrm{CH}_{2}-\right)$. Figure 5a) and 5b) show the spectral absorption coefficient of the $\mathrm{C}-\mathrm{H}$ bending and stretching peaks for heptane as a function of $T$. As expected, comparison of Figures 3 and 5 shows that 
heptane absorbs more radiant energy per unit mole than propane, due to the increased number of C-H bonds. Furthermore, heptane, with its increased chain length, has a reduced sharpness in the peaks compared to propane.

Figure 6 shows the absorption coefficient of propylene at $296 \mathrm{~K}$ and the temperaturedependent normalized blackbody spectral emissive power as a function of wavenumber. Propylene has several characteristic band groups such as a bending group $\left(1420 \mathrm{~cm}^{-1}\right)$, stretching of $=\mathrm{CH}_{2}\left(3080 \mathrm{~cm}^{-1}\right), \mathrm{C}-\mathrm{H}$ out of plane bending $\left(1860 \mathrm{~cm}^{-1}\right), \mathrm{C}=\mathrm{C}$ stretching $\left(1645 \mathrm{~cm}^{-1}\right)$, and $=\mathrm{CH}_{2}$ out of plane bending $\left(990 \mathrm{~cm}^{-1}\right.$ and $\left.910 \mathrm{~cm}^{-1}\right)$, in addition to a C-H stretching group (2960 $\mathrm{cm}^{-1}$ for $\mathrm{CH}_{3^{-}}$). Propylene's $=\mathrm{CH}_{2}$ out of plane bending enhances radiation absorption and emission at lower $T$. Figures $7 \mathrm{a}$ ), 7b), and 7c) show the spectral absorption coefficient of propylene $=\mathrm{CH}_{2}$ and $\mathrm{C}-\mathrm{H}$ out of plane bending peaks, and $\mathrm{C}=\mathrm{C}$ stretching, and $\mathrm{C}-\mathrm{H}$ in and out of plane bending and $=\mathrm{CH}_{2}$ stretching peaks as a function of $T$.

Figure 8 shows the Planck mean absorption coefficient for methane (obtained from HITRAN), and for propane, heptane and propylene (interpolated and extrapolated from the experimental data), as a function of temperature up to $1400 \mathrm{~K}$ in $50 \mathrm{~K}$ increments. Table 2 summarizes the fourth order polynomial fits given by Eq. 3 to the processed data.

$$
\kappa_{P}=a_{0}+a_{1} T+a_{2} T^{2}+a_{3} T^{3}+a_{4} T^{4}
$$

Figure 8 shows that propane and heptane have similar characteristics. The number of $-\mathrm{CH}_{2}-$ groups impacts the magnitude of the absorption coefficient, but it does not influence the general shape of $\kappa_{P}$ as a function of $T$. The peak of $\kappa_{P}$ for methane occurs at much lower $T$ than for the two larger alkanes due to an increased proportion of its absorption coming in the low-frequency bands. Figure 9 shows the absorption coefficient of $\mathrm{C}-\mathrm{H}$ bending peaks for methane, propane, and heptane at $296 \mathrm{~K}$. The bending motion for a methane molecule produces sharp well-defined 
peaks at $1300 \mathrm{~cm}^{-1}$, and $\kappa_{P}$ for methane is larger than propane up to about $400 \mathrm{~K}$ and similar to heptane at $300 \mathrm{~K}$ in spite of the fewer number of bonds.

Propylene has the largest $\kappa_{P}$ for $T \leq 500 \mathrm{~K}$ due to the additional contributions of $=\mathrm{CH}_{2}$ bending, but the effect of the bending band on $\kappa_{P}$ is diminished for $T>800 \mathrm{~K}$ where blackbody emissions peak well above the frequency of those bands. For $T>800 \mathrm{~K}$, propane with the two extra C-H bonds, has a slightly higher $\kappa_{P}$ than propylene since $\mathrm{t}$ he extra low frequency bands for propylene contribute very little to the blackbody radiation at these higher $T$. The results for propylene from the experiments in this paper compare very favorably with previous studies (Brosmer and Tien 1986). Since transmittance of the $\mathrm{ZnSe}$ window used in the gas cell experiments in this study rapidly falls off below $700 \mathrm{~cm}^{-1}$ (above $14.3 \mu \mathrm{m}$ ) as $T$ increases, the absorption spectrum of the low frequency $578 \mathrm{~cm}^{-1}$ band was not measurable in the current study. Brosmer and Tien calculated $\kappa_{P}$ for propylene with and without the $578 \mathrm{~cm}^{-1}$ band by approximation from the result of Lord (Lord and Venkateswarlu 1953) and Silvia (Silvia et al. 1973). They estimated the inclusion of the band gave 15,10 , and $5 \%$ of the total absorption for blackbody emissions at 300,400 , and $550 \mathrm{~K}$ respectively and rapidly dropped below $1 \%$ for higher T. $\kappa_{P}$ for propylene was corrected to include the $578 \mathrm{~cm}^{-1}$ band and results showed that the current Planck means absorption coefficient was typically $15 \%$ higher than those of the previous study for the temperatures measured.

Because the current study explored very high temperatures both experimentally and with fit extrapolations, it is important to consider how fuel pyrolysis influenced the measurements and subsequent calculations for the Planck mean absorption coefficient. Pyrolysis of the fuels of interest were calculated using the Aurora program in CHEMKIN (Kee et al. 2003) for temperatures up to $1800 \mathrm{~K}$. The detailed chemical kinetics mechanisms used for these 
calculations were taken from work by Petrova and Williams for propane and propylene (Petrova and Williams 2006) and by Seiser et al. for heptane (Seiser et al. 2000). The experimental cell conditions with the calculated residence times (ranging from $15 \mathrm{~s}$ at $300 \mathrm{~K}$ down to approximately $3 \mathrm{~s}$ at $1000 \mathrm{~K}$ ) were input into Aurora and pyrolysis of each species within the cell was calculated. Figure 10 shows results for each fuel of the volume (mole) fraction passing through the cell unreacted. Heptane is predicted to begin to have significant pyrolysis at about $900 \mathrm{~K}$ and have about $77 \%$ fuel conversion at $1000 \mathrm{~K}$. Figure 11 compares the heptane infrared spectrum obtained by experiment at $1000 \mathrm{~K}$ and by extrapolation of fits from lower temperature data to $1000 \mathrm{~K}$. The extrapolated data was obtained by using the simplified extrapolation technique (Wakatsuki et al. 2005) under the assumption that no fuel pyrolysis occurred at any temperature. Figure clearly shows that significant heptane pyrolysis has occurred at $1000 \mathrm{~K}$. For the other species, pyrolysis of methane, propane, and propylene starts at 1200, 900 and 950 $\mathrm{K}$ respectively. An alternative Planck mean absorption coefficient incorporating the effects of fuel pyrolysis temperature might be considered for $T>800 \mathrm{~K}$. These results suggest that the significance of various fuel species absorption in a fire will depend on the temperature of the radiative flame as well as on the gases themselves in the fuel rich core. Figure 8 indicates that absorption by the larger alkanes increases by 4 to 5 times as $T$ rises from $300 \mathrm{~K}$ to $800 \mathrm{~K}$.

Another important question regarding radiation feedback involves the impact of fuel pyrolysis on overall absorption. In this regard, propylene and methane are interesting molecules as both are prominent pyrolysis products during the breakdown of alkanes such as n-heptane. In fact two $\mathrm{C}_{3} \mathrm{H}_{6}$ molecules plus one $\mathrm{CH}_{4}$ molecule has the same number of C's and $\mathrm{H}^{\prime}$ s as $\mathrm{C}_{7} \mathrm{H}_{16}$, and for $T>800 \mathrm{~K}$ ), the sum of the Planck mean absorption coefficients for the smaller molecules is only slightly higher than that of the larger heptane molecule. At lower temperature $(T<600$ 
K), the smaller molecules have much higher Planck mean absorption coefficients whereas the larger n-heptane does not. This suggests that if pyrolysis products find their way either through diffusion or convection into cool regions of the flame core, the impact of pyrolysis on hydrocarbon radiation absorption may be very significant. This is an area for further study, both with additional data collection and with detailed modeling of large-scale pool fires in which chemically resolved fuel rich cores and detailed radiation transport calculations are developed.

\section{CONCLUSIONS}

Absorption coefficients of hydrocarbon fuels (propane, heptane and propylene) were obtained experimentally and the Planck mean absorption coefficients were calculated using a simplified fitting and extrapolation equation up to $1400 \mathrm{~K}$ and the HITRAN database (methane). Fourth order polynomial fitting equations for each fuel are provided as a function of temperature. Large differences in the absolute values of the coefficients were obtained for the different hydrocarbon molecules. Based on this observation, it is clear that an accurate description of radiative transfer in fires will require temperature dependent absorption coefficients for all fuels and decomposition products present in significant concentrations. As the carbon number increases, similar trends in the Planck mean absorption coefficients as a function of frequency were observed. However, at lower temperatures, a representative alkene, i.e., propylene, shows a large contribution for absorption and emission arising from the bending motion of the $\mathrm{C}=\mathrm{C}$ bond and the associated $=\mathrm{C}-\mathrm{H}$ bond. This suggests that other fuels such as toluene, which contain characteristic band groups that absorb at low wavenumber, will significantly impact radiation transfer in fuel rich cores at low temperature. The importance of fuel pyrolysis and conversion

of large alkanes to smaller alkenes and methane may or may not significantly impact radiative 
absorption as it depends on how much of the high temperature pyrolysis products migrate to cooler zones where their mean absorption coefficients increase due to their low wavenumber absorption bands. These results suggest the importance of further study on the effects of fuel absorption in large-scale fires.

\section{ACKNOWLEDGEMENT}

This work was supported by the Fire Research Grants Program (Contract \# 60NANB1D0075) of the Building and Fire Research Laboratory at the National Institute of Standards and Technology (NIST), and by the NASA Microgravity Program (Contract \#C32066T; Dr. Sandra Olson, scientific officer).

\section{REFERENCES}

Brosmer, M. A., and Tien, C. L. (1985a). "Infrared Radiation Properties Of Methane At Elevated-Temperatures." Journal of Quantitative Spectroscopy and Radiative Transfer, 33(5), 521-532.

Brosmer, M. A., and Tien, C. L. (1985b). "Thermal-Radiation Properties Of Acetylene." Journal of Heat Transfer, 107(4), 943-948.

Brosmer, M. A., and Tien, C. L. (1986). "Thermal-Radiation Properties Of Propylene." Combustion Science and Technology, 48(3-4), 163-175.

Brosmer, M. A., and Tien, C. L. (1987). "Radiative Energy Blockage in Large Pool Fires." Combustion Science and Technology, 51(1-3), 21-37.

Buckius, R. O., and Tien, C. L. (1977). "Infrared Flame Radiation." International Journal of Heat and Mass Transfer, 20(2), 93-106. 
Burgess, D., and Hertzberg, M. (1974). "Radiation From Pool Flames." Heat Transfer in Flames, N. H. Afgan, and Bear, J. M., ed., John Wiley, New York, 413-430.

Carruth, G. F., and Kobayashi, R. (1973). "Vapor-Pressure Of Normal Paraffins Ethane Through N-Decane From Their Triple Points To About 10 Mm Hg." Journal of Chemical and Engineering Data, 18(2), 115-126.

Chu, P. M., Guenther, F. R., Rhoderick, G. C., and Lafferty, W. J. (1999). "The NIST quantitative infrared database." Journal of Research of The National Institute of Standards And Technology, 104(1), 59-81.

De Ris, J. (1979). "Fire Radiation - A Review." Seventeenth Symposium (International) on Combustion/The Combustion Institute, 1003-1015.

Fuss, S. P., Ezekoye, O. A., and Hall, M. J. (1996). "The absorptance of infrared radiation by methane at elevated temperatures." Journal of Heat Transfer, 118(4), 918-923.

Fuss, S. P., Hall, M. J., and Ezekoye, O. A. (1999). "Band-integrated infrared absorptance of low-molecular-weight paraffin hydrocarbons at high temperatures." Applied Optics, 38(13), 2895-2904.

Fuss, S. P., and Hamins, A. (2002). "Determination of Planck mean absorption coefficients for HBr, HCl, and HF." Journal of Heat Transfer, 124(1), 26-29.

Hamins, A., Fischer, S. J., Kashiwagi, T., Klassen, M. E., and Gore, J. P. (1994). "Heat Feedback To The Fuel Surface In Pool Fires." Combustion Science and Technology, 97(1-3), 37-62.

Kee, R. J., Rupley, F. M., Miller, J. A., Coltrin, M. E., Grcar, J. F., Meeks, E., Moffat, H. K., Lutz, A. E., Dixon-Lewis, G., Smooke, M. D., Warnatz, J., Evans, G. H., Larson, R. S., Mitchell, R. E., Petzold, L. R., Reynolds, W. C., Caracotsios, M. W., Stewart, E., Glarborg, 
P., Wang, C., Adigun, O., Houf, W. G., Chou, C. P., and Miller, S. F. (2003). "AURORA Application User Manual - CHEMKIN Collection." Reaction Design, Inc., San Diego, CA. Klassen, M., and Gore, J. P. (1994). "Structure and Radiation Properties of Pool Fires." NISTGCR-94-651, Report, National Institute of Standards and Technology, Gaithersburg, MD. Lee, S. C., and Tien, C. L. (1980). "Optical Constants of Soot in Hydrocarbon Flames." Eighteenth Symposium (International) on Combustion/The Combustion Institute, 1159-1166. Lord, R. C., and Venkateswarlu, P. (1953). "The Infrared Spectra Of Propylene And PropyleneD6." Journal of The Optical Society of America, 43(11), 1079-1085.

Ludwig, C. B., Malkmus, W., Reardon, J. E., and Thomson, J. A. L. (1973). "Handbook Of Inrared Radiatioin From Combustion Gases." NASA SP-3080, National Aeronautics and Space Administration (NASA), Washingon, D.C.

Markstein, G. H. (1979). "Radiative Properties of Plastics Fires." Seventeenth Symposium (International) on Combustion/The Combustion Institute, 1053-1062.

Park, S. H., Stretton, A. J., and Tien, C. L. (1988). "Infrared Radiation Properties Of MethylMethacrylate Vapor." Combustion Science and Technology, 62(4-6), 257-271.

Petrova, M. V., and Williams, F. A. (2006). "A small detailed chemical-kinetic mechanism for hydrocarbon combustion." Combustion and Flame, 144(3), 526-544.

Rothman, L. S., Jacquemart, D., Barbe, A., Benner, D. C., Birk, M., Brown, L. R., Carleer, M. R., Chackerian, C., Chance, K., Coudert, L. H., Dana, V., Devi, V. M., Flaud, J. M., Gamache, R. R., Goldman, A., Hartmann, J. M., Jucks, K. W., Maki, A. G., Mandin, J. Y., Massie, S. T., Orphal, J., Perrin, A., Rinsland, C. P., Smith, M. A. H., Tennyson, J., Tolchenov, R. N., Toth, R. A., Vander Auwera, J., Varanasi, P., and Wagner, G. (2005a). 
"The HITRAN 2004 molecular spectroscopic database." Journal of Quantitative Spectroscopy and Radiative Transfer, 96(2), 139-204.

Rothman, L. S., Jacquemart, D., Barbe, A., Benner, D. C., Birk, M., Browne, L. R., Carleer, M. R., Chackerian Jr, C., Chance, K., Couderth, L. H., Dana, V., Devic, V. M., Flaud, J.-M., Gamache, R. R., Goldman, A., Hartmann, J.-M., Jucks, K. W., Maki, A. G., Mandin, J.-Y., Massie, S. T., Orphal, J., Perrin, A., Rinsland, C. P., Smith, M. A. H., Tennyson, J., Tolchenov, R. N., Toth, R. A., Vander Auwera, J., Varanasi, P., and Wagner, G. (2005b). "The HITRAN 2004 molecular spectroscopic database." Journal of Quantitative Spectroscopy and Radiative Transfer, 96, 139-204.

Seiser, R., Pitsch, H., Seshadri, K., Pitz, W. J., and Curran, H. J. (2000). "Extinction and autoignition of n-heptane in counterflow configuration." Proceedings of The Combustion Institute, 28, 2029-2037.

Siegel, R., and Howell, J. R. (1992). Thermal Radiation Heat Transfer, Hemisphere Publishing, Washington, DC.

Silvia, B., Labarbe, P., and Perchard, J. P. (1973). "Spectres de vibrations et coordonees normales de quatre especes isotopiques de propene." Spectrocimicha Acta, A29, 263.

Tripp, C. P., and McFarlane, R. A. (1994). "Discussion Of The Stray Light Rejection Efficiency Of Ft-Ir Spectrometers - The Effects Of Sample Emission On Ft-Ir Spectra." Applied Spectroscopy, 48(9), 1138-1142.

Wakatsuki, K., Fuss, S. P., Hamins, A., and Nyden, M. R. (2005). "A technique for extrapolating absorption coefficient measurements to high temperatures." Proceedings of The Combustion Institute, 30, 1565-1573. 
Zhang, H. M., and Modest, M. F. (2002). "Evaluation of the Planck-mean absorption coefficients from HITRAN and HITEMP databases." Journal of Quantitative Spectroscopy and Radiative Transfer, 73(6), 649-653. 


\section{TABLES}

Table 1 - Volume fraction of heptane in the heptane/nitrogen mixture used in the FTIR measurements.

\begin{tabular}{|c|c|c|c|}
\hline Temperature $(\mathrm{K})$ & \multicolumn{3}{|c|}{ Volume Fraction $\left(\times 10^{-6}\right)$} \\
\hline 293 & 510 & 1060 & 1671 \\
\hline 400 & 492 & 1023 & 1614 \\
\hline 450 & 516 & 1056 & 1684 \\
\hline 490 & 510 & 1037 & 1680 \\
\hline 593 & 516 & 1000 & 1593 \\
\hline 794 & 497 & 1009 & 1475 \\
\hline 1000 & 590 & 1045 & 1509 \\
\hline
\end{tabular}

Table 2: Values for $4^{\text {th }}$ order polynomial fits with equation 4 to Planck mean absorption coefficient data.

\begin{tabular}{|l||r|r|r|r|}
\hline \multicolumn{1}{|c||}{} & \multicolumn{1}{c|}{ Methane } & \multicolumn{1}{c|}{ Propane } & \multicolumn{1}{c|}{ Heptane } & Propene \\
\cline { 2 - 5 } & \multicolumn{4}{|c|}{$300 \mathrm{~K}-1400 \mathrm{~K}$} \\
\hline $\mathrm{a}_{0}$ & $4.00 \mathrm{E}+00$ & $-1.53 \mathrm{E}+01$ & $-3.59 \mathrm{E}+01$ & $3.88 \mathrm{E}+01$ \\
\hline $\mathrm{a}_{1}$ & $6.57 \mathrm{E}-03$ & $8.47 \mathrm{E}-02$ & $1.88 \mathrm{E}-01$ & $-6.46 \mathrm{E}-02$ \\
\hline $\mathrm{a}_{2}$ & $-1.37 \mathrm{E}-05$ & $-9.75 \mathrm{E}-05$ & $-2.08 \mathrm{E}-04$ & $4.67 \mathrm{E}-05$ \\
\hline $\mathrm{a}_{3}$ & $7.34 \mathrm{E}-09$ & $4.29 \mathrm{E}-08$ & $8.87 \mathrm{E}-08$ & $-1.63 \mathrm{E}-08$ \\
\hline $\mathrm{a}_{4}$ & $-1.27 \mathrm{E}-12$ & $-6.58 \mathrm{E}-12$ & $-1.33 \mathrm{E}-11$ & $2.20 \mathrm{E}-12$ \\
\hline $\mathrm{R}^{2}$ & $9.92 \mathrm{E}-01$ & $9.96 \mathrm{E}-01$ & $9.94 \mathrm{E}-01$ & $9.99 \mathrm{E}-01$ \\
\hline
\end{tabular}




\section{FIGURES}
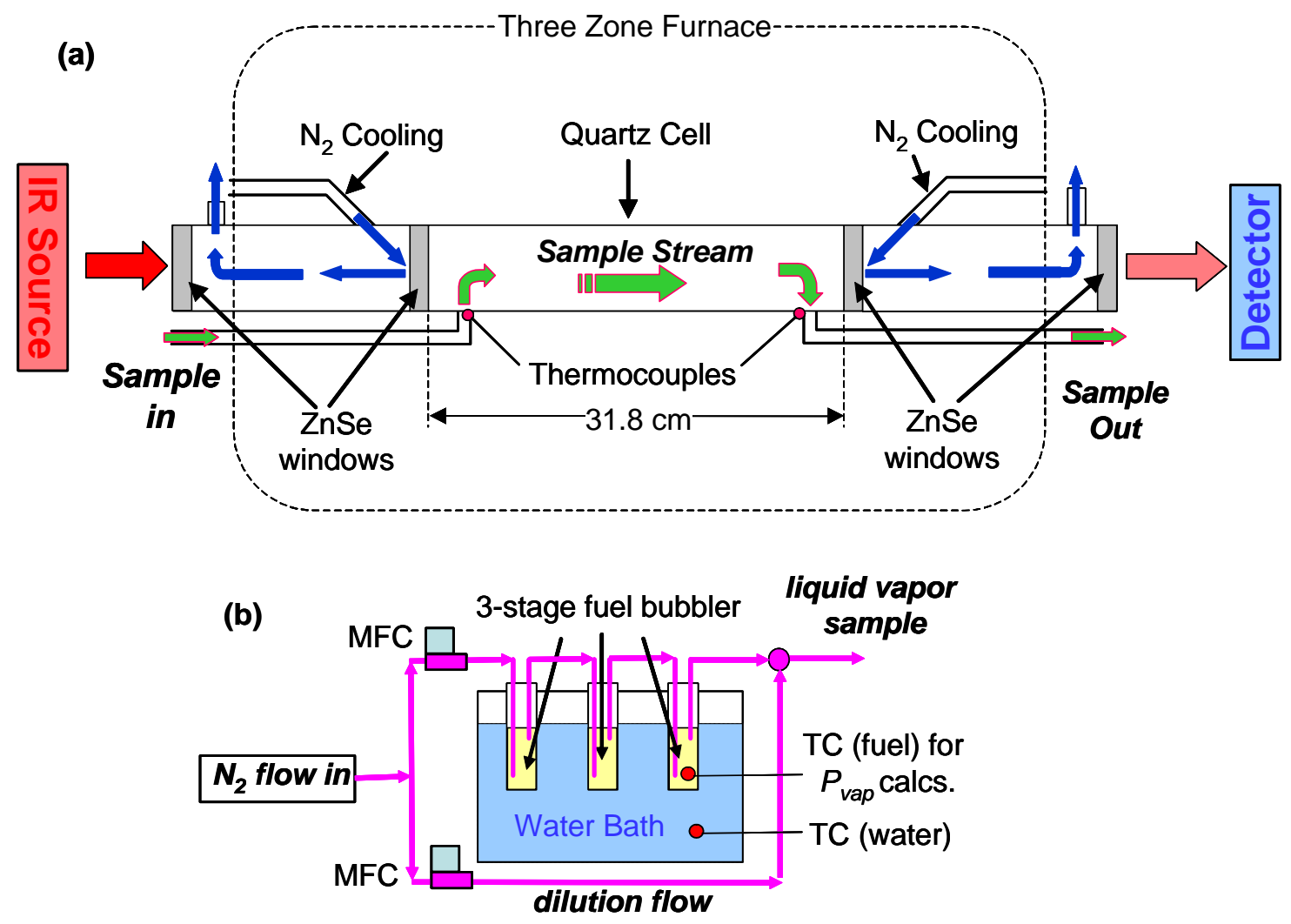

Figure 1 - Diagram a) of high temperature FTIR test facility with N2 cooling of ZnSe windows and b) continuous liquid fuel vapor supply for heptane vapor controlled by saturation and downstream dilution. 


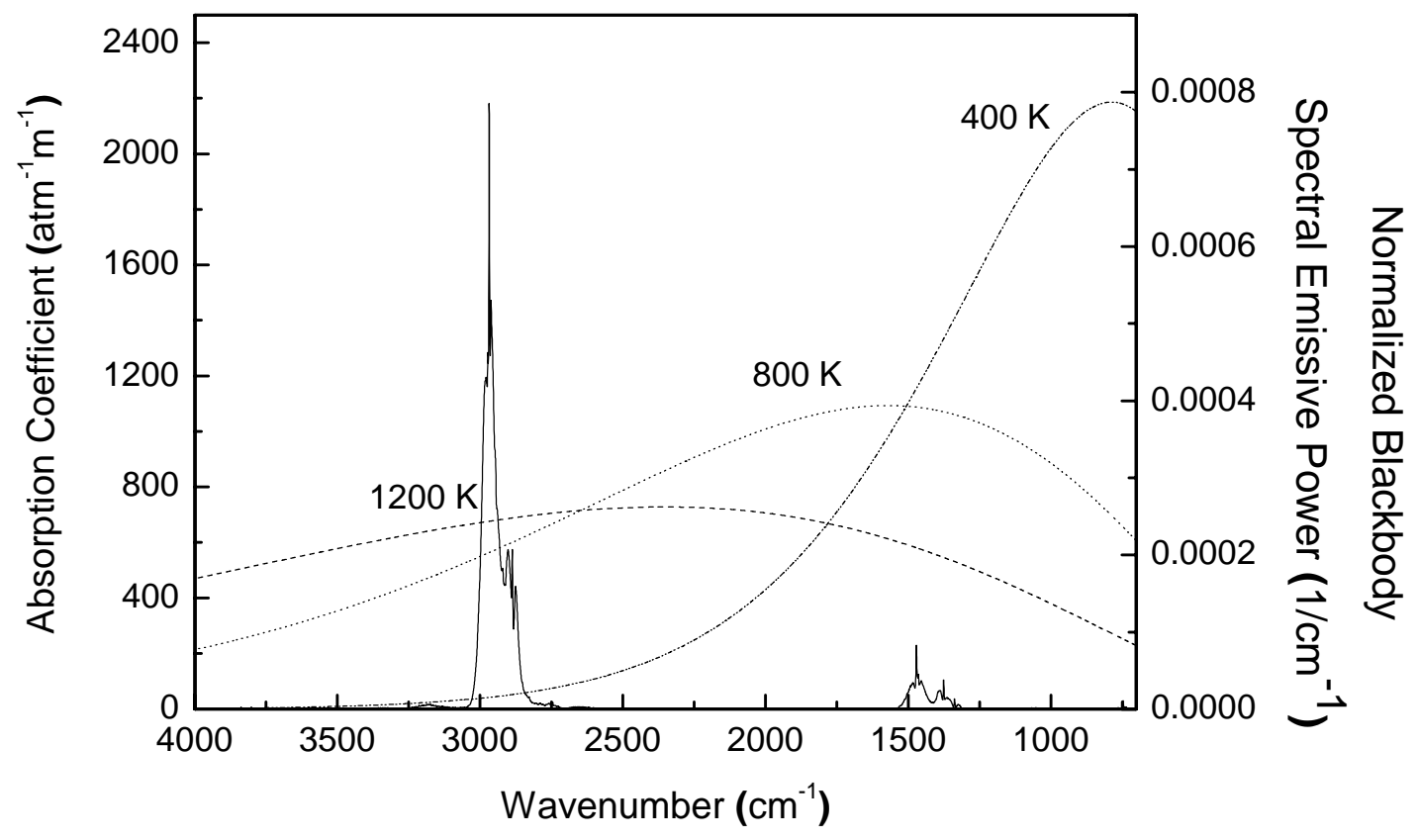

Figure 2 - The measured spectral absorption coefficient of propane $\left(\mathrm{C}_{3} \mathrm{H}_{8}\right)$ at $296 \mathrm{~K}$ and the temperature dependent normalized blackbody spectral emissive power as a function of wavenumber. 
(a)

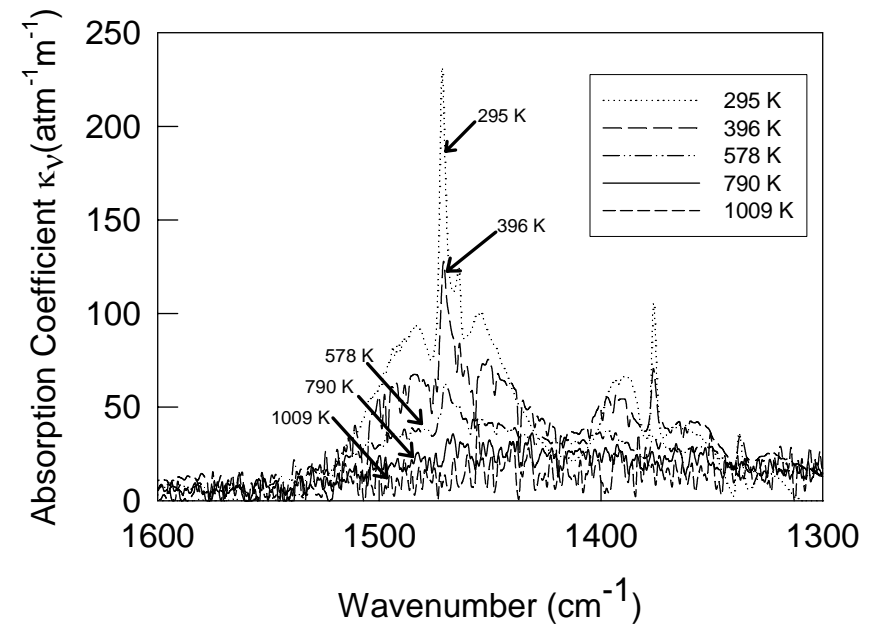

(b)

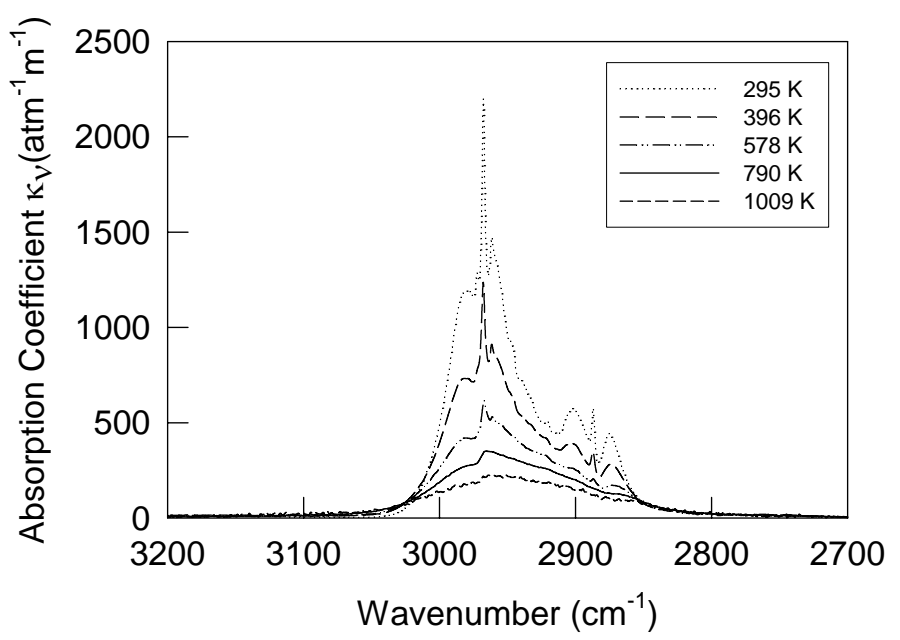

Figure 3 - Measured temperature-dependent spectral absorption coefficient of $\mathrm{C}_{3} \mathrm{H}_{8}$; (a) C-H bending and (b) $\mathrm{C}-\mathrm{H}$ stretching region. 


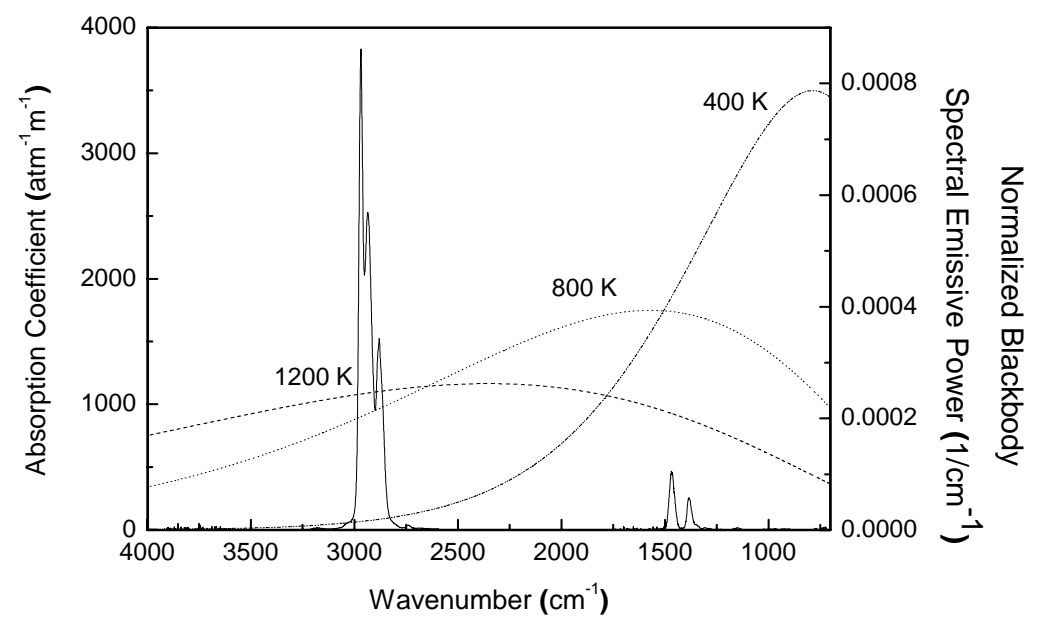

Figure 4 - Measured spectral absorption coefficient of $n-\mathrm{C}_{7} \mathrm{H}_{16}$ at $296 \mathrm{~K}$ and the temperature dependent normalized blackbody spectral emissive power as a function of wavenumber. 
(a)

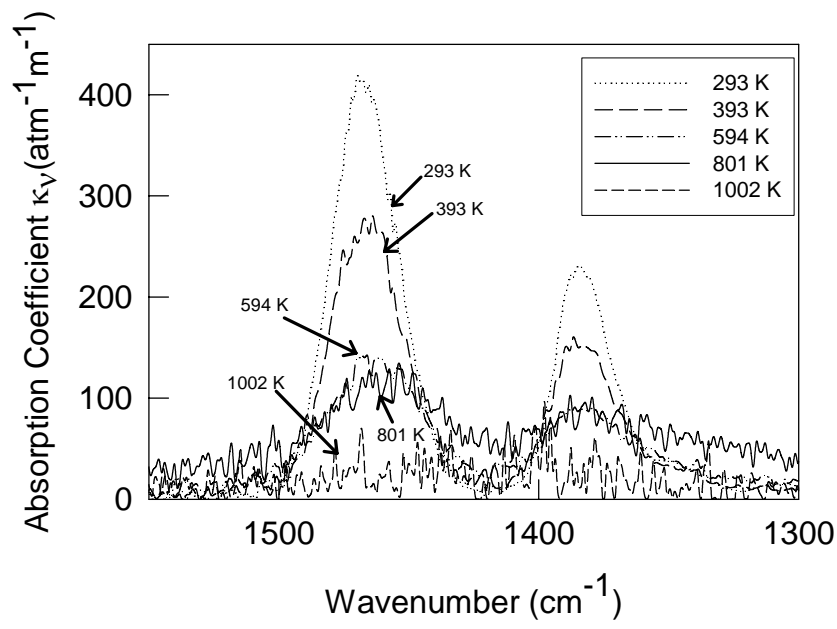

(b)

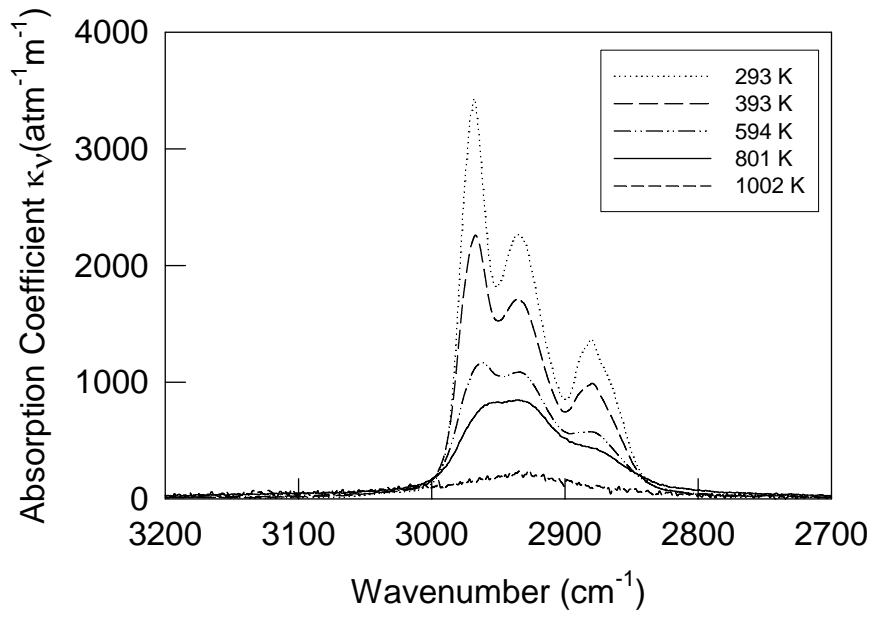

Figure 5 - The measured temperature dependent spectral absorption coefficient of n-heptane; (a) $\mathrm{C}-\mathrm{H}$ bending and (b) $\mathrm{C}-\mathrm{H}$ stretching. 


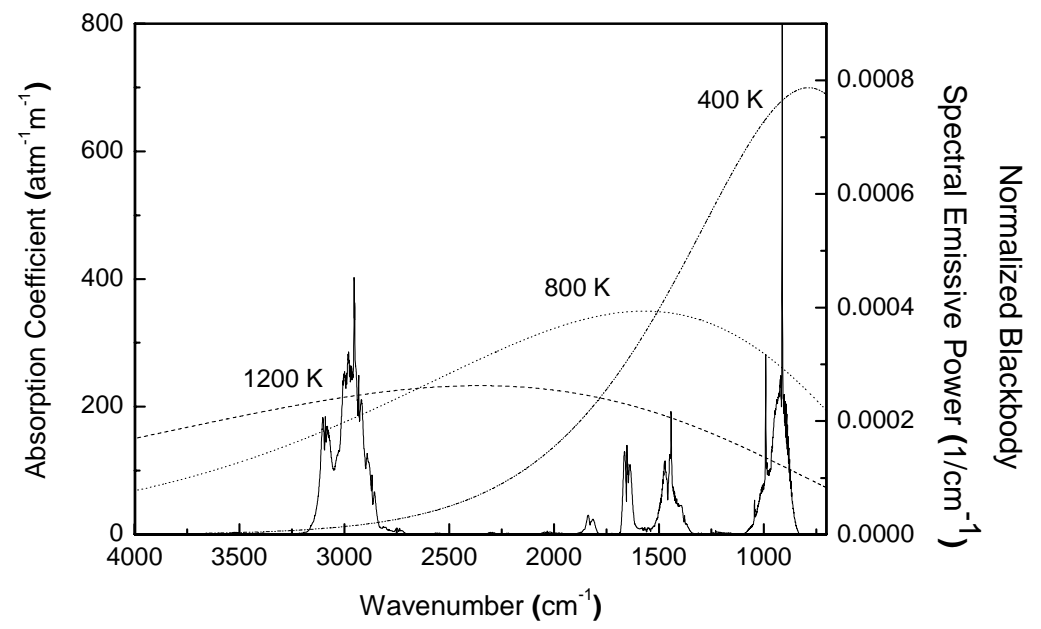

Figure 6 - The measured spectral absorption coefficient of $\mathrm{C}_{3} \mathrm{H}_{6}$ at $296 \mathrm{~K}$ and the temperaturedependent normalized blackbody spectral emissive power as a function of wavenumber. 
(a)

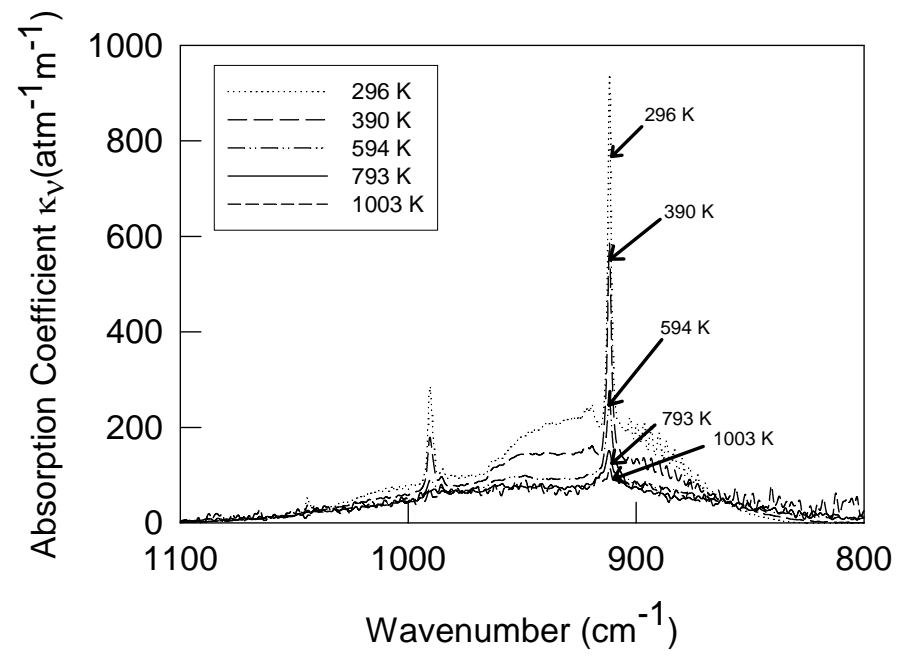

(b)

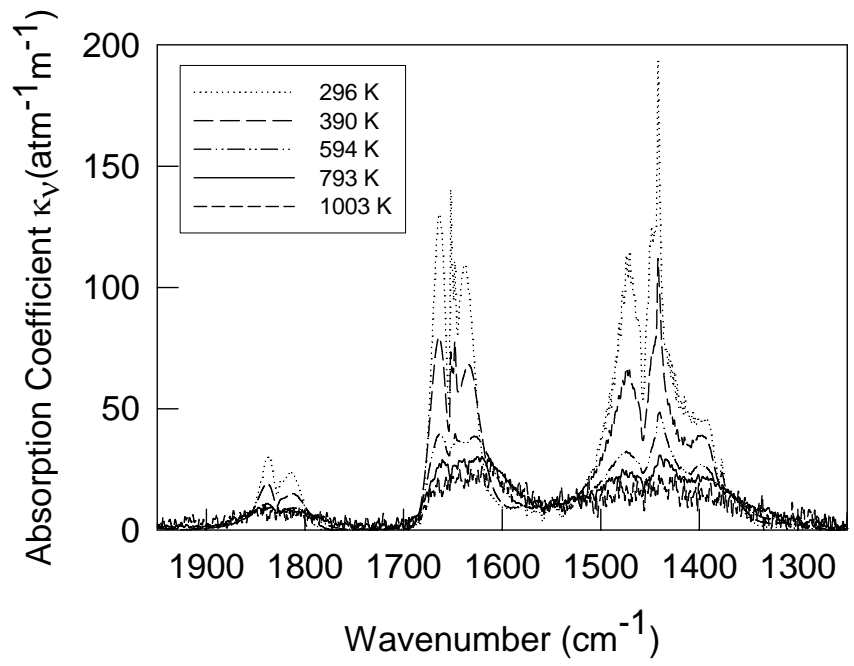

(c)

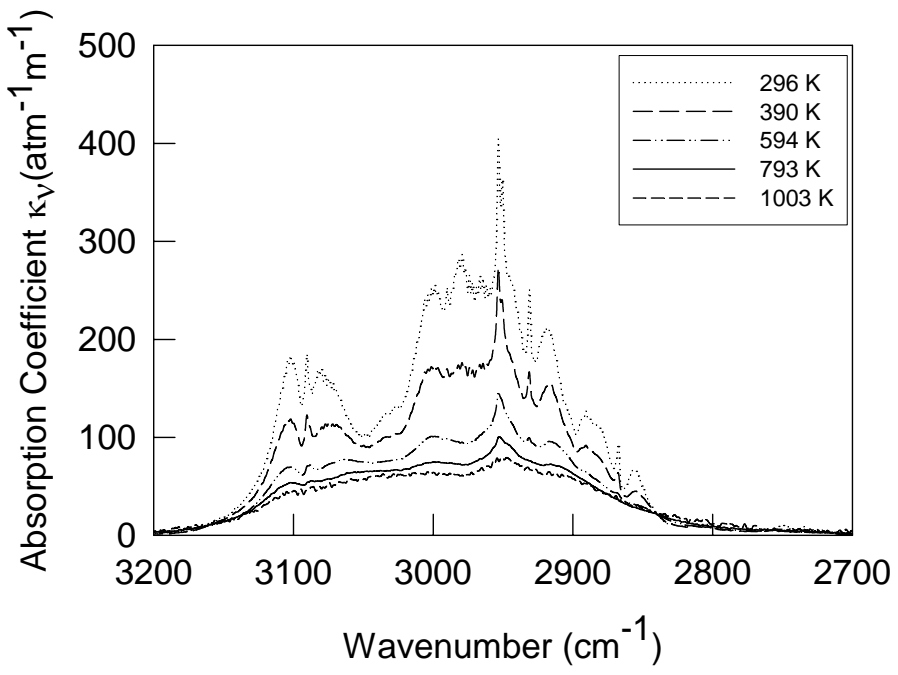

Figure 7 - The measured temperature dependent spectral absorption coefficient of Propene $\left(\mathrm{C}_{3} \mathrm{H}_{6}\right)$; (a) $=\mathrm{CH}_{2}$ out of plane bending (b) $\mathrm{C}-\mathrm{H}$ in plane and out of plane bending, and $\mathrm{C}=\mathrm{C}$ stretching and (c) $\mathrm{CH}_{3}$ - and $=\mathrm{CH}_{2}$ stretching. 


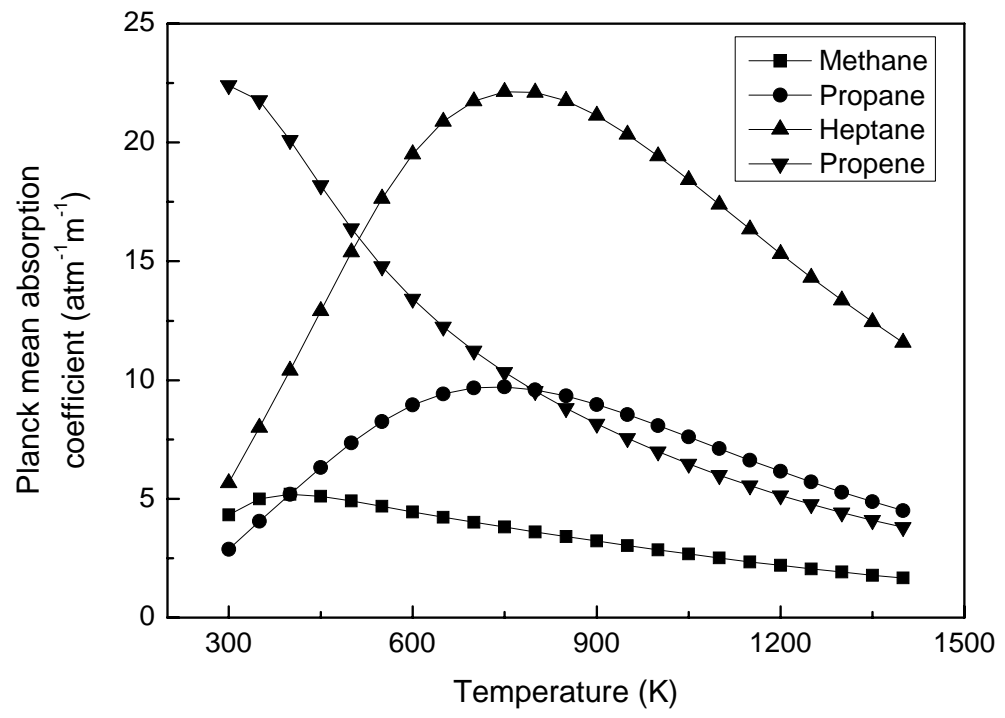

Figure 8 - The Planck mean absorption coefficient of $\mathrm{CH}_{4}$ (from HITRAN), $\mathrm{C}_{3} \mathrm{H}_{8}, \mathrm{n}_{-} \mathrm{C}_{7} \mathrm{H}_{16}$, and $\mathrm{C}_{3} \mathrm{H}_{6}$ (from fitting and extrapolation of measurements). 


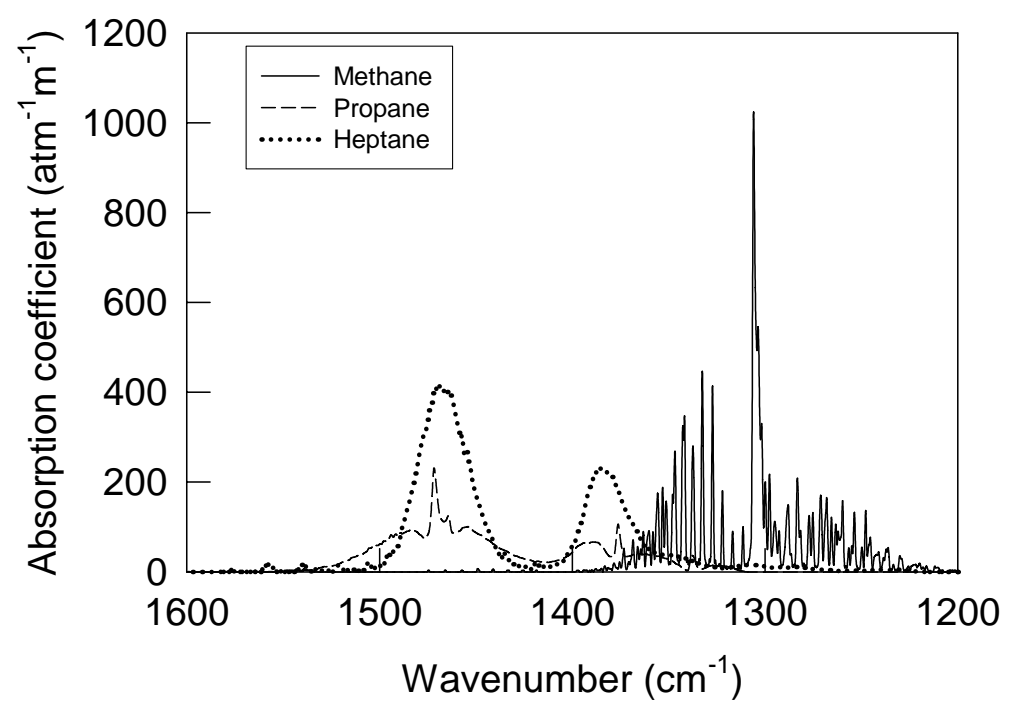

Figure 9 - Spectral absorption coefficients for C-H bending peaks for methane (HITRAN), and propane and heptane (experimental) at $296 \mathrm{~K}$. 


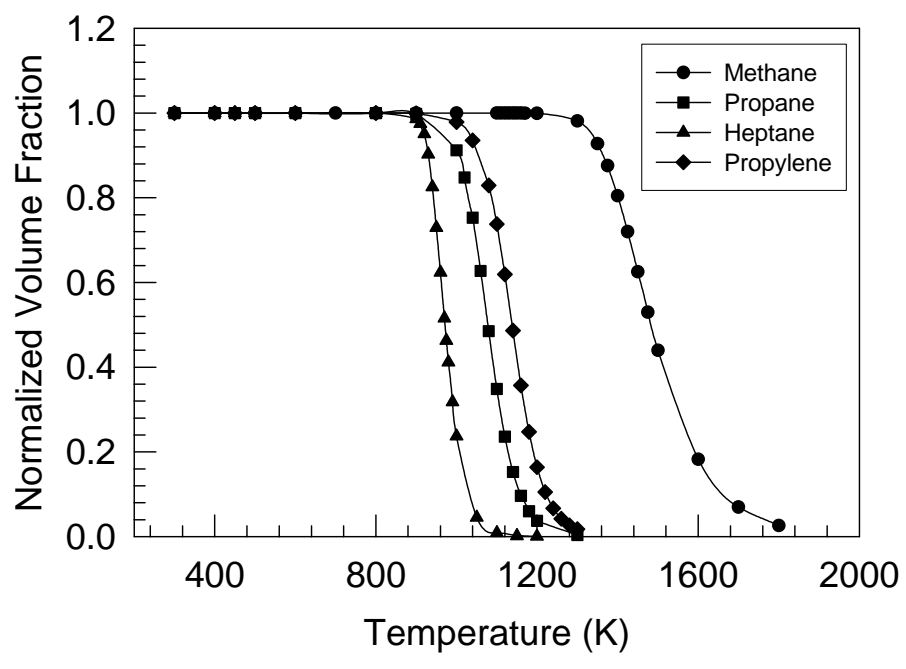

Figure 10 - Calculated normalized fuel volume fraction of hydrocarbon fuels remaining after residence in gas cell as a function of temperature (Kee et al. 2003). 


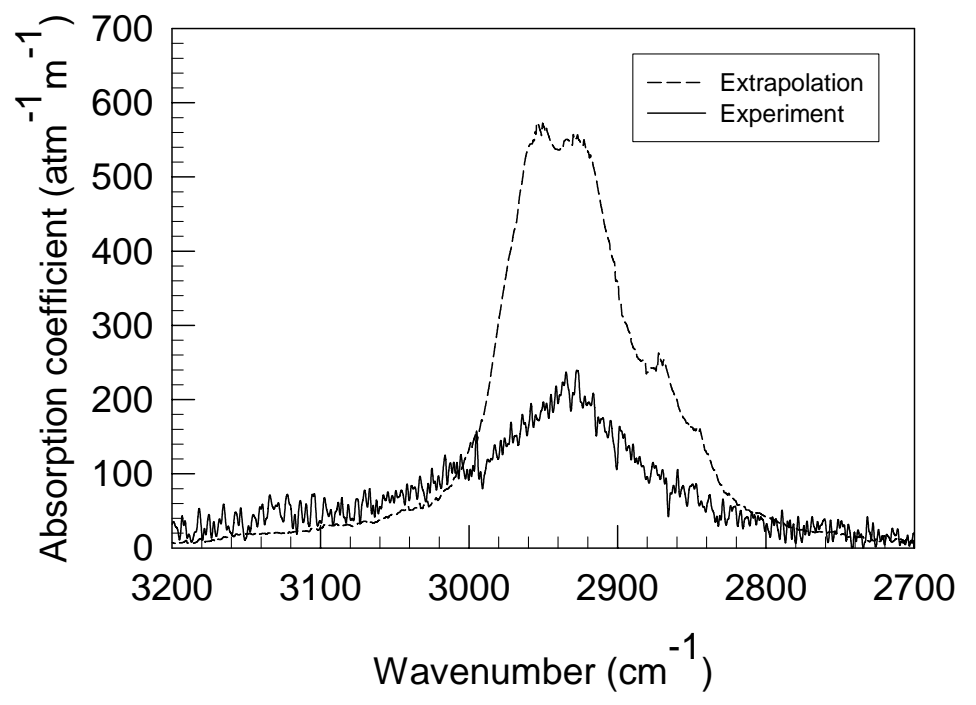

Figure 11 - Comparison of the extrapolated and experimentally measured spectral absorption coefficient of heptane $\left(\mathrm{C}_{7} \mathrm{H}_{16}\right)$ for the $\mathrm{C}-\mathrm{H}$ stretching band at $1000 \mathrm{~K}$. The difference between extrapolated and measured spectrum is due to pyrolysis. 